\title{
Probleme der modernen hochauflösenden Einkristall-Röntgenstrukturanalyse
}

\author{
Dissertation \\ zur Erlangung des Doktorgrades \\ der Mathematisch-Naturwissenschaftlichen Fakultäten \\ der Georg-August-Universität zu Göttingen
}

\author{
vorgelegt von \\ Peter Müller \\ aus Wörth
}

Göttingen 2001 
D 7

Referent: Prof. G. M. Sheldrick, Ph.D

Koreferent: Prof Dr. P. Susse

Tag der mündlichen Prüfung: 2. 5. 2001 


\section{Dank}

Die vorliegende Arbeit wurde in der Zeit von Oktober 1997 bis März 2001 unter der Leitung von Prof. G. M. Sheldrick, Ph.D., am Lehrstuhl für Strukturchemie des Instituts für Anorganische Chemie der Universität Göttingen angefertigt.

Mein Dank gilt vor allem Herrn Professor G. M. Sheldrick, dessen freundliche Unterstützung und dessen ständige Diskussions- und Hilfsbereitschaft meine Arbeit überhaupt erst ermöglicht haben.

Frau Dr. I. Usón danke ich für die Betreuung, die stete freundliche Diskussionsbereitschaft und ihre unschätzbare Hilfe beim Verfassen diverser englischer Texte.

Darüberhinaus sei allen Mitarbeiterinnen und Mitarbeitern der Abteilung Sheldrick für die sehr gute Zusammenarbeit, das hervorragende Arbeitsklima und die gezeigte Hilfsbereitschaft gedankt. Besonders danke ich Herrn H. Dehnhard für seine Hilfe in allen denkbaren technischen Fragen.

Für die gute Zusammenarbeit danke ich Herrn Dipl.-Chem. C. Ackerhans, Herrn Dipl.Chem. G. Bai, Herrn Priv.-Doz. Dr. J. Belzner, Herrn Prof. Dr. L. Fitjer, Herrn Dr. L. Häming, Herrn Prof. Dr. K. Hantke, Herrn Dipl.-Chem. T. Labahn, Herrn Dr. M. Noltemeyer, Herrn Dipl.-Chem. J. Prust, Herrn Dipl.-Chem. B. Räke, Herrn Dr. C. Rennekamp, Herrn Prof. Dr. H. W. Roesky, Herrn Dipl.-Chem. B. Rohde, Herrn Prof. Dr. A. D. Schlüter, Herrn Dr. O. Wagner und Herrn Dr. P. Yu.

Für gute Zusammenarbeit und die Unterstützung bei der Arbeit mit $\mathrm{T}_{\mathrm{E}} \mathrm{X}$ und $\mathrm{AT}_{\mathrm{E}} \mathrm{X}$ danke ich Herrn Prof. Dr. J. Magul, Herrn Dr. U. Schaller und Herrn Dr. T. R Schneider.

Ein Dank auch an Herrn Dr. E. Pohl und Herrn Dipl.-Biol. R. Krätzner für Rat und Hilfe bei der Kristallisation von FhuF.

Nicht zuletzt sei Frau Dr. R. Herbst-Irmer für viele sehr hilf- und aufschlußreiche Gespräche über Verzwillingung und andere kristallographische Feinheiten sehr herzlich gedankt.

Frau Dr. I. Usón, Herrn Dr. J. Dyckmans, Herrn Dr. J. Kärcher, Frau E. Alexopoulos und Frau G. Müller-Hermann danke ich für ihre Unterstützung beim Korrekturlesen.

Für die Übernahme des Koreferats danke ich Herrn Prof. Dr. P. Susse. 


\section{$\triangle \mathrm{AIM} \Omega \mathrm{N}$}

Wie an dem Tag, der Dich der Welt verliehen, Die Sonne stand zum Gruße der Planeten, bist alsobald und fort und fort gediehen Nach dem Gesetz, wonach du angetreten. So mußt du sein, dir kannst du nicht entfliehen, So sagten schon Sibyllen, so Propheten;

Und keine Zeit und keine Macht zerstückelt Geprägte Form, die lebend sich entwickelt.

J. W. Goethe 


\title{
Abkürzungen
}

\author{
ADP Anisotropic Displacement Parameter \\ CCD Charge Coupled Device \\ $\mathrm{Cp} \quad$ Cyclopentadienyl $\left(\mathrm{C}_{5} \mathrm{H}_{5}\right)$ \\ Cp* Pentamethyl-cyclopentadienyl $\left(\mathrm{C}_{5} \mathrm{Me}_{5}\right)$ \\ CSD Cambridge Structure Database \\ CVD Chemical Vapour Deposition \\ Da Dalton \\ DESY Deutsches Elektronen Synchrotron \\ DLS Dynamic Light Scattering \\ DTT 1,4-Dithio-DL-threitol \\ EDTA Ethylendiamintetraacetat \\ EMBL European Molecular Biological Laboratory \\ ESR Electron Spin Resonance \\ EXAFS Extended X-ray Absorpiton Fine Structure \\ FPLC Fast-Protein Liquid Chromatography \\ HEW Hen Egg-White \\ kDa Kilodalton (1000 Dalton) \\ kW Kilowatt (1000 Watt) \\ M molar $(\mathrm{mol} / \mathrm{l})$ \\ $\mathrm{mM} \quad$ millimolar $(\mathrm{mmol} / \mathrm{l})$ \\ MAD Multi wavelength Anomalous Dispersion \\ MES 2[N-Morpholino]ethan-sulfonsäure \\ MPD 2-Methyl-propandiol \\ MWPC Multi Wire Proportional Chamber \\ NCS Non Crystallographic Symmetry \\ NMR Nuclear Magnetic Resonance \\ NTA Nickel-Triacetic-Agarose \\ PEG Polyethylenglykol(e) \\ PDB Protein Data Bank \\ SDS Sodium-dodecylsulfate \\ ${ }^{t} \mathrm{Bu} \quad$ tert-Butyl \\ THF Tetrahydrofuran \\ TRIS Tris[hydroxymethyl]amminomethan
}




\section{Inhaltsverzeichnis}

Dank

$\triangle \mathrm{AIM} \Omega \mathrm{N}$

Abkürzungen

\begin{tabular}{lll}
\hline & Einleitung & 1
\end{tabular}

2 Kristallisation 3

2.1 Kleinmoleküle . . . . . . . . . . . . . . . . . . . . . . . . . . . . . 3

2.2 Proteine . . . . . . . . . . . . . . . . . . . . . . 4

2.2 .1 Gasdiffusionsmethode . . . . . . . . . . . . . . . . . . . . . . 4

2.2 .2 Die sparse-matrix-Technik . . . . . . . . . . . . . . . . . . . 5

2.2 .3 Seeding . . . . . . . . . . . . . . . . . . 5

2.2 .3 .1 Mikroseeding . . . . . . . . . . . . . . . . 6

2.2 .3 .2 Makroseeding . . . . . . . . . . . . . . . . . . 6

2.3 FhuF . . . . . . . . . . . . . . . . . . . . . . 7

$2.3 .1 \quad$ Aufreinigung und erste Kristallisationsansätze . . . . . . . . . . . . 8

2.3 .2 Glycerol und Dynamic Light Scattering . . . . . . . . . . . . . . . . 10

2.3.3 Entfernen des His-tags und erneute Kristallisationsversuche . . . . 12

2.3 .4 Zwei Mutanten . . . . . . . . . . . . . . . . . . . . . . . . . . 13

2.3 .5 Malonat . . . . . . . . . . . . . . . . . . . . 14

2.3 .6 Gelfiltration . . . . . . . . . . . . . . . . . . . . . . . 14

2.3 .7 Trypsin-Verdauung . . . . . . . . . . . . . . . . . . . . . . . . . . . 15

2.3 .8 EXAFS-Spektrum . . . . . . . . . . . . . . . . . . . 16

2.3 .9 Zusammenfassung . . . . . . . . . . . . . . . . . . . . . . 18

$\begin{array}{lll}3 & \text { Empfindliche Kristalle } & 19\end{array}$

3.1 Empfindlichkeit gegen Sauerstoff und Feuchtigkeit . . . . . . . . . . . . . . . 19

3.2 Temperaturempfindlichkeit . . . . . . . . . . . . . . . . . 20 
3.2.1 Schmelzpunkt . . . . . . . . . . . . . . . . . . . 20

3.2 .2 Verlust von Lösungsmittel . . . . . . . . . . . . . . . . . . 20

3.3 Kühlen vor der Messung . . . . . . . . . . . . . . . . . . . . . . 20

3.4 Empfindlicher Ti(III)-Komplex . . . . . . . . . . . . . . . . . . . . . 22

3.5 Cycloikositetraphenylen . . . . . . . . . . . . . . . . . . . 23

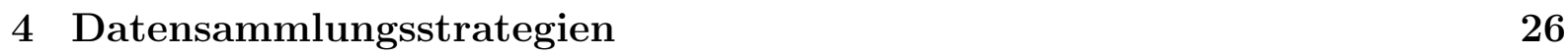

4.1 Röntgenquellen . . . . . . . . . . . . . . . . . . . . . . 26

4.1 .1 sealed tube . . . . . . . . . . . . . . . . . . 27

4.1 .2 Drehanode. . . . . . . . . . . . . . . . . 27

4.1.3 microsource . . . . . . . . . . . . . . . . . . . . . . 27

4.1 .4 Synchrotronstrahlung . . . . . . . . . . . . . . . . . . . . . . 28

4.2 Monochromatoren . . . . . . . . . . . . . . . . . . . . . . . . . . . . . . . . . . . . . . 28

4.2 .1 Kristalle . . . . . . . . . . . . . . . . . . . . . . . . . . . . . . 29

$4.2 .2 \quad$ Multilayer Optik $\ldots \ldots \ldots \ldots$

4.3 Optimale Wellenlänge $\ldots \ldots \ldots$. . . . . . . . . . . . . . . . . . . 30

4.4 Diffraktometergeometrien . . . . . . . . . . . . . . . . . . . . 30

4.4 .1 Vierkreisdiffraktometer . . . . . . . . . . . . . . . . . . 31

$4.4 .1 .1 \quad$ Euler-Geometrie . . . . . . . . . . . . . . . . . . . 31

4.4 .1 .2 Kappa-Geometrie . . . . . . . . . . . . . . . . . . . 31

4.4 .2 Dreikreisdiffraktometer (Platform-Geometrie) . . . . . . . . . . . . 32

4.4 .3 Einkreisdiffraktometer . . . . . . . . . . . . . . . . . . . . . . . . 33

4.5 Detektoren . . . . . . . . . . . . . . . . . . . . . . . 34

4.5 .1 Szintillations-Punktzähler . . . . . . . . . . . . . . . 35

4.5 .2 MWPC-Flächenzähler . . . . . . . . . . . . . . . . . 35

4.5 .3 imaging plate-Flächenzählen . . . . . . . . . . . . . . . . . . . 36

4.5 .4 CCD-Flächenzähler . . . . . . . . . . . . . . . . . . . . . . . 37

4.6 Strahlenschäden . . . . . . . . . . . . . . . . . . . . . . . . . . . . . 38

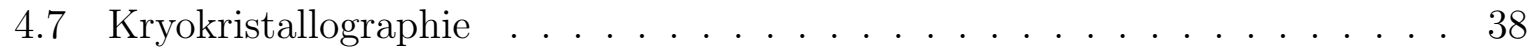

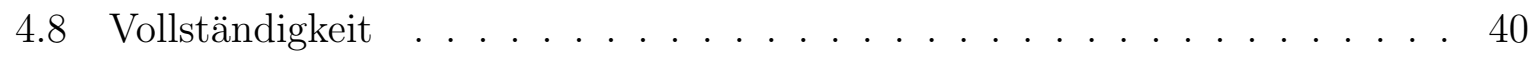

4.9 Redundanz $\ldots \ldots \ldots \ldots$

4.10 Ausarbeitung der Datensammlungsstrategie . . . . . . . . . . . . . . . 43

5 Vergleich verschiedener Geräte 45

5.1 Diffraktometer . . . . . . . . . . . . . . . . . . . . . 45

$5.1 .1 \quad$ Euler-Vierkreis-Goniometer / SMART 1K . . . . . . . . . . . . . . . 45

$5.1 .2 \quad$ Zweikreis-Goniometer /ipds-ii . . . . . . . . . . . . . . . . . 46

5.1 .3 Platform-Goniometer / HiStar . . . . . . . . . . . . . . . . 46 
5.1 .4 Platform-Goniometer /SMART $6000 \ldots$. . . . . . . . . . . . . 47

5.1 .5 Einkreis-Goniometer $/$ mar345 . . . . . . . . . . . . . . . . . . 49

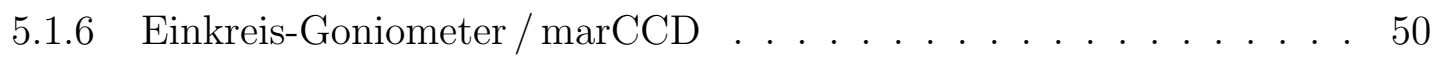

5.1 .7 Platform-Goniometer/SMART 6500 . . . . . . . . . . . . . . 50

5.2 Gütekriterien . . . . . . . . . . . . . . . . . . . . 51

5.3 Lysozyme . . . . . . . . . . . . . . . . . . 54

5.4 Actagardin . . . . . . . . . . . . . . . . . . 56

5.5 vergleich $\ldots \ldots \ldots \ldots \ldots \ldots \ldots \ldots$

$5.5 .1 \quad$ Euler-Vierkreis-Goniometer/SMART 1K . . . . . . . . . . . . . . 58

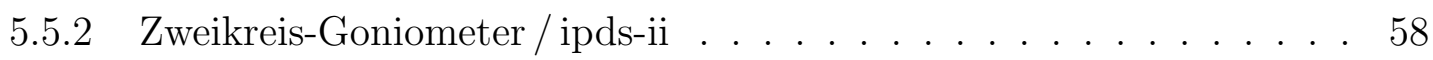

5.5 .3 Platform-Goniometer / HiStar . . . . . . . . . . . . . . . 59

5.5 .4 Einkreis-Goniometer $/ \operatorname{mar} 345$. . . . . . . . . . . . . . . . 59

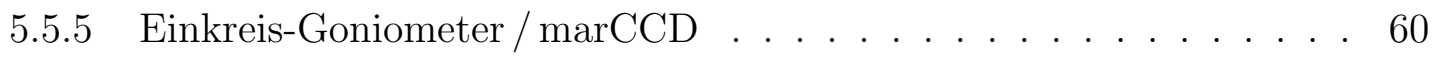

5.5 .6 Abschließender Vergleich . . . . . . . . . . . . . . . . . . . 60

6 Unklare Elementzuordnung $\quad 62$

6.1 Tetrameres $\mathrm{InCl}_{3} \ldots \ldots \ldots \ldots \ldots$. . . . . . . . . . . . . . . . . 63

6.2 Kobaltsalz . . . . . . . . . . . . . . . . . . . . 65

6.3 Unklares Zentralatom . . . . . . . . . . . . . . . . . . . . . 66

\begin{tabular}{lll}
\hline 7 & Fehlordnung & 69
\end{tabular}

7.1 Arten der Fehlordnung . . . . . . . . . . . . . . . . . . . . . 70

$7.1 .1 \quad$ Besetzungsfehlordnung . . . . . . . . . . . . . . . . 70

7.1 .2 Lagefehlordnung . . . . . . . . . . . . . . . . . . 71

7.1 .2 .1 Diskrete Fehlordnungen . . . . . . . . . . . . . 71

7.1.2.2 Kontinuierliche Fehlordnungen . . . . . . . . . . . 72

7.1 .3 Unordnung - ein Spezialfall von Fehlordnung . . . . . . . . . . . . . 72

7.2 Verfeinerung von Fehlordnung . . . . . . . . . . . . . . . . . . . . . . 73

7.2 .1 Verfeinerung mit SHELXL . . . . . . . . . . . . . . . . . . . 73

$7.2 .1 .1 \quad$ Fehlordnung um spezielle Lagen . . . . . . . . . . . . . . 75

7.2.1.2 Fehlordnungen mit mehr als zwei Lagen . . . . . . . . 75

7.2.1.3 Bulk-Solvent-Korrektur . . . . . . . . . . . . . 76

7.2 .1 .4 Fehlordnung und Restraints . . . . . . . . . . . . 76

7.3 Gallium-lminosilikat . . . . . . . . . . . . . . . . . . . . . . . . 78

7.4 Mischkristalle . . . . . . . . . . . . . . . . . . . . . . 80

7.5 Lösungsmittelfehlordnungen . . . . . . . . . . . . . . . . . . . . . 81

$7.5 .1 \mathrm{THF} \ldots \ldots \ldots \ldots \ldots . \ldots \ldots \ldots$

7.5 .2 Tolud . . . . . . . . . . . . . . . . . . . . . . . . 83 
8.5 .3 Chloroform . . . . . . . . . . . . . . . . 84

8.6 Cycloikositetraphenylen $\ldots \ldots \ldots \ldots \ldots \ldots$

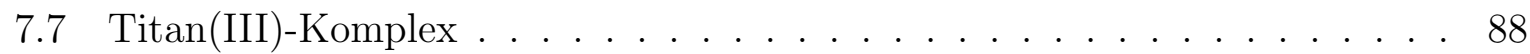

$\begin{array}{lll}8 & \text { NCS und Pseudosymmetrie } & 91\end{array}$

8.1 Globale Pseudosymmetrie . . . . . . . . . . . . . . . . . . . . 91

8.2 Echte NCS . . . . . . . . . . . . . . . . . . . . . . . . . . . . . 92

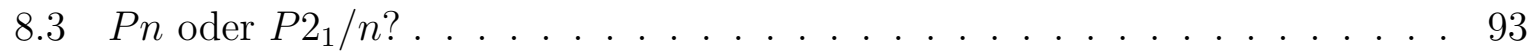

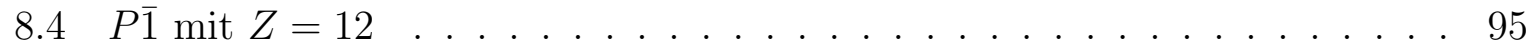

$\begin{array}{lll}9 & \text { Verzwillingung } & 97\end{array}$

$9.1 \quad$ Arten der Verzwillingung $\ldots \ldots \ldots \ldots$

9.1.1 Verzwillingung bei vollständiger exakter Uberlagerung der Kristall-

gitter. . . . . . . . . . . . . . . . . . . . . 99

9.1.1.1 meroedrische Verzwillingung . . . . . . . . . . . . . . . . 99

9.1.1.2 pseudo-meroedrische Verzwillingung . . . . . . . . . . . . 99

9.1.2 Verzwillingung ohne vollständige exakte Überlagerung der Kristall-

gitter. . . . . . . . . . . . . . . . . . . 100

9.1.2.1 nicht-meroedrische Verzwillingung . . . . . . . . . 100

$9.2 \quad$ Warnsignale für Verzwillingung $\ldots \ldots \ldots \ldots \ldots \ldots$

9.3 Mathematische Entzwillingung . . . . . . . . . . . . . . . . . 103

9.4 Verfeinerung gegen verzwillingte Daten . . . . . . . . . . . . . . . . 104

9.4 .1 Zwillingsverfeinerung mit SHELXD . . . . . . . . . . . . . 105

9.5 Verzwillingung oder Fehlordnung? . . . . . . . . . . . . . . . 106

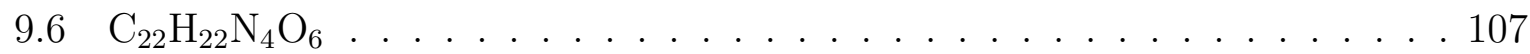

9.7 Racemische Verzwillingung . . . . . . . . . . . . . . . 113

10 Artefakte 115

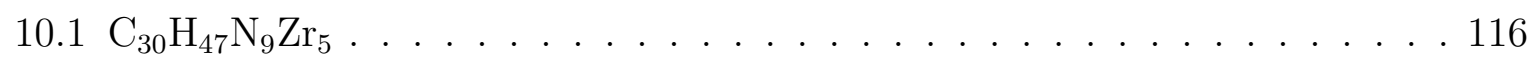

10.2 Gruppe-13-Iminosilikate . . . . . . . . . . . . . . . 117

$\begin{array}{ll}11 \text { Proteinkristallographie } & 119\end{array}$

11.1 Proteinstrukturen mit SHELXD . . . . . . . . . . . . . . . . . . . . 120

11.2 Tetragonales HEW-Lysozyme $\ldots \ldots \ldots$

11.3 Bond-Valence-Methode . . . . . . . . . . . . . . . . . . . 126

$\begin{array}{ll}12 \text { Ausblick } & 129\end{array}$

\begin{tabular}{ll}
\hline Literaturverzeichnis & 132
\end{tabular} 
13 Anhang 140

13.1 Kristallographische Daten der Strukturen . . . . . . . . . . . . . . . . . 140

$13.1 .1\left[\left(\eta^{5}-\mathrm{C}_{5} \mathrm{H}_{4} \mathrm{Me}\right)_{2} \mathrm{Ti}(\mu-\mathrm{F})_{2} \mathrm{AlEt}_{2}\right]_{2} \ldots \ldots \ldots \ldots 141$

13.1 .2 Cycloikositetraphenylen . . . . . . . . . . . . . . . . . 142

13.1 .3 Tetrameres $\mathrm{InCl}_{3} \ldots \ldots \ldots$. . . . . . . . . . . . . . . . 143

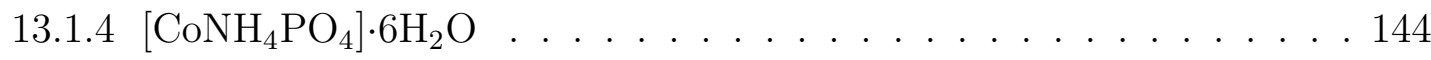

13.1 .5 Unklares Zentralatom. . . . . . . . . . . . . . . . . . . . . . . 145

13.1 .6 Gallium-Iminosilikat . . . . . . . . . . . . . . . . . . . . . . . . 146

13.1 .7 Bromo-Aluminium-Iminosilikat . . . . . . . . . . . . . . . . . . 147

13.1 .8 lodo-Aluminium-Iminosilikat . . . . . . . . . . . . . . . . . . . . . 148

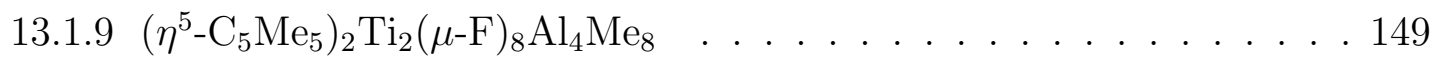

13.1.101-(3,3-Dimethyl-dithiolan-4-on)-2-(4,4-dimethyl-thiolan-3-on)-ethen 150

13.1.111,2-bis-(3,3-Dimethyl-dithiolan-4-on)-ethen . . . . . . . . . . . . . 151

$13.1 .12 \mathrm{Si}_{2}\left(\mathrm{NH}_{2}\right)_{4}\left((\mathrm{CHSiMe})_{2}\right)_{2} \ldots \ldots \ldots \ldots$

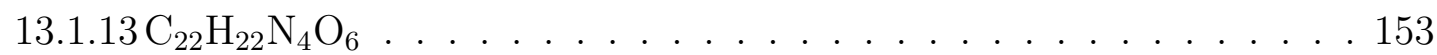

13.1.14Zr-Pyramide . . . . . . . . . . . . . . . . . 154

13.1.15 In-Iminosilikat. . . . . . . . . . . . . . . . . . . 155

13.2 Intensitätsstatistiken . . . . . . . . . . . . . . . . 156

13.2 .1 Lysozyme $\ldots \ldots \ldots$. . . . . . . . . . . . . . . . . . . . 156

13.2.1.1 Euler-Vierkreis /SMART 1K . . . . . . . . . . . 156

13.2 .1 .2 Zweikreis /IPDS . . . . . . . . . . . . . . 157

13.2.1.3 Platform / HiStar . . . . . . . . . . . . . . . . . . . . 158

13.2.1.4 Einkreis/MAR345 . . . . . . . . . . . . . . . . . . 159

13.2.1.5 Einkreis $/$ marCCD . . . . . . . . . . . . . . 160

13.2 .2 Actagardin . . . . . . . . . . . . . . . . . . . 161

13.2.2.1 Zweikreis /IPDS . . . . . . . . . . . . . . 161

13.2.2.2 Platform / HiStar . . . . . . . . . . . . . . . . 162

13.2.2.3 Einkreis/MAR345 . . . . . . . . . . . . . . 163

13.2.2.4 Einkreis $/$ marCCD . . . . . . . . . . . . . . . . . 164

13.3 Material und Methoden . . . . . . . . . . . . . . . . . . . . . . . . . . . 165

13.3 .1 FhuF . . . . . . . . . . . . . . . . . . . . . . . 165

13.3.1.1 Lösungen und Puffer . . . . . . . . . . . . . . . . . . 165

13.3.1.2 Resuspensierung, Aufreinigung und Aufkonzentrierung . . 166

13.3.1.3 Entfernen des His-tags . . . . . . . . . . . . . . . . . . . . 167

13.3.1.4 Gelfiltration . . . . . . . . . . . . . . . . 167

13.3.1.5 Trypsin-Verdauung . . . . . . . . . . . . . . . 167

13.3 .2 Lysozyme $\ldots \ldots \ldots$. . . . . . . . . . . . . . . . . . . . . . . . 168 
13.3.2.1 Lösungen und Puffer . . . . . . . . . . . . . . . . . . 168

13.3 .3 Actagardin . . . . . . . . . . . . . . . . . 168

13.3.3.1 Lösungen und Puffer . . . . . . . . . . . . . . . . . 168

13.3 .4 Diffraktometer . . . . . . . . . . . . . . . . . . . . 169

13.3 .5 Software . . . . . . . . . . . . . . . . . . . . . . . 169

13.4 Publikationen . . . . . . . . . . . . . . . . . . . . . . . . . . . . . 170

13.5 Lebenslauf . . . . . . . . . . . . . . . . . . . . . . . . . 173 


\section{Kapitel 1}

\section{Einleitung}

Seit dem ersten Beugungsexperiment durch Laue, Friedrich und Knipping im Jahre 1912, das ursprünglich dem Zweck diente, die Wellennatur der Röntgenstrahlung [1] zu beweisen und der wenig später durch Bragg erfolgten ersten Strukturbestimmung [2] hat sich die Methode der Röntgenstrukturanalyse enorm gewandelt: Strukturen, die noch vor wenigen Jahren nicht bestimmbar gewesen wären, gelten heute als Routinefälle. Zurückzuführen ist dieser Wandel auf Fortschritte in allen Teilbereichen der Röntgenstrukturanalyse. Die Entwicklung von Flächendetektionssystemen und die stark gestiegene Rechenleistung moderner Computer ermöglichen die Bewältigung immer größerer Strukturen; neue Tieftemperaturmethoden erlauben es, extrem empfindliche Kristalle - zum Teil sogar Kristalle bei Raumtemperatur flüssiger oder gasförmiger Substanzen - zu röntgen, und neue methodische Ansätze schaffen die Voraussetzungen, die genannten Neuheiten voll auszuschöpfen.

In diesem Zusammenhang muß betont werden, daß sich die Grenze lediglich verschoben hat: Trotz aller Erfolge in jüngerer Zeit steht die Röntgenstrukturanalyse auch heute oft vor tatsächlich oder scheinbar unlösbaren Problemen. Immer wieder gelingt es allerdings, durch Weiterentwicklung der Methode einige dieser Probleme zu lösen.

Neben der Kristallisationsarbeit an mehreren Proteinprojekten im Rahmen dieser Dissertation wurden immer wieder Kleinmolekülstrukturen bestimmt. In den vergangenen vier Jahren (die Diplomzeit mit eingeschlossen) wurden so nach und nach über 80 Datensätze gesammelt und über 100 Strukturen verfeinert, darunter viele sog. „Problemstrukturen“. Diese umfangreiche Sammlung verschiedener kristallographischer Probleme ermöglicht es, das ursprüngliche Thema der Dissertation (Vergleich der Sammlung von Proteindatensätzen an verschiedenen Diffraktometer- und Detektortypen) zu erweitern und eine 
allgemeinere Arbeit über die Probleme der modernen hochaufösenden Röntgenstrukturanalyse anzufertigen.

Die vorliegende Arbeit stellt einige der wichtigsten Problembereiche der Röntgenstrukturanalyse vor und zeigt anhand von Beispielen aus der eigenen Praxis, wie das jeweilige Problem im Einzelfall behoben oder umgangen wurde bzw. berichtet von Mißerfolgen.

Auf diese Weise soll ein Überblick über die gegenwärtige Situation der Methode der hochauflösenden Einkristall-Röntgenstrukturanalyse gegeben werden: wo steht die Kristallographie heute und wie könnte sie in einigen Jahren aussehen?

Ein Schwerpunkt der Arbeit gilt dem Vergleich verschiedener Flächenzähler- und Diffraktometertypen anhand von Testmessungen mit einem Protein (Lysozyme) und einem Peptidantibiotikum (Actagardin). Desweiteren entstand im Rahmen der Arbeit ein Tutorium zur Verfeinerung von Fehlordnungen mit dem Programm SHELXL [3], das als Teil dieser Dissertation im Internet veröffentlicht [4] und der gedruckten Ausgabe der Arbeit in Form einer CD-ROM beigefügt ist.

Aus Gründen der Übersichtlichkeit ist diese Arbeit zweigeteilt: Im ersten Teil befindet sich die eingehende Beschreibung und Diskussion der Probleme, während im Anhang die kristallographischen Details der im ersten Teil als Beispiele beschriebenen Strukturen aufgeführt sind.

Die allgemeinen Grundlagen der Kristallographie wie z. B. Theorie der Beugung von Röntgenstrahlen an Materie, Ewald-Konstruktion, Bragg'sche Gleichung, Absorptions-, Polarisations- und Lorentzkorrektur und ähnliches sind in der Literatur (z. B. [5, 6, 7]) eingehend diskutiert und werden hier nicht im Detail beschrieben. Lediglich zu den eher praktischen Problemen wie Verzwillingung oder Fehlordnung findet sich in dieser Arbeit eine ausführlichere theoretische Einleitung, da sich auf Workshops in Göttingen 1997, Frankfurt 1999 und College Station (Texas) 2000 und auch in verschiedenen Korrespondenzen gezeigt hat, daß speziell auf diesen Gebieten Informationsbedarf besteht. 


\section{Kapitel 2}

\section{Kristallisation}

Die Kristallqualität ist von fundamentaler Bedeutung für ein erfolgreiches Beugungsexperiment; der Zucht geeigneter Kristalle kommt daher eine entscheidende Rolle im Rahmen der Röntgenstrukturanalyse zu, und oftmals verhindert der Umstand, daß von einer Substanz keine geeigneten Kristalle gewonnen werden können, eine Röntgenstrukturbestimmung.

Der theoretische Hintergrund des Kristallwachstums ist in der Literatur eingehend beschrieben (z. B. [8]). Betont sei an dieser Stelle lediglich der Einfluß der Wachstumsgeschwindigkeit auf die Kristallqualität: Mit der Wachstumsgeschwindigkeit erhöht sich im allgemeinen die Anzahl der Gitterfehler im Kristall, so daß eine Kristallisationsmethode angewendet werden sollte, die das Gleichgewicht einer Lösung innerhalb mehrerer Tage oder sogar Wochen auf die Seite des Feststoffs verschiebt. Andererseits ist in einigen Fällen - vor allem, wenn sich die zu kristallisierende Substanz leicht zersetzt oder oxidationsempfindlich ist - zügiges Kristallisieren angebracht. Es gibt also für jedes Problem einen optimalen Bereich, der mitunter sehr breit sein kann.

\subsection{Kristallisation von Kleinmolekülen}

Die Anzahl der Methoden zur Kristallisation von Kleinmolekülen ist Legion, ihnen allen ist gemeinsames Ziel, die Lage des Lösungsgleichgewichtes langsam auf die Seite des Feststoffs zu verlagern. Die wichtigsten der im Rahmen dieser Arbeit zum Einsatz gekommenen Methoden seien hier kurz genannt: 
1. Verdunsten des Lösungsmittels,

2. Abkühlen der Lösung,

3. Binäre Lösungsmittelsysteme:

(a) Gasdiffusionsmethode,

(b) Zweischichtverfahren.

Eine ausführliche Beschreibung dieser Methoden findet sich z. B. in der dieser Dissertation vorausgehenden Diplomarbeit [9].

\subsection{Kristallisation von Proteinen}

Bei der Kristallisation von Proteinen ist man an das wäßrige System gebunden. Das eingangs erwähnte Buch von McPherson [8] behandelt das Thema Proteinkristallisation erschöpfend; für alle im Folgenden erwähnten Methoden finden sich Beispiele in diesem Buch. In diesem Zusammenhang soll lediglich die besondere Wichtigkeit der Reinheit der Proteinproben betont werden: Um Proteine erfolgreich zu kristallisieren, ist - von einigen Ausnahmen abgesehen - eine homogene wäßrige Lösung von relativ hoher Konzentration und Reinheit unverzichtbar. Das heißt, das Protein sollte möglichst nur in einer Form also etwa nur als Monomer oder nur als Dimer - und nicht als Gemisch vorliegen; seine Reinheit ist idealerweise besser als 99\%ig, und die Konzentration sollte im allgemeinen nicht unter $5 \mathrm{mg} / \mathrm{ml}$ liegen.

Diese Anforderungen sind im Vergleich zu den für biologische Experimente üblichen Werten als extrem anzusehen, aber für eine erfolgreiche Kristallisation essentiell.

\subsubsection{Gasdiffusionsmethode}

Die verbreitetste Methode zur Kristallisation von Proteinen ist die Gasdiffusionsmethode. Hierbei hängt ein wenige Mikroliter großer Tropfen (hanging drop Methode) einer Mischung aus Fällungsmittel und Proteinlösung (Konzentrationen zwischen $5 \mathrm{mg} / \mathrm{ml}$ und über $100 \mathrm{mg} / \mathrm{ml}$ sind dabei gebräuchlich) an einem silikonisierten Deckgläßchen über einem etwa $1 \mathrm{ml}$ großen Reservoir von Fällungsmittel. Innerhalb von Tagen oder Wochen in Extremfällen auch Monaten - stellt sich über Gasdiffusion ein Konzentrationsgleichgewicht zwischen Tropfen und Reservoir ein, das im günstigen Fall auf der Seite des Feststoffs 
liegt. Idealerweise liegt der Feststoff als Kristall vor, häufig jedoch erhält man amorphe Niederschläge in Form von manchmal sogar denaturiertem Präzipitat.

Größere Tropfen (bis etwa $50 \mu l$ ) können auf einer sog. „Brücke“ sitzend (sitting drop Methode) äquilibriert werden.

\subsubsection{Die sparse-matrix-Technik}

Im Jahr 1991 wurde erstmals eine Liste mit präzisen Angaben zur Herstellung 50 wäßriger Lösungen verschiedener Salze, Polyethylenglycole, Puffer usw. veröffentlicht [10], die ein systematisches Testen möglichst weniger unterschiedlicher Bedingungen (daher die Bezeichnung sparse-matrix) zur Proteinkristallisation ermöglichen sollte. Relativ bald wurden weitere Listen dieser Art publiziert [11], und heute kann man auf über 500 erprobte und zum großen Teil auch kommerziell erhältliche Formulierungen zurückgreifen.

Die Strategie ist zwar arbeitsintensiv, aber einfach und sehr erfolgreich: Jedes Protein, das man zu kristallisieren beabsichtigt, unterwirft man zuerst einer langen Reihe standardisierter Bedingungen und zieht aus den Ergebnissen Schlüsse für die weitere Vorgehensweise. Auf diese Weise lassen sich verhältnismäßig schnell eine Vielzahl von möglichen Bedingungen als für die Kristallisation des jeweiligen Proteins ungeeignet ausschließen (etwa bestimmte pH-Bereiche u. ä.). Andere Bedingungen können dagegen durch ein solches screening als vielversprechend erkannt werden - in einigen Fällen erhält man bereits aus diesen ersten Ansätzen für die Röntgenstrukturanalyse geeignete Kristalle.

Die Einführung der sparse-matrix-Technik hat erheblich zur Systematisierung der Proteinkristallisation beigetragen. Der Weg vom Protein zum meßbaren Kristall ist damit jedenfalls im Prinzip - relativ klar vorgezeichnet:

Aufreinigung $\rightarrow$ sparse-matrix-screening $\rightarrow$ finescreening erfolgversprechender Bedingungen aus dem vorherigen Schritt $\rightarrow$ Auffinden geeigneter Kryobedingungen $\rightarrow$ Beugungsexperiment.

\subsubsection{Seeding}

Sind die optimalen Kristallisationsbedingungen gefunden, steht man nicht selten vor dem Problem, daß die Kristalle trotz aller Versuche zu klein bleiben. Eine verbreitete und sehr häufig erfolgreiche Methode, die Kristalle zu vergrößern, stellt das Seeding dar. Hierbei werden in einen äquilibrierten Kristallisationstropfen, der eine Proteinlösung enthält, die 
zwar übersättigt ist, aber nur so gering übersättigt, daß keine spontane Kristallkeimbildung eintritt, gezielt wenige Kristallkeime eingebracht, die dann weiterwachsen sollen. Dadurch erhält man weniger Kristalle, als durch spontane Keimbildung entstehen würden, diese werden aber größer und sind meistens regelmäßiger aufgebaut.

Je nach Größe der eingebrachten Kristallkeime unterscheidet man zwischen Mikro- und Makroseeding. Gemeinsame Voraussetzung beider Varianten ist, daß man wenigstens einen Kristall - oder zumindest mikrokristallinen Niederschlag - des zu kristallisierenden Proteins (oder aber eines eng verwandten, etwa einer Mutante) haben muß.

\subsubsection{Mikroseeding}

Mikroseeding besteht in Übertragung mikroskopisch kleiner Kristallkeime in einen neuen äquilibrierten Tropfen. Hierzu gibt es prinzipiell zwei Methoden:

Mit einem flexiblen, nicht zu dünnen Gegenstand (sehr bewährt haben sich zu diesem Zweck Katzen-Schnurrhaare), berührt man einen bestehenden Kristall und streift so mikroskopisch kleine Kristallite von seiner Oberfläche ab. Beim Durchziehen des Gegenstandes durch den Tropfen】, landen einige der Kristallite in diesem, was im allgemeinen ausreicht, Kristallwachstum zu induzieren.

Bei der anderen Methode, Mikrokristalle in einen Kristallisationstropfen zu übertragen, wird ein Kristall oder kristalliner Niederschlag mit einer Nadel fein zermörsert und mit einer Lösung, in der sich der so erhaltene Kristallstaub nicht auflösen darf, sehr stark verdünnt. Zur gleichmäßigen Verteilung der Kristallite in der Lösung und auch zur weiteren Zerkleinerung kann die verdünnte Seed-Lösung zusätzlich mit Ultraschall behandelt werden.

Von dieser Lösung gibt man einen oder einen halben Mikroliter zu dem äquilibrierten Tropfen, wobei ausreichend viele Keime übertragen werden.

\subsubsection{Makroseeding}

Beim Makroseeding werden kleine oder mittelgroße Kristalle von dem Tropfen, in dem sie gewachsen sind, in einen anderen äquilibrierten Tropfen, in dem sie weiterwachsen sollen, übertragen. Im allgemeinen geschieht das mittels einer feinen Glaskapillare durch vorsichtiges Ansaugen und wieder Ausblasen mit einer Pipette.

\footnotetext{
${ }^{1}$ Des Durchziehens wegen wird diese Methode auch häufig als streak seeding bezeichnet.
} 
Da Kristalle praktisch nie eine perfekte Oberfläche haben, ist es nötig, die zu übertragenden Kristalle ein wenig anzulösen, damit sie in dem neuen Tropfen gleichmäßig weiterwachsen und nicht zu völlig verwachsenen, für die Röntgenstrukturanalyse unbrauchbaren Gebilden werden. Um dies zu erreichen, bringt man die Kristalle aus ihrem Ursprungstropfen zunächst in einen Tropfen mit einer Lösung, in der sie sich sehr langsam aufösen. Nach kurzer Zeit entnimmt man sie diesem „Ätzbad“ und überträgt sie endgültig in den Tropfen mit der moderat übersättigten Proteinlösung.

In einigen Fällen ist zum Züchten geeigneter Kristalle eine Kombination aus Mikro- und Makroseeding erforderlich: Mit Hilfe des Mikroseeding erzeugt man aus kristallinem Niederschlag kleine Kristalle, die durch Makroseeding zu Kristallen ausreichender Größe gebracht werden.

\subsection{Aufreinigung und Versuch der Kristallisation von FhuF}

Unter Eisenmangel sondern viele Bakterien sogenannte Siderophore ab, chelatbildende Liganden, die außerhalb der Zelle $\mathrm{Fe}^{3+}$-Ionen komplexieren und - mit Eisen beladen - in die Zelle zurückgebracht werden. Dort kann das Eisen zu Fe ${ }^{2+}$ reduziert und so freigesetzt und dem Zellstoffwechsel zugeführt werden. Bei der Untersuchung eines solchen siderophoren Eisenaufnahmesystems bei Escherichia Coli (das Ferrioxamin B System) war man auf FhuF gestoßen [12], ein mit 262 Aminosäuren (30.1 kDa) relativ kleines Protein, das an dem Prozeß beteiligt ist.

Der Gehalt an anorganischem Schwefel und die Ergebnisse von Mössbauer- und ESRSpektroskopie wiesen FhuF als Eisen-Schwefel-Protein aus, in dem ein [2Fe-2S]-Cluster mit zwei tetraedrisch von Schwefel umgebenen Eisenatomen vorliegt. Zwei dieser S-Atome sind anorganischer Natur und bilden mit den beiden Fe-Atomen einen zentralen viergliedrigen $\mathrm{Fe}_{2} \mathrm{~S}_{2}$-Ring aus, während die übrigen vier S-Atome von Cystein-Seitenketten des Proteins kommen [12]. Dies ist zwar eine der Standard-Formen für Fe-S-Clusterproteine [13], die $g$-Werte der ESR-Spektren und einige der Mössbauer-Parameter sind jedoch völlig atypisch für alle bekannten Formen von [2Fe-2S]-Clustern, so daß davon ausgegangen werden muß, daß FhuF ungewöhnliche strukturelle Eigenschaften aufweist [12].

Weitere Untersuchungen ergaben, daß FhuF mit hoher Wahrscheinlichkeit nicht unmit- 
telbar am Transport von Eisenatomen oder Ferrioxamin B Molekülen selbst beteiligt ist(2), sondern an dem Eisenaufnahmeprozeß auf andere Art, und zwar vermutlich als Elektronendonor für die Reduktion von $\mathrm{Fe}^{3+} \mathrm{zu} \mathrm{Fe}^{2+}$, teilnimmt [12].

FhuF besitzt sechs Cys-Residues. Durch Cys $\rightarrow$ Ser Punktmutationen wurden die vier Nterminalen Cysteine (Residues 244, 245, 256 und 259) eindeutig als clusterbildend bestimmt; die Cysteine 137 und 143 nehmen nicht am Aufbau des [2Fe-2S]-Clusters teil. Dieses so für FhuF ermittelte Motiv (Cys-Cys-Xaa $10-\mathrm{Cys}-\mathrm{Xaa}_{2}-\mathrm{Cys}$ ) unterscheidet sich signifikant von der sonst für [2Fe-2S]-Proteine üblichen Abfolge (Cys-Xaa 2 -Cys-Xaa ${ }_{9-15^{-}}$ Cys-Xaa 2 -Cys) [12], ein weiterer Hinweis auf eine ungewöhnliche Struktur dieses Proteins.

Der im Vorangegangenen kurz zusammengefaßte aktuelle Kenntnisstand über die Natur und Funktion von FhuF weist noch einige Fragen hinsichtlich Funktion und Aufgabe auf, deren Beantwortung man mit Hilfe einer dreidimensionalen Struktur des Moleküls sehr wahrscheinlich ein großes Stück näher kommen könnte.

Die Zucht geeigneter Kristalle erwies sich jedoch als besonders schwierig.

Aufgrund der auftretenden Mißerfolge wurden alle Möglichkeiten ausgeschöpft, die im Rahmen der Universität Göttingen und des EMBL Hamburg zur Verfügung stehen, weswegen sich FhuF gut als Beispiel für die Proteinkristallisation eignet. Im Folgenden ist der Weg von den tiefgefrorenen E.-Coli-Zellen bis hin zu den Kristallisationsansätzen und deren Auswertung detailliert beschrieben.

\subsubsection{Aufreinigung und erste Kristallisationsansätze}

FhuF lag in Form tiefgefrorener E.-Coli-Zellen vor, in denen es exprimiert worden war. Vor der eigentlichen Aufreinigungen mußten die Zellen aufgetaut, resuspensiert und ihre Zellwand in Gegenwart von Lysozyme mit Ultraschall zerstört werden. Nach Abzentrifugieren des unlöslichen Zellmaterials von der Proteinlösung konnte die eigentliche Aufreinigung also die Trennung des FhuF von den anderen in den E.-Coli-Zellen enthaltenen Proteinen - beginnen.

Zur Erleichterung der Aufreinigung war FhuF am N-Terminus genetisch um 23 Aminosäuren - zehn davon Histidin - verlängert worden. Die lange Reihe von His-Residues (,His-tag“ genannt) ermöglicht es, das Protein mit Hilfe einer mit Nickel beladenen Säule

\footnotetext{
${ }^{2}$ Daß FhuF in einigen Datenbanken trotzdem als Fe-Transport-Protein bezeichnet wird, ist auf veraltete Informationen zurückzuführen; nach Erkenntnissen der Arbeitsgruppe von Prof. Hantke in Tübingen ist FhuF kein Transportprotein [12].
} 

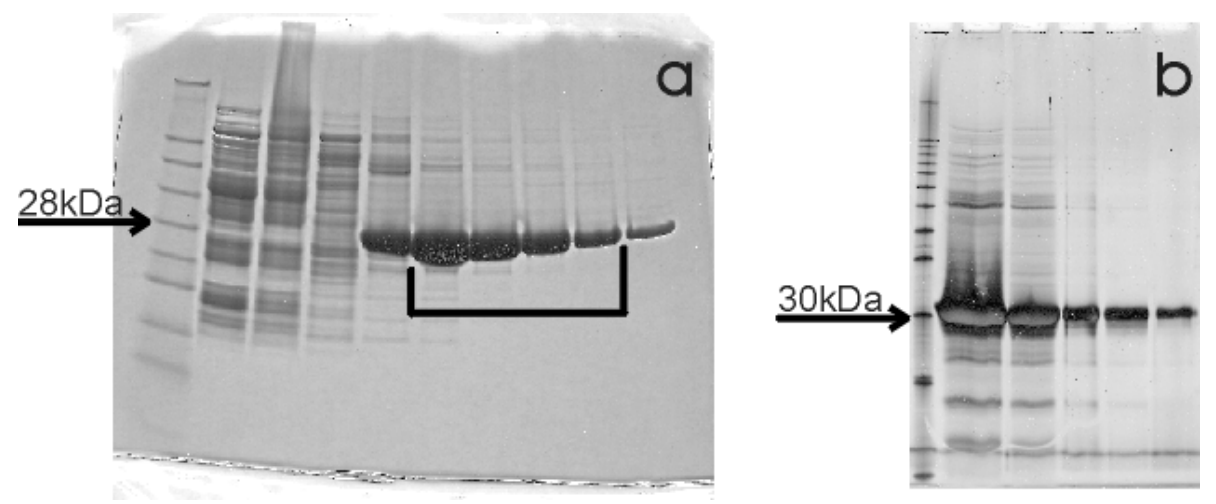

Abb. 2.1: Zwei SDS-Page-Elektrophoresegele von FhuF: a ein Coomassie gefärbtes Gel der Aufreinigung (die gekennzeichneten Fraktionen wurden zur Aufkonzentrierung verwendet), b ein Silber gefärbtes Gel des in verschiedenen Konzentrationen aufgetragen aufkonzentrierten FhuF.

(Ni-NTA) aufzureinigen: Läßt man eine Lösung des Proteins über die Säule laufen, koordinieren die Seitenketten der Histidine chelatartig an die $\mathrm{Ni}^{2+}$-Ionen auf der Säule, so daß das Protein festgehalten wird, während alle Verunreinigungen die Säule ungehindert passieren. Nach gründlichem Waschen kann das Protein mit Imidazol, das deutlich besser an $\mathrm{Ni}^{2+}$ bindet und so die Histidin-Seitenketten verdrängt, in hoher Reinheit von der Säule eluiert werden.

Abb. 2.1 zeigt ein Coomassie gefärbtes Elektrophoresegel, das die Fraktionen der Aufreinigung über die Ni-Säule wiedergibt; das Gel in Abb. 2.1 b ist mit $\mathrm{AgNO}_{3}$ gefärbt und veranschaulicht die sehr hohe Reinheit des FhuF nach der Aufreinigung über Ni-NTA. Im Anschluß an die Aufreinigung wurde die Konzentration der aufgrund der Gelanalyse (siehe Kennzeichnung der entsprechenden lanes in Abb. 2.1 a) ausgewählten Fraktionen mit Hilfe des Bradford-Assays bestimmt und die vereinigten Fraktionen mit Hilfe von Überdruck in einer sog. Amicon-Konzentratorzelle aufkonzentriert.

Details der Resuspensierung und weiteren Behandlung der tiefgefrorenen Zellen, sowie der Aufreinigung und -konzentration sind im experimentellen Teil des Anhangs zu finden (13.3.1, Seite 165).

Nach der ersten Aufreinigung und -konzentrierung lagen $3.5 \mathrm{ml}$ Proteinlösung mit einer Konzentration von etwa $7 \mathrm{mg} / \mathrm{ml}$ vor. Weiteres Erhöhen der Konzentration war nicht möglich, da das Protein bei Konzentrationen von über $7 \mathrm{mg} / \mathrm{ml}$ zu spontanem Aggregieren neigt.

Mit diesen $3.5 \mathrm{ml}$ wurden umfangreiche Kristallisationsversuche unternommen: Neben den kommerziell erhältlichen sparse-matrix-Kits der Firmen Hampton Research und Emerald Bio Structures (zusammen 338 verschiedene Bedingungen) wurden noch etwa 150 an- 


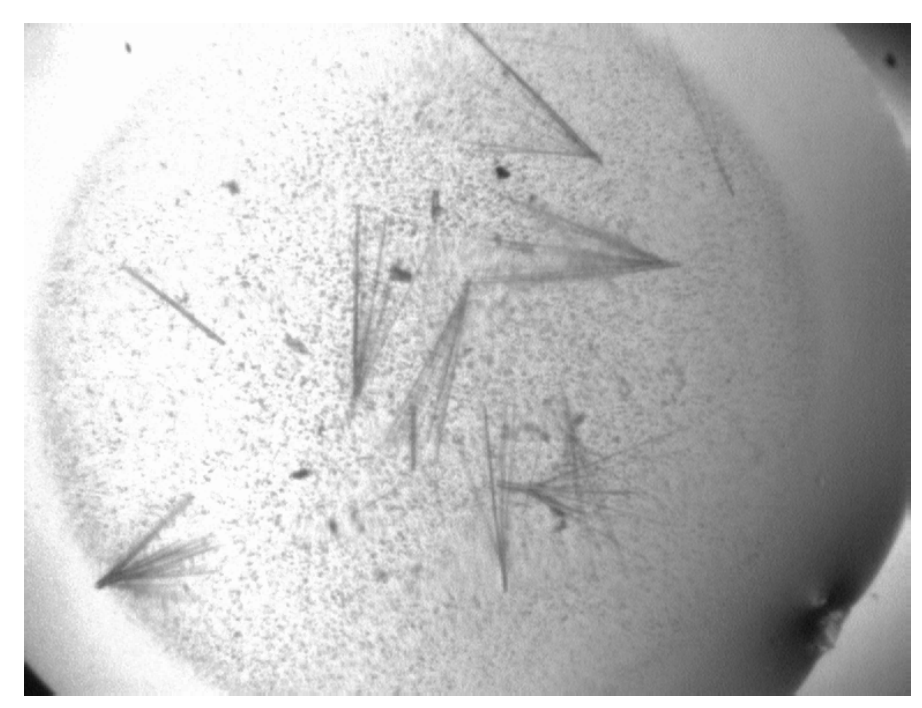

Abb. 2.2: Feine, nicht reproduzierbare Nadeln von FhuF, erhalten aus $0.2 \mathrm{M} \mathrm{Mg}(\mathrm{HCOO})_{2}$

dere Bedingungen versucht, die auf persönlicher Erfahrung von Mitarbeitern des EMBL Hamburg beruhen [14]. Alle Kristallisationsansätze wurden doppelt durchgeführt, wobei jeweils eine Version bei Raumtemperatur und eine bei $+4{ }^{\circ} \mathrm{C}$ gelagert wurde. Damit wurden insgesamt knapp 1000 Bedingungen für die erste Kristallisation von FhuF getestet. Nach diesen Ansätzen war das vorhandene Protein nahezu verbraucht, leider jedoch wurden keine geeigneten Kristalle oder auch nur vielversprechende Niederschläge erhalten. Zwischen den Ansätzen bei $4{ }^{\circ} \mathrm{C}$ und den bei Raumtemperatur gelagerten war kein Unterschied zu erkennen.

Lediglich in einem einzigen Tropfen wurden feine Nadeln des Proteins gefunden ${ }^{3}$ (siehe Abb. 2.2). Diese waren jedoch viel zu dünn, um für die Strukturanalyse geeignet zu sein, und es war nicht möglich, das Entstehen der Nadeln zu reproduzieren oder durch Seeding größere Kristalle zu erhalten.

\subsubsection{Glycerol und Dynamic Light Scattering}

In einer zweiten Aufreinigung wurden nach der oben beschriebenen Prozedur erneut E.Coli-Zellen resuspensiert, aufgereinigt und konzentriert. Von Anfang an wurde dabei allen Puffern $10 \%$ Glycerol zugegeben. Glycerol ist dafür bekannt, einen stabilisierenden Einfluß auf Proteine auszuüben [11], und es war tatsächlich möglich, die Konzentration auf bis zu $12 \mathrm{mg} / \mathrm{ml} \mathrm{zu}$ erhöhen, ohne daß Aggregation eintrat.

\footnotetext{
${ }^{3}$ Formulierung Nr. 44 aus Hampton Crystal Screen: $\mathrm{Mg}(\mathrm{HCOO})_{2} 0.2 \mathrm{M}$.
} 
Reste des Proteins aus der ersten Aufreinigung (ohne Glycerol) und ein kleiner Teil des neu aufgereinigten Proteins (mit 10\% Glycerol) wurden einem temperaturaufgelösten $D y$ namic Light Scattering (DLS) Experiment unterzogen.

Beim DLS wird ein Lichtstrahl an einer Probe des Proteins gestreut. Das Streulicht wird nach Winkel und Intensität aufgelöst gemessen, was Rückschlüsse auf Konzentration und Partikelgröße in der Probe zuläßt [15].

Idealerweise verhält sich ein gelöstes Protein, um zum Kristallisieren geeignet zu sein, im DLS monomodal (das heißt, es liegt nur eine Partikelgröße vor und nicht eine Mischung aus Mono-, Di- bzw. Oligomeren oder sogar Aggregaten des Proteins), wobei das Verhalten des Proteins hinsichtlich Di- bzw. Oligomerisierung mitunter stark von Temperatur, Konzentration und verschiedenen Zusätzen wie Salz oder Glycerol abhängen kann. Häufig gelingt es, mit Hilfe des DLS-Experiments Bedingungen zu finden, bei denen sich das untersuchte Protein tatsächlich monomodal verhält; zur Kristallisation sollte man dann möglichst nahe an diesen Bedingungen bleiben.

Im Falle von FhuF wurden drei Protein-Konzentrationen (ca. $12 \mathrm{mg} / \mathrm{ml}, 7 \mathrm{mg} / \mathrm{ml}$ und $4 \mathrm{mg} / \mathrm{ml}$ ), drei verschiedene NaCl-Konzentrationen (100 mM, $200 \mathrm{mM}$ und $550 \mathrm{mM}$ ) und als zusätzlicher Parameter Anwesenheit von Glycerol getestet folgende Ergebnisse:

1. FhuF liegt vermutlich unter allen getesteten Bedingungen als Dimer vor.

2. Glycerol hat keinen entscheidenden Einfluß auf das Aggregationsverhalten.

3. Hohe Salzkonzentration führt zu starker Verbreiterung der Linie des DLSSpektrums.

4. Die im DLS-Spektrum bei $20^{\circ} \mathrm{C}$ beobachtete Bande ist schärfer als die bei $4{ }^{\circ} \mathrm{C}$ beobachtete.

5. Niedrigkonzentrierte Proteinlösungen neigen weniger zur Aggregation als hochkonzentrierte.

Die Tatsache, daß durch DLS kein Einfluß von Glycerol auf das Aggregationsverhalten nachgewiesen werden konnte, ist ein überraschendes Resultat, da die Anwesenheit von Glycerol es erlaubte, die Konzentration fast zu verdoppeln, ohne daß sich Aggregation

\footnotetext{
${ }^{4}$ Die höchste Proteinkonzentration ließ sich nur mit Glycerol realisieren, so daß für $12 \mathrm{mg} / \mathrm{ml}$ keine Ergebnisse für die Abwesenheit von Glycerol vorliegen.
} 
bemerkbar macht; vermutlich sollte man die Aussagekraft der DLS-Experimente nicht überbewerten und die Ergebnisse eher als Hinweise auffassen.

Aufgrund der Ergebnisse der DLS-Experimente wurde für weitere Kristallisationsansätze eine Proteinkonzentration von $8 \mathrm{mg} / \mathrm{ml}, 100 \mathrm{mM} \mathrm{NaCl}$ und $10 \%$ Glycerol gewählt. Außerdem wurden alle weiteren Kristallisationsansätze lediglich bei Raumtemperatur ausgeführt und nicht mehr zusätzlich bei $+4{ }^{\circ} \mathrm{C}$, zumal bereits bei vorangegangenen Kristallisationsversuchen kein Unterschied zwischen Raum- und Tieftemperaturansätzen erkennbar war (vgl. Seite 10).

Alle oben beschriebenen Bedingungen wurden erneut versucht, jedoch ohne Erfolg - auch die einmal beobachteten Nadeln wurden nicht mehr erhalten.

\subsubsection{Entfernen des His-tags und erneute Kristallisationsversu- che}

Es kommt nicht selten vor, daß die zur Aufreinigung sehr geeigneten His-tags aufgrund ihrer hohen Beweglichkeit und Neigung zur Ausbildung von Fehlordnungen die Kristallisation stark erschweren oder sogar verhindern. Daher wurden für weitere Kristallisationsversuche 18 der zusätzlichen 23 Aminosäuren mit einer Protease abgeschnitten.

Die Protease Enterokinase schneidet selektiv nach der Sequenz Asp-Asp-Asp-Asp-Lys; mit dieser Sequenz beginnt der His-tag von FhuF. Nach einigen Versuchen zur Optimierung der Abspaltung wurde eine größere Menge von FhuF (neue Aufreinigung aus E.-Coli-Zellen wie beschrieben) bei für die Enterokinase günstigen Bedingungen $\square^{\emptyset}$ vier Stunden lang mit der Protease inkubiert. Alle 30 Minuten wurde eine Probe genommen und für ein Gel vorbereitet (siehe Abb. 2.3).

Die abgespaltenen His-tags sowie ungespaltenes Protein wurden über eine Ni-NTA-Säule abgetrennt. Die Entfernung der Enterokinase erfolgte mit Hilfe eines kommerziell erhältlichen Kits. Experimentelle Details zur Abspaltung des His-tags finden sich im experimentellen Teil des Anhangs (13.3.1, Seite 167).

Nach Aufkonzentrierung auf ca. $8 \mathrm{mg} / \mathrm{ml}$ wurden etwa $750 \mu l$ His-tag freies FhuF erhalten (entspricht einer Gesamtausbeute der Spaltung mit allen nachfolgenden Aufreinigungsschritten von etwa 40 \%). Diese Proteinlösung wurde allen oben erwähnten kommerziellen Kristallisationsbedingungen unterworfen, und in einem Tropfen wurden tatsächlich sehr

\footnotetext{
${ }^{5}$ Das (sachlich bessere) Synonym für Enterokinase ist Enteropeptidase.

${ }^{6}$ Raumtemperatur, pH 7.5, $2 \mathrm{mM} \mathrm{CaCl} 2$
} 


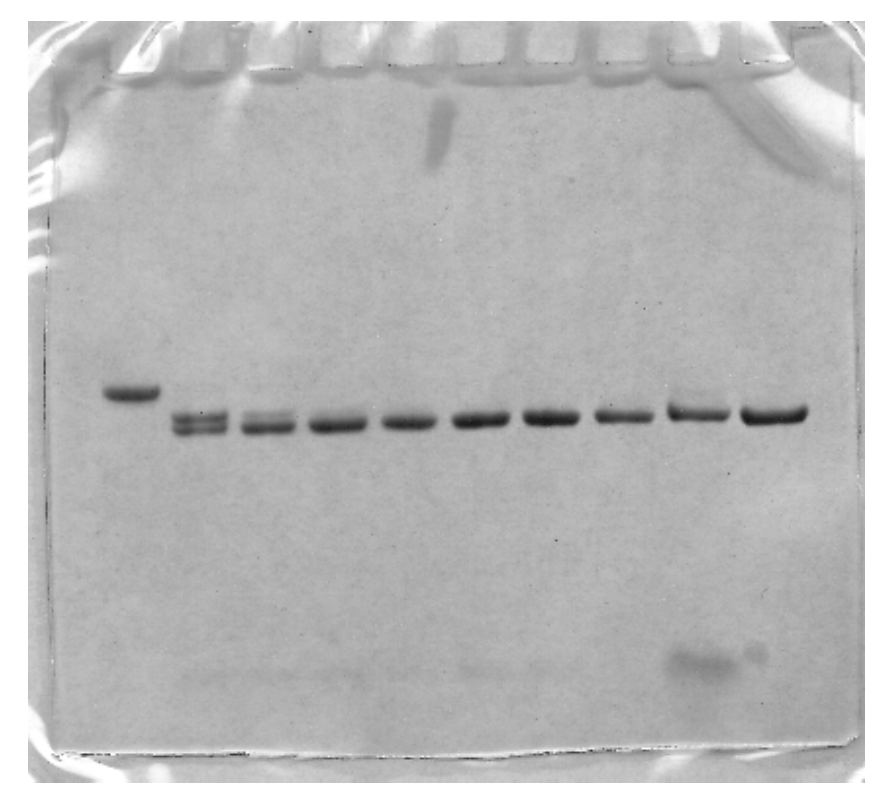

Abb. 2.3: Coomassie gefärbtes Gel von der Abspaltung des His-tags. Die erste lane zeigt das ungespaltene FhuF, die lanes 2 bis 8 den Fortgang der Spaltung (Probennahme im 30 Minuten-Abstand), lane 9 zeigt das Eluat von der Ni-NTA-Säule (unten ist der His-tag als grauer Fleck zu erkennen). Lane 10 entspricht dem fertig aufkonzentrierten His-tag-freien FhuF.

kleine, aber gut geformte Kristalle von blaßroter Farbe beobachtet]. Mit Hilfe von Mikroseeding (Zermörsern, Verdünnen und Zupipettieren; vgl. 2.2.3.1, Seite 6) gelang es, die Kristalle auf eine Größe von $0.01 \times 0.02 \times 0.50 \mathrm{~mm}$ zu bringen (siehe Abb. 2.4) und röntgenstrukturanalytisch zu untersuchen. Bereits das erste Beugungsbild zeigte jedoch, daß die Elementarzelle für ein Protein viel zu klein war, so daß es sich bei den gezüchteten Kristallen um ein Salz handeln mußte. Trotzdem wurden die Kristalle einer sorgfältigen Röntgenstrukturanalyse unterworfen; deren Ergebnis ist in den Kapiteln 6 (Seite 65) und 9 (Seite 113) dargestellt.

\subsubsection{Zwei Mutanten}

Wie eingangs erwähnt, waren zur Ermittlung der clusteraufbauenden Cystein-Residues sechs Cys $\rightarrow$ Ser-Punktmutationen durchgeführt worden. Die vier Mutanten, die den [2Fe2S]-Cluster nicht mehr aufzubauen vermochten, sind, da das entscheidende Motiv nicht mehr besteht, kaum zur Aufklärung der Struktur von FhuF geeignet, die anderen beiden Mutanten sollten sich jedoch hinsichtlich Faltung und dreidimensionaler Struktur nur geringfügig vom Wildtyp unterscheiden.

\footnotetext{
${ }^{7}$ Formulierung Nr. 26 aus Hampton Crystal Screen II: $1.8 \mathrm{M}\left(\mathrm{NH}_{4}\right)_{2} \mathrm{SO}_{4}, 0.1 \mathrm{M} \mathrm{MES}$ pH $6.5,0.01 \mathrm{M}$ $\mathrm{CoCl}_{2} \cdot 6 \mathrm{H}_{2} \mathrm{O}$

8 Aufgenommen bei Raumtemperatur mit einem MAR345 Imaging Plate Detektor; weitere Angaben zum Gerät unter 5.1.5 auf Seite 49
} 

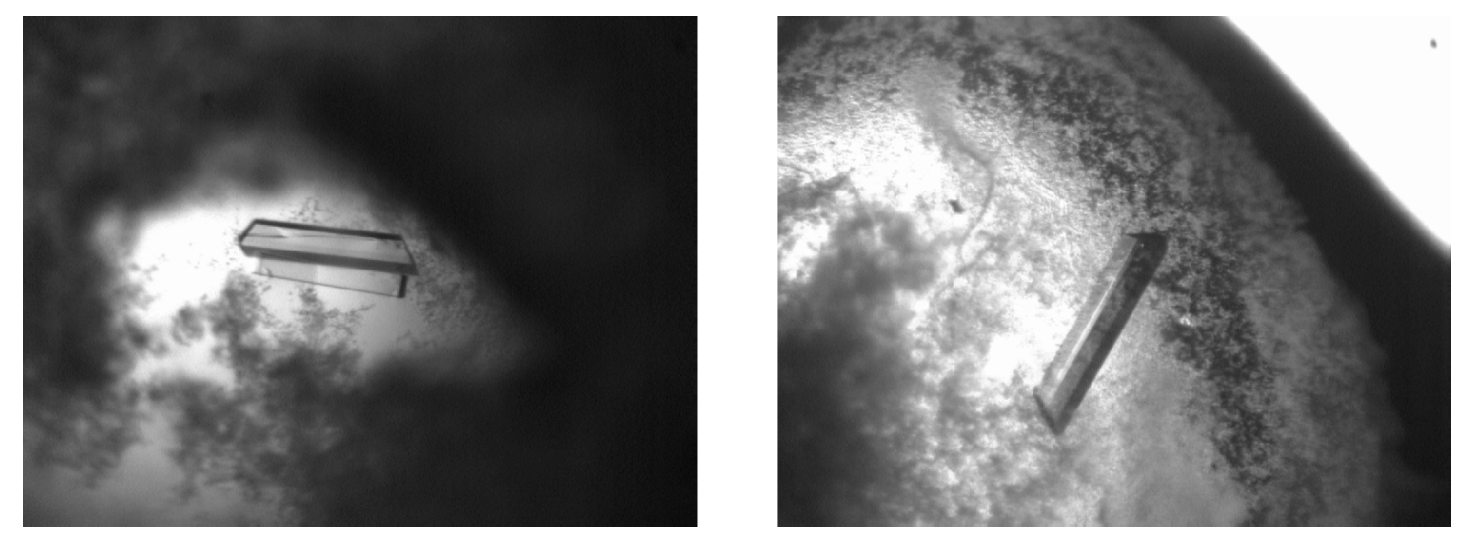

Abb. 2.4: Salzkristalle gewachsen in Anwesenheit von FhuF.

Nachdem alle Versuche der Kristallisation mit dem Wildtyp von FhuF - mit und ohne His-tag - fehlgeschlagen waren, wurden die beschriebenen Aufreinigungsschritte auch mit den Mutanten Cys137 $\rightarrow$ Ser (Mutante I) und Cys143 $\rightarrow$ Ser (Mutante II) durchgeführt. Wie bereits mit dem Wildtyp wurden auch mit beiden Mutanten sehr umfangreiche Kristallisationsversuche - sowohl mit, als auch ohne His-tag - unternommen. Wiederum stellte sich kein Erfolg ein: keine der beiden Mutanten kristallisierte.

\subsubsection{Malonat}

Alexander McPherson berichtete kürzlich von durchschlagenden Kristallisationserfolgen mit Hilfe von Natriummalonat [16]. Einen einfachen Salzgradienten verwendend sei es ihm gelungen, nahezu jedes Protein zu kristallisieren.

In einem Screening, das bei vier verschiedenen $\mathrm{pH}$-Werten ( $\mathrm{pH}$ 6.0, 7.0, 8.0 und 9.0) Malonatkonzentrationen von $0.5 \mathrm{M}$ bis $3.0 \mathrm{M}$ in $0.5 \mathrm{er}$ Schritten realisierte, wurden mit dem Wildtyp und den beiden Mutanten jeweils mit und ohne His-tag Kristallisationsversuche unternommen, die ohne Erfolg verliefen.

\subsubsection{Gelfiltration}

Die zur Kristallisation benötigte Reinheit ist enorm hoch. Wenn ein Protein nicht kristallisiert, sind in den meisten Fällen Verunreinigungen verantwortlich. Aus diesem Grunde wurde erneut Protein der Mutante II aus den Zellen isoliert und aufgereinigt, und von einem Teil wurde der His-tag entfernt. Beide Proben wurden anschließend zur Erhöhung der 
Reinheit (soweit noch möglich) einer Gelfiltration unterzogen? und - nach Aufkonzentrierung - allen erwähnten kommerziellen Kristallisationsbedingungen ausgesetzt. Kristalle wurden allerdings nicht erhalten. Außerdem war zwischen den Kristallisationsansätzen der Mutante II mit und ohne Gelfiltration kein Unterschied im Verhalten des Proteins gegenüber den verschiedenen Bedingungen feststellbar, so daß auf eine Gelfiltration für Wildtyp und Mutante I verzichtet wurde.

\subsubsection{Trypsin-Verdauung}

Neben unzureichender Reinheit ist Beweglichkeit des Proteins ein häufiger Hinderungsgrund für Kristallisation. Eine verbreitete Methode, bewegliche Bereiche von Proteinen zu entfernen, ist die Verdauung mit Trypsin. Trypsin ist eine Peptidase, die selektiv nach den Aminosäuren Arginin und Lysin schneidet, und zwar bei nativem Protein erheblich schlechter (und damit langsamer) als bei denaturiertem. Das heißt, die häufig relativ kompakte Faltung schützt das Protein vor dem Angriff durch Trypsin, und leichter zugängliche Teile des Proteins werden zuerst entfernt. Diesen Umstand kann man ausnutzen, indem man ein Protein kontrolliert der Peptidase aussetzt und die Verdauung genau dann stoppt, wenn alle beweglichen Teile weggeschnitten sind, der kompaktere Kernbereich aber noch nicht angegriffen ist.

Soweit die Theorie. In der Praxis jedoch sind viele Proteine nicht für die Trypsinverdauung geeignet, weil sie zu viele oder zu wenige Arginin- und Lysin-Residues enthalten oder weil ihre Faltung zu locker ist, so daß Trypsin sofort das gesamte Protein fragmentiert, statt einen definierten Kernbereich übrigzulassen. Auch ist diese Methode nicht unumstritten, weil das aus der Verdauung resultierende Proteinfragment unter Umständen nur noch wenig mit dem ursprünglichen Protein gemein hat; soweit möglich sollte das erhaltene Fragment also immer einer Aktivitätsprüfung unterzogen werden.

Im Falle von FhuF ist eine Aktivitätsprüfung nicht möglich, da die genaue Funktion des Proteins bislang unbekannt ist. Dagegen kann das Vorhandensein des [2Fe-2S]-Clusters leicht überprüft werden, weil das Protein bei Zerstörung des Clusters seine intensive braune Farbe verliert. Das Hauptaugenmerk der geplanten Röntgenstrukturanalyse lag auf der Aufklärung des vermutlich ungewöhnlichen Aufbaus des [2Fe-2S]-Clusters, so daß, wenn die Trypsinverdauung ein definiertes Kernfragment brauner Farbe zurücklassen sollte, davon ausgegangen werden kann, daß die Röntgenstruktur dieses Fragments die wichtigsten Fragen zu beantworten in der Lage sein sollte. Ob Trypsinverdauung sinnvoll ist, kann

\footnotetext{
${ }^{9}$ Experimentelle Details hierzu finden sich im Anhang (Seite 167).
} 


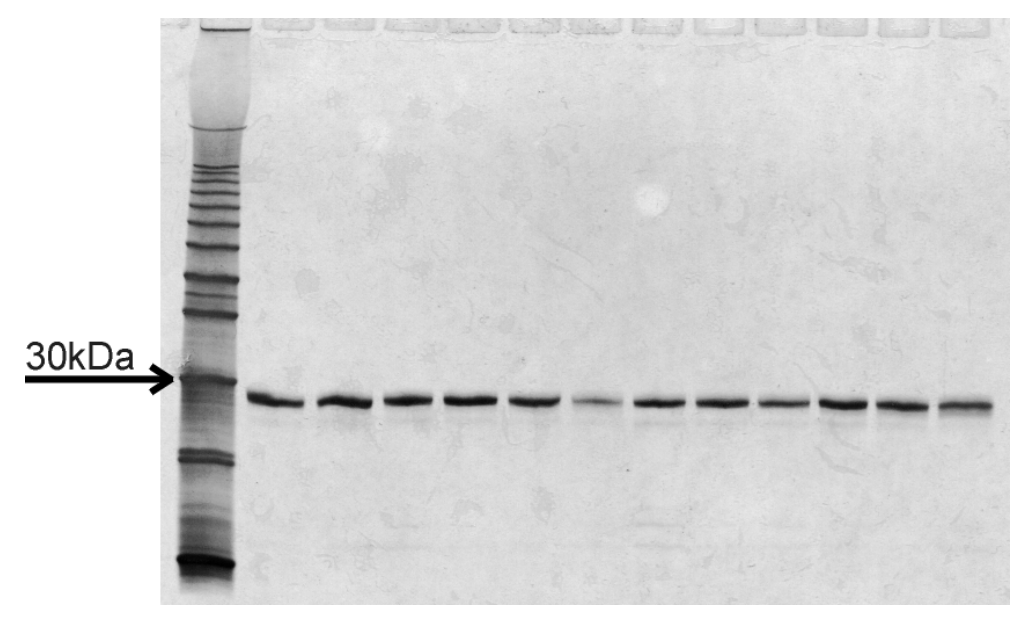

Abb. 2.5: $\mathrm{AgNO}_{3}$ gefärbtes Elektrophoresegel des Trypsin-Verdauungsversuchs von FhuF (Wildtyp ohne His-tag). Proben wurden nach 0, 5, 10, 20, 30, 45, 60, 90, 120, 240 und 360 Minuten genommen (lanes 3 bis 13); lane 2 zeigt das Protein ohne Trypsin, lane 1: marker.

man anhand der Sequenz lediglich vage abschätzen, wirklichen Aufschluß bringt nur das Experiment: Eine verdünnte Probe von FhuF (Wildtyp ohne His-tag) wurde bei Raumtemperatur sechs Stunden lang mit Trypsin inkubiert (genaue Bedingungen im Anhang, Seite 167). Nach 0, 5, 10, 20, 30, 45, 60, 90, 120, 240 und 360 Minuten wurde jeweils eine Probe für ein Elektrophoresegel genommen (siehe Abb. 2.5).

Wie anhand des Elektrophoresegels leicht zu erkennen ist, hat die Verdauung mit Trypsin keine sicht- bzw. meßbaren Auswirkungen; FhuF scheint bemerkenswert immun gegen Trypsin zu sein. Angesichts dieses Resultats wurde auf Verdauungsexperimente mit den beiden Mutanten verzichtet.

\subsubsection{EXAFS-Spektrum}

Es gibt viele Strukturaufklärungsmethoden, die die Einkristallröntgenstrukturanalyse sinnvoll ergänzen können. Eine davon ist die sog. EXAFS-Spektroskopie (Extended $\boldsymbol{X}$ ray $\boldsymbol{A}$ bsorption $\boldsymbol{F}$ ine $\boldsymbol{S}$ tructure), deren entscheidender Vorteil es ist, nicht auf Kristalle angewiesen zu sein. Gravierender Nachteil der Methode ist der Umstand, daß man strukturelle Information lediglich über die unmittelbare Umgebung der untersuchten Schweratome erhält.

Beim EXAFS wird der in der Nähe der Röntgenabsorptionskante auftretende Photoeffekt von schweren Atomen (gefordert ist $Z>19$ ) ausgenutzt: Man bestrahlt eine in flüssigem Stickstoff tiefgefrorene Probe mit Röntgenstrahlen variabler Wellenlängetण und erhöht

\footnotetext{
10 Schon aus diesem Grund, aber auch, weil man für ein EXAFS-Spektrum sehr hohe Energiedichten benötigt, ist man auf einen Speicherring als Strahlenquelle angewiesen.
} 
während der Messung kontinuierlich die Energie des Röntgenlichts bis über die Absorptionskante hinaus. Bei Energien um die Absorptionskante wird in dem Schweratom ein kernnahes Elektron (im allgemeinen aus der K-Schale), das sog. Photoelektron freigesetzt, das mit Atomen in der unmittelbaren Nachbarschaft wechselwirkt. Durch Interferenz dieses Photoelektrons mit den von den Nachbaratomen zurückgestreuten Wellen kommt eine sinusartige Feinstruktur des EXAFS-Spektrums zustande, die Rückschlüsse auf die unmittelbare chemische Umgebung des Schweratoms zuläßt.
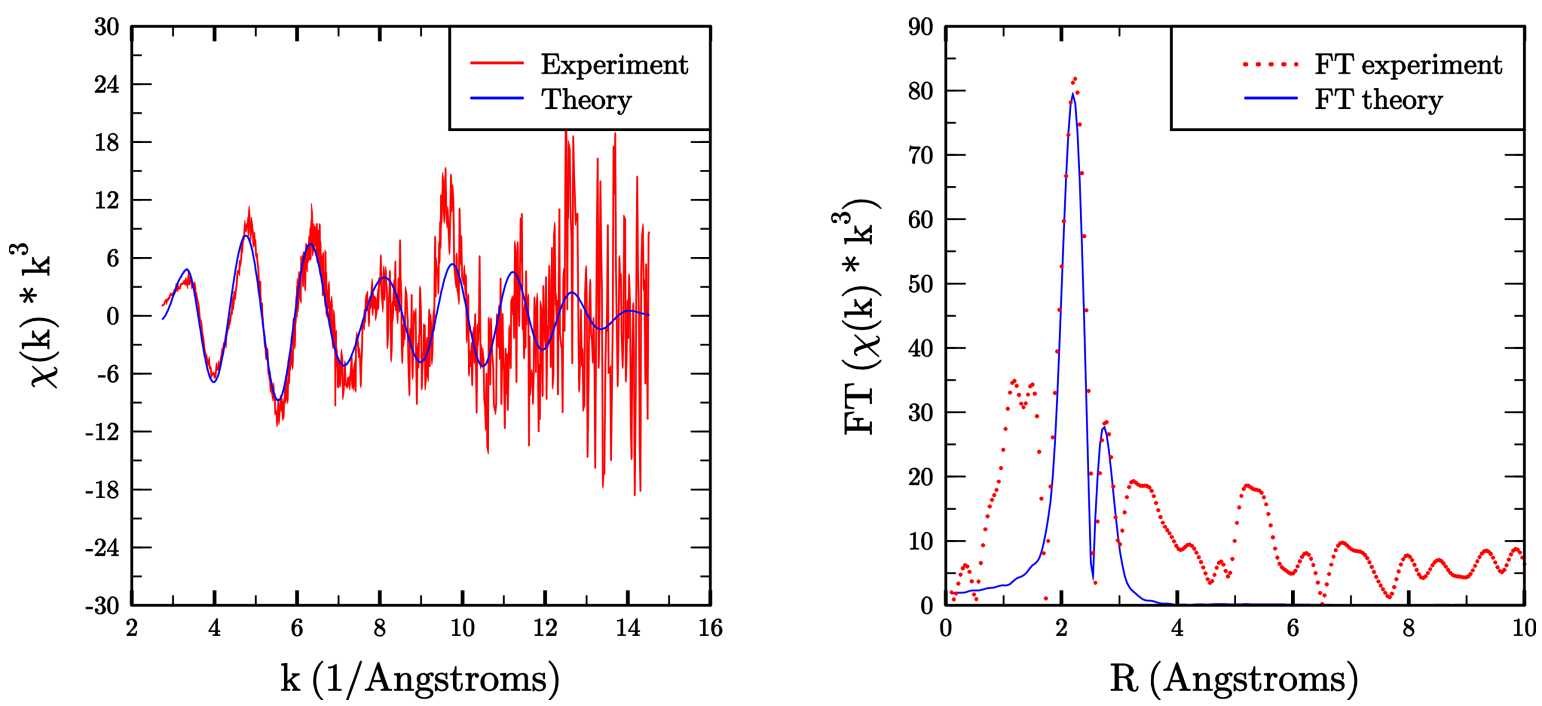

Abb. 2.6: EXAFS-Spektrum von FhuF (links) und die über eine Fourier-Transformation daraus berechnete Radial-Verteilungsfunktion (rechts).

Da von FhuF weder der Wildtyp noch die beiden vorhandenen Mutanten kristallisierbar waren, wurde eine Probe des Wildtyps für die EXAFS-Spektroskopie vorbereitet.

Die einzige Anforderung der EXAFS-Spektroskopie an die Probenbeschaffenheit bezieht sich auf die Konzentration, die im allgemeinen bei mindestens $15 \mathrm{mg} / \mathrm{ml}$ liegen sollte. Mit $10 \%$ Glycerol lassen sich diese Konzentrationen mit FhuF wenigstens kurzfristig realisieren, so daß es möglich war, zwei Proben herzustellen und sofort in flüssigem Stickstoff einzufrieren.

Das erhaltene Spektrum ist in Abb. 2.6 wiedergegeben. Seine Auswertung bestätigt das Vorliegen eines planaren viergliedrigen $\mathrm{Fe}_{2} \mathrm{~S}_{2}$-Ringes; die Abstände errechnen sich zu $\mathrm{d}_{F e-F e}=2.713(12) \AA$ und $\mathrm{d}_{F e-S}=2.264(12) \AA$, durchaus typische Werte für Fe-Feund $\mathrm{Fe}-\mathrm{S}-\mathrm{Bindungen}$ in $[2 \mathrm{Fe}-2 \mathrm{~S}]$-Clustern. 


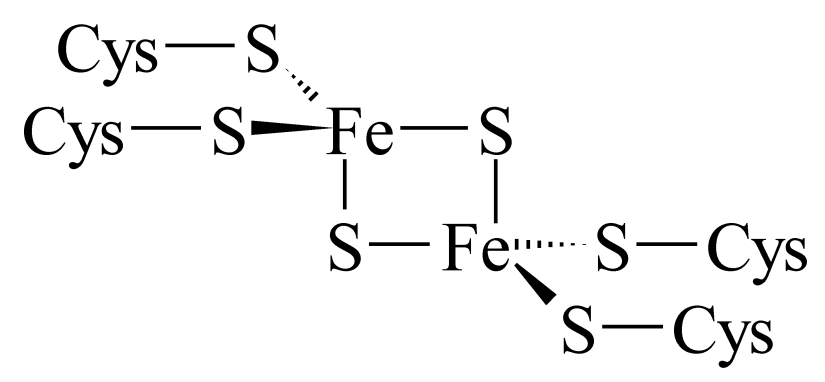

Abb. 2.7: Strukturvorschlag für den [2Fe2S]-Cluster in FhuF.

\subsubsection{Zusammenfassung}

Trotz intensiver Bemühungen ist es nicht gelungen, Kristalle des Eisen-Schwefel-Proteins FhuF zu erhalten. In den einschlägigen Datenbanken (swissprot, PDB) befindet sich derzeit kein Protein, das zu FhuF nennenswerte Sequenzhomologie zeigte, so daß auch Modelling nicht möglich ist. Daher kommt die einzig zugängliche Strukturinformation aus dem EXAFS-Spektrum. Bedauerlicherweise sind die Aussagen, die das EXAFS-Spektrum zuläßt, relativ begrenzt: lediglich die Geometrie des Fe-S-Clusters kann abgeschätzt werden.

Das Beispiel des FhuF zeigt einerseits deutlich die Bedeutung der Kristallzucht für die Einkristallröntgenstrukturanalyse, verdeutlicht jedoch andererseits, daß selbst größte Sorgfalt und Akuratesse nicht immer zum Ziel führen. 


\section{Kapitel 3}

\section{Empfindliche Kristalle}

Seit die meisten Minerale röntgenstrukturanalytisch charakterisiert sind, werden nur noch selten robuste Kristalle untersucht. Vielfach kann man unter dem Mikroskop beobachten, wie sich der zu untersuchende Kristall zu zersetzen beginnt (vgl. Abb. 3.3). Leider schreitet diese Zersetzung manchmal so schnell voran, daß auch sehr zügiges Montieren den Kristall nicht retten kann. Immer wieder werden daher Kristalle als nicht handhabbar verworfen, obwohl es - wie im Folgenden beschrieben ist - Methoden gibt, auch extrem empfindliche Verbindungen erfolgreich zu montieren.

\subsection{Empfindlichkeit gegen Sauerstoff und Feuchtig- keit}

Speziell bei anorganischen Verbindungen ist die Oxidationsempfindlichkeit der Kristalle ein verbreitetes Phänomen. Zum Beispiel überleben Kristalle metallorganischer Verbindungen von $\mathrm{Ti}(\mathrm{III})$ oder gar $\mathrm{Zr}$ (III) an Luft nur Sekunden, aber auch Li-Alkyle wie ${ }^{t} \mathrm{BuLi}$, das an Luft spontan zu brennen beginnt, sind nicht leicht zu montieren.

Um hochgradig luft- und feuchtigkeitsempfindliche Kristalle montieren zu können, muß man sie konsequent vor Raumluft schützen: Dem Kolben, in dem sie gewachsen sind, entnimmt man sie im Argon Gegenstrom, unter dem Mikroskop hält man sie in einer am besten kalten - Stickstoffatmosphäre, und der Weg vom Mikroskop zum Diffraktometer muß so kurz wie möglich sein. 


\subsection{Temperaturempfindlichkeit}

Nicht selten sind auch Kristalle luftstabiler Verbindungen von Zersetzung unter dem Mikroskop betroffen. Hierfür gibt es zwei Gründe, die im Folgenden dargestellt werden.

\subsubsection{Schmelzpunkt}

Wenn der Schmelzpunkt einer Substanz unter Raumtemperatur liegt, kann man die Kristalle nicht für längere Zeit ungekühlt handhaben. Man muß solche Kristalle entweder ständig - also auch unter dem Mikroskop - kühlen, oder den Kristall direkt auf dem Diffraktometer züchten, wie es Roland Boese unter anderem mit einer homologen Reihe von $n$-Alkanen gemacht hat [17].

\subsubsection{Verlust von Lösungsmittel}

Bei Kristallen, in deren Gitter nennenswerte Mengen eines leichtflüchtigen Lösungsmittels wie z. B. Hexan, Diethylether oder Chloroform integriert sind, beobachtet man häufig eine Zersetzung unter dem Mikroskop (ein Beispiel zeigt Abb. 3.3). Bei Raumtemperatur verdampft das Lösungsmittel, sobald der Kristall aus der Mutterlauge entfernt wird, und die dadurch entstehenden Lücken im Gitterverbund lassen das Kristallgitter zusammenbrechen, wobei der Kristall häufig zerfällt oder zumindest unbrauchbar für die Röntgenstrukturanalyse wird".

Auch im Falle des Lösungsmittelverlustes ist der einzige Weg, einen Kristall intakt zu montieren, ihn zu kühlen, um das Lösungsmittel am Verdampfen zu hindern, und möglichst zügig zu arbeiten.

\subsection{Kühlung des Kristalls vor Beginn der Messung}

Es gibt eine relativ einfache Möglichkeit, allen in diesem Kapitel beschriebenen Problemen erfolgreich zu begegnen: Ein von Dietmar Stalke und Thomas Kottke in Göttingen entwickeltes Gerät [18] verdampft flüssigen Stickstoff und bläst diesen durch ein Glasrohr

\footnotetext{
${ }^{1}$ Aus diesem Grund sollten Kristalle auch grundsätzlich niemals länger als unbedingt notwendig vor der röntgenographischen Untersuchung aus der Mutterlauge entfernt oder gar an der Vakuumpumpe trockengesaugt werden.
} 


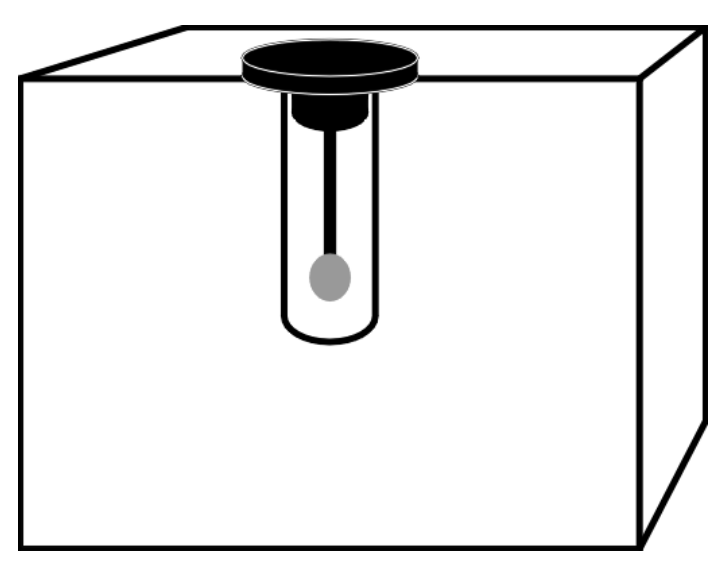

Abb. 3.1: Schematische Darstellung eines Trockeneisblocks zum Kristalltransport; gezeigt ist ein Schnitt durch den Block auf Höhe der Bohrung.

mit - zum Schutz vor Eisbildung - beheizter Düse über den Objektträger. Mit Hilfe eines Steuergerätes kann man Durchfluß und Temperatur des Stickstoffs unabhängig voneinander regeln und so die Kristalle unter dem Mikroskop problemlos auf Temperaturen bis $-100{ }^{\circ} \mathrm{C}$ kühlen.

Der Weg zum Diffraktometer muß sehr schnell zurückgelegt werden, und das Montieren sollte reibungslos klappen?.

Die Untersuchung aller in diesem Kapitel gegebenen Beispiele, sowie etlicher weiterer Verbindungen, die aufzuzählen den Rahmen dieser Arbeit sprengen würde, wurde erst mit dieser Methode überhaupt möglich.

Notfalls - für extrem empfindliche Kristalle oder bei unvermeidlich langen Wegen - kann ein Trockeneisblock zum Transport des Kristalls benutzt werden. Wie in Abb. 3.1 gezeigt, wird dazu in einen kleinen Klotz aus Trockeneis ein Loch gebohrt, in welches der Kristall auf dem Glasfaden „kopfüber" versenkt wird. So lassen sich auch größere Strecken zurücklegen, ohne daß der Kristall auftaut.

Problem dieser Methode ist, daß man den Kristall sehr häufig unterwegs im Trockeneis verliert und daß die zu untersuchende Verbindung natürlich nicht mit $\mathrm{CO}_{2}$ reagieren darf.

\footnotetext{
2 Es empfiehlt sich, wenn man einen empfindlichen Kristall auf ein unbekanntes Gerät montieren soll, den Weg vom Mikroskop zum Goniometer einige Male ohne Kristall zurückzulegen und einen leeren Glasfaden zu montieren, um sich mit der Situation vertraut zu machen. Diese Übung spart bei der nachfolgenden Montierung häufig wertvolle Sekunden!
} 


\section{$3.4\left[\left(\eta^{5}-\mathrm{C}_{5} \mathrm{H}_{4} \mathrm{Me}\right)_{2} \mathbf{T i}(\mu-\mathbf{F})_{2} \mathrm{AlEt}_{2}\right]_{2}$ : Eine extrem luft- empfindliche Ti(III)-Verbindung}

Titanorganische Verbindungen - vor allem in der gegenüber der Stufe IV $\left(\mathrm{d}^{0}\right)$ ohnehin benachteiligten Oxidationsstufe III $\left(\mathrm{d}^{1}\right)$ - sind sehr instabil: sie reagieren heftig mit Sauerstoff und Luftfeuchtigkeit und zeigen nicht selten Thermolabilität. Wegen ihrer hohen Aktivität als Ziegler-Natta-Katalysatoren sind diese Verbindungen jedoch vielfach Gegenstand der Forschung [19].

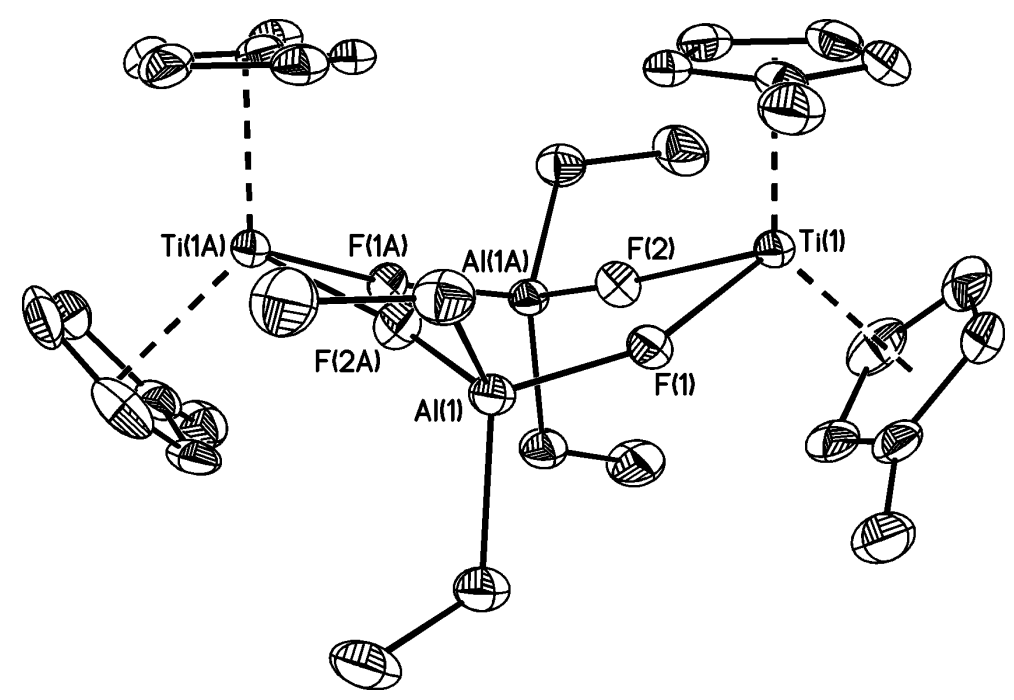

Abb. 3.2: Kristallstruktur von $\left[\left(\eta^{5}-\mathrm{C}_{5} \mathrm{H}_{4} \mathrm{Me}\right)_{2} \mathrm{Ti}(\mu-\mathrm{F})_{2} \mathrm{AlEt}_{2}\right]_{2}$ mit $50 \%$ Ellipsoiden. Auf die Darstellung von H-Atomen wurde aus Gründen der Übersichtlichkeit verzichtet.

Der Titan(III)-Komplex $\left[\left(\eta^{5}-\mathrm{C}_{5} \mathrm{H}_{4} \mathrm{Me}\right)_{2} \mathrm{Ti}(\mu-\mathrm{F})_{2} \mathrm{AlEt}_{2}\right]_{2}$ [20] kristallisiert aus Toluol in Form blauer Blöcke in der monoklinen Raumgruppe $C 2 / c$ mit einem halben Molekül in der asymmetrischen Einheit; die andere Hälfte wird durch die kristallographische zweizählige Achse erzeugt. Der Kern der Struktur besteht aus einem bootförmigen achtgliedrigen $\mathrm{Ti}_{2} \mathrm{~F}_{4} \mathrm{Al}_{2}$-Ring, durch dessen Schwerpunkt die zweizählige Achse hindurchgeht. Daher liegen die Atome eines Elements einander jeweils paarweise gegenüber, und eines wird durch die zweizählige Drehung in das andere überführt. Die tetraedrischen Koordinationssphären der Metallatome werden bei Titan durch je zwei CpMe-Liganden und im Falle von Aluminium durch jeweils zwei Ethylgruppen komplettiert.

Wird ein Kristall dieser Verbindung dem Kolben entnommen, verliert er innerhalb von Sekunden seine blaue Farbe, wird blaßgelb und beginnt sich erkennbar zu zersetzen. Werden die Kristalle jedoch auf die oben beschriebene Weise unter dem Mikroskop mit gasförmigem Stickstoff gekühlt (auf etwa $-60^{\circ} \mathrm{C}$ ), lassen sie sich minutenlang handhaben. Das 
Montieren gestaltet sich bei zügigem Arbeiten problemlos. Abb. 3.2 zeigt ein Bild der Struktur dieses Komplexes.

Eine weitere sehr luftempfindliche Ti(III)-Verbindung, die nur bei tiefer Temperatur handhabbar war, ist der im Zusammenhang mit Fehlordnungen (unter 7.7 auf Seite 88) beschriebene Komplex $\left(\eta^{5}-\mathrm{C}_{5} \mathrm{Me}_{5}\right)_{2} \mathrm{Ti}_{2}(\mu-\mathrm{F})_{8} \mathrm{Al}_{4} \mathrm{Me}_{8}$.

Ebenfalls überaus empfindlich und nur mit Hilfe von Tieftemperaturmethoden handhabbar waren die Kristalle der $\operatorname{Zr}(\mathrm{IV})$-Verbindung, die als Beispiel für das Auftreten von Artefakten unter 10.1, auf Seite 116 angeführt ist.

\subsection{Probleme mit Kristallen eines Cycloikositetra- phenylens}

Die Röntgenstrukturanalyse des Cycloikositetraphenylens [3] [21,22] gestaltete sich aus verschiedenen Gründen sehr problematisch, weshalb das Molekül auch in mehreren Kapiteln dieser Arbeit erwähnt ist.

Kristalle des größten der bislang bekannten formstabilen Makrozyklen konnten nur aus Chloroform erhalten werden (trotz vieler intensiver Versuche mit anderen Lösungsmitteln und Lösungsmittelgemischen), und es waren sehr viele Ansätze nötig, um Kristalle ausreichender Größe und Qualität zu gewinnen. Die im Kolben sehr schön und klar aussehenden Kristalle zersetzten sich unter dem Mikroskop innerhalb von Sekunden, so daß es zunächst nicht möglich war, mehr als die Elementarzelle zu bestimmen. Dieses Verhalten legte die Vermutung nahe, daß in das Kristallgitter Chloroformmoleküle eingebaut sein müssen, die unter dem Mikroskop verdampfen und so das Gitter zusammenbrechen lassen.

Abb. 3.3 zeigt den Zerfall des Kristallgitters innerhalb einer Minute.

Erst die Kühlung der Kristalle unter dem Mikroskop - wie oben beschrieben - machte die Kristalle relativ gut handhabbar und erlaubte so die Datensammlung.

Die Verbindung kristallisiert in der rhomboedrischen Raumgruppe $R \overline{3}$ mit einem sechstel des Moleküls in der asymmetrischen Einheit; der Rest des Moleküls wird durch die $\overline{3}$-Achse erzeugt. Die Verfeinerung der Struktur (Details der Verfeinerung sind in 7.6, Seite 84 beschrieben) ergab den Grund für die Empfindlichkeit gegen Lösungsmittelverlust:

\footnotetext{
${ }^{3}$ In der Literatur, die die Synthese des Moleküls beschreibt [21], ist zwar von einem „Cyclotetraikosaphenylen" die Rede, in Anlehnung an den Vierundzwanzigflächner, der nicht Tetraikosaeder sondern Ikositetraeder heißt, soll an dieser Stelle das Wort „Cycloikositetraphenylen“ gebraucht werden.
} 

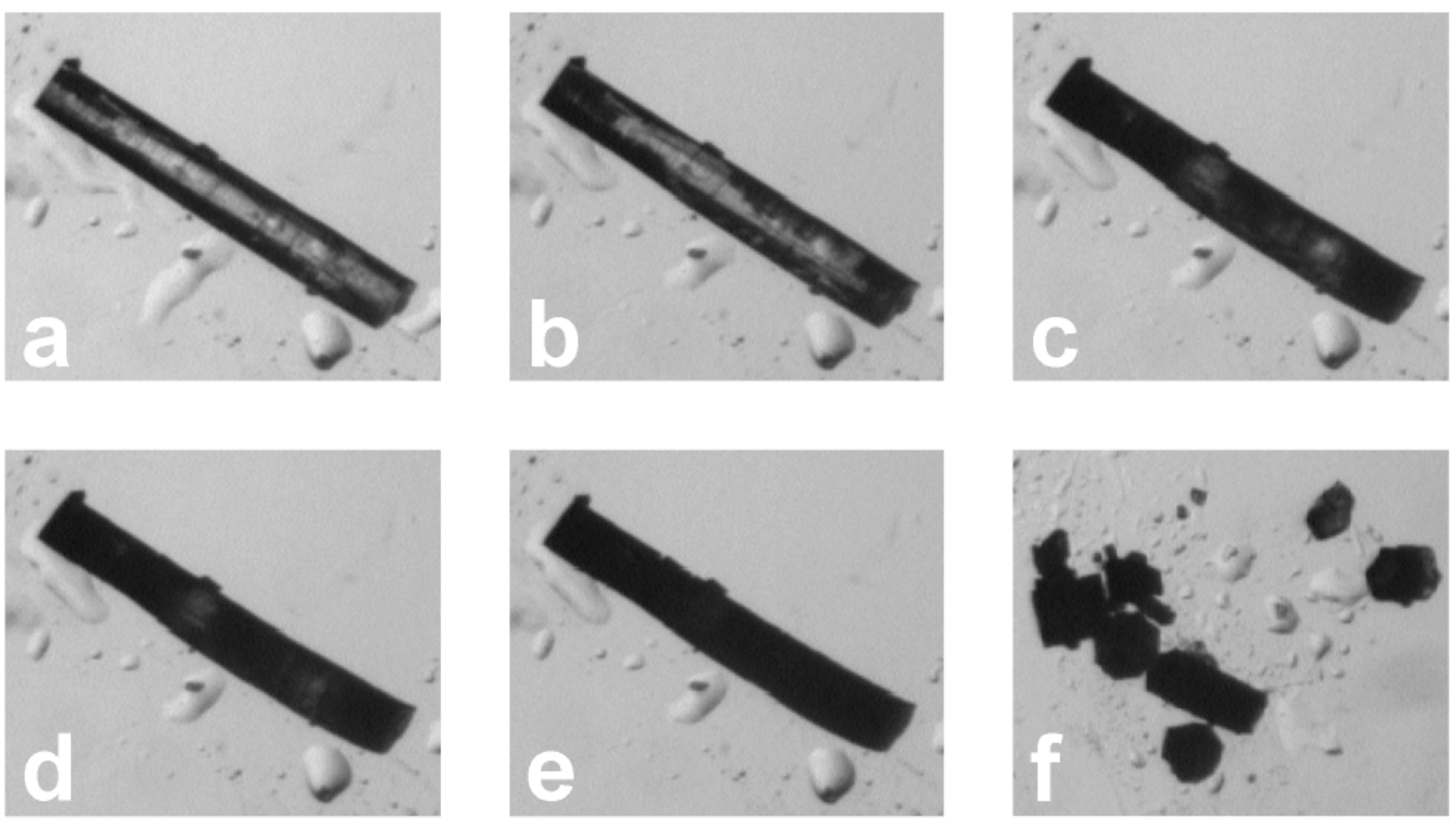

Abb. 3.3: Kristall des Cycloikositetraphenylens unmittelbar nach Entnahme aus dem Kolben (a), nach 10 Sekunden (b), 30 Sekunden (c), 40 Sekunden (d) und 60 Sekunden (e), sowie nach Berühren des Kristalls mit einer Nadel (f).

Die Makrozyklen, die, der $\overline{3}$-Geometrie gehorchend, die Form eines großen Cyclohexansessels annehmen, stapeln sich im Kristall wie Gartenstühle auf( siehe Abb. 3.4), so daß potentiell unendliche Kanäle entstehen. Der gesamte Kristall ist von Röhren mit einem Innendurchmesser von etwa $30 \AA$ durchzogen, die mit flüssigem Chloroform gefüllt sind. Es ist leicht nachvollziehbar, daß ein Kristall, der etwa zur Hälfte aus leicht flüchtigem Lösungsmittel besteht, bei Raumtemperatur nicht stabil sein kann. 


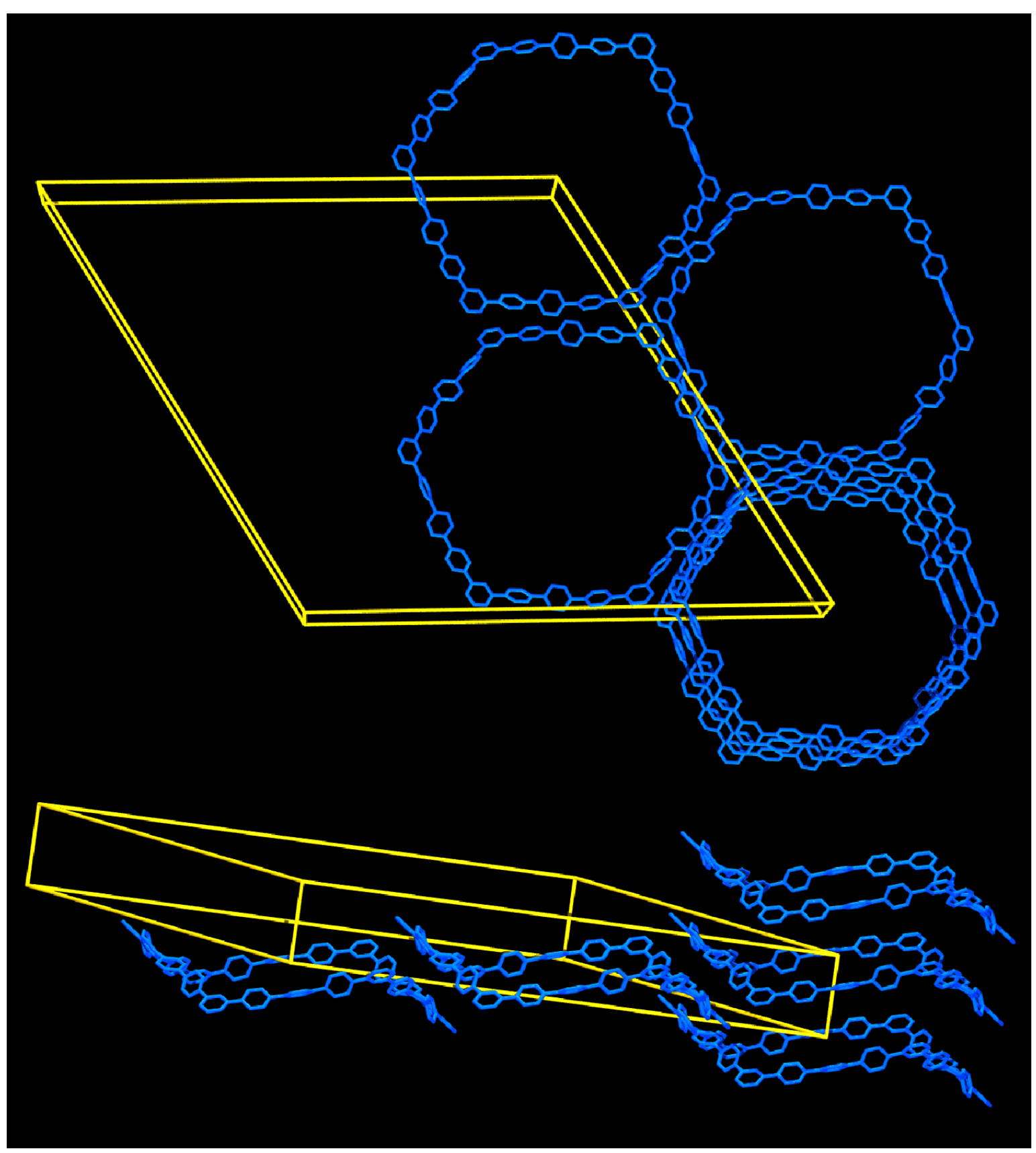

Abb. 3.4: Kristallpackung des Cycloikositetraphenylens in der Projektion entlang der kristallographischen $c$-Achse (oben) und in Seitenansicht (unten). Wasserstoffatome, Chloroformmoleküle und Hexylketten sind der Übersichtlichkeit halber nicht dargestellt. 


\section{Kapitel 4}

\section{Datensammlungsstrategien}

Die theoretischen Grundlagen zur Erzeugung von Röntgenstrahlung, sowie der Wechselwirkung von schnellen Elektronen mit Materie werden in großer Ausführlichkeit in der Literatur beschrieben, [5, 7] so daß an dieser Stelle nur eine kurze Rekapitulation der vorhandenen Möglichkeiten gegeben werden soll. Größeres Gewicht liegt auf der Diskussion der Vor- und Nachteile der verschiedenen Anordnungen zur Erzeugung und Detektion von Röntgenstrahlen.

\subsection{Verschiedene Röntgenquellen}

Röntgenstrahlung für Einkristall-Beugungsexperimente muß erstens monochromatisch sein円 und zweitens in seiner Wellenlänge etwa zwischen 0.5 und $2.5 \AA$ liegen (näheres zur optimalen Wellenlänge unter 4.3 auf Seite 30). Außerdem sollte der Röntgenstrahl eine möglichst geringe Divergenz aufweisen und von hoher Intensität sein. Zwar verursacht ein sehr intensiver Strahl stärkere Strahlenschäden im Kristall als ein schwacher, dafür verkürzt sich aber die Belichtungszeit pro Bild und damit die Meßzeit. Zur Erzeugung von Röntgenstrahlung gibt es unterschiedliche Anordnungen, deren Vor- und Nachteile im Folgenden beschrieben werden.

\footnotetext{
${ }^{1}$ Abgesehen von der mit „weißem“ Röntgenlicht arbeitenden Laue-Methode.
} 


\subsection{1 sealed tube}

Die einfachste und bei weitem preisgünstigste Möglichkeit, Röntgenstrahlung zu erzeugen, ist die sog. sealed tube, die abgeschmolzene Röhre. In dieser Anordnung treffen Elektronen, die aus einer Glühkatode freigesetzt und im Vakuum in einem Hochspannungs-E-Feld beschleunigt werden, auf eine starre wassergekühlte Anode (target) aus dem gewünschten Material (etwa $\mathrm{Cu}$ oder Mo). Neben der Bremsstrahlung (sog. weiße Röntgenstrahlung) entsteht dabei auch die für das Beugungsexperiment erwünschte charakteristische Röntgenstrahlung des Anodenmaterials.

Nachteil der sealed tube ist die relativ geringe Leistung, die auf etwa $2 \mathrm{~kW}$ beschränkt ist. Der Betrieb der Röhre bei höherer Leistung hätte ein Abschmelzen bzw. Verdampfen des Anodenmaterials zur Folge.

\subsubsection{Drehanode}

Bei diesem Modell dreht sich das target der Drehanode mit hoher Geschwindigkeit. Dadurch wird die Energie des Elektronenstrahls auf eine erheblich größere Fläche verteilt, was das Betreiben der Anode bei Leistungen von $5 \mathrm{~kW}$ und darüber erlaubt.

Der Nachteil dieser Anordnung liegt in dem erheblich höheren Preis und dem wartungsintensiven Betrieb der Drehanode.

\subsection{3 microsource}

Eine relativ neue Anordnung zur Erzeugung von Röntgenstrahlen stellt das sog. microsource- oder BEDE-System dar. Die Anlage wird mit der Leistung einer gewöhnlichen Glühbirne (etwa $80 \mathrm{~W}$ ) betrieben, liefert als microfocus Röntgenquelle aber trotzdem eine Intensität, die sich mit der einer $5 \mathrm{~kW}$ Drehanode vergleichen läßt. Teil der Anlage ist ein Kollimator-Monochromatorsystem, das eine Kombination aus einem elliptischen Spiegel zur Abtrennung der weißen Strahlung und Fokussierung des Primärstrahls mit einem dünnen Ni-Filter, der die $K_{\beta}$-Strahlung entfernt, darstellt. Durch die Geometrie des Spiegels kann ein erheblich größerer Winkelbereich der an der Anode erzeugten Röntgenstrahlung erfaßt werden als üblich, was dem erstaunlichen Wirkungsgrad der Anlage zugute kommt.

Entwickelt wurde BEDE ursprünglich für den Einsatz im Weltall [23], wo Gewicht und Energieverbrauch limitierende Faktoren sind. Unter "ground conditions" hat die BEDE- 
Anlage ihre Vorteile vor allem als microfocus beamline (typischer Strahlquerschnitt 0.2 $0.3 \mathrm{~mm}$ ), um besonders kleine Kristalle zu röntgen. Bei größerem Strahlradius sinkt die Energiedichte rasch in Bereiche, die für sealed tubes typisch sind ab, wobei ihr relativ hoher Preis (eine BEDE kostet kaum weniger als eine gewöhnliche Drehanode) sie kaum in Konkurrenz zur abgeschmozenen Röhre treten läßt.

\subsubsection{Synchrotronstrahlung}

Die mit großem Abstand intensivste Röntgenstrahlung erhält man beim Betrieb eines Speicherrings, bei dem die polychromatische sog. Synchrotronstrahlung tangential zur Flugbahn der Elektronen bzw. Positronen austritt. Durch Schalten von Wigglern und Undulatoren in die Teilchenbahn werden die Elektronen kurzfristig auf eine Art ZickZack-Bahn gezwungen, was die Strahlenausbeute enorm erhöht. Synchrotronstrahlung hat eine Reihe von Vorteilen:

1. variable Wellenlänge,

2. sehr hohe Intensität,

3. sehr hohe Brillanz,

4. hohe Kohärenz des Strahls.

Die enormen Kosten für den Bau und Betrieb eines Elektronen-Speicherrings und die daraus resultierende relativ geringe Anzahl weltweit existierender Synchrotrons sind der entscheidende Nachteil dieser Röntgenquelle. Trotzdem ist Synchrotronstrahlung vielfach unverzichtbar: Gerade bei der Proteinstrukturanalyse ist man auf die Vorteile in aller Regel angewiesen, wobei neben der hohen Intensität auch die Variabilität der Wellenlänge entscheidende Vorteile mit sich bringt (etwa für MAD-Experimente).

\subsection{Monochromatoren}

Bragg-Beugung benötigt monochromatische Röntgenstrahlung. Mit Hilfe von Monochromatoren wird aus dem Spektrum der Röntgenquelle die gewünschte Wellenlänge isoliert. 
Prinzipielles Problem ist, daß man möglichst hohe Monochromatizität und geringe Divergenz bei gleichzeitig möglichst geringem Intensitätsverlust erreichen möchte. Hierzu gibt es einige Methoden. Die beiden gängigsten sind im Folgenden kurz beschrieben.

\subsubsection{Kristalle}

Einkristall-Monochromatoren finden vor allem in Verbindung mit sealed tubes, aber auch mit Drehanoden und an Synchrotrons, Verwendung: Ein Einkristall wird so in den die Röntgenquelle verlassenden Strahlengang gebracht, daß nur für die Strahlung der gewünschten Wellenlänge (im allgemeinen die $K_{\alpha}$-Strahlung des jeweiligen Anodenmaterials) die Bragg'sche Beugungsbedingung erfüllt ist. Im Falle von Graphit, dem am häufigsten verwendeten Monochromatormaterial, wählt man den starken Reflex (l 0 2 $)$; der gebeugte Strahl ist dann der Primärstrahl für das eigentliche Beugungsexperiment. Vorteil dieser Methode sind die hohe Monochromatizität (lediglich Strahlung der halben Wellenlänge tritt in Folge des $\lambda / 2$-Effekts als Reflex ( $\left.\begin{array}{lll}0 & 0 & 4\end{array}\right)$ auf) und der vergleichsweise geringe Preis eines Graphit-Monochromators. Der entscheidende Nachteil liegt in der erheblichen Minderung der Strahlintensität. Dies fällt bei Kleinmolekülstrukturen gewöhnlich weniger ins Gewicht, kann aber im Falle von Proteinen über Erfolg oder Mißerfolg der Messung entscheiden.

\subsubsection{Multilayer Optik}

Das Prinzip der sog. multilayer Optik, die häufig auch als Röntgenspiegel bezeichnet wird, beruht im Grunde auf Bragg'scher Beugung an Schichten unterschiedlicher Dicke, die auf einen Edelstahlträger aufgedampft sind. Sie sind in der Fertigung überaus aufwendig und daher sehr teuer, ihre Vorteile gegenüber den Einkristall-Monochromatoren sind jedoch enorm: Die den Monochromator verlassende Strahlung ist bei sonst identischer Anordnung um Faktor fünf bis sieben intensiver als bei Graphit-Monochromatoren, ohne daß die Monochromatizität stark leidet. Darüberhinaus besteht bei einigen Spiegelsystemen die Möglichkeit, den Röntgenstrahl zu fokussieren. 


\subsection{Optimale Wellenlänge für Röntgenbeugung}

Kürzere Wellenlängen haben den Vorteil der besseren Auflösung bei gleichem Beugungswinkel.² Photonen höherer Wellenlängen wechselwirken stärker mit den Atomen der Kristalle und ergeben daher bei gleicher Intensität des Primärstrahls ein intensiveres Beugungsbild, zeigen aber auch erheblich stärkere Absorptionseffekte.

Das heißt, für Proteine, bei denen man ohnehin nur in wenigen Fällen Auflösungen von $<1 \AA$ erreicht, dabei aber so gut wie immer mit Intensitätsproblemen zu kämpfen hat, wählt man langwelligeres Röntgenlicht (etwa Cu-Strahlung mit $\lambda_{C u_{K \bar{\alpha}}}=1.54178 \AA$ ). Die Kristalle von Kleinmolekülen sind normalerweise besser geordnet als Proteinkristalle, so daß bis zu atomarer Auflösung gemessen werden kann. Außerdem hat man aufgrund der häufig und in großer Zahl vorhandenen Schweratome im allgemeinen geringere Intensitätsprobleme, dagegen treten Absorptionsprobleme mit zunehmender Ordungszahl der Elemente mehr und mehr in den Vordergrund. Man ist daher bestrebt, bei möglichst kurzen Wellenlängen zu arbeiten - sehr bewährt hat sich Mo-Strahlung mit $\lambda_{M_{K \bar{\alpha}}}=0.71073 \AA$.

Am Synchrotron hat man zumindest prinzipiell die Möglichkeit, die Wellenlänge innerhalb gewisser Grenzen frei zu wählen. Die meisten Proteindatensätze werden bei Wellenlängen zwischen 0.9 und $1.5 \AA$ gemessen.

Zur Durchführung eines MAD-Experiments müssen Daten vom selben Kristall bei mindestens zwei, besser drei oder vier, Wellenlängen gesammelt werden. Die optimalen Wellenlängen ergeben sich dabei aus der jeweiligen Lage der Absorptionskante des im Kristall anwesenden Schweratoms.

\subsection{Verschiedene Diffraktometergeometrien}

Es gibt auf dem Markt eine Vielzahl verschiedener Gerätetypen, die sich im Prinzip durch die Anzahl der variablen geometrischen Parameter - also der Achsen, um die der Kristall gedreht werden kann - unterscheiden. Die weltweit am gebräuchlichsten sind das Vierkreis-, das Dreikreis- und das Einkreisdiffraktometer. Diese werden im Folgenden kurz beschrieben.

\footnotetext{
${ }^{2}$ Aus der Bragg'schen Gleichung folgt für die maximale Auflösung: $d_{\max }=\lambda / 2$. Dies entspricht einem - praktisch nicht zu realisierenden - Beugungswinkel von $180^{\circ}$.
} 


\subsubsection{Vierkreisdiffraktometer}

\subsubsection{Euler-Geometrie}

Ein Kristall, der auf einem Vierkreisdiffraktometer mit Euler-Geometrie (siehe Abb. 4.1a) montiert ist, kann im Prinzip in jede beliebige Orientierung gebracht werden. Dies geschieht durch Drehung um drei Achsen bzw. Kreise: Zunächst läßt sich das gesamte Diffraktometer um den $\omega$-Kreis in der Gerätehorizontalen drehen, senkrecht darauf steht der $\chi$-Kreis, der es erlaubt, den Goniometerteller, der auch als Eulerwiege bezeichnet wird, vertikal im Kreis zu fahren. Schließlich ist der Goniometerkopf um seine eigene Achse, den $\phi$-Kreis, drehbar. Der vierte Kreis, $2 \Theta$ genannt, ist zum $\omega$-Kreis koaxial und dient dazu, den Detektor in der Diffraktionsebene ${ }^{3}$ um das eigentliche Goniometer herumzufahren.

Der Nachteil der Euler-Geometrie liegt in der relativ sperrigen Konstruktion: Durch den massiven $\chi$-Kreis ist die Möglichkeit der $\omega$-Drehung stark eingeschränkt, vor allem, wenn zusätzliche Geräte wie eine Videokamera oder eine Tieftemperaturanlage installiert werden sollen.

\subsubsection{Kappa-Geometrie}

Der Euler-Geometrie prinzipiell gleichwertig ist die sogenannte Kappa-Geometrie: $2 \Theta-$ und $\omega$-Kreis sind der Euler-Geometrie analog angeordnet, an die Stelle des $\chi$-Kreises tritt ein $\kappa$-Kreis, der sich um eine um $50^{\circ}$ zur Horizontalen geneigte Achse dreht. Auf diesem befindet sich - um $50^{\circ}$ zur $\kappa$-Achse geneigtt - der $\phi$-Kreis (Abb. 4.1b).

Im Unterschied zur Euler-Geometrie gibt es bei der weniger massiven Bauweise des $\kappa$ Diffraktometers geringere Restriktionen hinsichtlich Drehung um $\omega$. Auch die Montage der Tieftemperaturanlage verursacht weniger Probleme, da der Zugang von oben prinzipiell frei ist. Allerdings sind mit der $\kappa$-Geometrie Kristallorientierungen, die $\chi$-Winkeln von mehr als $100^{\circ}$ entsprechen, nicht zu realisieren.

${ }^{3}$ Der Begriff Diffraktionsebene stammt aus einer Zeit, als der auf das Vierkreisdiffraktometer montierte Zähler ein Szintillationszählrohr oder ein anderer Punktzähler war. Es war nötig, mit Hilfe der Kreise $\omega, \chi$ und $\phi$, einen Reflex in die Diffraktionsebene zu drehen und diesen durch Drehung des Zählerkreises $2 \Theta$ gezielt anzufahren. Bei der Verwendung von Flächenzählern sollte man anstelle von einer Diffraktionsebene besser von einem Diffraktionskeil oder etwas ähnlichem sprechen.

${ }^{4}$ Ein $\kappa$-Winkel von $50^{\circ}$ ist lediglich die üblichste, nicht die einzige Ausführung dieser Geometrie. Ebenfalls gängig sind Winkel von $54.75^{\circ}$ oder $60^{\circ}$. 

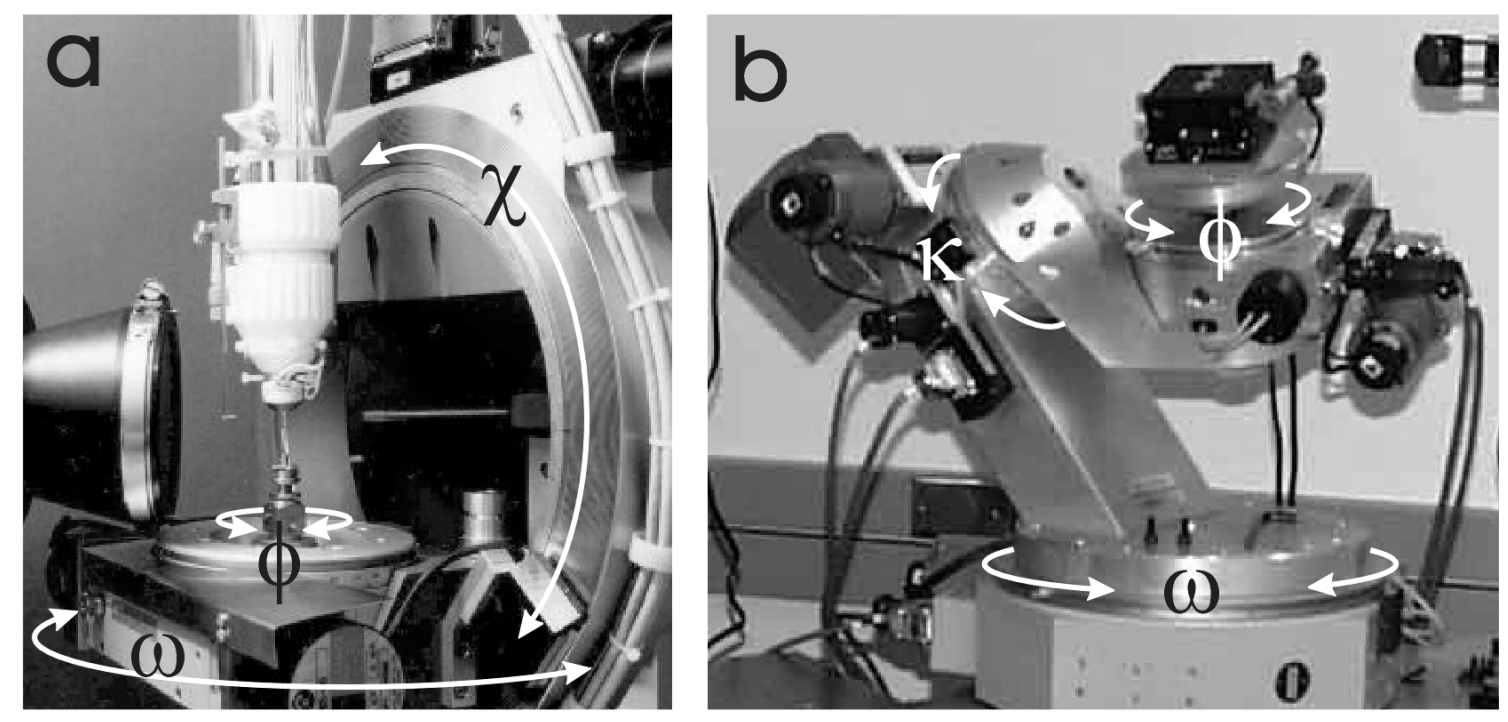

Abb. 4.1: a: Vierkreisdiffraktometer mit offset-Eulerwiege und b: mit Kappa-Geometrie (Abdruck des Bildes mit freundlicher Genehmigung von Dr. D. Balzar). Der vierte Kreis $(2 \Theta)$ ist in beiden Bildern nicht zu sehen; lediglich der CCD-Zähler ist links außen im linken Bild erkennbar.

\subsubsection{Dreikreisdiffraktometer (Platform-Geometrie)}

Seit Flächenzähler eine weite Verbreitung gefunden haben, wird die Vierkreis-Geometrie immer seltener angewandt. Weil die Reflexe nicht mehr exakt in die Diffraktionsebene gebracht werden müssen, entfällt für fast alle Situationen die Notwendigkeit von drei Kreisen plus $2 \Theta$-Kreis.

Sehr gebräuchlich in Kombination mit einem Flächenzähler ist dagegen die Dreikreisgeometrie (sog. Platform-Geometrie), die sich von der oben beschriebenen Euler-Geometrie lediglich durch das Fehlen des $\chi$-Kreises unterscheidet (siehe Abb. 4.2 a). Statt auf der sperrigen, schweren und teuren Eulerwiege ist der $\phi$-Motor fest auf den $\omega$-Kreis montiert. Dadurch ist für den $\chi$-Winkel ein fester Wert vorgegeben, wobei sich als besonders effektiv der halbe Tetraederwinkel (also $\chi=54.75^{\circ}$ ) erwiesen hat.

Diese Geometrie hat den Vorteil, daß man sehr umfangreiche $\omega$-scans durchführen kann, ohne eine Kollision befürchten zu müssen. Auch die oben erwähnten Probleme bei der Montierung einer Tieftemperaturanlage entstehen bei der Platform-Geometrie nicht.

Nachteil des Verzichts auf den $\chi$-Kreis ist ein theoretischer Mangel an Vollständigkeit der Daten, der sich bei sehr hoher Auflösung in der niedrigsten Lauegeometrie $\overline{1}$ störend bemerkbar machen kann. 

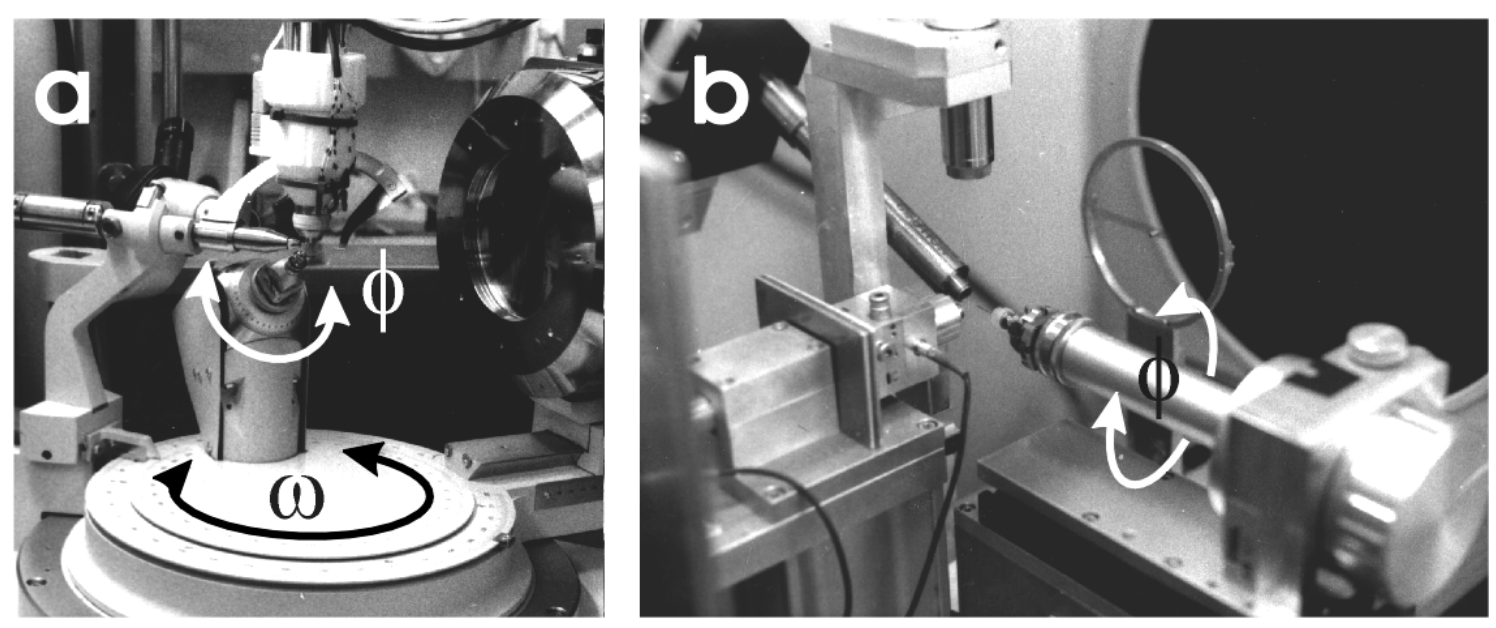

Abb. 4.2: a: Dreikreisdiffraktometer mit Platform-Geometrie und b: Einkreisdiffraktometer. Auf den beiden Bildern ist jeweils rechts im Hintergrund der Flächenzähler erkennbar, im Falle des Dreikreisers ein multi wire-Zähler; das Einkreisdiffraktometer ist mit einem imaging plate Detektor ausgestattet.

\subsubsection{Einkreisdiffraktometer}

Das vor allem an Synchrotrons und in Verbindung mit imaging plate Detektoren verbreitete Einkreisdiffraktometer verzichtet auf nahezu alle beweglichen Teile. Von den drei beschriebenen Kreisen bleibt lediglich der $\phi$-Kreis erhalten, für die übrigen „Kreise“ gilt: $2 \Theta=0^{\circ}, \omega=0^{\circ}$ und $\chi=90^{\circ}$, d. h. die Spindelachse ist senkrecht zum Röntgenstrahl orientiert. Eine solche Anordnung ist in Abb. 4.2 b dargestellt.

Vorteil dieser minimalistischen Anordnung ist neben dem günstigen Preis die relativ große Robustheit und die, aus der Übersichtlichkeit der Geometrie resultierende, Benutzerfreundlichkeit. Die Nachteile liegen in den gravierenden geometrischen Restriktionen des Einkreisdiffraktometers: Dadurch, daß der Kristall im Rahmen einer Messung nur um eine Achse drehbar ist, sind Reflexe, die im reziproken Raum nahe an dieser Drehachse liegen, nicht erfaßbar. Abb. 4.3 stellt diesen sog. Totkonus dar. Bei höhersymmetrischen Lauegruppen kann die Lücke des Totkonus häufig durch Äquivalente geschlossen werden. Wenn der Kristall jedoch zufällig so montiert ist, daß die Spindelachse parallel zu einer der Zellachsen verläuft, gibt es keine Möglichkeit, die zu dieser Richtung gehörenden seriellen systematischen Auslöschungen zu messen. Aus diesem Grund sind unter Umständen für die Raumgruppenbestimmung essentielle Informationen über Schraubenachsen nicht zugänglich. 


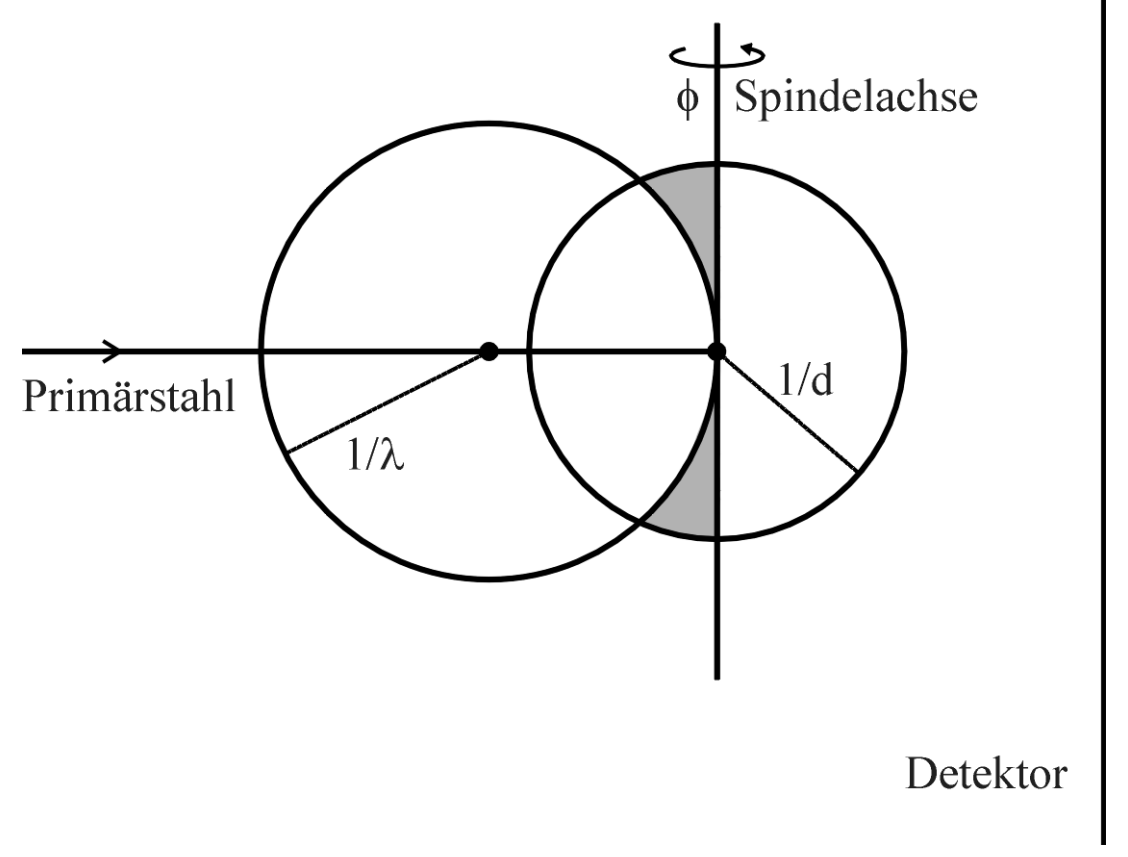

Abb. 4.3: Ewaldkonstruktion für eine $\phi$-Rotation senkrecht zum Röntgenstrahl. Grau hinterlegt ist der sog. Totkonus, der Bereich des reziproken Raumes, der bei der Einkreis-Geometrie unzugänglich bleibt. $1 / \lambda$ ist der Durchmesser der Ewald-Kugel, 1/d der Durchmesser des reziproken Raumes bei der maximalen Auflösung d.

\subsection{Verschiedene Detektoren}

Aufgabe des Detektors ist es, die vom Kristall gestreuten Lichtquanten aufzufangen und quantitativ zu registrieren. Der optimale Zähler hat eine möglichst große aktive Fläche und geringes Eigenrauschen. Weitere Vorteile sind kurze Auslesezeiten und geringe Werte der point spread function. Letztere beschreibt die Signalverbreiterung auf der Zähleroberfläche, also die zählerimmanente Radiusvergrößerung eines Reflexes. Außerdem sollte ein Zähler über hohe Empfindlichkeit und eine möglichst große dynamische Breite verfügen. Die dynamische Breite ist definiert als die maximal meßbare Reflexintensität dividiert durch das geringste noch vom Grundrauschen unterscheidbare Signal. Je höher die Empfindlichkeit eines Zählers ist, desto weniger Photonen sind nötig, um maximale Signalstärke zu erzeugen, desto geringer ist auch die Differenz zwischen maximal und minimal detektierbarem Signal. Daher nimmt die dynamische Breite mit wachsender Empfindlichkeit ab [24]. Berechnungen ergaben als optimale Empfindlichkeit (quantum gain) für Kleinmolekül-Beugungsexperimente 100 bis 150 Elektronen pro Röntgenphoton. Konventionelle CCD-Detektoren erreichen lediglich Werte von zehn bis $20 e^{-} / x$-ray [25, 26]. 
Tabelle 4.1 gibt einen groben und rein qualitativen Überblick über die wichtigsten Eigenschaften der verschiedenen Zählertypen, die im Folgenden eingehend beschrieben werden.

\begin{tabular}{lccccc}
\hline \hline Detektortyp & Fläche & Rauschen & Auslesezeit & point spreading & Empfindlichkeit \\
\hline Punktzähler & - & gering & keine & - & gering \\
MWPC & klein & sehr gering & keine & gering & hoch \\
imaging plate & groß & gering & lang & mittel & mittel \\
CCD & klein & hoch & kurz & gering & sehr hoch \\
\hline \hline
\end{tabular}

Tab. 4.1: Qualitativer Vergleich der wichtigsten Eigenschaften verschiedener Zählertechnologien.

\subsubsection{Szintillations-Punktzähler}

Der Vollständigkeit halber sei an dieser Stelle auch der Szintillationszähler erwähnt, der nach dem Prinzip des Photomultipliers funktioniert. In den letzten Jahren haben die vielfältigen neuen Flächenzähler-Technologien die Punktzähler zu verdrängen begonnen, wenngleich noch viele dieser robusten Zählrohre existieren und auch eingesetzt werden. Trotz des wesentlich günstigeren Preises der Punktzähler überwiegen die Vorteile der Flächenzähler eindeutig, und es ist lediglich eine Frage der Zeit, wann der letzte Punktzähler außer Dienst gestellt werden wird.

\subsubsection{MWPC-Flächenzähler}

Der MWPC (multi wire proportional chamber) ist einer der ersten Flächenzähler. Wie der Szintillationszähler gehört er zur Gruppe der Proportionaldetektoren und kann im Grunde als Photonenzähler bezeichnet werden. Im Innern des MWPC befinden sich drei rechtwinklig zueinander verlaufende Lagen von Drähten in einer mit Xenon gefüllten Kammer. Die Drähte sind elektrisch geladen, so daß sich zwischen den Lagen ein elektrisches Feld aufbaut. Wenn ein Röntgenphoton die Kammer durchquert wird es einige der Xe-Atome ionisieren. Sowohl die dabei entstehenden Xe-Kationen, als auch die freigesetzten Photoelektronen werden im elektrischen Feld beschleunigt und treffen schließlich auf einen der Drähte, wo sie entladen werden. Der so auftretende Stromfluß ist proportional zur

\footnotetext{
${ }^{5}$ Ein $\mathrm{CuK}_{\alpha}$ Photon ist in der Lage, auf die beschriebene Weise etwa 320 Ionenpaare zu erzeugen, wobei berücksichtigt ist, daß bei der Primärionisation freiwerdende Elektronen ihrerseits Xe-Atome ionisieren können [27].
} 
Anzahl der Röntgenphotonen, also zur Intensität des Reflexes. Der Ort des Reflexes läßt sich über die Kreuzungspunkte der Drähte, die wie ein Koordinatensystem aufgebaut sind, ermitteln. Zwischen zwei Ereignissen dieser Art muß eine bestimmte Zeitspanne vergehen, die sog. Totzeit, innerhalb derer kein neues Photon an der selben Stelle detektiert werden kann. Wenn zu viele Photonen auf den Zähler treffen, was bei sehr starken Röntgenquellen der Fall sein kann, wird der Zähler gesättigt und die Aufnahme ist nicht zu verwenden.

Die Vorteile des MWPC liegen im relativ niedrigen Preis und dem sehr geringen Eigenrauschniveau der Meßanordnung. Außerdem ist die Energiediskriminierung dieses Systems sehr gut, so daß bestimmte Monochromatizitätsprobleme, wie etwa der $\lambda / 2$-Effekt, vernachlässigbar sind. Der entscheidende Nachteil ist die relativ schnell erreichte Sättigung des MWPC, die es verbietet den Zähler in Verbindung mit sehr starken Röngtenquellen etwa am Synchrotron - einzusetzen. Außerdem muß der Zähler aufgrund der Beweglichkeit der Drähte nach jeder Änderung des Detektor-Kristall-Abstandes geeicht werden. Da zur Eichung der Kristall vom Goniometer genommen werden muß, verbieten sich Messungen eines Kristalls bei mehreren Detektorabständen.

\subsection{3 imaging plate-Flächenzähler}

Der imaging plate Detektor läßt sich prinzipiell als Photonenspeicher beschreiben: Auf den Zähler auftreffende Photonen regen die Moleküle in der sensiblen Schicht elektronisch an und erzeugen so ein latentes Bild, das sich über mehrere Stunden erhält. Durch Bestrahlen mit Ne-He-Laserlicht $(\lambda=633 \mathrm{~nm})$ wird die mit Lichtemission $(\lambda=390 \mathrm{~nm})$ einhergehende Relaxation der angeregten Moleküle induziert. Diese photostimulierte Lumineszenz wird von einem Lesekopf im Detektor ausgelöst, der die aktive Schicht z. B. in einer engen Spirale abfährt und die Detektorfläche so Punkt für Punkt ausliest. Der Lesekopf erfüllt dabei zwei Aufgaben: Erstens beleuchtet er die Platte und zweitens leitet er die emittierten Photonen an einen Photomultiplier weiter, der das Photonensignal in ein elektrisches umwandelt. Um die Platte erneut belichten zu können, muß sie kurzfristig weißem Licht ausgesetzt werden, das alle Moleküle der aktiven Schicht wieder in ihren elektronischen Grundzustand bringt.

Die Vorteile des imaging plate Detektors liegen vor allem in der großen aktiven Fläche, dem geringen Eigenrauschen, das auch lange Belichtungszeiten zuläßt und dem relativ niedrigen Preis. Außerdem haben sich die Geräte als robust und relativ wartungsfreundlich erwiesen. Nachteil ist vor allem die lange Auslesezeit (je nach Modell zwischen knapp 
zwei und etwa fünf Minuten), die sich häufig als zeitlich limitierender Faktor der Datensammlung erweist und sein sehr hohes Gewicht, das eine Montierung auf einem $2 \Theta$-Arm verbietet. Außerdem ist die „point spread function“ ungünstiger als bei MWPC und CCDDetektoren.

\subsubsection{CCD-Flächenzähler}

Der CCD Zähler (Charge Coupled Device) ist im Grunde eine elektronische Variante des fotografischen Films: Einfallende Röntgenquanten treffen auf eine dünne Phosphorschicht und werden dort in sichtbares Licht umgewandelt, das über eine reduzierende Glasfaseroptik auf den gekühlten CCD-Chip geleitet wird. Bei einem CCD-Zähler der Firma Bruker, dem Apex [26], der mit einem sehr großen Chip arbeitet, entfällt die Glasfaseroptik, in einem anderen CCD-Zähler (ebenfalls von Bruker) kommt ein Linsensystem zum Einsatz, das den Phosphor auf den Chip abbildet. In der Halbleiterschicht des Chips erzeugt Lichtabsorption Ladungstrennung, wodurch die Röntgenstrahlung der Reflexe indirekt analog gespeichert wird. Nach der Belichtung wird die Information des Chips ausgelesen, digitalisiert und abgespeichert; der Chip steht dann zur erneuten Belichtung zur Verfügung.

Der CCD-Zähler hat seine Vorteile in erster Linie in der hohen Empfindlichkeit. Dadurch sind kurze Belichtungszeiten möglich, woraus ein hoher Durchsatz resultiert. Der CCD-Zähler ist daher sehr gut für die Servicekristallographie geeignet. Nachteil der CCDTechnologie ist das hohe Eigenrauschniveau, das bei den meisten CCD-Zählern Belichtungszeiten von mehr als zwei oder drei Minuten ausschließt, weil dann das Signal-RauschVerhältnis zu schlecht wird. Außerdem sind CCD-Zähler relativ teuer, so daß in der Vergangenheit vielfach die erheblich billigeren MWPC angeschafft wurden. Dieser Trend hält angesichts neuerer Entwicklungen auf dem CCD-Sektor, die zu enormen Verbesserungen hinsichtlich Aufösung, Empfindlichkeit und Eigenrauschen geführt haben, allerdings nicht an, da die Nachteile der CCD-Technologie immer stärker in den Hintergrund treten [24,26].

Der oben erwähnte neuartige CCD-Zähler der Firma Bruker, bei dem die reduzierende Glasfaseroptik durch ein Linsensystem ersetzt wurde, könnte in Zukunft eventuell eine interessante Alternative zum imaging plate Detektor darstellen, da diese neue Technologie die entscheidenden Vorteile beider Zählertypen vereinigt: Neben den CCD typischen positiven Eigenschaften (hohe Empfindlichkeit, geringe Signalverbreiterung und kurze Auslesezeit) erhält der neue Zähler durch die Linsenoptik ebenfalls eine sehr große aktive Fläche. 


\subsection{Strahlenschäden}

Ein Phänomen, von dem Kleinmolekülkristalle allenfalls am Rande betroffen sind, ist die Zersetzung des Kristalls im Röntgenstrahl [28,29, 30]. Man unterscheidet hierbei zwischen primären Effekten wie Photoionisation und Comptonstreuung und sekundären Effekten wie punktuelle Temperaturerhöhung oder die Bildung von freien Radikalen. Die freien Radikale, die vornehmlich aus Wassermolekülen erzeugt werden, richten dabei vermutlich den größten Schaden an [31].

Zwar kann das Ausmaß von Strahlenschäden durch Kühlen des Kristalls deutlich reduziert werden, trotzdem bleibt die Lebensdauer eines Proteinkristalls im Röntgenstrahl begrenzt [32,33]. Die Lebensdauer hängt dabei vor allem von der Intensität der Strahlung ab, so daß ein Kristall, der an einem Synchrotron der zweiten Generation (wie z. B. das DESY in Hamburg) nach sechs bis acht Stunden merklichen Schaden aufweist, an einer $5 \mathrm{~kW}$-Drehanode ein bis zwei Wochen überdauern kann. Natürlich sind die erforderlichen Belichtungszeiten am Synchrotron erheblich kürzer, so daß diese Folge der großen Intensität der Synchrotronstrahlung normalerweise nicht zum Tragen kommt. In diesem Zusammenhang macht sich die lange Auslesezeit von imaging plate Detektoren besonders störend bemerkbar, da die Schädigung des Kristalls auch dann weitergeht, wenn der Strahl kurzfristig abgeschirmt ist, wie es beim Auslesen des Detektors im allgemeinen geschieht.

Es ist also nötig, das mögliche Auftreten von Strahlenschäden in die Planung der Datensammlungsstrategie einzubeziehen, indem man versucht, die Meßzeit so kurz wie möglich zu halten. Um gleichzeitig eine ausreichende Vollständigkeit und Redundanz der Daten zu erhalten, ist es wichtig, Belichtungszeit und Startwinkel der Diffraktometerkreise sorgfältig zu wählen.

\subsection{Kryokristallographie}

Wie in Kapitel 10 (Seite 115) erwähnt, zählt Roland Boese die Datensammlung bei Raumtemperatur zu den „wirklich vermeidbaren Fehlern“ [34]. Diese provokante Äußerung hat - obwohl sie in dieser Absolutheit nicht haltbar ist - durchaus ihre Berechtigung: Der Verzicht auf Tieftemperaturdatensammlung ist sicherlich als Fehler einzustufen, es sei denn es gäbe zwingende Gründe, eine Messung nicht bei tiefer Temperatur durchzuführen. Zwingende Gründe können z. B. sein: ein bei tiefer Temperatur auftretender Phasenüber- 
gang im zu untersuchenden Kristall, der das Gittergefüge zerstören würde oder eine nicht hinnehmbare Vergrößerung der Mosaizität - letzteres vor allem im Falle von Proteinkristallen.

Die Vorteile der Datensammlung bei tiefer Temperatur sind immens [35]: Kühlen reduziert die Beweglichkeit der Moleküle im Kristall, wodurch sich häufig Fehlordnungen verringern oder beseitigen lassen. Außerdem nähert sich bei tiefer Temperatur die Eigenschwingung der Atome der Nullpunktsschwingung an, was sich neben der Verringerung der diffusen Streustrahlung in einer erheblichen Reduktion von Librationseffekten und anderen Artefakten niederschlägt. Weiterhin verringert tiefe Temperatur, wie erwähnt, das Auftreten von Strahlenschäden - insbesondere bei Proteinkristallen - und erhöht so die Lebensdauer des Kristalls im Röntgenstrahl zum Teil um Faktor zehn und mehr. Dadurch wird es möglich, vollständige Daten mit mittlerer, manchmal sogar hoher Redundanz von einem einzigen Kristall zu sammeln. Schließlich lassen sich viele Proteinkristalle sehr gut in gefrorenem Zustand transportieren und lagern, was eine sorgfältige Vorauswahl der Kristalle und damit eine besonders effiziente Gestaltung des Synchrotronbesuchs ermöglicht.

Neben allen Vorteilen bringt die Kryokristallographie auch Probleme mit sich: Die größte Schwierigkeit besteht im Auffinden der richtigen Kryobedingungen: Während sich die meisten Kleinmolekülkristalle problemlos in Mineral- bzw. Silikonölen oder in viskosen perfluorierten Polyethern frieren lassen, ergibt sich beim Einfrieren von Proteinkristallen das Problem der Salz- und Eiskristallbildung. Sowohl das Wasser im Inneren eines Proteinkristalls (Proteinkristalle bestehen zu etwa 30 bis $70 \%$ aus Wasser), als auch die den Kristall umgebende Flüssigkeit (es ist nötig, Proteinkristalle immer in wäßriger Umgebung zu halten, damit sie nicht austrocknen) neigen dazu, bei tiefen Temperaturen zu Eis zu erstarren. Dieses Eis würde den Proteinkristall zerdrücken und außerdem selbst den Röntgenstrahl beugen. Dadurch würde die Messung unmöglich. Dieser Problematik begegnet man, indem man Proteinkristalle in einer wäßrigen Lösung eines Frostschutzmittels, Kryopuffer genannt, einfriert, die bei tiefer Temperatur nicht zu Eis, sondern zu einem Glas erstarrt. Geeignete Kryoprotektanden sind z. B. Alkohole, Glycerol, 2-Methyl-propandiol (MPD) und niedermolekulare Polyethylenglykole (PEG), aber auch hohe Konzentrationen von Li- oder Phosphat-Ionen. Das Problem beim Auffinden des optimalen Kryopuffers ist, daß Proteinkristalle sehr empfindlich auf Veränderung der Ionenstärke, des pH-Werts und anderer Parameter reagieren. Infolgedessen scheiden sehr viele Kryopuffer aus, weil die zu untersuchenden Kristalle in ihnen zerbröckeln oder sich aufösen. Die Ermittlung der bestmöglichen Kryobedingungen erfordert daher große Sorgfalt und Erfahrung.

Ein weiteres Problem der Tieftemperaturmessung ist die Mosaizität: Auch hier tritt das 

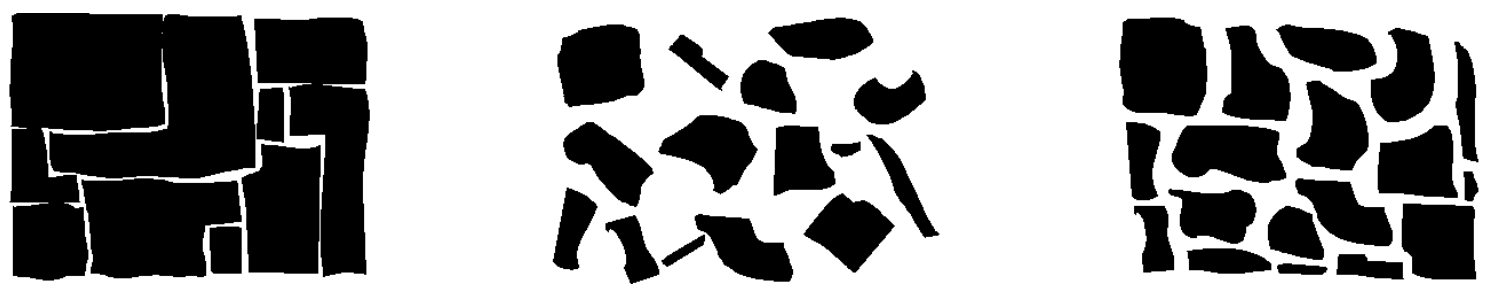

Abb. 4.4: Schematische Darstellung der Auswirkungen des crystal annealing auf die Mosaizität: links: Kristall vor dem ersten Frieren, Mitte: nach den ersten Frieren, rechts: nach dem annealing.

Problem fast ausschließlich in Verbindung mit Proteinkristallen in Erscheinung, deren Mosaizität sich beim Einfrieren im allgemeinen deutlich erhöht. Zwar ist diese Erhöhung geringer, wenn der Kryopuffer optimal gewählt wurde, in einigen Fällen wird aber trotz aller Vorsichtsmaßnahmen die Mosaizität des Kristalls beim Einfrieren so stark vergrößert, daß der Kristall ungeeignet für ein erfolgreiches Beugungsexperiment wird. Positive Auswirkungen auf die Mosaizität hat die Verwendung eines kleinen Kristalls, da erstens die Anzahl der Gitterfehler geringer ist als bei einem großen und zweitens ein kleinerer Kristall aufgrund des geringeren Volumens schneller und gleichmäßiger abkühlt.

Falls trotz aller Sorgfalt die Mosaizität sehr schlecht ist, kann unter Umständen das sog. crystal annealing helfen [36]: Die Idee ist, daß sich ein Kristall beim Einfrieren zusammenzieht, und zwar nicht in erster Linie als Gesamtheit, sondern in vielen kleinen Blöcken, wodurch die Mosaizität ansteigt. Wird ein Kristall wieder aufgetaut und für etwa zwei bis zehn Minuten zurück in den Kryopuffer gebracht, können sich diese Blöcke reorganisieren und anschließend mit geringerer Mosaizität als zuvor erneut eingefroren werden. Dabei erreicht man zwar kaum die Mosaizität, die der Kristall vor dem ersten Frieren hatte, aber manchmal eine Verbesserung im Vergleich zum Resultat des ersten Einfrierens. Abb. 4.4 gibt die Vorgänge beim crystal annealing schematisiert wieder.

\subsection{Vollständigkeit der Daten}

Von nicht zu unterschätzender Bedeutung für die Qualität einer Röntgenstrukturanalyse ist die Vollständigkeit der Daten [37]: Je unvollständiger ein Datensatz ist, desto mehr häufen sich Artefakte in Form von scheinbaren Restelektronendichtemaxima auf speziellen Lagen, da eine Fouriersynthese immer von 100\% Vollständigkeit ausgeht. Dadurch ist auch das allgemeine Rauschniveau eines unvollständigen Datensatzes erheblich höher als das eines vollständigen. Eine completeness von > 98\% über den gesamten Auflösungsbereich sollte daher immer angestrebt werden. 
Je nach Lauesymmetrie des Kristalls und Geometrie des verwendeten Diffraktometers kann das Erreichen dieser Vollständigkeit trivial (z. B. kubischer Kristall an einem Vierkreisdiffraktometer) oder relativ problematisch sein (trikliner Kristall an einem Einkreisdiffraktometer).

So wie in früheren Zeiten am Vierkreisdiffraktometer mit Szintillationszähler die Datensammlungen lauegruppenabhängig geplant und gezielt nur die unabhängigen Reflexe angefahren wurden, wird heute an modernen Einkreisdiffraktometern häufig nur der unabhängige Teil des reziproken Raumes vermessen. Dies läßt sich durch geschickte Wahl des Start- $\phi$-Winkels erreichen, birgt aber dieselben Probleme wie die zeitsparende „Punktzählertaktik“: Wenn bei der Datensammlung von orthorhombischer Geometrie ausgegangen wurde, sich hinterher aber herausstellt, daß der Kristall doch monoklin ist, steht man vor einem nicht lösbaren Vollständigkeits-Problem. Zwar entsteht diese Problematik heute seltener als bei den alten Vierkreis-Diffraktometern, da die Hauptfehlerquelle - falsche Zelle aufgrund zu weniger Daten - bei Flächenzählern so gut wie vernachlässigbar ist, es gibt aber auch bei Proteinkristallen immer wieder meroedrische Verzwillingungen (siehe Kapitel 9, Seite 97), so daß man sich bei der Datensammlung einer unbekannten Struktur des Kristallsystems nie zu sicher sein sollte.

Daher, aber auch im Hinblick auf Redundanz (vgl. 4.9) empfiehlt es sich, wenn möglich immer mehr als nur die unbedingt benötigten Daten zu sammeln. Moderne, sehr empfindliche und ausleseschnelle Flächenzähler ermöglichen dabei mehr und mehr ausgedehnte Datensammlungen. An einigen Synchrotrons der dritten Generation ist bereits die Kristallauswahl und -montierung der zeitlich limitierende Faktor, nicht mehr die Aufnahme des Datensatzes.

\subsection{Redundanz}

Redundanz ist imstande, die Qualität eines Datensatzes erheblich zu verbessern: Wie bei jeder physikalischen Meßgröße erhöht sich durch mehrmaliges Vermessen des selben Reflexes die Genauigkeit seiner Bestimmung, und der Wert der zugehörigen Standardabweichung $(\sigma)$ wird kleiner. Zwar steigt der $R_{\text {int }}$ (siehe Gleichung 4.1) mit der Redundanz geringfügig an, dies ist aber in seiner Definition begründet und gibt nicht die Realität wieder 38]:

$$
R_{\text {int }}=\frac{\sum F_{o}^{2}-<F_{o}^{2}>}{\sum F_{o}^{2}}
$$


Hierbei ist $F_{o}^{2}$ ein einzelner quadrierter beobachteter Strukturfaktor und $\left\langle F_{o}^{2}\right\rangle$ der Mittelwert aller zu diesem äquivalenten; die Division durch $\sum F_{o}^{2}$ dient lediglich der Normierung. Die Summation über alle Aufösungsschalen gibt ein gutes Bild von der inneren Konsistenz eines Datensatzes. Allerdings wird der Wert für $R_{\text {int }}$ für sehr niedrige und sehr hohe Redundanz deutlich verzerrt: Im Extremfall - Redundanz Eins (d. h. jeder Reflex einmal gemessen) - würde der $R_{\text {int }}$ den Wert Null annehmen, da in diesem Fall gilt $F_{o}^{2}=<F_{o}^{2}>$. Trotzdem ist der entsprechende Datensatz nicht besser als ein hochredundanter. Durch hohe Redundanz wird der $R_{\text {int }}$ dagegen tendenziell erhöht, was ebenfalls nicht korrekt ist 38].

Sinnvoll ist in diesem Zusammenhang die Einführung eines anderen, die Redundanz berücksichtigenden Gütekriteriums:

$$
R_{\text {sigma }}=\frac{\sum\left[\sigma\left(F_{o}^{2}\right)\right]}{\sum\left[F_{o}^{2}\right]}
$$

Dieser $R$-Wert berücksichtigt die Standardabweichungen $\sigma$ der Strukturfaktoren und gibt die Güte eines Datensatzes gerade bei hoher und sehr hoher Redundanz besser wieder als der $R_{\text {int }}$ [38].

Wenn die Meßzeit keine oder nur eine geringe Rolle spielt, sollte man immer versuchen, möglichst hohe Redundanz zu erreichen [37]. In vielen Fällen ist eine sehr hohe Redundanz unvermeidlich zur Lösung der gestellten Aufgabe:

Bei sehr schwach streuenden Kristallen kann durch hohe Redundanz (> 8) die verwertbare maximale Auflösung teilweise um mehr als $0.5 \AA$ verbessert werden, was mitunter eine Lösung des Phasenproblems überhaupt erst ermöglicht.

Auch für die Bestimmung der oftmals sehr geringen anomalen Differenzen ist hohe Redundanz essentiell: Mit Hilfe eines hochredundanten Datensatzes von tetragonalem HEWLysozyme (Redundanz 22) gelang es 1998, alle Schwefelatome, sowie einige Chloridionen in der Differenzpatterson zu lokalisieren [39]. Auch der in 5.1.3 beschriebene Datensatz verdankt seine Güte überwiegend der hohen Redundanz. 


\subsection{Ausarbeitung der Datensammlungsstrategie}

Die Wahl der Datensammlungsstrategie hängt wesentlich von den konkreten Gegebenheiten und der Fragestellung ab [37]:

Die Routine-Kleinmolekülmessung wird in aller Regel bei tiefer Temperatur mit Molybdän-Strahlung an einem Flächenzähler erfolgen, der mit einem Drei- oder Vierkreisdiffraktometer gekoppelt ist; seltener ist die Variante imaging plate / Einkreisdiffraktometer. Da Kleinmolekülkristalle zumeist gut streuen und zugleich relativ robust gegenüber Strahlenschäden sind, sollte man es sich zur Regel machen, möglichst immer mindestens mittlere Redundanzen (etwa um sechs) zu sammeln. Lediglich bei triklinen Kristallen kann dies unter Umständen schwierig bzw. zeitaufwendig werden. Die immense Zeitersparnis, die der Einsatz von Flächenzählern mit sich bringt, sollte zum Teil zur Verbesserung der Datenqualität durch höhere Redundanz genutzt werden. Überhaupt ist Meßzeit selten der limitierende Faktor bei Kleinmolekülstrukturen.

Daher ist es in den meisten Fällen nicht nötig, für jeden Kristall eine individuelle Meßstrategie zu entwickeln: Eine gute Standard-Strategie, die bei mittlerer Redundanz die halbe Diffraktionskugel lückenlos abdeckt, kann für fast alle Kleinmolekülstrukturen routinemäßig verwendet werden [40]. Für eine solche Standard-Strategie hat sich die Kombination von $\phi$ - und $\omega$-scans als sinnvoll erwiesen [41], wobei je nach Geometrie des Diffraktometers die Strategie $\phi$ - oder $\omega$-dominiert sein wird: Durch die geometrischen Restriktionen der Euler-Wiege ist der mögliche $\omega$-Bereich der Euler-Geometrie stark eingeschränkt (im Falle des im Rahmen dieser Arbeit benutzten Gerätes ist nur ein Bereich von $\Delta \omega=50^{\circ}$ anfahrbar; und selbst das nur bei $\chi=90^{\circ}$ ), so daß der Standard-Run für Vierkreisdiffraktometer tendenziell arm an $\omega$-scans sein wird. Dagegen steht dem Ausführen von ausgedehnten $\omega$-scans bei der Platform-Geometrie nichts im Wege (je nach Zählerabstand sind Bereiche bis zu $\Delta \omega=250^{\circ}$ realisierbar). Da Drehungen des Kristalls um $\omega$ den Vorteil haben, daß bei unterschiedlichen konstanten $\phi$-Winkeln jeweils um unterschiedliche Achsen im reziproken Raum gedreht wird, während die Beugungsvektoren bei jeder beliebigen $\phi$-Drehung immer um die selbe reziproke Achse rotieren, werden in einen Standard-Run für Dreikreisdiffraktometer vorwiegend $\omega$-scans zum Einsatz kommen.

Eine erprobte Standard-Meßstrategie für das im Rahmen dieser Arbeit für Kleinmolekülstrukturen nahezu ausschließlich verwendete Vierkreisdiffraktometer (zu sehen in Abb. 4.1 a) ist in Tab. 4.2 gegeben.

Wie bei der Kleinmoleküldatensammlung, sollten Proteindaten nach Möglichkeit nur bei tiefer Temperatur gemessen werden. Aufgrund des schlechteren Streuvermögens 


\begin{tabular}{crrrrrrr} 
run & \multicolumn{1}{c}{$2 \Theta$} & \multicolumn{1}{c}{$\omega$} & \multicolumn{1}{c}{$\phi$} & \multicolumn{1}{c}{$\chi$} & axis & width & $\sharp$ frames \\
\hline 1 & 30.00 & 15.00 & 0.00 & 30.00 & $\phi$ & 0.50 & 730 \\
2 & -30.00 & -20.00 & 0.00 & -60.00 & $\phi$ & 0.50 & 730 \\
3 & 30.00 & 0.00 & 0.00 & 0.00 & $\phi$ & 0.50 & 730 \\
4 & 30.00 & 23.00 & 90.00 & 90.00 & $\omega$ & -0.50 & 96 \\
5 & 30.00 & 23.00 & 270.00 & 90.00 & $\omega$ & -0.50 & 96 \\
\hline
\end{tabular}

Tab. 4.2: Standard-Strategie für Datensammlungen an einem Vierkreis-CCD-Diffraktometer bei $5 \mathrm{~cm}$ Zählerabstand.

und der zu erwartenden niedrigeren Auflösung und größeren Elementarzelleø empfiehlt sich für Labor-Datensammlungen die charakteristische Wellenlänge von Kupfer $\left(\mathrm{Cu}_{K \alpha^{-}}\right.$ Strahlung). Am Synchrotron wählt man im allgemeinen Wellenlängen um $1 \AA$ bzw. paßt bei MAD-Experimenten die Wellenlänge der Absorptionskante der im Kristall enthaltenen Schweratome an.

Aufgrund der teilweise sehr großen Elementarzellen von Proteinkristallen ist der Einsatz von Flächenzählern unverzichtbar, die vorwiegend auf Ein- bzw. Dreikreisdiffraktometer montiert sind. Die mit großem Abstand populärste Anordnung ist gegenwärtig die Kombination Einkreisdiffraktometer / imaging plate-Detektor. In den letzten Monaten konnte sich jedoch der sehr viel schnellere, aber auch erheblich teurere CCD-Zähler auch an Synchrotrons immer mehr durchsetzen.

Die Strategie der Datensammlung muß sich bei Proteinen mehr nach der verfügbaren Meßzeit richten als bei Kleinmolekülen, da die Kristalle im Strahl nur eine begrenzte Lebensdauer haben und Synchrotron-Strahlzeit nicht immer verfügbar ist. Eine wertvolle Hilfe bei der Ermittlung der für das jeweilige Problem optimalen Datensammlungsstrategie stellt das von J. Kärcher entwickelte Programm COSMO dar [42]. Aus der Kenntnis der Diffraktometergeometrie, Zählercharakteristik und der Orientierungsmatrix des zu vermessenden Kristalls berechnet das Programm die optimale Kombination von runs, die innerhalb möglichst kurzer Zeit eine möglichst hohe Vollständigkeit bei möglichst guter Redundanz ergibt.

Das folgende Kapitel zeigt am Beispiel der tetragonalen Form von HEW-Lysozyme und der kubischen Form des Lantibiotikums Actagardin die verschiedenen Möglichkeiten der gängigen Diffraktometer und Zählertypen auf.

\footnotetext{
${ }^{6}$ Aufgrund der Beziehung zwischen Wellenlänge und Beugungswinkel in der Bragg'schen Gleichung wächst der Winkelunterschied zweier Reflexe - und damit der Abstand zwischen den Reflexen auf der Detektorfläche - mit der Wellenlänge.
} 


\section{Kapitel 5}

\section{Vergleich verschiedener Diffraktometergeometrien und Röntgendetektoren}

Die Bedeutung guter Kristalle für die Röntgenstrukturanalyse ist offensichtlich. Aus guten Kristallen den optimalen Datensatz zu erzeugen erfordert allerdings ein präzises Diffraktometer und einen erstklassigen Detektor (vgl. Kapitel 4, Seite 26ff ).

Im Rahmen dieser Arbeit wurden Kristalle von tetragonalem Hühnereiweiß-Lysozyme und von Actagardin auf vielen verschiedenen Diffraktometern untersucht, und zwar mit unterschiedlichen Geometrien, Wellenlängen und Strahlungsquellen von der sealed tube bis zur wiggler-beamline am Synchrotron.

Zunächst sollen die verwendeten Versuchsanordnungen beschrieben werden, dann die Datensätze. Schließlich werden die Datensäze vergleichend diskutiert.

\subsection{Beschreibung der verwendeten Diffraktometer}

\subsubsection{Euler-Vierkreis-Goniometer / SMART 1K}

Das Gerät, das in der Arbeitsgruppe Sheldrick zur Routinebestimmung von Kleinmolekülstrukturen benutzt wird, ist ein Vierkreisdiffraktometer mit Offset-Eulerwiege der Firma Huber, ausgestattet mit einem Siemens (heute Bruker) SMART 1K CCD-Zähler der 
ersten Generation mit einer aktiven Fläche von $63 \times 63$ mm. Die Röntgenoptik (Röhrengehäuse, Monochromator, shutter, Kollimator) stammt von der Firma Stoe. Die Strahlung wird in einer sealed tube mit Mo-target erzeugt und an einem Graphitkristall monochromatisiert. Dieses Gerät ist aufgrund der Wellenlänge und Strahlintensität im Grunde nicht zur Untersuchung von Proteinstrukturen geeignet (vgl. Kapitel ⿶), trotzdem wurde 1999 der Versuch unternommen, Lysozyme-Kristalle zu röntgen. Etwa ein Jahr später wurde auch ein Kristall von Actagardin an diesem Gerät gemessen. Außerdem wurden - mit Ausnahme der Struktur des Cycloikositetraphenylens - alle Kleinmolekülstrukturen der vorliegenden Arbeit mit Daten von dieser Anlage bestimmt. Ein Foto des Geräts ist in Abb. 4.1a (Seite 32) zu sehen.

\subsubsection{Zweikreis-Goniometer / ipds-ii}

Das Zweikreisdiffraktometer mit imaging plate-Detektor und Mo-sealed tube der Firma Stoe, wie es in der Arbeitsgruppe um J. Magul in Göttingen zur Routinedatensammlung eingesetzt wird, ist im Vergleich zur Vier- und Dreikreis-Geometrie eine bisher relativ selten verwendete Anlage in der chemischen Kristallographie. Die Zweikreisgeometrie besteht aus $\phi$ - und $\omega$-Kreis, wobei die Anlage lediglich zur Durchführung von $\omega$-Scans ausgelegt ist. Der $\phi$-Kreis dient dazu, den Kristall zwischen zwei $\omega$-Scans in eine andere Position zu drehen (häufig um $90^{\circ}$ ). Auf diese Weise wird das Problem des Totkonus beseitigt (siehe 4.4 .3 und Abb. 4.3). Der Stoe ipds-ii-Detektor hat einen Plattendurchmesser von $340 \mathrm{~mm}$ und eine Lösch- und Auslesezeit über die maximale Fläche von etwa dreieinhalb Minuten. Wie auch das Vierkreisdiffraktometer mit SMART 1K ist dieses Gerät für Proteindatensammlungen im Grunde ungeeignet. Allerdings ist der ipds-ii ein relativ empfindlicher Zähler, und die Röntgenoptik stellt mit Graphit-Monochromator und Glaskapillarkollimator den neuesten Stand der Technik dar円, so daß die Intensitätsausbeute deutlich die der in 5.1 .1 beschriebenen Anlage übertrifft.

\subsubsection{Platform-Goniometer / HiStar}

Die Kombination Platform-Geometrie / Cu-Drehanode / Graphit-Monochromator / multi wire-Zähler (alle Geräte von Bruker) stellt den Stand der Technik von vor etwa sechs Jahren dar - zu dieser Zeit wurde das Gerät auch von der Abteilung Sheldrick angeschafft.

\footnotetext{
${ }^{1}$ multilayer Optiken für Mo-Strahlung stehen unmittelbar vor der Markteinführung, sind derzeit aber noch nicht erhältlich, so daß ein Graphitkristall (noch) der Monochromator der Wahl ist.
} 
Auch heute noch leisten solche Anlagen gute Dienste, Neuanschaffungen werden jedoch eher mit multilayer Optik und CCD- oder imaging plate-Detektoren ausgestattet. Häufig werden auch alte Anlagen entsprechend nachgerüstet.2] Neben den beiden Datensätzen von Lysozyme und Actagardin (letzterer gemessen 1999 von J. Kärcher 43]) wurden auch die Daten der Cycloikositetraphenylen-Struktur mit dieser Anlage gesammelt. Abb. 4.2 a (Seite 33) zeigt ein Foto des Geräts.

\subsubsection{Platform-Goniometer / SMART 6000}

Eine relativ moderne Anlage, die man derzeit als state of the art bezeichnen kann, ist das in der Arbeitsgruppe Sheldrick stehende Platform-Dreikreisdiffraktometer mit moderner 5 kW Cu-Drehanode und SMART 6000 CCD-Zähler mit einer aktiven Fläche von $92 \times$ $92 \mathrm{~mm}$ (alle Komponenten von Bruker). Die Monochromatisierung und Fokussierung der Röntgenstrahlung erfolgt mit Hilfe einer max flux multilayer Optik der Firma Osmic. Dieses Gerät sollte besonders geeignet sein zur in house Datensammlung bei atomarer Auflösung von kleineren Proteinen und sehr kleinen Kristallen größer Naturstoffe wie Peptidantibiotika und ähnlichem.

Die Qualität aller bislang auf der beschriebenen Anlage gesammelten Daten ist allerdings deutlich schlechter als erwartet. Bei genauer Betrachtung der Bilder fielen Schwankungen des Gesamtsignals - und damit indirekt der Strahlintensität - zwischen den Aufnahmen um etwa Faktor vier auf, wie in Abb. 5.1 dargestellt ist.

Berücksichtigt man die Auslesezeit des Detektors von ca. 10 Sekunden und außerdem die Tatsache, daß manche Bilder, bei denen eine Übersättigung des Zählers auftrat, mit einem Achtel der Belichtungszeit ein zweites Mal aufgenommen wurden, errechnet sich eine Schwankungsfrequenz von etwa 35 bis 40 Minuten. Durch diese Intensitätsschwankungen entstehen enorme systematische Fehler, die nicht befriedigend korrigiert werden können; die Daten sind - obwohl die einzelnen Bilder sehr vielversprechend aussehen nicht verwertbar.

Auf der Suche nach der Ursache für die beobachteten Schwankungen wurde auch eine Messung der Umgebungstemperatur im Diffraktometerraum über einen Zeitraum von etwa 12 Stunden (vgl. Abb. 5.2) vorgenommen. Sie ergab eine periodische Schwankung der Raumtemperatur um knapp $2{ }^{\circ} \mathrm{C}$ mit einer Schwankungsfrequenz von 40 Minuten.

\footnotetext{
2 Tatsächlich wurde auch bei der beschriebenen Anlage der multi wire-Zähler durch einen mar345 imaging-plate-Detektor getauscht; diese neue Anlage ist unter 5.1.5 beschrieben.
} 


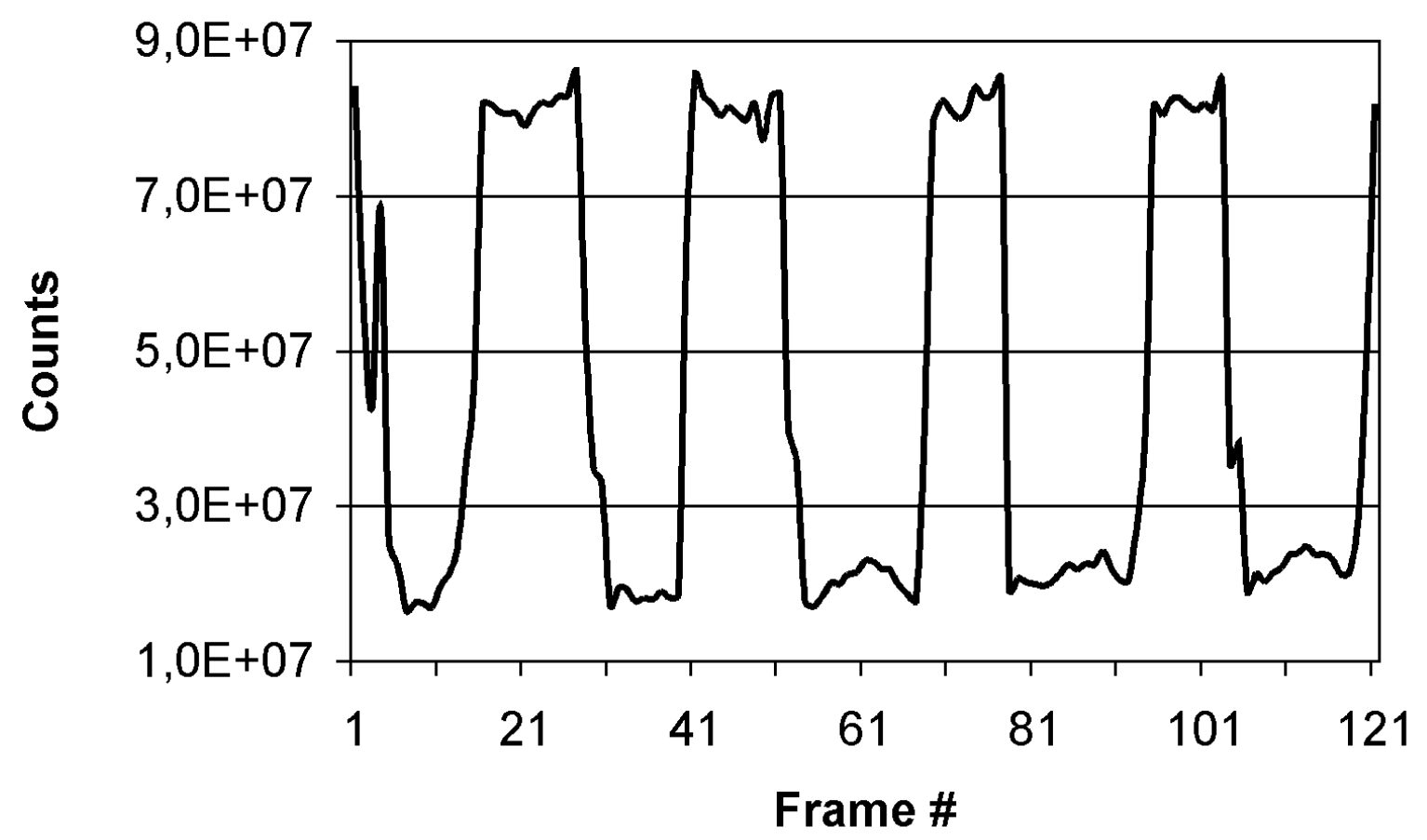

Abb. 5.1: Auftragung der Anzahl von gezählten Ereignissen (Counts) pro Einzelbild (Frame) von 121 Bildern einer Lysozyme Messung (Belichtungszeit 60 Sekunden).

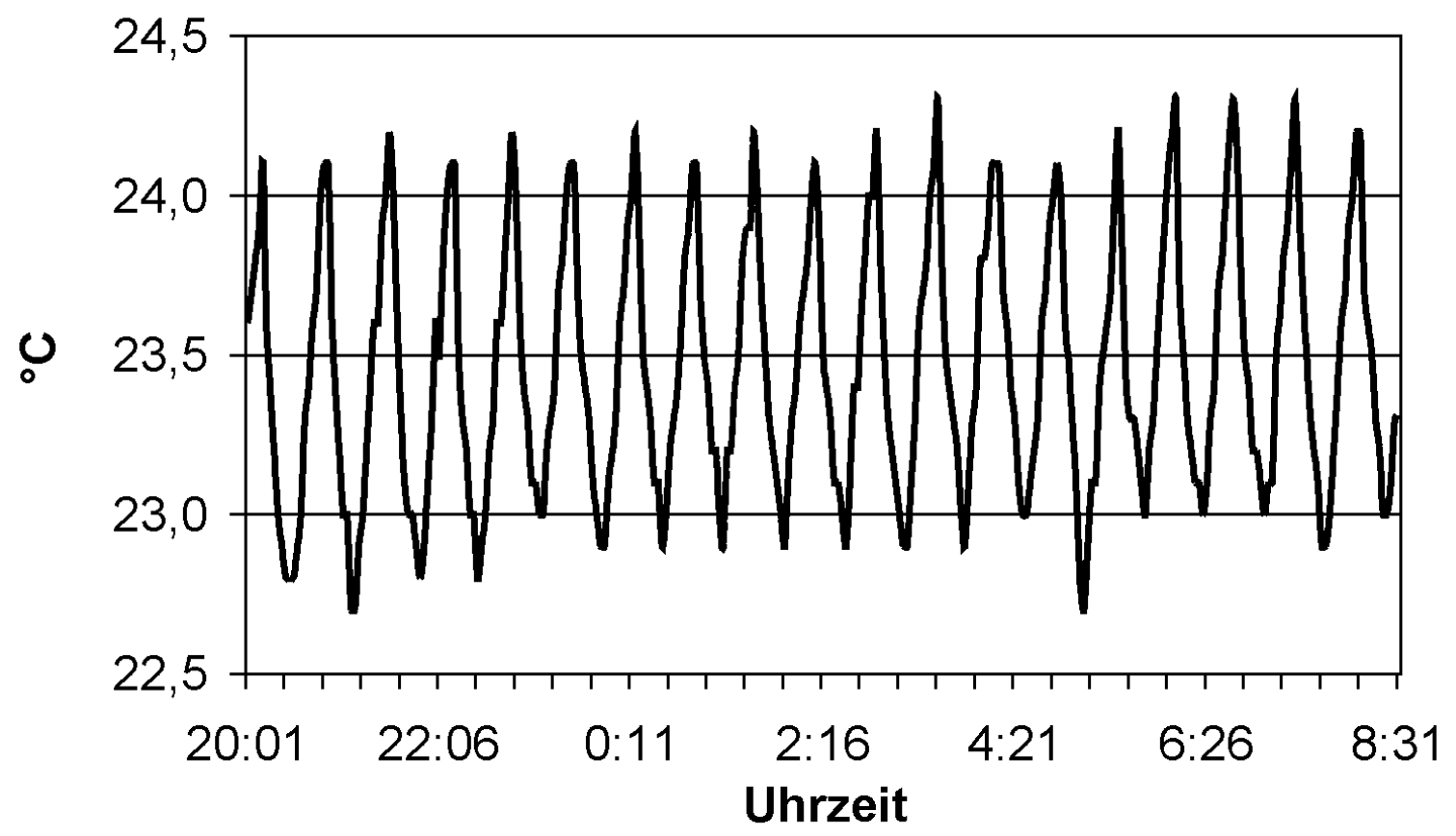

Abb. 5.2: Auftragung der Temperatur im Diffraktometerraum gegen die Uhrzeit über gut 12 Stunden. 
Beide Effekte sind sehr regelmäßig und haben etwa die gleiche Periodizität. Es besteht also mit hoher Wahrscheinlichkeit ein Zusammenhang zwischen den Temperatur- und Intensitätsschwankungen, wenngleich diese These nicht endgültig bewiesen ist. Interessant ist, daß die beobachteten Intensitätsschwankungen in ihrem Verlauf eine kastenartige Kurve darstellen, d. h. die Intensität des Röntgenstrahls wechselt abrupt zwischen zwei Grenzwerten, während die Temperaturwechsel naturgemäß stufenlos erfolgen.

Offen ist auch, wie genau die relativ geringen Temperaturschwankungen einen so erheblichen Effekt auf die Strahlintensität haben können. Möglicherweise liegt ein mechanischer Defekt in der multilayer-Optik vor, der bei geringen Änderungen der Temperatur einen der Spiegel zwischen zwei Positionen hin- und herklappen läßt. Eventuell könnte auch der sehr hohe Einschaltstrom des Kompressors der Klimaanlage Spannungsschwankungen erzeugen. Beeinflussungen der Röntgenleistung durch starke Verbraucher wie Klimaanlagen wurden in der Vergangenheit vereinzelt beobachtet [44], allerdings konnte ausgeschlossen werden, daß sich der Generator der Drehanode im selben Stromkreis oder auch nur an der selben Drehstromphase befindet wie die Klimaanlage.

Nicht grundsätzlich ausgeschlossen werden sollten allerdings auch Fehler in der Elektronik des Detektors oder den Komponenten des Steuerrechners. Dies wäre zwar nicht ohne Weiteres mit den Temperaturschwankungen im Diffraktometerraum korrelierbar, allerdings ist ein Zusammenhang zwischen den beiden Effekten nicht bewiesen. Die eingehende Untersuchung dieses Problems mit Hilfe der Firma Bruker wird vermutlich einige Wochen, wenn nicht Monate in Anspruch nehmen und soll nicht Gegenstand dieser Arbeit sein.

\subsubsection{Einkreis-Goniometer / mar345}

Ebenfalls state of the art ist das Einkreisdiffraktometer mit (allerdings etwas älterer) Siemens (heute Bruker) Cu-Drehanode und mar345 imaging plate-Detektor, das in der Abteilung Sheldrick steht. Wie bei der Anlage des SMART 6000 erfolgt die Monochromatisierung und Fokussierung mit einer max flux Optik der Firma Osmic. Der mar345 ist derzeit der schnellste imaging Plate Detektor; seine Auslese- und Löschzeit beträgt über die maximale Fläche (Durchmesser der aktiven Fläche $345 \mathrm{~mm}$ ) knapp zwei Minuten. Diese Anlage ist optimal zur Sammlung von Proteindaten bei Aufösungen bis maximal etwa 1.6 A. Auch die Vorbereitung von Synchrotronbesuchen läßt sich mit diesem sehr einfach zu handhabenden Gerät schnell und effektiv gestalten. Atomare Auflösung wird dagegen nicht erreicht. 


\subsubsection{Einkreis-Goniometer / marCCD}

Der marCCD ist der erste CCD-Zähler der Firma MAR-Research. Mit einer relativ großen aktiven Fläche (Durchmesser $165 \mathrm{~mm}$ ) ist er vor allem für Proteinkristallographie am Synchrotron mit Wellenlängen zwischen 1 und 2 Å ausgelegt. Die Datensammlungen erfolgten mit Einkreisdiffraktometern am DESY in Hamburg, und zwar an der wiggler-beamline BW7A bei einer Wellenlänge von $1.000 \AA$ (Lysozyme) und an Beamline X11 bei $0.909 \AA$ (Actagardin, Daten gesammelt von J. Kärcher [43]).

Die Kombination von Einkreisdiffraktometer und CCD-Detektor ist als nicht optimal anzusehen, weil die aktive Fläche des Zählers zu klein ist, um auf einen $2 \Theta$-Arm verzichten zu können. Die bei der gegebenen Wellenlänge maximal erreichbare Auflösung lag daher für Lysozyme bei nur etwa $1.5 \AA$, auch wenn der verwendete Kristall erheblich weiter gestreut hätte. Dies wird deutlich durch die sehr guten Werte für $R_{\text {int }}$ und $R_{\text {sigma }}$ in der äußersten Auflösungsschale. Die Elementarzelle von Actagardin ist kleiner als die von Lysozyme, daher war ein kleinerer Abstand des Zählers vom Kristall und damit eine bessere Auflösung von fast $1.2 \AA$ realisierbar.

\subsubsection{Platform-Goniometer / SMART 6500}

Der SMART 6500 der Firma Bruker ist dem SMART 6000 sehr eng verwandt, lediglich die Glasfaseroptik reduziert etwas stärker, so daß die aktive Fläche (der Durchmesser beträgt $165 \mathrm{~mm}$ ) etwas größer ist. Dadurch ist der SMART 6500 vor allem für SynchrotronMessungen ausgelegt und tritt in direkte Konkurenz zum marCCD. Die Daten wurden gesammelt auf einem Diffraktometer mit Platform-Geometrie an der wiggler-beamline BW7B des DESY Hamburg bei einer Wellenlänge von $1.0 \AA$.

Allerdings waren sowohl das Diffraktometer, als auch der Zähler selbst lediglich zu Demonstrationszwecken und provisorisch montiert, so daß während der Messung immer wieder Probleme mit der Justage der Anlage auftraten. Diese Probleme haben negativen Einfluß auf die Qualität der Daten; vornehmlich die Prozessierbarkeit mit dem Datenreduktionsprogramm SAINT [45] ist dadurch nur bedingt gegeben. Auf den Beugungsbildern - es konnten nur Daten von Lysozyme gesammelt werden - sind Reflexe bis etwa $1.1 \AA$ deutlich wahrzunehmen. Die mangelnde Prozessierbarkeit der Daten verbietet aber eine weitergehende Auswertung, so daß eine Intensitäts-Statistik an dieser Stelle nicht angeführt wird und eine weitere Diskussion der Anlage unterbleibt. 


\subsection{Gütekriterien}

Um die Qualität eines Datensatzes zu beurteilen, haben sich zahlreiche Gütekriterien etabliert. Die im Rahmen dieses Vergleiches herangezogenen sind im Folgenden kurz beschrieben:

\section{Maximale Auflösung:}

Mit der Auflösung steigt und fällt das Daten-Parameter-Verhältnis und damit die Exaktheit einer Röntgenstrukturanalyse. Zum Erreichen hoher Aufösung sind neben der Qualität und Größe des verwendeten Kristalls verschiedene weitere Faktoren ausschlaggebend, nämlich in erster Linie Röntgenintensität, Empfindlichkeit des Detektors und die Goniometer-Geometrie: Je höher die Intensität der verwendeten Röntgenstrahlung ist, desto näher kommt man dem kristalleigenen Limit. Ein empfindlicher Zähler mit geringem Eigenrauschniveau und guter point spread function ermöglicht es, auch die sehr schwachen Reflexe der höchsten Auflösung zu erfassen. Schließlich muß es die Geometrie des Goniometers erlauben, den Zähler so zu orientieren, daß alle meßbaren Reflexe auch den Detektor erreichen. In diesem Zusammenhang macht sich unter Umständen das Fehlen des $2 \Theta$-Armes bei Einkreis-Goniometern störend bemerkbar.

\section{Vollständigkeit:}

Die Bedeutung der Vollständigkeit wurde bereits unter 4.8 (Seite 40) beschrieben. Daten, die nicht zu mehr als $95 \%$ vollständig sind, sollten mit Vorsicht betrachtet werden. Auch sollte die Vollständigkeit in der äußersten Auflösungsschale allenfalls geringfügig unter der des gesamten Datensatzes liegen.

\section{Redundanz:}

Der Nutzen der Redundanz ist unter 4.9 (Seite 41) ausführlich erläutert. Auch die Auswirkungen der Redundanz auf $R_{\text {int }}$ (Gleichung 4.1) und $R_{\text {sigma }}$ (Gleichung 4.2) sind in diesem Abschnitt beschrieben.

\section{$I / \sigma:$}

Die Aussagekraft eines Strukturfaktors wird am besten beschrieben, indem man dessen Intensität mit seiner Standardabweichung normiert, wobei man den $I / \sigma$-Wert erhält. Ein Wert von $I / \sigma=1.0$ entspricht dabei exakt dem durchschnittlichen Rauschen des Datensatzes, ab $I / \sigma$-Werten von etwa 2.0 bis 2.5 kann man einen Reflex als beobachtet bezeichnen. Wichtig ist, daß bei Datensätzen der Wert für $I / \sigma$ auch in der äußersten Auflösungsschale noch größer als 2.0 ist. 


\section{$\boldsymbol{R}_{\text {int }}$ und $\boldsymbol{R}_{\text {sigma }}$ :}

Die Mittelungs- $R$-Werte $R_{\text {int }}$ (Gleichung 4.1) und $R_{\text {sigma }}$ (Gleichung 4.2) sind unter 4.9 (Seite 41) beschrieben. Zwar ist der $R_{\text {sigma }}$ aufgrund seines realistischeren Verhaltens in Verbindung mit der Redundanz dem $R_{\text {int }}$ vorzuziehen [38], letzterer ist jedoch als Gütekriterium sehr weit verbreitet, so daß er hier nicht fehlen soll. Daten, die einen $R_{\text {sigma }}>0.4$ aufweisen, sind kaum mehr verwendbar. Wie auch der Wert für $I / \sigma$ und die Vollständigkeit in den äußeren Auflösungsschalen wurde der $R_{\text {sigma }}$ als Kriterium zum Verwerfen von Daten ab einer bestimmten Auflösung herangezogen.

\section{Elementarzelle:}

Alle Daten wurden bei tiefer Temperatur gesammelt; die jeweils bestimmten Elementarzellen sollten daher nahezu identisch sein.

\section{Systematische Auslöschungen:}

Ob vorhandene systematische Auslöschungen als solche erkannt werden, hängt von mehreren Faktoren ab: Bei dejustierter Tieftemperaturanlage oder ungeeignetem Kryopuffer kann Eisbildung zum Auftreten von Intensität an Stellen systematisch ausgelöschter Reflexe führen. Vor allem bei CCD-Detektoren, die ein relativ hohes Eigenrauschniveau haben, kann ein bei der Datenreduktion falsch interpretierter Hintergrund dazu führen, daß nicht vorhandene Reflexe aus dem Rauschen erzeugt werden. Probleme der Fehlerskalierung im Rahmen der Datenreduktion können zur Überschätzung der $I / \sigma$-Werte der Daten führen, wovon auch die systematisch ausgelöschten Reflexe betroffen sind. Unter Umständen kann auch ein ausgeprägter $\lambda / 2$ Effekt (vgl. 4.2.1) zum Auftreten einzelner systematisch ausgelöschter Reflexe führen. Allgemein kann das Fehlen der systematischen Auslöschungen als Hinweis auf ungenügend korrigierte systematische Fehler angesehen werden. Da diese Verzerrung der Intensitätsverhältnisse alle Daten betrifft, reicht es nicht aus, die betreffenden Reflexe zu ignorieren; ein Datensatz von Lysozyme oder Actagardin, bei dem die Raumgruppe nicht eindeutig bestimmbar ist, sollte als verdächtig angesehen werden.

Alle diskutierten Datensätze zeigen deutliche systematische Auslöschungen, so daß dieses Kriterium nicht in die vergleichenden Tabellen aufgenommen wurde. Im Anhang befindet sich jedoch zu jedem Datensatz auch eine statistische Analyse der systematischen Auslöschungen (vgl. 13.2).

\section{$\left|E^{2}-1\right|$-Statistik:}

Die $\left|E^{2}-1\right|$-Statistik gibt Auskunft über die Intensitätsverteilung. Für Proteine, die relativ wenige oder keine Schweratome und praktisch keine Atome auf speziellen Lagen enthalten, sollte der Erwartungswert von 0.736 relativ gut erreicht werden. Wenn Verzwillingung ausgeschlossen werden kann sprechen Abweichungen nach unten für eine Ausschmierung 
der Intensitätsunterschiede entweder durch den Detektor selbst oder aber durch Fehlinterpretation des Hintergrundes bzw. durch ungenaue $\sigma$-Skalierung bei der Datenreduktion. Da weder die tetragonale Form des HEW-Lysozymes noch die kubische Form von Actagardin verzwillingt vorliegt, ist die $\left|E^{2}-1\right|$-Statistik ein geeignetes Gütekriterium im Rahmen dieses Vergleichs.

\section{Anomales Signal:}

Da das Friedel'sche Gesetz $\left(F_{h k l}=F_{-h-k-l}\right)$ nur bei zentrosymmetrischen Raumgruppen streng gilt, können in Strukturen biologischer Moleküle, die ausschließlich in azentrischen Raumgruppen kristallisieren, bei Anwesenheit von Schweratomen anomale Differenzen bestimmt werden, die sog. $\Delta F$-Werte, für die gilt:

$$
\Delta F=F_{h k l}-F_{-h-k-l}
$$

Die $\Delta F$-Werte sind desto größer, je schwerer ein Atom ist und je weiter sich die verwendete Wellenlänge der Absorptionskante des entsprechenden Atoms von unten (also von langen Wellenlängen her) nähert (nach Überschreiten der Absorptionskante wird das Atom ionisiert). Das anomale Signal von Schwefel ist bei den verwendeten Wellenlängen $\left(\lambda_{C u_{K \bar{\alpha}}}=1.54178 \AA\right.$ und $\lambda_{M o_{K \bar{\alpha}}}=0.71073 \AA$ ) sehr gering (wenngleich prinzipiell meßbar [39]), so daß lediglich für die Daten der iodidhaltigen Actagardinkristalle eine Analyse des anomalen Signals erfolgte.

\section{$\boldsymbol{R}$-Werte der Verfeinerung:}

Ziel der Datensammlung ist im allgemeinen die Anfertigung eines dreidimensionalen Strukturmodells. Daher ist die Verfeinerbarkeit ein wichtiges Kriterium zur Beurteilung eines Datensatzes. Als Gütekriterien der Verfeinerung werden hier die R1-Werte für alle Daten angegeben. Da die $R$-Werte stark abhängig sind von der Auflösung des verwendeten Datensatzes, wurden alle angegebenen $R$-Werte der besseren Vergleichbarkeit wegen aus Verfeinerungen gewonnen, denen bei $2.0 \AA$ (Lysozyme) bzw. $2.3 \AA$ (Actagardin) geschnittene Daten zugrunde lagen.

\section{Absolute Meßzeit:}

Die Dauer eines Beugungsexperimentes ist zwar nicht unmittelbar ein Kriterium zur Bewertung der Datenqualität, da sich aber Proteinkristalle aufgrund von Strahlenschäden im Verlauf der Messung zersetzen und Meßzeit nicht unbegrenzt zur Verfügung steht (vgl. Kapitel (4), kann die absolute Meßzeit durchaus zum Urteil über eine Diffraktometer-Anlage beitragen. 
$\boldsymbol{R}_{\text {merge: }}$

Analog zum $R_{\text {int }}$ läßt sich ein Mittelungs- $R$-Wert auch für äquivalente Reflexe zweier Datensätze berechnen. Aufgrund der Erfahrungen früherer ähnlicher Untersuchungen [46] wurde im Rahmen dieser Arbeit jedoch darauf verzichtet, die zu vergleichenden Datensätze auf einen Referenzdatensatz zu skalieren und die Mittelungs- $R$-Werte anzugeben.

Im Anhang (Abschnitt 13.2) befindet sich zusätzliches ausführliches Tabellenmaterial zu jedem einzelnen Datensatz.

\subsection{Datensätze von Lysozyme}

Eine der weltweit meistuntersuchten Proteinstrukturen ist die des Lysozyme aus Hühnereiweiß (HEW), das normalerweise in der tetragonalen Raumgruppe $P 4_{3} 2_{1} 2$ kristallisiert. Als 1997 die Arbeit an dem Lysozyme-Projekt aufgenommen wurde, war der beste in der PDB veröffentlichte tetragonale HEW-Lysozyme Datensatz die unter dem Code 193L deponierte Struktur von M. C. Vaney et al.: Diese Daten der unter Schwerelosigkeit gewachsenen Kristalle waren bei Raumtemperatur an einem Synchrotron gesammelt worden. Ihre höchste Auflösung entspricht $1.33 \AA$; die Vollständigkeit beträgt $87.1 \%$ [47].

Nachdem es gelungen war, die Kristallisationsbedingungen zu optimieren (50 mg/ml Protein, 1.0 M NaCl, 0.1 M Acetatpuffer $\mathrm{pH}=4.7$ ) und geeignete Kryobedingungen zu finden (1.5 M NaCl, 0.2 M Acetatpuffer $\mathrm{pH}=4.7,40 \%$ Glycerol), wurden an verschiedenen Diffraktometern und mit unterschiedlichen Detektoren Daten von tetragonalem Lysozyme gesammelt.

Im Folgenden ist eine Übersicht über alle gesammelten Lysozyme-Datensätze, deren statistische Gütekriterien und die abschließenden $R$-Werte der Verfeinerung gegeben. Die ausführliche Beschreibung der Verfeinerung selbst findet sich in Kapitel 11 (Abschnitt 11.2). 


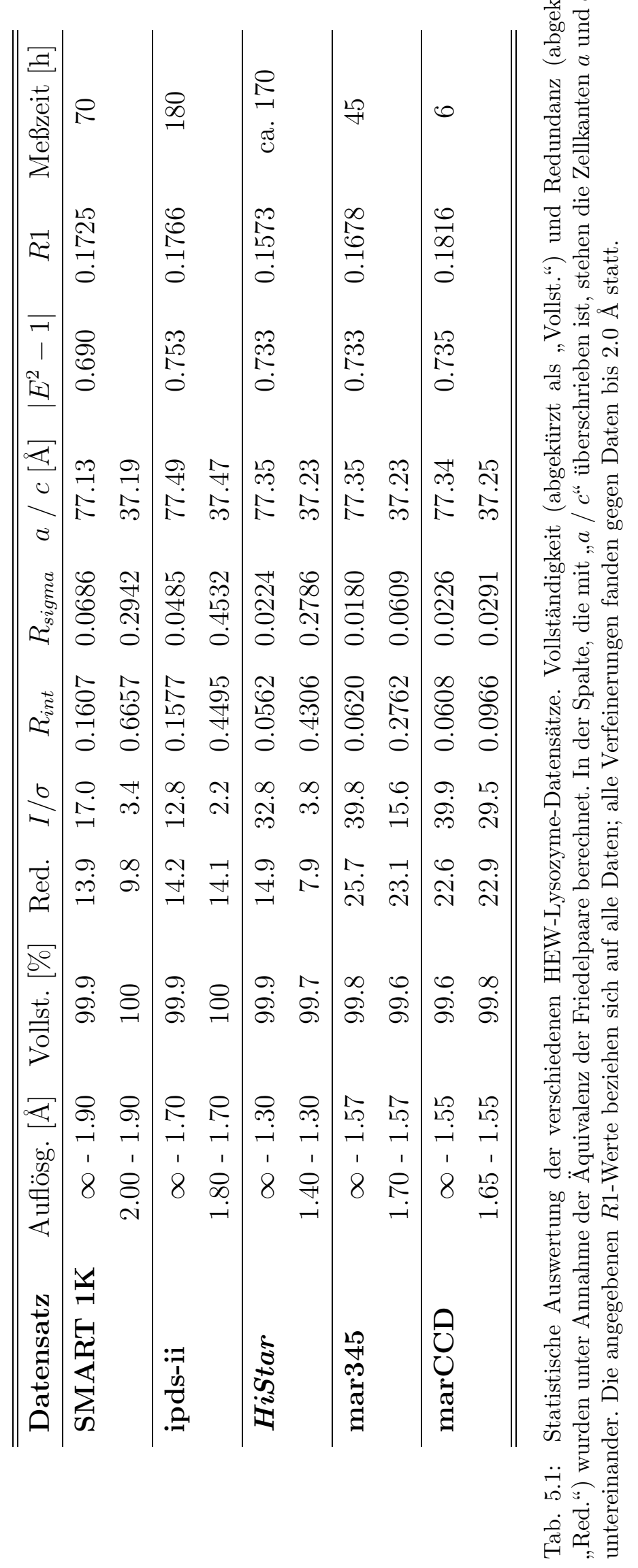




\subsection{Datensätze von Actagardin}

Zwar ist Lysozyme der Standard-Testkristall in der biologischen Kristallographie, so daß ihm in diesem Rahmen eine besondere Rolle zukommt, die kubischen Kristalle des Lantibiotikums Actagardin sind aber ebenfalls sehr zum Vergleich der verschiedenen Diffraktometertypen geeignet:

Actagardin gehört in die Substanzklasse der Peptidantibiotika (präziser zu den Lantibiotika). Mit einer Größe, die sich zwischen Protein und Kleinmolekül bewegt (19 kristallographisch unabhängige Aminosäuren), reiht sich Actagardin in eine Gruppe von Molekülen ein, die ein besonderes Problem für die Röntgenstrukturanalyse darstellen: Diese Moleküle sind zu klein, um proteintypische Sekundärstrukturelemente wie $\beta$-Faltblätter oder $\alpha$-Helizes oder gar eine Tertiärstruktur zu besitzen. Damit schließt sich die für Proteine etablierte Strukturlösungsmethode des molekularen Ersatzes aus. Die verbleibenden Möglichkeiten zur Lösung des Phasenproblems sind Schweratomderivate, um die Struktur mit Hilfe von anomaler Streuung zu lösen, oder direkte Methoden.

Beide Möglichkeiten stellen besondere Anforderungen an die Qualität des Datensatzes: Zur Berechnung der im allgemeinen sehr schwachen anomalen Differenzen müssen die Intensitäten eines Datensatzes sehr exakt bestimmt sein; die Aufösung spielt eine eher untergeordnete Rolle. Für direkte Methoden dagegen ist gerade die Auflösung der wichtigste limitierende Faktor.

Abgesehen von den am Synchrotron gesammelten Daten reicht keiner der Datensätze bis zu atomarer Auflösung, so daß ein Test der Lösbarkeit mit Hilfe von direkten Methoden unterbleibt. Allerdings eignet sich Actagardin für den Test von Methoden, die das anomale Signal ausnutzen, da es mit Iodid kokristallisierbar ist. Ein zusätzlicher Vorteil ist die kubische Lauesymmetrie, die die Sammlung vollständiger Daten bei hoher Redundanz in relativ kurzer Zeit ermöglicht.

Zusätzlich zu den oben genannten Gütekriterien und abschließenden $R$-Werten der Verfeinerung wird im Folgenden auch eine Analyse des anomalen Signals angegeben. Die ausführliche Beschreibung der Verfeinerung findet sich in bei J. Kärcher [43], der auch die Actagardin-Datensätze mit dem marCCD und dem HiStar gesammelt hat. 


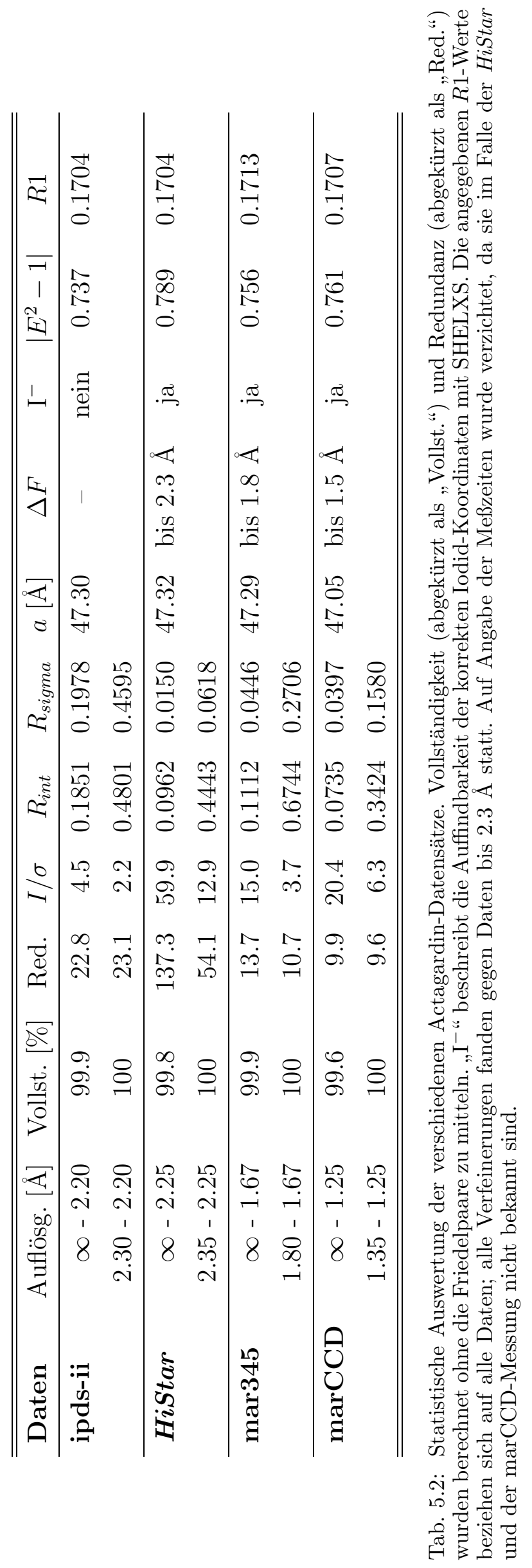




\subsection{Vergleich der Datensätze}

Den Tabellen 5.1 und 5.2 ist zu entnehmen, daß alle getesteten Geräte in der Lage sind, gute Daten zu erzeugen. Eine Bewertung der Datensätze soll zunächst nach Geräten getrennt erfolgen und dann in einem vergleichenden Überblick.

\subsubsection{Euler-Vierkreis-Goniometer / SMART 1K}

Wie unter 5.1.1 ausgeführt, ist die hier verwendete Anlage zur Sammlung von Proteindaten kaum geeignet, da die konventionelle Mo-sealed tube lediglich Röntgenstrahlung geringer Leistung und für Proteine ungünstiger Wellenlänge liefert und der relativ alte CCD-Detektor nicht empfindlich genug ist, um die schwachen Proteindaten befriedigend zu registrieren, zumal sich bei CCD-Detektoren sehr lange Belichtungszeiten verbieten (vgl. 4.5.4).

Dementsprechend war es unmöglich, von Actagardin überhaupt verwertbare Daten zu messen: Selbst bei Belichtungszeiten von 180 - und probehalber auch 240 - Sekunden ließen sich nur einzelne Reflexe bei Auflösungen bis etwa $8 \AA$ detektieren, die nicht einmal eine Zellbestimmung zuließen.

Daß die Datensammlung von Lysozyme trotzdem so erfolgreich war, ist erstaunlich. Der verwendete Lysozyme-Kristall war jedoch relativ groß (etwa $0.9 \times 0.9 \times 0.7 \mathrm{~mm}$ ) und hatte relativ gute Mosaizität (etwa $0.6^{\circ}$ ). Vermutlich war dieser Kristall von allen im Rahmen dieser Arbeit vermessenen mit einigem Abstand der beste.

Wie die $I / \sigma$ - und die Mittelungs- $R$-Werte zeigen sind die SMART 1K-Daten von Lysozyme trotz des hervorragenden Kristalls relativ schwach, was sich auch in einem hohen $R 1$-Wert niederschlägt.

\subsubsection{Zweikreis-Goniometer / ipds-ii}

Dieses Gerät ist wie das im vorangegangenen Abschnitt beschriebene ebenfalls nicht zum Sammeln von Proteindaten gebaut worden. Aufgrund der moderneren Technologie ist die Intensitätsausbeute jedoch deutlich höher (vgl. 5.1.2), und der imaging plate Detektor läßt erheblich längere Belichtungszeiten zu.

Entsprechend sind die erreichte Auflösung und die Mittelungs- $R$-Werte bei Lysozyme etwas besser (nicht aber die $I / \sigma$-Werte), was jedoch mit einer erheblich längeren Meßzeit 
erkauft ist. Die Verfeinerung ergibt $R$-Werte, die mit denen der SMART 1K-Daten durchaus vergleichbar sind.

Deutlicher wird der Unterschied bei der Messung von Actagardin: Obwohl der verwendete Kristall etwas kleiner war als der am SMART 1K montierte, war es möglich, mit sehr langen Belichtungszeiten (60 Minuten pro Bild!) Daten bis zu einer Auflösung von $2.2 \AA$ zu messen. Das erwartete anomale Signal verschwindet jedoch völlig im Rauschen, was vermutlich zum Teil an der Wellenlänge von $0.71073 \AA$ liegt, bei der das anomale Signal von Iodid geringer ausfällt als bei Kupfer-Strahlung, aber vor allem auf Probleme mit der $\sigma$-Skalierung bei der Datenreduktion zurückgeht. Einen weiteren Hinweis auf $\sigma$ Skalierungsprobleme gibt der bei einer Redundanz von $>20 \mathrm{im}$ Vergleich zum $R_{\text {int }}$-Wert zu große $R_{\text {sigma }}$.

\subsubsection{Platform-Goniometer / HiStar}

Die Daten, die an dieser Anlage gesammelt wurden, zeichnen sich durch hohe Exaktheit und sehr gute Verfeinerbarkeit aus (jeweils bester $R_{\text {int }}, R_{\text {sigma }}$ und $R 1$-Wert, wenn man die Aufösungsbereiche berücksichtigt). Das anomale Signal von Actagardin ist über den vollen Aufösungsbereich signifikant und bis etwa $2.6 \AA$ sogar sehr stark (vgl. 13.2.2.2 im Anhang); mit SHELXS läßt sich aus den anomalen Daten die Position des Iodid-Ions finden. Das sehr geringe Eigenrauschen des Zählers ermöglicht nicht nur lange Belichtungszeiten, sondern auch eine exakte Integration der Daten, so daß selbst mit graphitmonochromatisierter Strahlung eine sehr gute Auflösung bei Lysozyme erzielt wurde (die mit Actagardin erreichte Auflösung ist trotz sehr hoher Redundanz geringer als die mit dem ipds-ii mit Mo-Strahlung aus einer sealed tube erhaltene, was vermutlich vor allem an dem relativ kleinen verwendeten Kristall liegt [48]).

Entscheidender Nachteil dieser Anlage ist die relativ kleine aktive Fläche des multi wire Zählers und die geringe Röntgenleistung der Kombination DrehanodeGraphitmonochromator. Dadurch werden die benötigten Meßzeiten sehr lang, was erstens zu Problemen mit Strahlenschäden führen und zweitens den Durchsatz deutlich limitieren kann.

\subsubsection{Einkreis-Goniometer / mar345}

Diese Anlage ist geeignet, in relativ kurzer Zeit sehr gute Daten bis etwa $1.6 \AA$ zu sammeln (die lange Auslesezeit wird durch die große aktive Fläche kompenisert). Sowohl die 
Mittelungs- $R$-Werte, als auch die Gütekriterien der Verfeinerung sind uneingeschränkt als gut zu bezeichnen. Das anomale Signal ist relativ stark und bis etwa $1.8 \AA$ signifikant; die Iodid-Position ist mit Hilfe der anomalen Daten in SHELXS auffindbar.

Die geometrisch bedingte Restriktion der Auflösung verhindert allerdings die Strukturbestimmung großer Naturstoffe, da die zur Lösung mit direkten Methoden benötigte atomare Auflösung nicht erreicht wird. Auf dem Proteinsektor kann die Anlage jedoch nicht nur dazu dienen, Synchrotronmessungen effizient vorzubereiten, sondern sicherlich auch einige Reisen zum Synchrotron überflüssig machen.

\subsubsection{Einkreis-Goniometer / marCCD}

Erwartungsgemäß sind die Synchrotron-Daten die stärksten und zeichnen sich durch höchste Auflösung aus (die Auflösung von Lysozyme war rein geometrisch auf $1.55 \AA$ beschränkt, da das verwendete Gerät nicht mit einem $2 \Theta$-Arm ausgestattet war). Auffallend sind die im Vergleich dazu relativ schlechten $R$-Werte der Verfeinerung, die für nur unzureichend korrigierte systematische Fehler sprechen. Ebenfalls fällt das anomale Signal erstaunlich schwach aus (wenngleich es ausreicht, um das Iodid-Ion zu lokalisieren), und die Daten der inneren Auflösungsbereiche sind, verglichen mit der Gesamt-Datenqualität, zu schlecht (vgl. Abschnitt 13.2.2.4 im Anhang).

Für den extrem schlechten $R 1$-Wert der Lysozyme-Verfeinerung müssen noch andere Gründe verantwortlich sein als einfache systematische Fehler. Die LysozymeDatensammlung erfolgte 1999 auf einem der ersten Geräte dieses Typs, das zudem erst einige Wochen zuvor aufgebaut worden war. Dieser Umstand und die Tatsache, daß der Zähler knapp 24 Stunden nach der Messung größere Defekte zu zeigen begann, spricht für das Vorliegen von Problemen, die nur schwer korrigierbare systematische Fehler erzeugen können. Es wäre interessant, einen weiteren Datensatz von Lysozyme mit einem marCCD aufzunehmen, der erfolgreich im Routinebetrieb eingesetzt ist.

\subsubsection{Abschließender Vergleich}

Alle beschriebenen Detektoren und Diffraktometergeometrien sind prinzipiell zur Sammlung von Proteindaten geeignet. Allerdings sollte die Strahlenquelle deutlich stärker sein als eine abgeschmolzene Röhre, um verwertbare Daten in vertretbarer Zeit zu erhalten. Das anomale Signal der mit dem marCCD, dem mar345 und dem Bruker HiStar gesam- 
melten Daten war stark und präzise genug, um die Position des Iodidions mit SHELXS aus den anomalen Daten zu bestimmen.

Die moderneren Zähler (mar345 und marCCD) sind dem älteren HiStar hinsichtlich ihrer Geschwindigkeit klar überlegen. Die Qualität der HiStar-Daten steht jedoch in keiner Weise hinter der der jüngeren Geräte zurück.

Die Geometrie des Goniometers wirkt sich vor allem bei Lauegruppen niedriger Symmetrie aus, so daß im vorliegenden Vergleich keine Vor- oder Nachteile festzustellen sind.

Grundsätzlich ist es vorteilhaft, ein Goniometer zu verwenden, das mit einem $2 \Theta$-Arm ausgestattet ist, da anderenfalls die mögliche Auflösung deutlich limitiert ist und unter Umständen keine atomar aufgelösten Daten gesammelt werden können. 


\section{Kapitel 6}

\section{Unklare Zuordnung des Elements}

Nach Datensammlung und Lösung des Phasenproblems steht man prinzipiell vor der Aufgabe, die gefundene Lösung zu interpretieren. Da die in der Strukturlösung gefundenen Elektronendichtemaxima von dem zur Lösung verwendeten Programm - bei Kleinmolekülen fast immer SHELXS [49] - nur in Einzelfällen allesamt der richtigen Atomsorte zugeordnet werden, benötigt der Kleinmolekülkristallograph ein fundiertes chemisches Wissen.

In vielen Fällen, etwa bei Phenyl- oder $\mathrm{Cp}^{*}$-Resten, die bereits durch ihre Geometrie zweifelsfrei erkannt werden können, ist die Zuordnung unkritisch, in einigen anderen Situationen dagegen kann das Erkennen der Atomsorte durchaus ein Problem sein. Speziell im Periodensystem nahe beieinanderstehende relativ leichte Atome können in Gegenwart von Schweratomen nicht immer zweifelsfrei unterschieden werden. Häufigstes Beispiel ist vermutlich die Verwechslung von Stick- und Sauerstoff, die unter Umständen ähnliche Koordinationsgeometrie zeigen können und deren Elektronendichten sich nur durch ein Elektron voneinander unterscheiden. Dieses Problem wird im ersten Beispiel dieses Kapitels gezeigt, während das zweite Beispiel die ähnlich gelagerte Problematik, zwischen Schwefel und Phosphor zu unterscheiden, beschreibt. In Einzelfällen kann allerdings auch die Zuordnung des (einzigen) Schweratoms selbst zum Problem werden, wie das dritte Beispiel dieses Kapitels zeigt. 


\subsection{Tetrameres $\mathrm{InCl}_{3}$}

Bei dem Versuch, durch eine Eliminierung von $\mathrm{Me}_{3} \mathrm{SiCl}$ aus $\mathrm{Et}_{2} \mathrm{NSiMe}_{3}$ und $\mathrm{InCl}_{3}$ einen InN-Precursor für CVD darzustellen, war im Reaktionsgefäß kristalliner Niederschlag erhalten worden, der durch Umkristallisieren aus Diethylether in für die Röntgenstrukturanalyse geeignete Kristalle überführt werden konnte. Die Strukturanalyse ergab das Vorliegen von tetramerem $\mathrm{InCl}_{3}$ in der triklinen Raumgruppe $P \overline{1}$ mit einem halben Molekül in der asymmetrischen Einheit. Die vier In-Zentren sind verbunden durch sechs $\mu$-verbrückende Cl-Atome, wodurch drei viergliedrige $\mathrm{In}_{2} \mathrm{Cl}_{2}$-Ringe entstehen. Zusätzlich sind an die inneren In-Atome jeweils ein, an die äußeren jeweils zwei terminale Chloratome gebunden. Die verzerrt oktaedrischen Koordinationssphären der In-Atome werden durch insgesamt sechs koordinierte Lösungsmittelmoleküle komplettiert (siehe Abb. 6.1). Die Lösungsmittelmoleküle als Diethylether anzunehmen lag dabei nahe, weil die Kristalle aus diesem gewachsen waren. Unbefriedigend bzw. auffällig bei diesem Modell

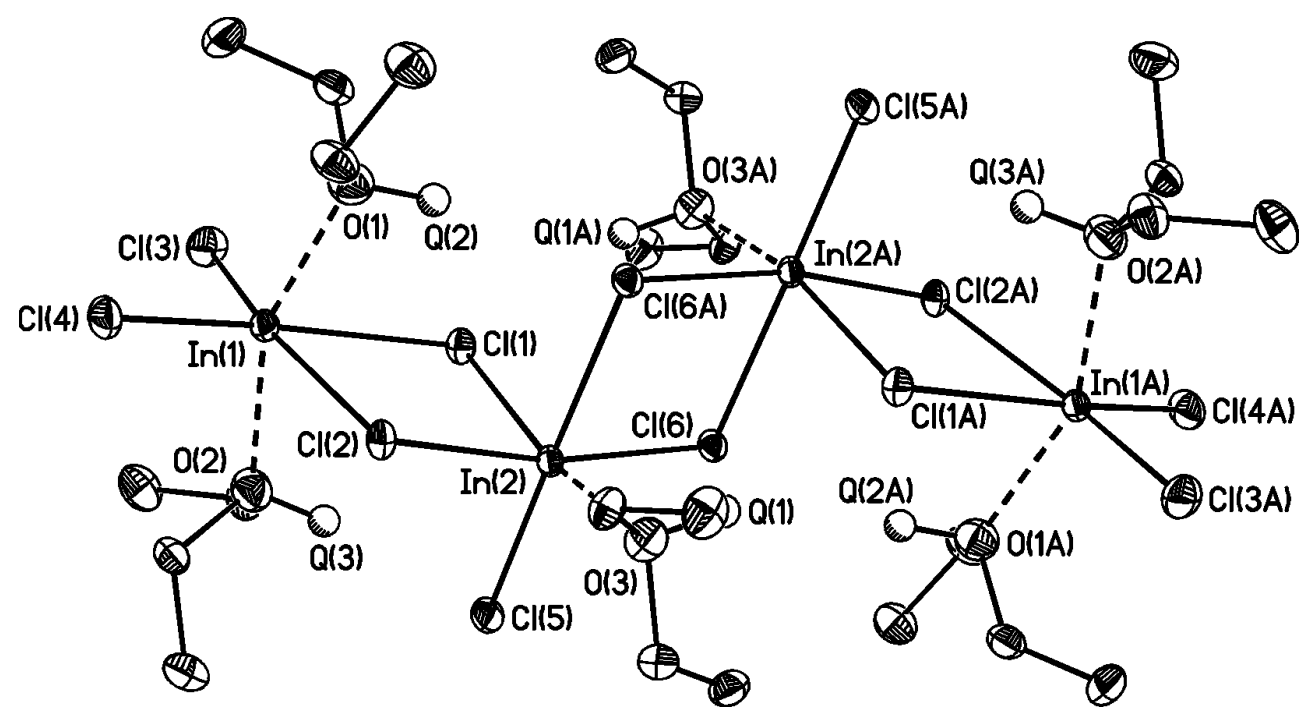

Abb. 6.1: Anfängliches Strukturmodell des tetrameren $\mathrm{InCl}_{3}$ mit $\mathrm{Et}_{2} \mathrm{O}$ als koordiniertes Lösungsmittel. Außerdem sind die drei höchsten Restelektronendichtemaxima und ihre Symmetrieäquivalenten dargestellt.

waren die folgenden Punkte: Die Auslenkungsparameter der Sauerstoffatome waren im Vergleich zu denen der anderen Atome etwas zu groß (Für O: mittlerer $U_{e q}=0.031 \AA^{2}$, für die terminalen Cl-Atome: $\left.U_{e q}=0.026 \AA^{2}\right)$ 円. Außerdem waren die C-O-Bindungen mit im Mittel $1.50 \AA$ A länger als vermutet (Standardwert für eine $\mathrm{C}-\mathrm{O}$-Einfachbindung ist $1.43 \AA[19]$ ), wobei aufgrund der Koordination an die In-Atome mit einer Verlängerung der C-O-Bindung gerechnet werden mußte.

\footnotetext{
${ }^{1} U_{e q}$ ist definiert als ein Drittel der Spur der orthogonalisierten Matrix $U_{i j}$, die das anisotrope Auslenkungsellipsoid beschreibt, ist also ein Maß für die Größe des Auslenkungsellipsoids [3].
} 


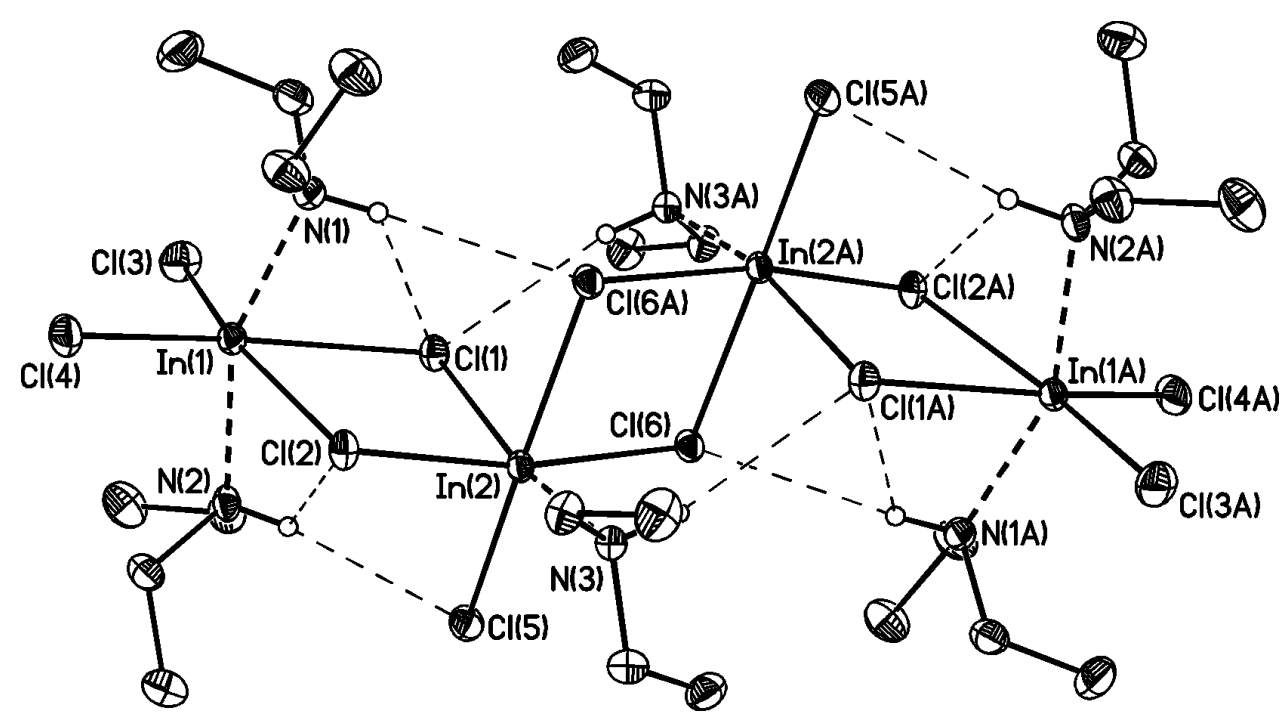

Abb. 6.2: Endgültiges Strukturmodell des tetrameren $\mathrm{InCl}_{3}$ mit koordiniertem $\mathrm{Et}_{2} \mathrm{NH}$ und eingezeichneten N-H-Cl-Wasserstoffbrücken.

Diese beiden Punkte sind eher als auffällig denn als unbefriedigend zu bezeichnen und könnten, ließe sich der Verdacht auf falsch gewählte Atomsorte nicht anderweitig erhärten, ohne weiteres hingenommen werden.

Auf der Suche nach etwaigen weiteren Unstimmigkeiten wurde auch die Restelektronendichte analysiert: Zwar waren die Restelektronendichtemaxima für eine In-Struktur nicht auffällig gewesen (höchstes Maximum: $0.883 \mathrm{e} \cdot \AA^{-3}$, tiefste Restelekronensenke: -1.357 e. $\AA^{-3}$ ), bei näherer Betrachtung konnten jedoch drei Restelektronendichtepeaks gefunden werden, deren Positionen für an die drei unabhängigen „Sauerstoffatome“ gebundene Wasserstoffatome geeignet waren. Damit mußte im Strukturmodell Diethylether durch Diethylamin ersetzt werden (siehe Abb. 6.2). Zwar hatte $\mathrm{Et}_{2} \mathrm{NH}$ weder bei der ursprünglichen Reaktion, noch beim Umkristallisieren Verwendung gefunden, doch war offensichtlich nicht ausreichend getrocknetes THF verwendet worden. Daher reagierte das $\mathrm{Et}_{2} \mathrm{NSiMe}_{3}$ zu Diethylamin und dem entsprechenden Siloxan, so daß die tatsächlich abgelaufene Reaktion die folgende war:

$$
6 \mathrm{Et}_{2} \mathrm{NH}+4 \mathrm{InCl}_{3} \rightarrow\left[\left(\mathrm{InCl}_{3}\right)_{4} \cdot\left(\mathrm{Et}_{2} \mathrm{NH}\right)_{6}\right]
$$

Aufgrund der Änderung der Atomsorte verschwanden alle oben genannten Auffälligkeiten: Der mittlere $U_{e q}$-Wert für die drei N-Atome beträgt im endgültigen Modell $0.0017 \AA^{2}$, was identisch ist mit dem mittleren $U_{e q}$-Wert der $\mu$-verbrückenden Cl-Atome. Die mittlere CN-Bindungslänge berechnet sich nach wie vor zu $1.50 \AA$ und ist nur wenig länger als der Standardwert für eine C-N-Einfachbindung (1.47 $\AA[19])$. Als weitere Bestätigung der drei 
neuen Wasserstoffpositionen kann aufgefaßt werden, daß sich fünf kristallographisch unabhängige N-H-Cl-Wassersoffbrückenbindungen finden lassen (siehe Abb. 6.2). Außerdem verbesserten sich durch die Änderung alle Gütekriterien der Verfeinerung signifikant, was die Richtigkeit des neuen Modells zusätzlich untermauert. Eine ausführliche Beschreibung der Struktur findet sich in [50].

\subsection{Kobaltsalz}

Bei dem Versuch, das Fe-S-Clusterprotein FhuF zu kristallisieren (vgl. 2.3, Seite 7) wurden durch zweimaliges Seeding schöne Kristalle eines Kobaltsalzes erhalten (vgl. auch 2.3.3, Seite 12). Das $\left[\mathrm{Co}\left(\mathrm{H}_{2} \mathrm{O}\right)_{6}\right]^{2+}-$ Kation war eindeutig als von sechs Wassermolekülen umgebenes Kobalt(II)-Ion zu identifizieren (eine Beschreibung der Struktur findet sich in 9.7 auf Seite 113), das noch fehlende Anion dagegen bereitete Schwierigkeiten:

Zunächst gestaltete sich die Verfeinerung als $\mathrm{Co}\left(\mathrm{H}_{2} \mathrm{O}\right)_{6} \mathrm{SO}_{4} \cdot \mathrm{H}_{2} \mathrm{O}$ unproblematisch, und die statistischen Werte waren überaus befriedigend]. Auffällig waren jedoch die zwischen 1.533(2) und 1.541(2) ^ schwankenden, ungewöhnlich langen S-O-Bindungslängen, die eher für $\mathrm{PO}_{4}^{3-}$ als für $\mathrm{SO}_{4}^{2-}$ sprechen [51], und eine erstaunlich klar erkennbare Fehlordnung der H-Atome im siebten, nicht an Co koordinierten Wassermolekül.

Das „fehlgeordnete Wassermolekül“ ließ sich relativ leicht als Ammoniumion identifizieren, Ladungsausgleich wäre über ein $\mathrm{OH}^{-}$-Ion denkbar, das, da sich alle $\mathrm{H}$-Atome an den Wassermolekülen eindeutig in der Differenzfouriersynthese auffinden ließen, über alle verbleibenden Wasserpositionen fehlgeordnet sein müßte. Es ist ohnehin anzunehmen, daß bei dem im Ansatz herrschenden pH-Wert von 6.5 Sulfat zwar als $\mathrm{SO}_{4}^{2-}$, Phosphat hingegen als Dihydrogenphosphat, $\mathrm{H}_{2} \mathrm{PO}_{4}^{-}$, vorliegt, so daß in jedem Fall ein Ladungsausgleich über $\mathrm{OH}^{-}$-Ionen erfolgen muß.

Phosphat sollte von Sulfat erstens aufgrund der X-O-Bindungslängen [51] und zweitens anhand des $R$-Wertes unterscheidbar sein. Die Bindungslängen und der $R$-Wert sprechen eindeutig für Phosphor als Zentralatom. Ein Argument für Sulfat als Anion ist die Tatsache, daß das Protein weder im Verlauf der Aufreinigung und Aufkonzentrierung, noch bei der Kristallisation mit Phosphaten in Berührung gekommen war.

Um Klarheit zu schaffen, wurden in einem Gefäß Lösungen von $\left(\mathrm{NH}_{4}\right)_{2} \mathrm{HPO}_{4}$ und $\mathrm{CoCl}_{2}$ und in einem anderen Gefäß Lösungen von $\left(\mathrm{NH}_{4}\right) \mathrm{HSO}_{4}$ und $\mathrm{CoCl}_{2}$ äquimolar mitein-

\footnotetext{
${ }^{2} R 1=0.0189$ für $F_{o}>4 \sigma\left(F_{o}\right) ; w R 2=0.0518$ für alle Daten
} 
ander gemischt, um so die beiden möglichen Salze gezielt darzustellen und zu kristallisieren. Im Rahmen dieser Experimente stellte sich heraus, daß das entstehende Sulfat erheblich besser löslich ist als das Phosphat. Die sehr geringe Löslichkeit des postulierten $\left[\mathrm{CoNH}_{4} \mathrm{HPO}_{4}\right]^{+}$machte es sogar unmöglich, auf die geplante Weise Kristalle zu züchten.

Umgekehrt macht diese geringe Löslichkeit klar, daß bereits Spuren von Phosphat in der Proteinlösung ausreichend sein müssen, um in Gegenwart von Kobalt(II) Kristalle von $\left[\mathrm{CoNH}_{4} \mathrm{HPO}_{4}\right]^{+}$-Salz zu erhalten. Dies würde auch erklären, weshalb zweimaliges seeding nötig war, um die Kristalle zu ausreichender Größe wachsen zu lassen, da bei jedem seeding neue Proteinlösung - und damit eventuell weiteres $\mathrm{PO}_{4}^{2-}$ - in das System eingebracht wurde.

Dies klärt die wahre Natur der Kristalle zwar nicht endgültig, legt aber doch den Schluß nahe, daß das Gegenion Phosphat und nicht Sulfat ist. Die Frage, wie das Phosphat in den Kristallisationsansatz gekommen sein kann, bleibt aber weiter offen.

\subsection{Unklares Zentralatom}

Aus einem Kolben, der eine Silizium-Stickstoff-Verbindung enthielt, die neben den beiden genannten Elementen nur Kohlenstoff und Wasserstoff in Form von Isityl|3-Liganden enthalten sollte, wurde ein Kristall entnommen, montiert und geröntgt, wobei es sich um den einzigen Kristall handelte, der in dem Kolben überhaupt gefunden werden konnte. Analyse der Daten ergab die trikline Raumgruppe $P \overline{1}$ mit einem halben Molekül in der asymmetrischen Einheit. Das Molekül, das die Strukturlösung zeigte, besteht aus einem viergliedrigen $\mathrm{M}_{2} \mathrm{X}_{2}$-Ligand ( $\mathrm{M}=$ Metall, in der Lösung als Si identifiziert; $\mathrm{X}=$ verbrückendes Atom, in der Lösung lediglich als Elektronendichtemaximum aufgeführt). Darüberhinaus ist an jedes Metallatom ein klar erkennbarer $\mathrm{Cp}^{*}$-Ligand und noch ein weiteres Atom endständig gebunden (siehe Abb. 6.3).

Bereits die ersten Verfeinerungszyklen machten klar, daß das Metallatom im viergliedrigen Ring unmöglich Silizium sein konnte, sondern erheblich schwerer sein mußte: die besten $R$-Werte erzielt man mit Metallen zwischen Lu und Pt (siehe Tabelle 6.1). Auch die Cp*Liganden waren aufgrund des Strukturvorschlags nicht erwartet worden. Rücksprache mit der Arbeitsgruppe, aus der der Kolben stammte, ergab eindeutig, daß die Abteilung keine schweren Metalle oder Cp*-Liganden verwendet, auch nicht in Form von Katalysatoren.

\footnotetext{
${ }^{3}$ 2,4,6-Triisopropylphenyl.
} 


\begin{tabular}{ll|ll|ll}
\hline \hline Metall & $R 1[\%]$ & endo & $R 1[\%]$ & exo & $R 1[\%]$ \\
\hline $\mathrm{Yb}$ & 4.43 & $\mathrm{~N}$ & 4.31 & $\mathrm{~N}$ & 4.40 \\
$\mathrm{Lu}$ & 4.41 & $\mathrm{O}$ & 4.38 & $\mathrm{O}$ & 4.31 \\
$\mathrm{Hf}$ & 4.39 & $\mathrm{~F}$ & 4.50 & $\mathrm{~F}$ & 4.32 \\
$\mathrm{Ta}$ & 4.39 & & & & \\
$\mathrm{~W}$ & 4.38 & & & & \\
$\mathrm{Re}$ & 4.38 & & & & \\
$\mathrm{Os}$ & 4.39 & & & & \\
$\mathrm{Ir}$ & 4.39 & & & & \\
$\mathrm{Pt}$ & 4.41 & & & & \\
$\mathrm{Au}$ & 4.42 & & & & \\
\hline \hline
\end{tabular}

Tab. 6.1: R1-Werte bei Verfeinerung mit verschiedenen Elementen. Bei der Suche nach dem Metallatom wurden die verbrückenden und die terminalen Atome als Sauerstoff verfeinert, bei der Suche nach dem verbrückenden Atom (endo) wurde $\mathrm{M}=\mathrm{W}$ und bei der Suche nach dem terminalen Atom (exo) $\mathrm{M}=\mathrm{W}$ und endo $=\mathrm{N}$ angenommen.

\begin{tabular}{|c|c|c|}
\hline Atompaar & mittlerer Abstand CSD $[\AA]$ & Abstand in Struktur $[\AA]$ \\
\hline W-N (einfach) & 2.09 & 2.04 \\
\hline W-N (mehrfach) & 1.90 & 2.04 \\
\hline W-O (einfach) & 2.06 & 2.04 \\
\hline W-O (carbonyl) & 1.71 & 1.71 \\
\hline
\end{tabular}

Tab. 6.2: Berechnete Bindungslängen bei Verfeinerung mit verschiedenen Elementen im Vergleich zu Werten aus der CSD.

Die Frage, woher der Kristall gekommen war, ist nicht vollständig geklärt worden. Es spricht vieles für die Theorie, daß der Kristall bereits am Spatel gewesen sein muß, bevor mit ihm in dem Kolben nach Kristallen gesucht wurde (das würde auch erklären, warum sich nur ein einziger Kristall finden ließ). Es war jedoch nicht möglich, nachträglich einen „Besitzer“ zu ermitteln.

Die chemische Zusammensetzung des Moleküls ließ sich tatsächlich nicht endgültig klären: Verschiedene Suchen in der CSD [52] ergaben, daß Moleküle mit viergliedrigem $\mathrm{M}_{2} \mathrm{X}_{2}$-Ring (mit $\mathrm{M}=$ Metall und $\mathrm{X}=\mathrm{N}$ oder $\mathrm{O}$ ) nur für Cr, Mo und $\mathrm{W}$ bekannt sind. Cr und Mo sind zu leicht, daher wurde für das Metallatom mit einer gewissen Wahrscheinlichkeit Wolfram angenommen. Bis auf einen Fall, bei dem W-N-Mehrfachbindungen vorliegen, erfolgt die Verknüpfung im Ring entweder über $\mathrm{O}$ oder über N-R. Da am verbrückenden Atom kein Rest zu finden ist und die W-X-Abstände zu groß für Mehrfachbindungen sind, spricht 


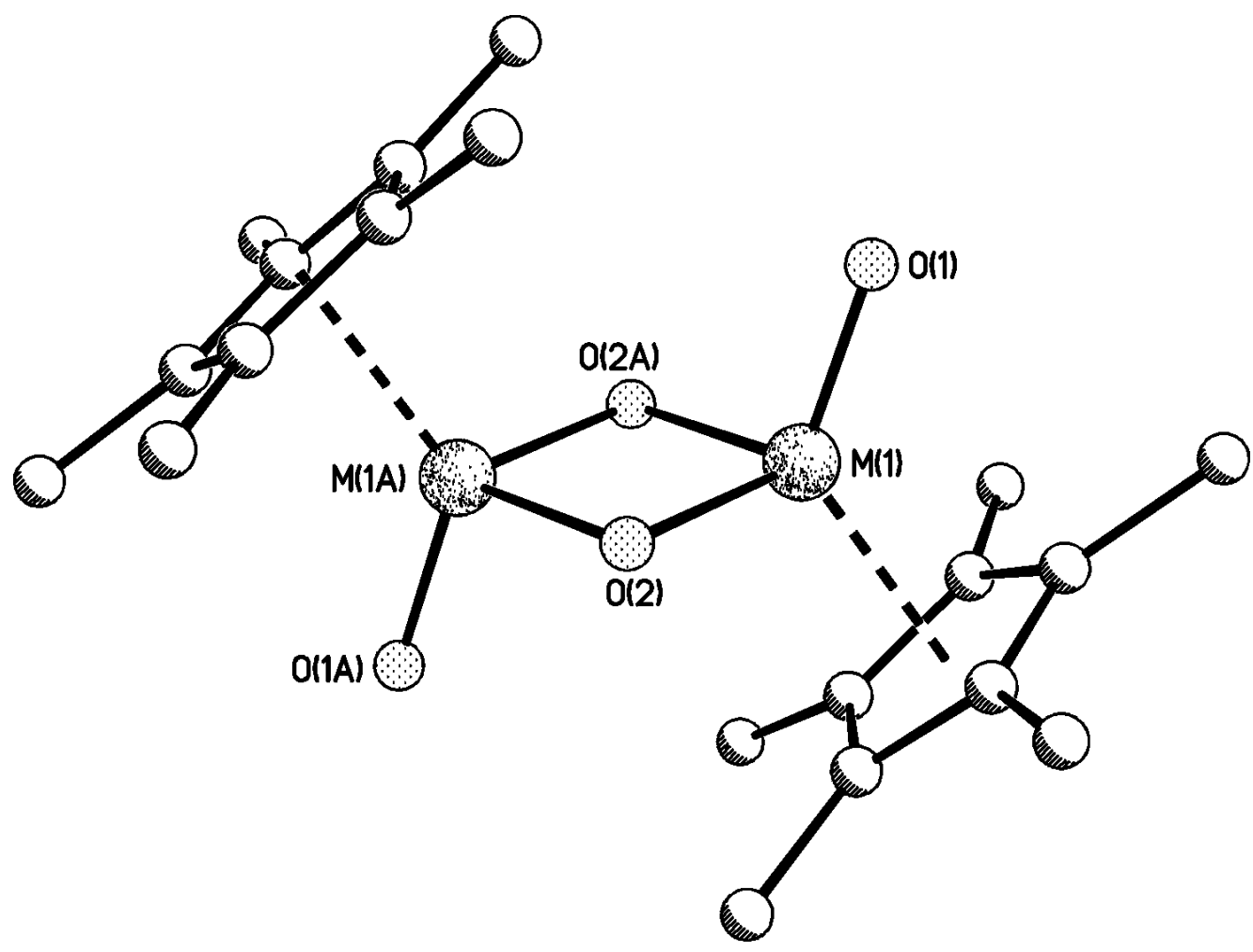

Abb. 6.3: Kristallstruktur der unbekannten Schwermetallverbindung; M wurde als Wolfram verfeinert.

vieles für Sauerstoff als verbrückendes Atom, wobei $\mathrm{N}-\mathrm{R}$ mit $\mathrm{R}=\mathrm{H}$ nicht ausgeschlossen werden kann. Das verbleibende endständige Atom ist wahrscheinlich ebenfalls Sauerstoff, der eine Doppelbindung zum Metall ausbildet.

Die sich aus diesem Strukturmodell ergebenden Bindungslängen sind zumindest vernünftig und mit den in der CSD für ähnliche Verbindungen gefundenen vergleichbar (vgl. Tabelle 6.2). 


\section{Kapitel 7}

\section{Fehlordnung}

Ein Kristall ist ein dreidimensionales periodisches Diskontinuum von theoretisch unbegrenzter Ausdehnung, aufgebaut aus Atomen, Ionen oder Molekülen. Die in dieser Definition geforderte Periodizität verlangt, daß - bei Molekülkristallen - die Moleküle jeder Elementarzelle in exakt der selben räumlichen Orientierung wie die in den direkt benachbarten Zellen angeordnet sind; es darf keinen Unterschied machen, welchen Ausschnitt eines Kristallgitters man betrachtet. Natürlich ist der ideale Einkristall ebenso akademisch wie obige Definition. Gitterfehler und Verwachsungen sind unvermeidbar, der Übergang zwischen amorpher und kristalliner Materie ist fließend.

Relativ häufig kommen Teile des Moleküls (in Extremfällen auch das ganze Molekül) in mehr als einer kristallographisch unabhängigen Orientierung oder Konformation im Kristall vor. Neben dem Vorliegen mehrerer unabhängiger Moleküle in der asymmetrischen Einheit (vgl. Kapitel 8, Seite 91) und Verzwillingung (vgl. Kapitel 9, Seite 97 und 9.5, Seite 106) kommt hierfür noch das Phänomen der Fehlordnung in Frage.

Bei der Fehlordnung sind die verschiedenen Molekülpositionen statistisch über den Kristall verteilt. Die aus dem Beugungsbild bestimmte Struktur stellt das räumliche Mittel aller im Kristall vorkommenden Orientierungen dar.

In den meisten Fällen beschränkt sich eine Fehlordnung auf kleine Teile des Moleküls wie organische Seitenketten oder die in der metallorganischen Chemie häufig zu findenden $\mathrm{SiMe}_{3}$-Gruppen. Beispielsweise findet man in einem Kristall häufig mehrere Stellungen einer tert-Butylgruppe, die sich im allgemeinen nahezu frei drehen kann. Sehr verbreitet sind auch Fehlordnungen von Lösungsmittelmolekülen, die in Lücken des Kristallgitters eingebaut sind. 
Zwar widersprechen Fehlordnungen prinzipiell der Definition eines regelmäßigen Kristalls, im allgemeinen - gerade, wenn es nur zwei oder drei verschiedene Orientierungen gibt überwiegt jedoch die Ordnung. Die entscheidenden Voraussetzungen für Röntgenbeugung sind damit gegeben, und das Beugungsbild sieht völlig unauffällig aus (allerdings leidet unter Fehlordnung häufig die Auflösung). Auch Strukturlösung und -verfeinerung gestalten sich normalerweise unproblematisch. Lediglich die anisotropen Auslenkungsparameter der fehlgeordneten Atome nehmen pathologische Formen an, weil das Verfeinerungsprogramm versucht, zwei oder mehrere Positionen mit Hilfe eines Ellipsoids zu beschreiben. Auch das Auftauchen relativ hoher Restelektronendichtemaxima und Elektronensenken direkt neben fehlgeordneten Atomen ist typisch für Fehlordnungen.

Es hat sich immer wieder gezeigt, daß manche Fehlordnungen unterhalb bestimmter Temperaturen nicht mehr auftreten. Das bedeutet, daß zumindest in einigen Fällen Fehlordnungen nicht statisch sondern dynamischer Natur sind: Die beobachtete Fehlordnung kann tatsächlich als Bewegung im Kristall interpretiert werden, die unterhalb einer bestimmten Energieschwelle nicht länger möglich ist. Zur Vermeidung oder wenigstens Verringerung von dynamischen Fehlordnungen ist daher die Datensammlung bei möglichst tiefer Temperatur ratsam (vgl. auch 4.7, Seite 38).

In anderen Fällen zeigt sich Fehlordnung als unabhängig von der Meßtemperatur. In diesem Fall kann die Existenz zweier (oder selten mehrerer) verschiedener Typen von Elementarzellen im Kristall angenommen werden; die Fehlordnung ist also bei der Kristallisation selbst entstanden [53]. Hier kann die Kristallzucht bei möglichst tiefer Temperatur erfolgen, um die Wahrscheinlichkeit der Fehlordnung zu verringern.

\subsection{Arten der Fehlordnung}

Prinzipiell lassen sich zwei Typen der Fehlordnung unterscheiden, die diskrete und kontinuierliche Lagefehlordnung, sowie die Besetzungsfehlordnung.

\subsubsection{Besetzungsfehlordnung}

Bei Besetzungsfehlordnung besteht die Störung der Ordnung nicht, wie oben beschrieben, im Einnehmen verschiedener Positionen des selben Atoms, sondern in der Besetzung der selben Position durch zwei oder mehrere verschiedene Atome. Vor allem in salzartigen und mineralischen Kristallen kann es vorkommen, daß sich zwei oder mehr Atomsorten 
statistisch eine Position teilen. Beispielsweise sind die Al- und Si-Atome in Zeolithen relativ häufig auf diese Art fehlgeordnet. In der Praxis des chemischen Kristallographen kommt diese Art der Fehlordnung zwar relativ selten vor, und die korrekte Behandlung bei der Verfeinerung ist nicht schwierig, trotzdem sollte man um ihre Existenz wissen, damit eine solche Fehlordnung, wenn sie auftritt, auch erkannt wird. Bestes - häufig einziges Erkennungsmerkmal sind die anisotropen (bzw. isotropen) Auslenkungsparameter, die im Falle einer Besetzungsfehlordnung merklich zu groß oder zu klein erscheinen.

Ein relativ häufiger Spezialfall der Besetzungsfehlordnung ist die unvollständige Besetzung von Atompositionen. Vor allem nicht koordinierte Lösungsmittelmoleküle besetzen gelegentlich die ihnen zur Verfügung stehenden Lücken im Kristallgitter nur teilweise (ganz typisch ist das Auftreten von "halbem Wasser" in nahezu allen Proteinverfeinerungen!). Ungewöhnlich hohe Temperaturfaktoren weisen auf teilbesetzte Lösungsmittelmoleküle hin; man sollte jedoch beachten, daß unkoordiniertes Lösungsmittel im allgemeinen ohnehin stärkerer thermischer Bewegung unterworfen ist, so daß eine gewisse Vergrößerung der ADPs als normal anzusehen ist. Klarheit verschafft hier häufig ein Blick auf die Differenzelektronendichtekarte $\left(F_{o}-F_{c}\right)$ : Im Falle von Minderbesetzung tritt im allgemeinen negative Elektronendichte in der Nähe der betroffenen Atome auf.

Auch Mischkristalle können als Besetzungsfehlordnung in Erscheinung treten, wenn zwei isomorphe Moleküle gemeinsam kristallisieren.

\subsubsection{Lagefehlordnung}

Die Lagefehlordnung ist sozusagen der „Normalfall“ der Fehlordnung und entspricht dem eingangs beschriebenen. Man kann zwei Grenzfälle unterscheiden, die diskrete und die kontinuierliche Lagefehlordnung.

\subsubsection{Diskrete Fehlordnungen}

Eine diskrete Fehlordnung liegt vor, wenn ein Molekül, oder ein Teil eines Moleküls, zwei (oder selten mehrere) energetisch etwa gleichwertige Vorzugspositionen einnimmt. Diese Positionen tauchen dann im räumlichen Mittel, also der zu verfeinernden Struktur, als separate Atomlagen auf. Einmal erkannt, ist eine solche Fehlordnung relativ leicht verfeinerbar (siehe 7.2). 


\subsubsection{Kontinuierliche Fehlordnungen}

Schwieriger ist die kontinuierliche Fehlordnung. Wenn beispielsweise eine tert-Butylgruppe im Kristall nahezu beliebig rotieren kann und jeder Drehwinkel energetisch fast gleichwertig ist, dann tritt die Gruppe im räumlichen Mittel als Rotationstoroid in Erscheinung. Eine solche Situation ist in der Verfeinerung nur schwer beschreibbar. Im allgemeinen beschränkt man sich auf die Modellierung von zwei oder höchstens drei Lagen und nimmt auffällige Auslenkungsparameter in Kauf.

Kontinuierliche Fehlordnungen haben einen deutlich stärkeren Einfluß auf das Beugungsbild als die diskreten. Je nach Ausprägung der Fehlordnung und je nachdem, wie groß der Anteil der fehlgeordneten an der Gesamtstreumasse ist, kann die Auflösung, bis zu der der Kristall zu streuen vermag, zum Teil erheblich reduziert und in Extremfällen sogar das Reflexprofil auffällig werden (ein Beispiel zeigt Abb. 7.7 auf Seite 85).

Glücklicherweise kann kontinuierlicher Fehlordnung durch Datensammlung bei möglichst tiefer Temperatur sehr effektiv entgegengewirkt werden: Vielfach treten bei Raumtemperatur beobachtete Rotationen bereits bei $-100{ }^{\circ} \mathrm{C}$ nicht mehr in Erscheinung, oder die Fehlordnung reduziert sich auf zwei oder drei energetisch günstige Positionen.

So wie man in der NMR-Spektroskopie Moleküldynamik durch Aufnahme von Spektren bei verschiedenen Temperaturen untersucht, gibt es auch in der Kristallographie vielfach eine Art Koaleszenztemperatur, unterhalb derer bestimmte Effekte wie z. B. dynamische Fehlordnungen nicht mehr beobachtbar sind.

\subsubsection{Unordnung - ein Spezialfall von Fehlordnung}

Vor allem bei Proteinen, aber auch bei anderen Strukturen, die größere Hohlräume aufweisen, kommt völlig ungeordnetes Lösungsmittel vor, das als Flüssigkeit aufgefaßt werden kann, die erst bei der Datensammlung bei tiefer Temperatur amorph gefriert.

Dieser Extremfall der kontinuierlichen Fehlordnung wird nach Moews und Kretsinger als „bulk solvent", also „Lösungsmittelmasse“, beschrieben und mit Hilfe von zwei Parametern verfeinert [54].

Je nachdem, wie groß der Anteil der ungeordneten an der Gesamtstreumasse ist, kann „bulk solvent" erheblichen Einfluß auf das Beugungsbild haben: Bulk solvent hat aufgrund der Phasenverschiebung, die bei der Streuung an den ungeordneten Lösungsmit- 
telmolekülen auftritt, eine Verringerung der Intensität der gemessenen Reflexe zur Folge. Davon sind vor allem die Daten bei niedriger Auflösung betroffen. Die Auflösung selbst wird allenfalls geringfügig reduziert [54].

\subsection{Verfeinerung von Fehlordnung}

In der überwiegenden Mehrzahl aller Fehlordnungen kann man sich zur befriedigenden Beschreibung der Situation auf zwei Positionen für jedes fehlgeordnete Atom beschränken. Die meisten Verfeinerungsprogramme sehen daher nur diese Möglichkeit vor.

Verfeinerung von Fehlordnungen ist im Prinzip einfach: Das Verfeinerungsprogramm muß lediglich die Koordinaten der beiden Lagen kennen. Die relative Besetzung der Lagen zueinander kann verfeinert oder angegeben werden, wobei nicht alle Programme eine freie Verfeinerung der Besetzung zulassen.

Nicht ganz so einfach ist es mitunter, die Koordinaten für beide Lagen einer Fehlordnung zu ermitteln. Meistens hilft es, die Fehlordnung im isotropen Modell zu verfeinern, weil stark anisotrope Auslenkungsparameter leicht die Positionen der Atomlagen verwischen können.

Zur Verfeinerung von Fehlordnung mit dem Programm SHELXL wurde ein Tutorium erstellt, das als Teil dieser Arbeit im Internet veröffentlicht ist [4]. Anhand interaktiv bearbeitbarer Beispiele werden typische Fälle von Fehlordnung unterschiedlicher Schwierigkeit behandelt, die dem Benutzer Einblick geben sowohl in die Grundlagen, als auch in die Feinheiten der Fehlordnungsverfeinerung mit SHELXL.

Die meisten Beispiele, die im folgenden Abschnitt aufgeführt sind, finden sich ausführlich beschrieben auch in dem Tutorium, weshalb sie hier nicht in aller Tiefe behandelt werden.

\subsubsection{Verfeinerung von Fehlordnung in SHELXL}

Durch die Einführung verfeinerbarer freier Variablen凹 wird die Beschreibung von Fehlordnungen in SHELXL sehr einfach und zugleich universell. Der besseren Verständlichkeit wegen sei hier zunächst die Fehlordnung auf nur zwei Lagen beschrieben.

\footnotetext{
${ }^{1}$ Freie Variable können noch in sehr vielen anderen Situationen zur Anwendung kommen. Beispiele hierzu finden sich im SHELX-97 Handbuch [3].
} 
Zuerst werden mit Hilfe des PART Befehls die fehlgeordneten Atome in Bereiche unterteilt, so daß in jedem Bereich eine Lage der Fehlordnung zu finden ist. Dies geschieht, indem man direkt vor dem ersten fehlgeordneten Atom den Befehl PART 1 einfügt, der von allen fehlgeordneten Atomen der ersten Lage gefolgt wird. Unmittelbar vor die Atome der zweiten Lage der Fehlordnung wird der Befehl PART 2 eingefügt, nach der Fehlordnung muß PART 0 stehen. Sinnvollerweise sollten die Atome beider Lagen in ihrem jeweiligen Bereich in der selben Reihenfolge stehen; das macht die Anwendung von Ähnlichkeitsrestraints (SAME, SADI, u. ä.) einfacher. SHELXL schreibt im Falle stark anisotroper Auslenkungsparameter einen Vorschlag für zwei Atompositionen in die .lst-Datei, was das Auffinden der richtigen Koordinaten für die beiden Parts oft sehr erleichtert.

Im nächsten Schritt muß das Verhältnis der beiden fehlgeordneten Lagen zueinander berücksichtigt werden: Wenn es sich nicht um eine Fehlordnung um ein kristallographisches Symmetrieelement handelt (näheres hierzu unter 7.2.1.1 auf Seite 75), dürfen die beiden Parts jedes beliebige Verhältnis zueinander haben - wichtig ist nur, daß sich die Besetzungsfaktoren beider Teile auf exakt eins addieren, da im allgemeinen von Vollbesetzung ausgegangen werden kann. Das Besetzungsverhältins wird in Form einer freien Variablen verfeinert. Praktisch bedeutet das, daß an die Zeile, die sich vor dem ersten Atom der Struktur befindet und in der FVAR, gefolgt von der ersten freien Variablen, steht, eine weitere Zahl, deren Wert kleiner als eins sein muß, angehängt wird. Dies ist dann der Startwert für die zweite freie Variable und gibt das Besetzungsverhältnis an (ein Wert von 0.6 entspricht dabei einem Verhältnis von 6:4).

Schließlich müssen die Besetzungsfaktoren (im SHELXL-Handbuch [3] als sof (site occupation factors) bezeichnet) der von der Fehlordnung betroffenen Atome so verändert werden, daß sie sich auf die oben definierte zweite freie Variable beziehen. Dies geschieht, indem aus dem ursprünglichen Wert von 11.0000, den der sof hat, für die Atome in PART 121.0000 und für die Atome in PART 2 -21.0000 gemacht wird. 21.0000 bedeutet, der sof erhält 1.0000 mal den Wert der zweiten freien Variablen, wohingegen -21.0000 den sof auf die Ergänzung der zweiten freien Variablen zu eins festsetzt (also $\left[1-F V_{2}\right]$, wenn $F V_{2}$ die zweite freie Variable ist). Damit ist gewährleistet, daß sich die Besetzungsfakoren der beiden Lagen der Fehlordnung auf exakt eins addieren und das Verhältnis trotzdem frei verfeinert werden kann.

Manchmal kommt es vor, daß ein Atom, das an einer Fehlordnung teilnimmt, in einer seiner Positionen speziell liegt; dann ist der sof am Anfang nicht 11.0000 sondern z. B. 10.5000 oder 10.2500. Diese Minderbesetzung, die unmittelbar mit der speziellen Lage verknüpft ist, muß auch bei der Formulierung der Fehlordnung berücksichtigt werden, statt 21.0000 muß dann beispielsweise 20.5000 oder 20.2500 stehen. 
Beschränkt sich die Fehlordnung nicht auf zwei Lagen, ist eine freie Variable nicht ausreichend, um die Situation zu beschreiben. Unter 7.2.1.2 ist der Gebrauch des SUMP-Befehls beschrieben, der dieses Problem löst.

Grundsätzlich müssen Fehlordnungen immer chemisch sinnvoll sein, so daß nicht jedes signifikante Restelektronendichtemaximum einer Fehlordnung zugeschrieben werden kann. Andere Gründe für das Auftreten von wirklichen oder scheinbaren Restelektronendichtemaxima finden sich in Kapitel 10 auf Seite 115.

\subsubsection{Fehlordnung um spezielle Lagen}

Wenn sich ein Molekül (meistens ein Lösungsmittelmolekül) auf einer speziellen Lage befindet, deren Geometrie es nicht erfüllt, bleiben nur zwei Möglichkeiten, das geometrische Problem zu beseitigen: entweder, man wechselt zu einer niedrigsymmetrischeren Raumgruppe, in der diese spezielle Lage nicht vorkommt, oder - was fast immer besser ist man nimmt eine Fehlordnung des entsprechenden Moleküls um den Symmetrieoperator der speziellen Lage an. Ein typisches Beispiel wäre ein Toluol-Molekül auf einem Inversionszentrum. Keines der Atome liegt speziell, trotzdem muß das Molekül im räumlichen Mittel 1:1 inversionsfehlgeordnet sein. Das heißt, in exakt der Hälfte aller Elementarzellen liegt das Molekül in der einen, in der anderen Hälfte in der invertierten Orientierung vor. Zur Verfeinerung solcher Fehlordnungen, bei denen die zweite Lage aus kristallographischen Gründen unmittelbar aus der ersten Lage folgt, reicht es aus, die Koordinaten nur einer Lage anzugeben. Anstelle von PART 1 und PART 2 werden die betroffenen Atome von PART -1 und PART 0 eingerahmt. PART -1 sorgt dafür, daß die Raumgruppensymmetrie auf die betreffenden Atome nicht angewendet wird. Die Besetzungsfaktoren müssen entsprechend der speziellen Lage auf 10.5000 oder - bei höherer Zähligkeit der speziellen Lage, bei der diese Methode ebenso wie bei Zweizähligkeit funktioniert - geringer gesetzt werden.

Die selbe Überlegung gilt für Moleküle, die so dicht an Symmetrieelementen liegen, daß die Anwendung der Raumgruppensymmetrie zu chemisch nicht sinnvollen Gebilden führen würde.

\subsubsection{Fehlordnungen mit mehr als zwei Lagen}

SHELXL erlaubt es, mit Hilfe des SUMP-Befehls beliebig viele freie Variablen dergestalt linear miteinander zu verknüpfen, daß die gewichtete Summe beliebig vieler freier Va- 
riablen innerhalb einer anzugebenden Standardabweichung einen ebenfalls anzugebenden Zahlenwert annehmen soll.

Sollte also eine Fehlordnung nur mit drei Lagen beschreibbar sein, kommt jeder einzelnen Lage eine eigene freie Variable (z. B. die freien Variablen 2, 3 und 4) und entsprechende Besetzungsfaktoren zu (im selben Beispiel: 21.0000, 31.0000 und 41.0000). Die Summe der drei freien Variablen muß genau den Wert eins ergeben, was sich wie folgt in einem SUMP-Befehl ausdrücken läßt:

SUMP 1.00 .011 .021 .031 .04

Als erstes nach SUMP steht dabei der angestrebte Zahlenwert (hier 1.0), unmittelbar gefolgt von der Standardabweichung (0.01). Danach kommen immer paarweise die Gewichtungsfaktoren (hier alle 1.0, da alle freien Variablen gleichberechtigt sind) mit den Nummern der freien Variablen (2, 3 und 4).

Die Anwendungsmöglichkeiten des SUMP-Befehls beschränken sich nicht auf die Beschreibung von Fehlordnungen; weitere Möglichkeiten sind dem SHELX-97 [3] Handbuch zu entnehmen.

\subsubsection{Bulk-Solvent-Korrektur}

Den Algorithmus von Moews \& Kretsinger [54] verwendend, verfeinert SHELXL zwei Parameter: Der erste wächst mit dem Anteil des ungeordnet verteilten Lösungsmittels und nimmt gewöhnlich Werte um eins an. Ein hoher Wert des zweiten Parameters weist darauf hin, daß nur die Daten bei sehr niedriger Auflösung von der diffusen Streuung des bulk solvent betroffen sind; typische Werte sind zwei bis fünf.

Um eine bulk-solvent-Korrektur durchzuführen, muß man lediglich den Befehl SWAT in die .ins-Datei einfügen; das Programm bestimmt und verfeinert die beiden Parameter selbständig.

\subsubsection{Fehlordnung und Restraints}

Bei Lagefehlordnung kann man annehmen, daß die Bindungslängen und -winkel der Atome beider Lagen identisch sind. Wenn in beiden Parts die Atome in der selben Reihenfolge aufgelistet sind, kann man dieser Annahme mit Hilfe des SAME-Befehls Rechnung tragen: 


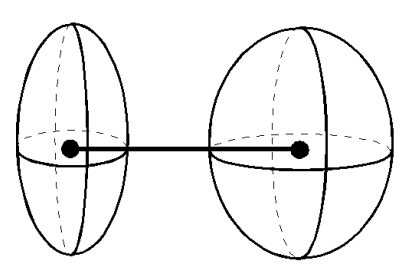

DELU

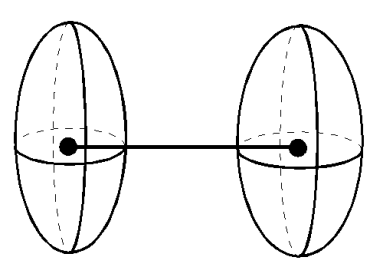

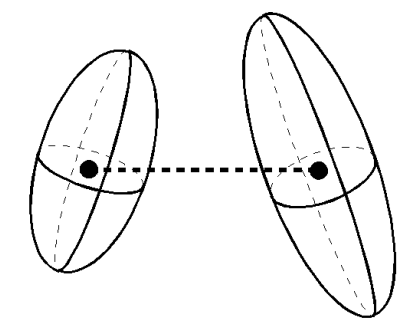

SIMU
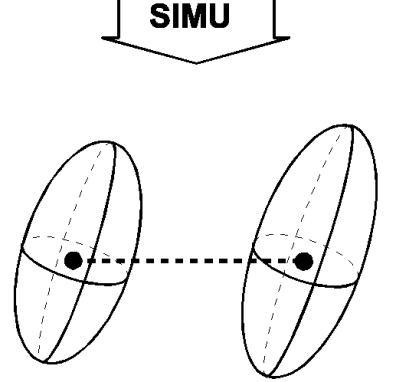

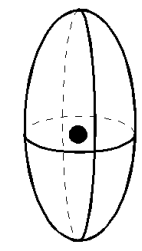

ISOR

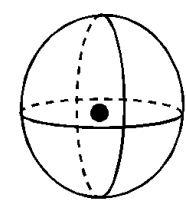

Abb. 7.1: Schematische Darstellung der Wirkung der drei Restraints DELU, SIMU und ISOR (entnommen [55]).

SAME wird immer zusammen mit einer Reihe von Atomnamen angegeben; das erstgenannte Atom wird dabei als geometrisch äquivalent zu dem in der .ins-Datei nächsten Nichtwasserstoffatom behandelt, das zweitgenannte als äquivalent zum zweiten und so fort. Als geometrisch äquivalent behandelt bedeutet, daß alle 1,2- und 1,3-Abstände (also Bindungslängen und -winkel) innerhalb einer anzugebenden Standardabweichungð einander angeglichen werden. Alternativ zu SAME können beliebige Abstände zwischen Atomen auch mit dem Restraint SADI einander angenähert werden. SADI wird zusammen mit einer Anzahl von Atompaaren angegeben, wobei die Abstände zwischen allen genannten Paaren einem gemeinsamen Wert angenähert werden.

Auch der sog. similar ADP Restraint SIMU und der rigid bond Restraint DELU werden bei Fehlordnungen häufig eingesetzt. Wie in Abb. 7.1 gezeigt, sorgen sie für eine gewisse Annäherung hinsichtlich Größe und Richtung benachbarter Auslenkungsellipsoide.

Ein weiterer Restraint, der in schwierigeren Fällen (vor allem bei LösungsmittelFehlordnungen) angebracht sein kann, ist ISOR. ISOR nähert die anisotropen Auslenkungsparameter innerhalb einer Standardabweichung der isotropen Form an.

Auch constraints können bei der Verfeinerung von Fehlordnungen helfen: EXYZ zwingt zwei oder mehrere Atome auf die selben Koordinaten, was bei Besetzungsfehlordnung hilfreich sein kann. EADP macht die anisotropen Auslenkungsparameter aller genannten Atome gleich denen des erstgenannten.

\footnotetext{
${ }^{2}$ Default-Wert ist 0.02 für 1,2- und 0.04 für 1,3-Abstände
} 


\subsection{Fehlordung zweier Ethylgruppen im Gallium- Iminosilikat $\left[\mathrm{RSi}(\mathrm{NH})_{3} \mathrm{GaEtGaEt}_{2}\right]_{2}$}

Das Gallium-Iminosilikat [RSi(NH) $\left.{ }_{3} \mathrm{GaEtGaEt}_{2}\right]_{2}\left(\mathrm{R}=2,5-i \mathrm{Pr}_{2} \mathrm{C}_{6} \mathrm{H}_{3} \mathrm{NSiMe}_{2} i \mathrm{Pr}\right)$ [56] kristallisiert in der monoklinen Raumgruppe $C 2 / c$ mit einem halben Molekül in der asymmetrischen Einheit; die andere Hälfte des Moleküls wird durch das Inversionszentrum erzeugt. Der Kern des Moleküls läßt sich beschreiben als zweifach gekappte tetragonale Bipyramide. Sie wird gebildet von vier sechsgliedrigen $\mathrm{SiGa}_{2} \mathrm{~N}_{3}$-Ringen in der Bootkonformation, die sich jeweils die drei Bug- und die drei Heckatome paarweise mit den Nachbarringen teilen und so zwei im Rahmen der Standardabweichungen planare viergliedrige $\mathrm{SiGaN}_{2^{-}}$ Ringe bilden, wobei in allen Ringen Ga- und N-Atome alternieren (siehe auch Abb. 7.3). Dieses Grundgerüst ist bekannt vom Tetraasteran $\left(\mathrm{C}_{12} \mathrm{H}_{16}\right)$ [57]. Eine ausführliche Beschreibung des Moleküls sowie der zugehörigen Chemie findet sich in [56].

Daß Ethylgruppen zu Fehlordnungen neigen, ist bekannt. Der hier beschriebene Galliumkäfig bietet ein gutes Beispiel: Zwei der drei kristallographisch unabhängigen Ethylgruppen - eine an jedem Ga-Atom - sind um die Ga-C-Achse rotationsfehlgeordnet.
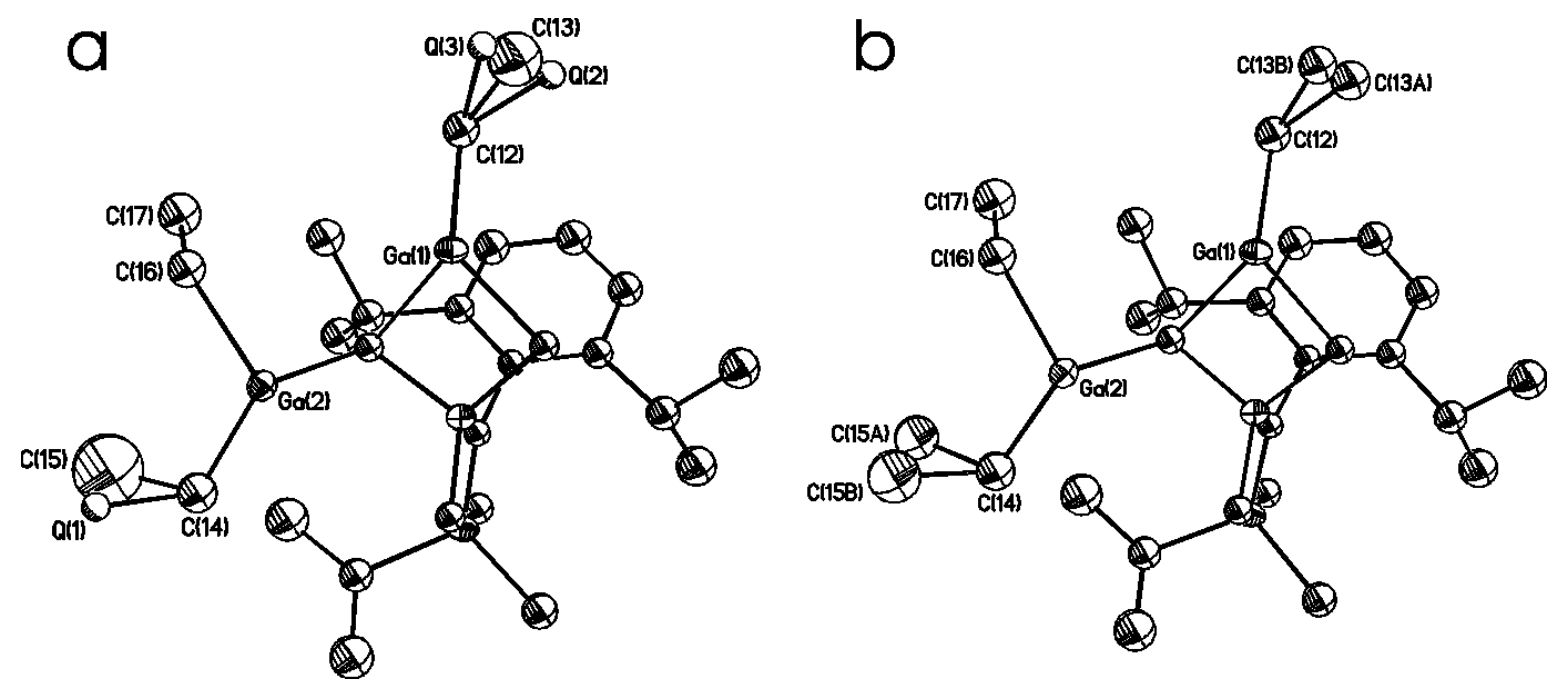

Abb. 7.2: Kristallstruktur des Gallium-Iminosilikats a ohne und b mit Modellierung der Fehlordnung.

Abb. 7.2 zeigt die asymmetrische Einheit in einem relativ frühen Verfeinerungsstadium, in dem das vollständiges Modell ohne Wasserstoffatome mit anisotrop verfeinerten Metallatomen vorlag. In Abb. 7.2 a wird die Fehlordnung deutlich: Neben C(15), das auch durch einen relativ großen $U$-Wert auffällt, tritt das höchste Restelektronendichtemaximum, Q(1) (2.17 $\left.\mathrm{e}^{-} / \AA^{2}\right)$, in Erscheinung. Diese Position kann als zweite Lage des Atoms 
$\mathrm{C}(15)$ angenommen werden. Unmittelbar rechts und links von $\mathrm{C}(13)$ befinden sich die beiden nächstniedrigeren Restelektronendichtemaxima: $\mathrm{Q}(2)\left(1.71 \mathrm{e}^{-} / \AA^{2}\right)$ und $\mathrm{Q}(3)(1.33$ $\left.\mathrm{e}^{-} / \AA^{2}\right)$. Diese Positionen beschreiben die beiden Lagen von $\mathrm{C}(13)$ und ersetzen so die bislang verfeinerte.

$\mathrm{Q}(4)\left(1.23 \mathrm{e}^{-} / \AA^{2}\right)$, das nächstniedrigere Restelektronendichtemaximum, liegt in der Mitte einer aromatischen Bindung. Q(5) (1.09 $\left.\mathrm{e}^{-} / \AA^{2}\right)$ und folgende sind deutlich kleiner, so daß die Berücksichtigung der drei höchsten Differenzmaxima zur Beschreibung der Fehlordnungen ausreichen sollte.

Zur expliziten Formulierung dieser Fehlordnung wurden folgende Umbenennungen vorgenommen: $\mathrm{C}(15) \rightarrow \mathrm{C}(15 \mathrm{~A}), \mathrm{Q}(1) \rightarrow \mathrm{C} 15(\mathrm{~B}), \mathrm{Q}(2) \rightarrow \mathrm{C} 13(\mathrm{~A}), \mathrm{Q}(3) \rightarrow \mathrm{C}(13 \mathrm{~B}) . \mathrm{C}(13)$ wurde gelöscht, ebenso die übrigen Restelektronendichtemaxima. Wie oben beschrieben, wurden $\mathrm{C}(13 \mathrm{~A})$ und $\mathrm{C}(15 \mathrm{~A})$ jeweils in PART 1, C(13B) und $\mathrm{C}(15 \mathrm{~B})$ in PART 2 geschrieben und die sof-Werte entsprechend geändert. Außerdem wurden mit SAME die 1,2- und 1,3-Abstände der fehlgeordneten Teile jeweils einander angenähert.

Nach acht Verfeinerungszyklen mit SHELXL sah die Struktur aus wie in Abb. 7.2 b gezeigt. Die höchsten Restelektronendichtemaxima waren für ein im wesentlichen isotropes Modell unauffällig, und die zweite bzw. dritte freie Variable verfeinerten sich auf Werte von 0.42 bzw. 0.56 .

Nachdem alle Atome anisotrop verfeinert worden waren, mußte beim Berechnen der Wasserstoffpositionen darauf geachtet werden, daß die H-Atome an den zwar selbst nicht fehlgeordneten Atomen $\mathrm{C}(12)$ und $\mathrm{C}(14)$ sich analog zur Fehlordnung der Atome $\mathrm{C}(13)$ und $\mathrm{C}(15)$ jeweils auf zwei unterschiedlichen Positionen befinden. Um diese Situation zu beschreiben, wurde für die Koordinaten der fehlgeordneten Wasserstoffatome jeweils $0 \quad 0 \quad 0$ eingesetzt; SHELXL verwirft diese Angaben und berechnet aufgrund der durch AFIX definierten Geometrie die korrekten Atompositionen.

Abb. 7.3 zeigt das abschließende Modell des Gallium-Iminosilikats nach Abschluß der Verfeinerung. Alle statistischen Werte sind sehr gut, und die Höhe der Restelektronendichtemaxima ist völlig unauffällig[?].

Die Verfeinerung dieser Struktur wird in dem Tutorium Refinement of Disorder with SHELXL, das Teil der vorliegenden Arbeit ist'f, ausführlich und detailliert beschrieben.

\footnotetext{
${ }^{3} R 1=0.0317$ für $F_{o}>4 \sigma\left(F_{o}\right) ; w R 2=0.0739$, GooF $=1.097$ für alle Daten. Höchstes Restelektronendichtemaximum: 0.37 ; niedrigste Elektronensenke: -0.55 .

4 http://shelx.uni-ac.gwdg.de/ peterm/tutorial/
} 


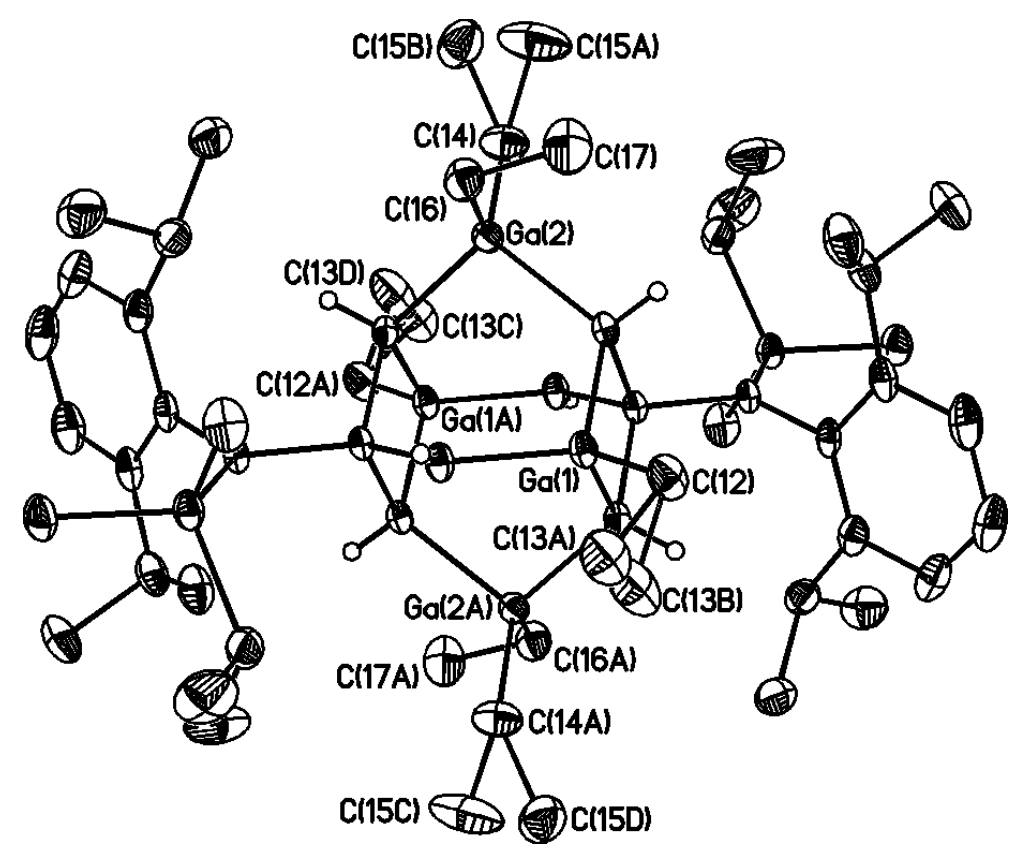

Abb. 7.3: Kristallstruktur des Gallium-Iminosilikats nach Abschluß der Verfeinerung.

\subsection{Mischkristallbildung bei Bromo- und Iodo- Aluminium-Iminosilikaten}

Das Al-Iminosilikat $\left[\mathrm{RSi}(\mathrm{NH})_{3} \mathrm{GaMeGaMe}_{2}\right]_{2}$ aus der selben Substanzfamilie wie das gerade beschriebene Molekül unterscheidet sich von diesem lediglich durch das Metall ( $\mathrm{Al}$ anstelle von Ga) und die Alkylgruppen am Metall (Me anstelle von Et). Es läßt sich durch Zugabe von elementarem Brom bzw. Iod am Aluminium halogenieren, wobei pro addiertem Halogenatom eine Methylgruppe substituiert wird [56]. Mit dieser Methode werden ausschließlich zwei- und vierfach halogenierte Käfige erhalten, die jeweils gemeinsam als Mischkristalle kristallisieren. Beide, sowohl die Brom-, als auch die Iod-Mischkristalle, kristallisieren aus Toluol in der monoklinen Raumgruppe $P 2_{1} / n$ mit einem halben Molekül in der asymmetrischen Einheit; die zweite Hälfte des Moleküls wird durch das kristallographische Inversionszentrum erzeugt.

Die Mischkristallbildung läßt sich bei der Verfeinerung als Fehlordnung formulieren, indem man an einer Position sowohl ein Halogen-Atom, als auch eine Methylgruppe annimmt und diese wie beschrieben mit Hilfe von PART 1 und PART 2, sowie einer freien Variablen verfeinert. Im Unterschied zur „normalen“ Fehlordnung, bei der der Inhalt von PART 1 und PART 2 identisch ist, die Atomlagen hingegen unterschiedlich sind, ist es hier umgekehrt: PART 1 und PART 2 beziehen sich beide auf die selbe Position, aber ihr 

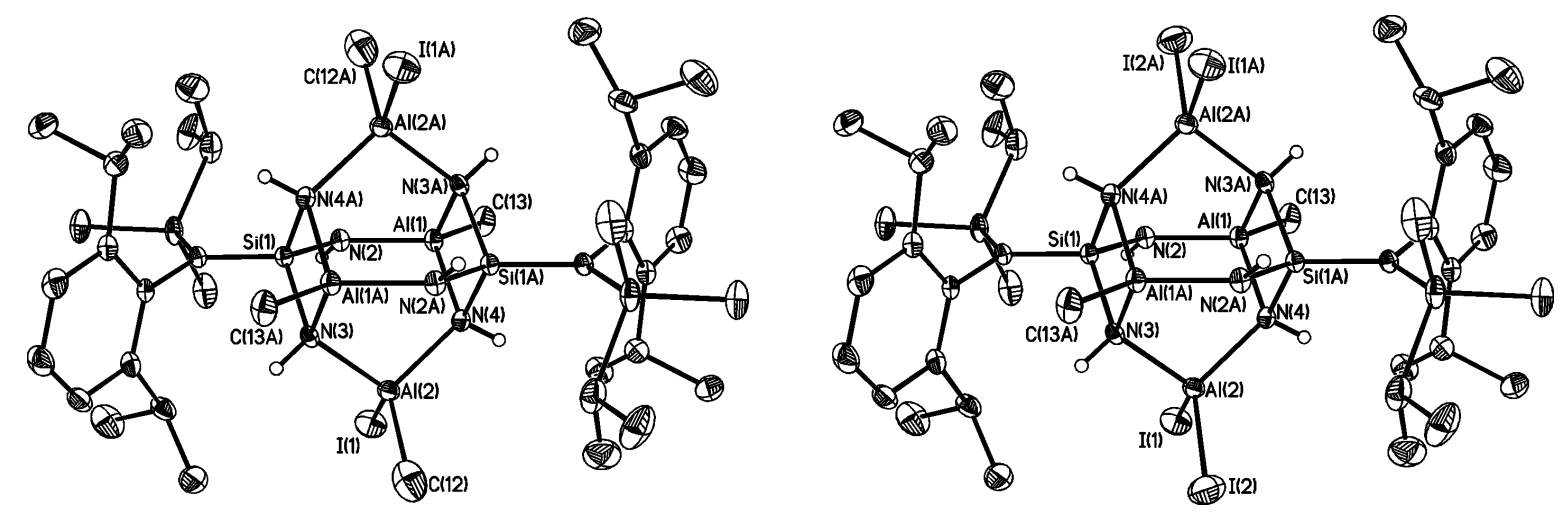

Abb. 7.4: Kristallstruktur der beiden unterschiedlich iodierten Aluminium-Iminosilikate nach Abschluß der Verfeinerung: Links der zweifach iodierte, rechts der vierfach iodierte Käfig.

Inhalt ist verschieden. Auf Anwendung des bei Positionsfehlordnung häufig angebrachten constraints EXYZ auf die fehlgeordneten Atome wurde verzichtet, da die Al-C-Bindung kürzer ist als die Al-Br- bzw. die Al-I-Bindung.

Die zweite freie Variable verfeinerte sich auf 0.85, was $85 \%$ zweifach iodiertem und $15 \%$ vierfach iodiertem Iminosilikat entspricht. Im Falle des Brom-Derivats verfeinerte sich das Produktverhältnis auf $80 \%$ zweifach bromiert zu $20 \%$ vierfach bromiert.

Diese Zahlen geben nicht notwendigerweise das Produktverhältnis der Halogenierungsreaktion wieder: Es hat sich gezeigt, daß die Halogenierung der Käfige deren Löslichkeit deutlich reduziert [56], es kann daher vermutet werden, daß die vierfach halogenierten Iminosilikate schlechter löslich sind als die zweifach halogenierten, was sich in einer Anreicherung der erstgenannten Spezies im Kristall niederschlagen würde.

Abb. 7.4 zeigt die Struktur der beiden unterschiedlich iodierten Al-Iminosilikate; die bromierten Käfige sind isostrukturell.

\subsection{Typische Lösungsmittelfehlordnungen}

Lösungsmittelmoleküle, die in das Kristallgitter eingelagert sind, sind für Fehlordnungen geradezu prädestiniert. Vor allem, wenn sie nicht an das Molekül, das die eigentliche Struktur ausmacht, koordinieren, füllen Lösungsmittelmoleküle häufig nur die Lücken in der Kristallpackung. Wenn, was fast immer der Fall ist, die Lücken etwas größer sind, als die Lösungsmittelmoleküle, gibt es für letztere häufig mehrere mögliche, energetisch nahezu gleichwertige Orientierungen. 
Relativ häufig liegen Lösungsmittelmoleküle auf speziellen Lagen, deren Geometrie sie nicht erfüllen, was im räumlichen Mittel ebenfalls zu einer Fehlordung führt (wie bereits unter 7.2.1.1 (Seite 75) beschrieben).

Während sich die Moleküle mancher Lösungsmittel vergleichsweise selten fehlordnen (zum Beispiel sind bei Acetonitril die geometrischen Möglichkeiten zur Fehlordnung aufgrund der Linearität des Moleküls deutlich eingeschränkt), liegen andere Lösungsmittel wie Chloroform fast immer fehlgeordnet vor.

Im Folgenden werden drei typische Beispiele für Lösungsmittelfehlordnungen gegeben, wie sie in der Praxis öfters vorkommen.

\subsubsection{THF}

Tetrahydrofuran gehört zu den sog. koordinierenden Lösungsmitteln, und in der Tat findet man es in Kristallstrukturen sehr häufig als über das Sauerstoffatom an Metallatome koordiniertes Molekül. Dies beugt sehr effektiv einer Fehlordung der Sauerstoffposition vor, die Rotation um die M-O-Achse ( $\mathrm{M}=$ Metall) ist aber meistens ungehindert (siehe Abb. 7.5). Der THF-Ring selbst bietet aufgrund seiner Briefumschlagkonformation weitere Möglichkeiten für Lagefehlordnung.

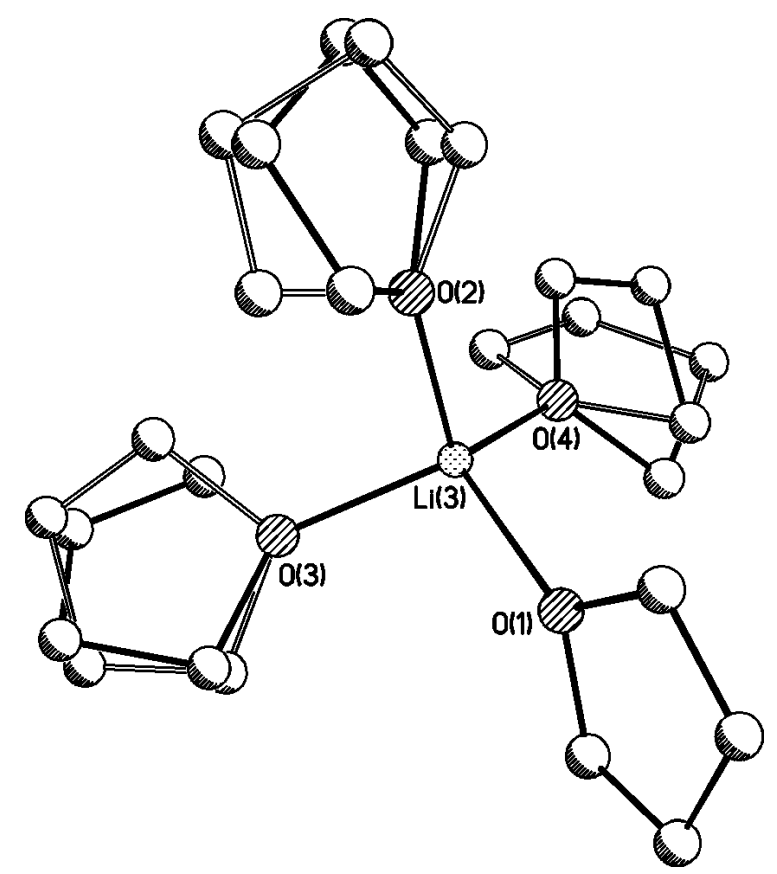

Abb. 7.5: Vier an ein Li-Kation koordinierte THF Moleküle, von denen drei in typischer Weise fehlgeordnet sind. 


\subsubsection{Toluol}

Toluol (Punktgruppe $C_{2 v}$ ) hat der Methylgruppe wegen eine niedrigere Symmetrie als Benzol (Punktgruppe $D_{6 h}$ ). Trotzdem findet man Toluol immer wieder auf speziellen Lagen, wie z. B. Inversionszentren oder zweizähligen Achsen senkrecht zur Ph-Me-Bindung, die zwar von Benzol, nicht aber von Toluol erfüllt werden. Aber auch wenn Toluol allgemein liegt, ist es häufig fehlgeordnet. Es gibt zwei typische, immer wieder auftretende Erscheinungsformen der Toluolfehlordnung:

Im ersten Fall sind zwei diskrete Lagen zu unterscheiden, wobei die zweite Lage um $180^{\circ}$ gegen die erste so verdreht ist, daß sich die Methylgruppe der einen Lage ungefähr auf der Position des Kohlenstoffatoms C4 der anderen Lage befindet, wobei beide Lagen etwa koplanar zueinander sind. Häufig tritt diese Fehlordnung im Zusammenspiel mit einer speziellen Lage auf. Ein typisches Beispiel für diese Art der Fehlordnung zeigt Abb. 7.6. Die Abbildung entstammt dem Tutorium zur Verfeinerung von Fehlordnung mit SHELXL, in dem dieses Beispiel detailliert behandelt wird. Die zweite für Toluol typische Fehl-

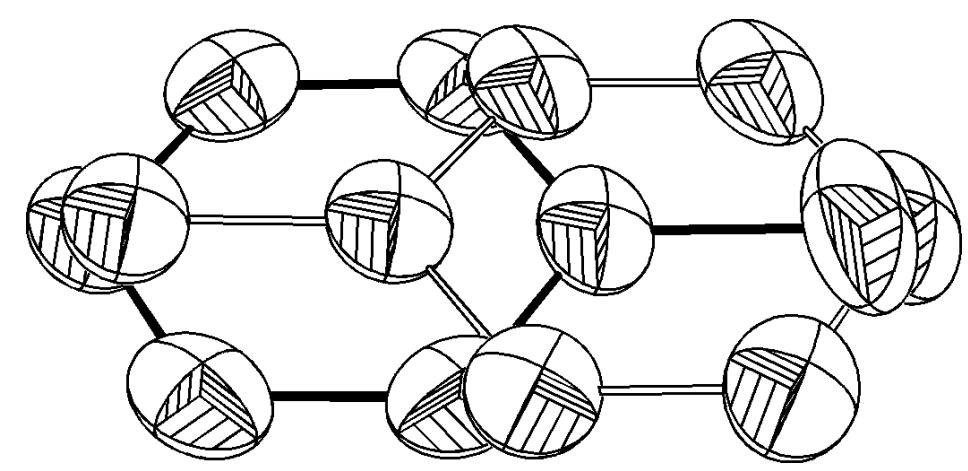

Abb. 7.6: Typische Toluolfehlordnung.

ordnung äußert sich durch ausgeprägte Unauffindbarkeit der Methylgruppe. Dies wird hervorgerufen von einer „Rotation“四 des Toluolmoleküls um die - von Toluol nicht erfüllte - sechszählige Achse des Benzols, was die Methylgruppe auf sechs Positionen verteilt. An jeder der sechs Kohlenstoffatome des fehlgeordneten Toluols befinden sich damit im räumlichen Mittel 1/6 Kohlenstoff und 5/6 Wasserstoff, zusammen also etwa 1.8 Elektronen. Das ist nicht viel mehr als ein Wasserstoffatom alleine. Man begegnet einer solchen Fehlordnung am besten, indem man sie ignoriert und das Toluol als Benzolmolekül verfeinert.

\footnotetext{
${ }^{5}$ Natürlich rotiert nicht das einzelne Toluolmolekül, im räumlichen Mittel entsteht jedoch der Eindruck der Rotation.
} 


\subsubsection{Chloroform}

Das Chloroform-Molekül ist zwar nicht gerade ein hochsymmetrisches Gebilde (Punktgruppe $C_{3 v}$ ), in erster Näherung kann $\mathrm{CHCl}_{3}$ jedoch als nahezu tetraedrisch (Punktgruppe $T_{d}$ ) beschrieben werden. Diese Eigenschaft führt dazu, daß $\mathrm{CHCl}_{3}$ fast immer fehlgeordnet vorkommt - häufig auch über mehrere Lagen. Die besondere Problematik dabei liegt in den relativ schweren und damit elektronenreichen Chloratomen. Dadurch ist bei Fehlordnung von Chloroform häufig ein nicht unbeträchtlicher Teil der Streumasse der gesamten Struktur fehlgeordnet, was mitunter zu Problemen bei der Verfeinerung führen kann. Dies gilt insbesondere für organische Verbindungen, die häufig als schwerstes Atom Sauerstoff enthalten.

Bedauerlicherweise kristallisieren gerade organische Verbindungen besonders gut aus Chloroform oder Dichlormethan, weshalb diese Lösungsmittel häufig zur Kristallisation verwendet werden (hinsichtlich der Fehlordnungsproblematik unterscheidet sich $\mathrm{CH}_{2} \mathrm{Cl}_{2}$ nur unwesentlich von $\mathrm{CHCl}_{3}$ ). Eine typische Fehlordnung von Chloroform ist in Abb. 7.10 zu sehen.

\subsection{Drei Fehlordnungstypen in einer Struktur: Cy- cloikositetraphenylen}

Die Röntgenstrukturanalyse des bereits in Kapitel 3 beschriebenen Cycloikositetraphenylens] [21,22] war in allen Stadien problematisch (lediglich die Strukturlösung gestaltete sich völlig problemlos). Nachdem es gelungen war, einen Kristall erfolgreich zu montieren (vgl. 3.5, Seite 23), traten Probleme mit dem Beugungsbild in Erscheinung: Die Daten bei niedriger Auflösung zeigten ein sehr hohes Rauschniveau und in manchen Orientierungen war das Reflexprofil ungewöhnlich langgezogen (siehe Abb. 7.7).

Nach der Lösung der Struktur mit SHELXS [49] enthielt das erste Modell bereits alle Atome des aromatischen Ringgerüsts, die Atompositionen der $n$-Hexylketten fehlten dagegen noch. Diese Hexylketten stellten sich als hochgradig fehlgeordnet heraus und geben ein gutes Beispiel für kontinuierliche Fehlordnung. Wie man an den sehr kleinen Thermalparametern erkennen kann (vgl. Abb. 7.8), sind die Atompositionen der 24 Phenylringe der Makrozyklen gut geordnet und liegen in der Kristallpackung zu langen Röhren sesselförmig übereinandergestapelt nebeneinander (siehe Abb. 3.4, Seite 25). Die Hexylketten dagegen,

\footnotetext{
${ }^{6}$ Siehe Fußnote 3 auf Seite 23.
} 

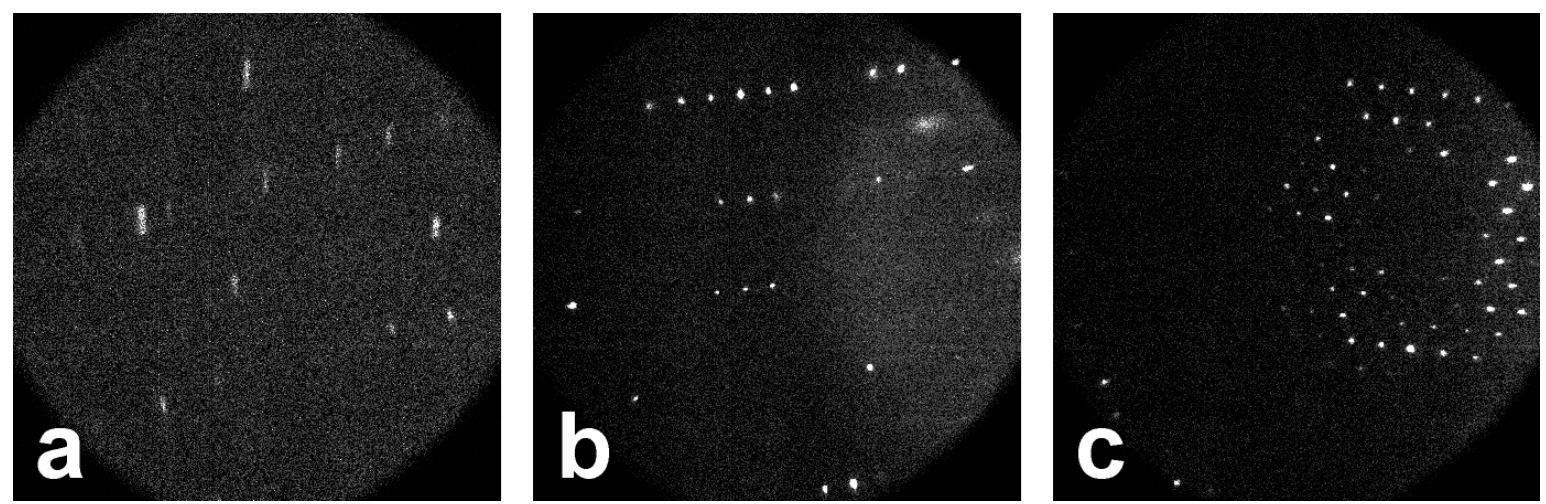

Abb. 7.7: Drei Beugungsbilder des Cycloikositetraphenylens: a: ungewöhnliches Reflexprofil in manchen Orientierungen, b: auffallend hoher Untergrund bei niedriger Auflösung, c: ein „gut" aussehendes Beugungsbild

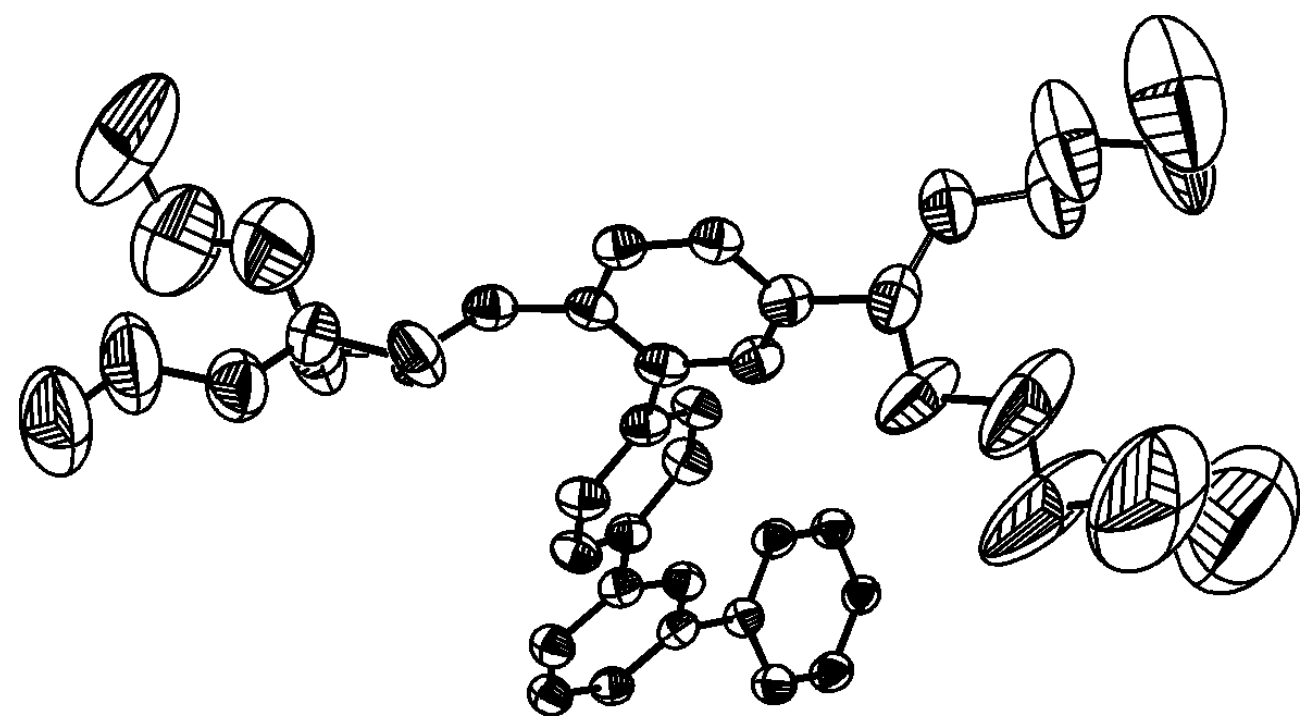

Abb. 7.8: Gabelartige Fehlordnung der n-Hexylketten, dargestellt an der asymmetrischen Einheit ohne H-Atome.

die nach innen und aus dem Makrozyklus herauszeigen, sind offensichtlich in der Lage, sich zwischen zwei Grenzpositionen nahezu ungehindert zu bewegen. Trotz verschiedener Versuche war es nicht möglich, eine Fehlordnung über mehr als zwei Lagen zu formulieren, so daß lediglich die beiden Grenzpositionen als PART 1 und PART 2 modelliert und relativ große Auslenkungsparameter in Kauf genommen wurden. Somit entsteht ein Bild von der Fehlordnung, in dem etwa die Hälfte der Hexylketten über und die andere Hälfte unter dem Makrozyklus liegen (die Besetzungsfaktoren der aus dem Ring herausweisenden Seitenketten verfeinerten sich auf $0.50 / 0.50$, die in den Ring hinein zeigenden Hexylreste sind im Verhältnis 0.55 / 0.45 zueinander fehlgeordnet). Im räumlichen Mittel entsteht eine gabelartige Struktur, die für die Kristallpackung vorteilhaft sein mag (siehe Abb. 7.8). In der Tat sind die Hexylketten im Kristall benachbarter Moleküle zu einem dichten Geflecht verwoben, wie Abb. 7.9 zeigt. 


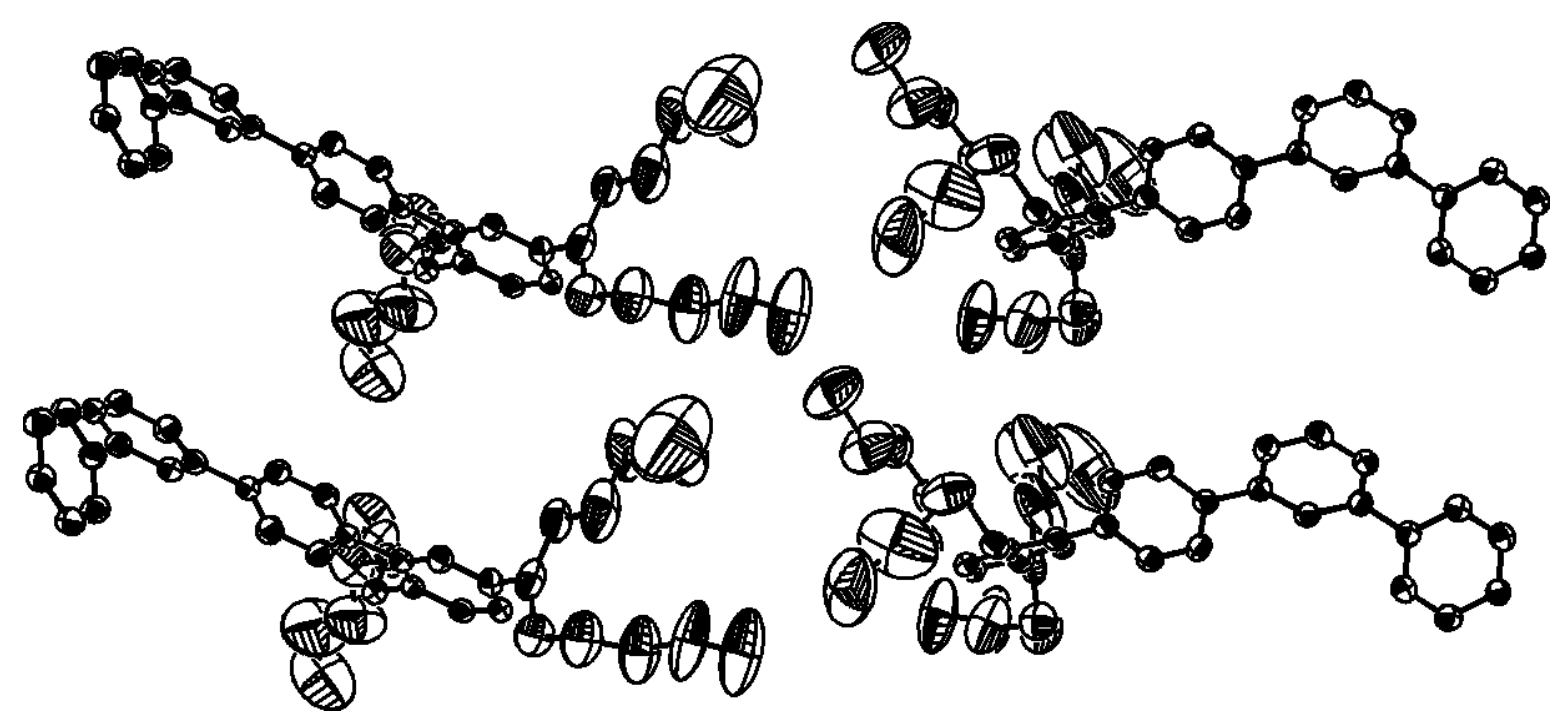

Abb. 7.9: Verzahnung der fehlgeordneten Hexylketten. Dargestellt sind nur asymmetrische Einheiten ohne Wasserstoffatome.

In den Abbildungen [7.8, 7.9 und 7.11 sind die thermalen Auslenkungsellipsoide dargestellt. Man sieht an den sehr kleinen Ellipsoiden der aromatischen Ringe, wie gut diese geordnet sind und erkennt, wie die nach außen immer größer werdenden Schwingungsellipsoide der Hexylketten die kontinuierliche Fehlordnung zwischen den beiden Lagen zu beschreiben versuchen.

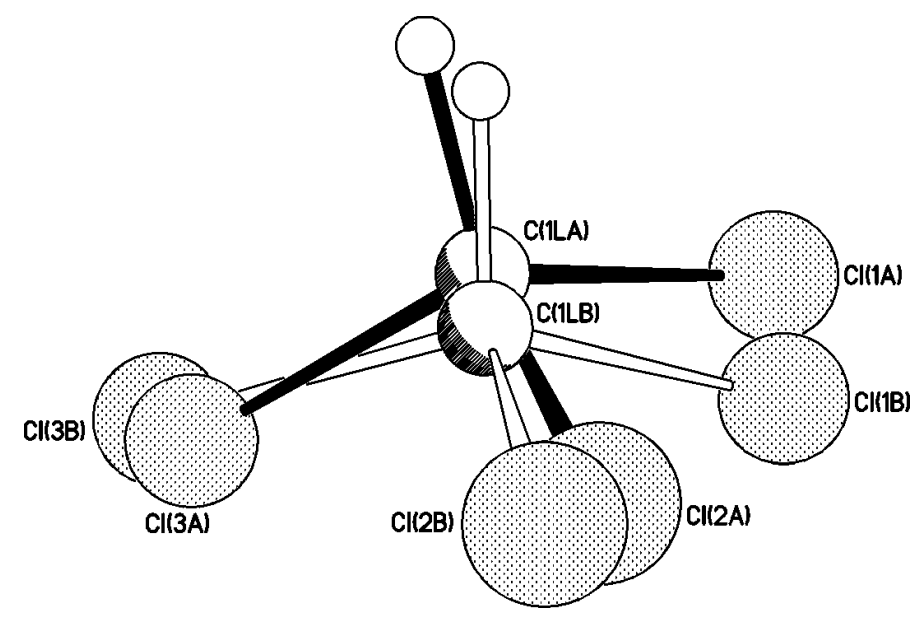

Abb. 7.10: Fehlordnung des Chloroform-Moleküls in der Struktur des Cycloikositetraphenylens.

In jeder asymmetrischen Einheit ist zusätzlich zu dem Sechstel des Makrozyklus noch ein Molekül Chloroform enthalten. Dieses Molekül ist über eine schwache $\mathrm{C}-\mathrm{H}-\pi$ Wasserstoffbrücke an einen der Phenylringe gebunden (siehe Abb. 7.11). Solche Wechselwirkungen sind - wenn auch etwas schwächer - von der Struktur des Cyclooctaphenylens bekannt [58]. Andere schwache Wasserstoffbindungen des selben Typs wurden ausführlich am Beispiel des Acetylens beschrieben [59]. 


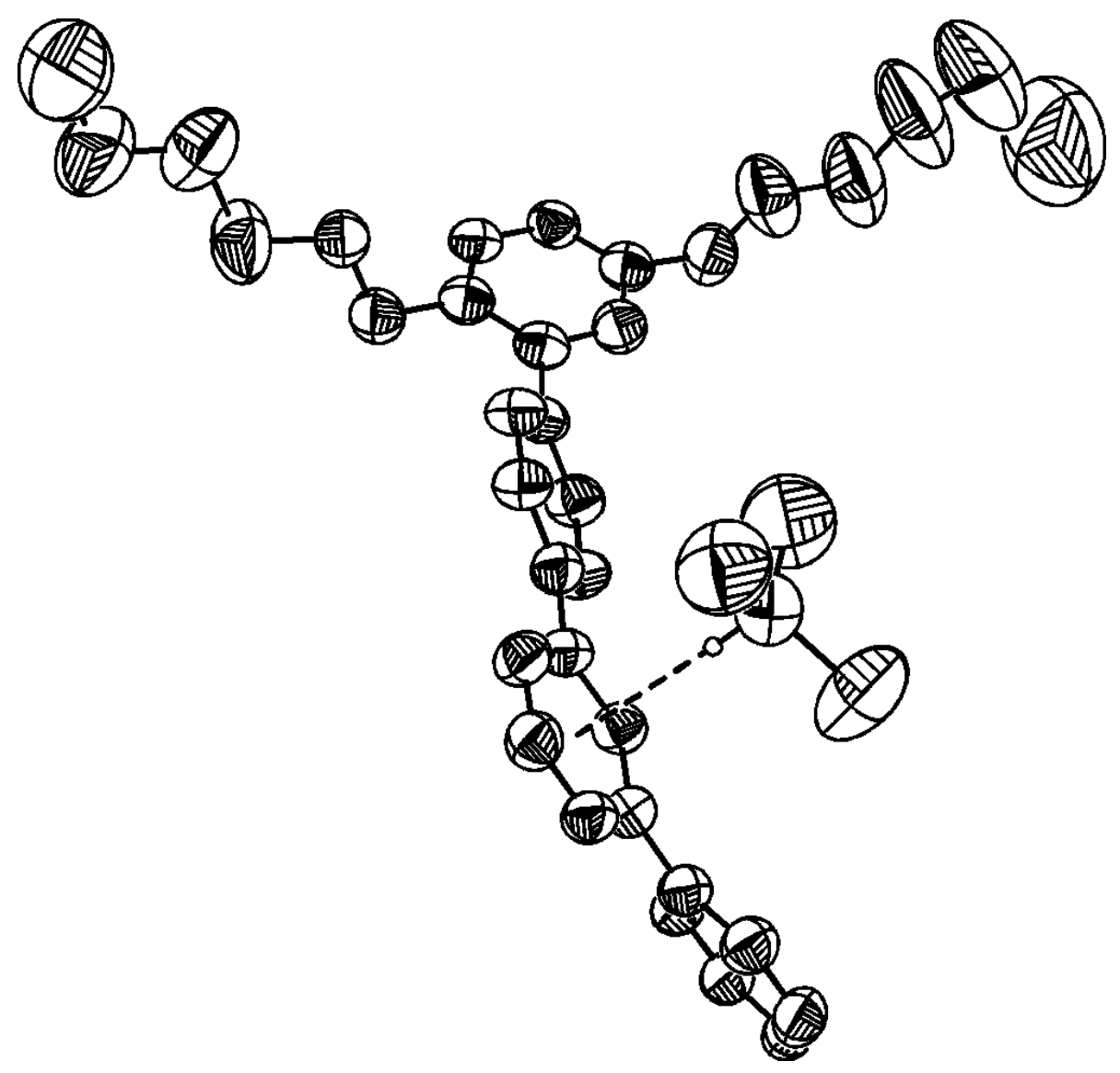

Abb. 7.11: CH- $\pi$-Wechselwirkungen zwischen einem Chloroform-Molekül und einem Ph-Ring des Cycloikositetraphenylens. Es finden sich folgende Abstände: C $\cdots \pi: 3.38 \AA, \mathrm{H} \cdots \pi: 2.38 \AA$. Der Winkel C-H- $\pi$ beträgt $174.3^{\circ}$.

Das Chloroformmolekül ist außerdem fehlgeordnet, und zwar nicht exakt aber doch näherungsweise um die $\mathrm{C}-\mathrm{H} \cdots \pi$-Achse, wie in Abb. 7.10 gezeigt ist. Mit den beiden abgebildeten Lagen ist diese Fehlordnung zufriedenstellend beschreibbar. Wie in 3.5 (Seite 23) bereits beschrieben, finden sich in den Röhren der Struktur des Cycloikositetraphenylens neben dem mehr oder weniger diskret über zwei Lagen fehlgeordneten Chloroformmolekül und den kontinuierlich fehlgeordneten Hexylketten noch eine größere Menge an vollständig ungeordnetem, nämlich flüssigem, Chloroform. Daher wurde, wie unter 7.2.1.3 erläutert, eine bulk solvent-Korrektur durchgeführt, indem in die .ins-Datei der Befehl SWAT eingeführt wurde (vgl. 7.2.1.3, Seite 76). Die beiden Parameter, die nach Moews und Kretzinger in erster Näherung das Streuverhalten des bulk solvent beschreiben [54], verfeinerten sich auf 13 bzw. auf neun, was ein Zeichen dafür ist, daß erstens ein ungewöhnlich großer Teil der Streumasse von der Unordnung betroffen ist und zweitens lediglich die Daten bei sehr niedriger Auflösung beeinflußt sind. 


\subsection{Fehlordnungsproblem bei dem Ti(III)-Komplex $\left(\eta^{5}-\mathbf{C}_{5} \mathbf{M e}_{5}\right)_{2} \mathbf{T i}_{2}(\mu-\mathbf{F})_{8} \mathbf{A l}_{4} \mathbf{M e}_{8}$}

Der Ti(III)-Komplex $\left(\eta^{5}-\mathrm{C}_{5} \mathrm{Me}_{5}\right)_{2} \mathrm{Ti}_{2}(\mu-\mathrm{F})_{8} \mathrm{Al}_{4} \mathrm{Me}_{8}$ kristallisiert in der monoklinen Raumgruppe $C 2 / c$ mit einem halben Molekül in der asymmetrischen Einheit; die andere Hälfte wird über die kristallographische zweizählige Achse durch $\mathrm{Al}(1)$ und $\mathrm{Al}(3)$ erzeugt. Die grünen Kristalle wachsen aus Toluol und sind extrem luftempfindlich: unmittelbar nach Entnahme aus dem Kolben beginnen sie sich erkennbar zu zersetzen, und die grüne Farbe geht verloren. Nur das Kühlen der Kristalle unter dem Mikroskop, wie in Kapitel [3 beschrieben, ermöglichte überhaupt die Strukturanalyse.

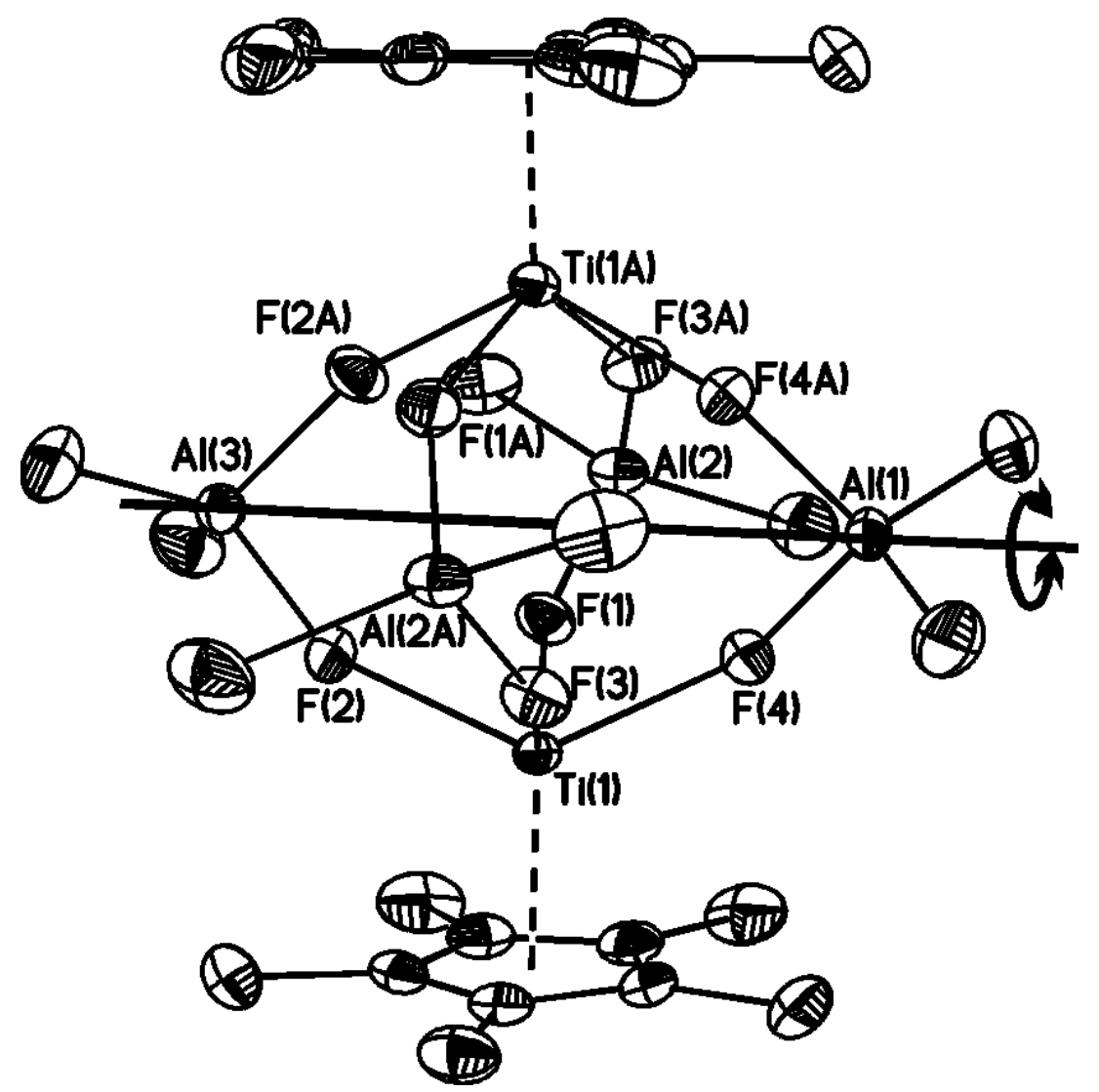

Abb. 7.12: Kristallstruktur von $\left(\eta^{5}-\mathrm{C}_{5} \mathrm{Me}_{5}\right)_{2} \mathrm{Ti}_{2}(\mu-\mathrm{F})_{8} \mathrm{Al}_{4} \mathrm{Me}_{8}$ in $C 2 / c$. Eingezeichnet ist die kristallographische zweizählige Achse, die die beiden asymmetrischen Einheiten ineinander überführt.

Der Kern der Struktur kann beschrieben werden als $\mathrm{Al}_{4} \mathrm{Ti}_{2}$-Oktaeder mit den beiden Ti-Atomen in trans-Stellung zueinander. Das Oktaeder ist über acht $\mu$-F-Liganden kantenverbrückt, wobei die F-Atome leicht von ihrer geometrisch exakten Position verrückt sind. Dadurch besitzt der $\mathrm{Al}_{4} \mathrm{Ti}_{2} \mathrm{~F}_{8}$-Käfig zwar eine nicht-kristallographische vierzählige Symmetrieachse durch die beiden Titanatome, nicht jedoch eine Spiegelebene durch die 
vier Aluminiumatome. Die tetraedrische Koordinationssphäre der Al-Atome wird jeweils durch zwei Ethylgruppen vervollständigt, jeweils ein Cp*-Ligand komplettiert die Koordinationssphäre der Ti-Atome, die quadratisch pyramidal ist (siehe Abb. 7.12).

Der gesamte $\mathrm{Al}_{4}\left(\mathrm{Me}_{2}\right)_{4} \mathrm{Ti}_{2} \mathrm{~F}_{8}$-Kern der Struktur ist um die vierzählige Achse durch $\mathrm{Ti}(1)$ und Ti(1A) fehlgeordnet: In etwa der Hälfte aller Fälleđ liegt der Käfig in einer Position, in den übrigen Elementarzellen dagegen ist er um $45^{\circ}$ gedreht. Dadurch sind die beiden Ti-Atome selbst nicht von der Fehlordnung betroffen.

Besonders interessant ist, daß die Methyl-Kohlenstoffatome zwar nicht hinsichtlich ihrer Position, wohl aber in ihrer Konnektivität fehlgeordnet sind: Die acht C-Atome befinden sich in beiden Lagen der Fehlordnung auf dem selben Platz und wechseln lediglich die Al-Atome, an die sie gebunden sind; die H-Atome der Methylgruppen sind dagegen fehlgeordnet. Abb. 7.13 zeigt den fehlgeordneten Kern.

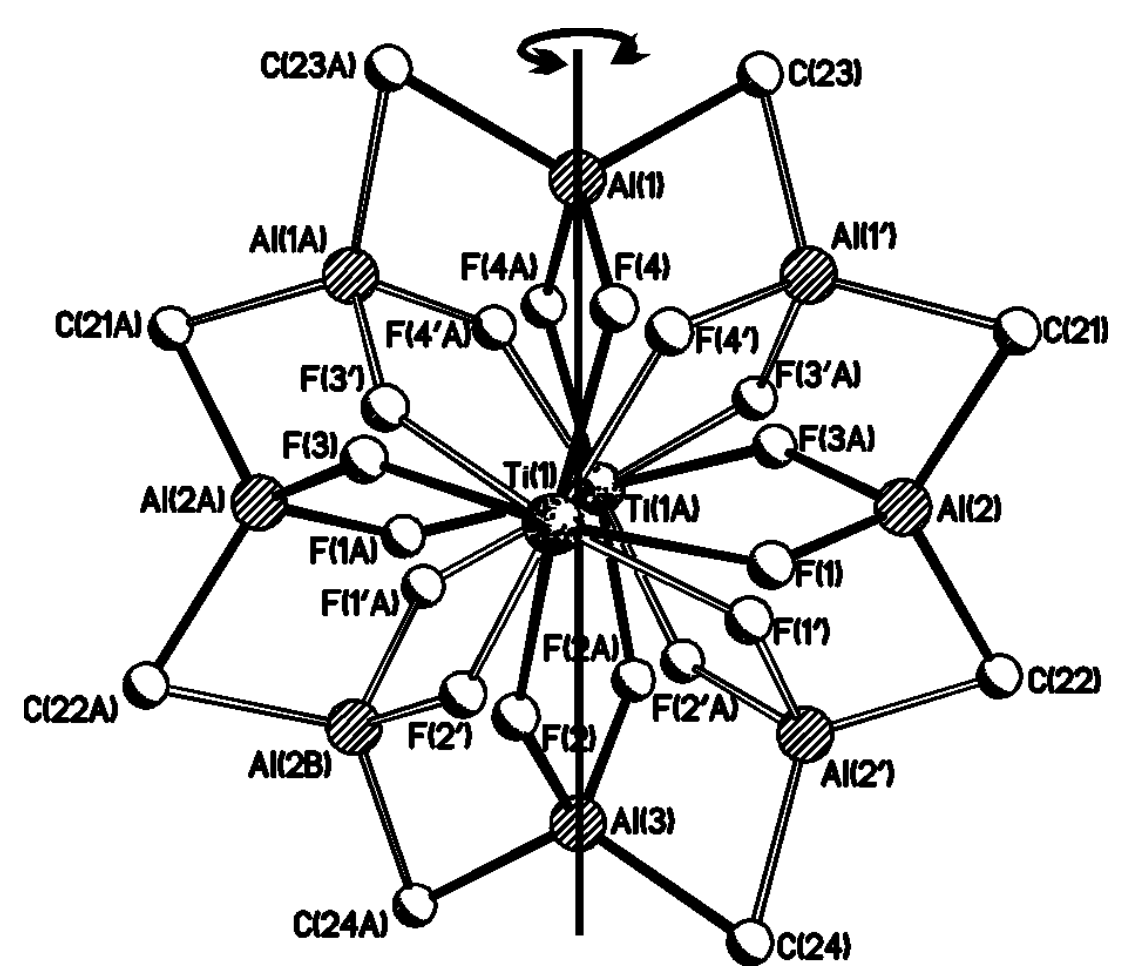

Abb. 7.13: Fehlordung des $\mathrm{Al}\left(\mathrm{Me}_{2}\right)_{4} \mathrm{Ti}_{2} \mathrm{~F}_{8}$-Kerns mit eingezeichneter kristallographischer Drehachse. Die Cp*-Ringe sind nicht dargestellt.

Ein bemerkenswerter Nebeneffekt der Fehlordnung ist, daß der eine Teil zwei spezielle Lagen enthält (Die Atome $\mathrm{Al}(1)$ und $\mathrm{Al}(3)$ liegen auf der kristallographischen zweizähligen Achse (nach Wyckoff a)), der andere jedoch nicht. Dies ist in Abb. 7.13 ebenfalls zu erkennen.

\footnotetext{
${ }^{7}$ Die zweite freie Variable verfeinert sich auf 0.52 .
} 
Die Verfeinerung dieser Fehlordnung ist nicht trivial: Die Strukturlösung mit direkten Methoden (SHELXS [49]) enthält zwar bereits alle Nichtwasserstoffatome, ohne Wissen um die Fehlordnung erkennt man die Lösung jedoch nicht. Lediglich die Ti- und F-Atome, sowie die Cp*-Ringe lassen sich zuordnen.

Die Verfeinerung mit SHELXL [3] bringt keine Klarheit - im Gegenteil: die schon in der Lösung enthaltenen, scheinbar uninterpretierbaren Positionen kommen unverändert wieder und die zunächst noch erkennbaren F-Positionen werden unklar, weil die Fluoratome auch von der Fehlordnung betroffen sind.

Erst die richtige Idee machte diese Struktur verfeinerbar. Allerdings war es nicht einfach, auf die richtige Lösung zu kommen, da das wahre Aussehen des Käfigs nur mit Phantasie zu erkennen ist und die Geometrie des Moleküls unbekannt war.

Der Einsatz von restraints, der bei Fehlordnungen immer angebracht ist, gestaltet sich in diesem Falle relativ kompliziert, da viele Abstände zu symmetrieäquivalenten Atomen in die Restraints einbezogen werden müssen.

Die Verfeinerung der Fehlordnung von $\left(\eta^{5}-\mathrm{C}_{5} \mathrm{Me}_{5}\right)_{2} \mathrm{Ti}_{2}(\mu-\mathrm{F})_{8} \mathrm{Al}_{4} \mathrm{Me}_{8}$ ist ebenfalls Gegenstand des erwähnten Tutoriums. Dort wird jeder Schritt von der Strukturlösung bis hin zum fertig verfeinerten Molekül beschrieben und illustriert, wobei auch die Anwendung der Restraints erläutert wird. 


\section{Kapitel 8}

\section{Nichtkristallographische- und Pseudosymmetrie}

Vor allem in Raumgruppen niedriger Symmetrie wie $P \overline{1}$ oder $P 2_{1}$ kommt es häufig vor, daß zwei oder mehr unabhängige Moleküle in der asymmetrischen Einheit vorliegen. In den meisten Fällen sind die beiden Moleküle nicht durch eine einfache Symmetrieoperation ineinander überführbar, manchmal tritt jedoch das Phänomen der Pseudosymmetrie auf. Hierbei muß unterschieden werden zwischen der sogenannten echten nichtkristallographischen Symmetrie (NCS) [60,61], die als Spezialfall von Pseudosymmetrie $\mathrm{zu}$ verstehen ist und der globalen Pseudosymmetrie. Während erstere im allgemeinen keine störenden Auswirkungen auf die Verfeinerung hat und eher als - mitunter sogar nützliche (vgl. 8.2) - Kuriosität, denn als Problem anzusehen ist, können von globaler Pseudosymmetrie systematische Fehler hervorgerufen werden [62].

\subsection{Globale Pseudosymmetrie}

Im Falle der globalen Pseudosymmetrie sind zwei Moleküle durch einen kristallographischen Symmetrieoperator fast ineinander überführbar. Ein kristallographisches Symmetrieelement befindet sich auf einer speziellen Lage, so daß seine Auswirkungen über die einzelne Elementarzelle hinaus auf die gesamte Struktur reichen. Wenn beispielsweise in der Raumgruppe $P 2_{1}$ zwei unabhängige Moleküle in der asymmetrischen Einheit so angeordnet sind, daß sie fast durch einen Gleitspiegel senkrecht zur monoklinen Achse ineinander überführbar sind, dann liegt globale Pseudosymmetrie vor, die Pseudo-Raumgruppe ist 
$P 2_{1} / c$. Da der Gleitspiegel nahezu erfüllt ist, ist auch das zugehörige zonale Auslöschungsgesetz ( $h 0 l$ ausgelöscht für $l \neq 2 n$ ) fast erfüllt, das heißt die entsprechenden Reflexe sind vorhanden aber sehr schwach. Mitunter sind diese Reflexe so schwach, daß es schwer sein kann, die Raumgruppe eindeutig zu bestimmen. In einigen Fällen - vor allem, wenn die beiden pseudo-symmetrieverwandten Moleküle das Symmetrieelement nur sehr geringfügig verletzen - kann es auch sinnvoll sein, die höhere Symmetrie anzunehmen und eine Fehlordnung zu verfeinern. Einen Fall, bei dem dies versucht wurde, schildert das erste Beispiel dieses Kapitels (8.3).

\subsection{Echte NCS}

Bei der echten nicht-kristallographischen Symmetrie sind zwei (oder auch mehr) Moleküle in der asymmetrischen Einheit zwar völlig oder nahezu durch ein Symmetrieelement (beispielsweise ein Inversionszentrum oder eine zweizählige Achse) ineinander überführbar, dieses Symmetrieelement ist aber ein nicht-kristallographisches, das heißt es ist so positioniert, daß es nur innerhalb einer Elementarzelle gilt. Ein Beispiel wäre eine zweizählige Achse, die nicht entlang einer der kristallographischen Blickrichtungen verläuft, sondern sozusagen „schräg“ im Raum liegt. Dabei muß geprüft werden, ob die Position des PseudoSymmetrieelements auch nach einer eventuell möglichen Umstellung des Gitters in eine andere metrische Symmetrie noch allgemein läge. Ist dies nicht der Fall, handelt es sich möglicherweise um Pseudosymmetrie in einer anderen Raumgruppe oder es liegt in der anderen metrischen Symmetrie sogar keine Auffälligkeit der Symmetrie mehr vor.

Echte NCS kommt weit häufiger vor als globale Pseudosymmetrie. Das größte Problem, das durch sie entsteht, ist der erhöhte Verfeinerungsaufwand bedingt durch die größere Anzahl von Atomen in der asymmetrischen Einheit. In manchen Fällen, etwa bei Proteinstrukturen, in denen es Probleme mit der Auflösung und damit mit dem DatenParameter-Verhältnis gibt, kann nicht-kristallographische Symmetrie sogar nützlich sein: Mit der Größe der Zelle wächst die Anzahl der beobachtbaren Daten, aber gewöhnlich auch die der zu verfeinernden Parameter. Wenn das Zellvolumen jedoch aufgrund von NCS erhöht ist, kann man die einzelnen durch NCS verwandten Moleküle mit restraints verknüpfen, was die Anzahl der Daten indirekt erhöht und damit zu einem verbesserten Daten-Parameter-Verhältnis führt. 


\subsection{Pn oder $P 2_{1} / n$ ?}

Das Molekül des 1-(3,3-Dimethyl-dithiolan-4-on)-2-(4,4-dimethyl-thiolan-3-on)-ethen (Abb. 8.1 links) unterscheidet sich vom 1,2-bis-(3,3-Dimethyl-dithiolan-4-on)-ethen (Abbildung 8.1 rechts) lediglich durch den Austausch eines Schwefelatoms gegen eine $\mathrm{CH}_{2^{-}}$ Gruppe [63]. Dadurch wird die Symmetrie des Moleküls erniedrigt: Während das zweitgenannte Molekül (Punktgruppe $\mathrm{C}_{2 i}$ ) ein Inversionszentrum enthält, fehlt dieses dem erstgenannten (Punktgruppe $\mathrm{C}_{2}$ ). Allerdings ist die Abweichung von der Punktgruppe $\mathrm{C}_{2 i}$ nur sehr gering, da lediglich ein einziges Nichtwasserstoffatom zur Symmetriebrechung führt.

Das 1,2-bis-(3,3-Dimethyl-dithiolan-4-on)-ethen kristallisiert in der monoklinen Raumgruppe $P 2_{1} / n$ mit einem halben Molekül in der asymmetrischen Einheit; die andere Hälfte wird durch das Inversionszentrum der Raumgruppe erzeugt. Die Elementarzelle des 1-(3,3Dimethyl-dithiolan-4-on)-2-(4,4-dimethyl-thiolan-3-on)-ethen ist nahezu identisch [63], da das Molekül jedoch nicht inversionssymmetrisch ist, kommt die selbe Raumgruppe nicht ohne weiteres in Frage.

\begin{tabular}{lcccc}
\hline \hline & $-21-$ & $-a-$ & -c- & -n- \\
\hline $\mathrm{N}$ & 33 & 609 & 618 & 585 \\
$\mathrm{~N} \mathrm{I}>3 \mathrm{~s}$ & 17 & 311 & 312 & 1 \\
$<\mathrm{I}>$ & 5.9 & 61.3 & 60.4 & 0.2 \\
$<\mathrm{I} / \mathrm{s}>$ & 9.1 & 12.9 & 12.7 & 0.5 \\
\hline \hline
\end{tabular}

Tab. 8.1: Verletzungen der systematischen Auslöschungen: Man erkennt den Unterschied zwischen der $n$-Gleitspiegelebene, die von der Fehlordnung nicht beeinflußt ist und der $2{ }_{1}$-Achse.

Tab. 8.1 zeigt die Auslöschungsstatistik aus XPREP [64]. Während die Auslöschungsbedingungen für die $n$-Gleitspiegelebene klar erfüllt und für die $a$ - bzw. $c$-Gleitspiegelebene klar nicht erfüllt sind, sind die Reflexe $0 k 0$ mit $k \neq 2 n$ zwar vorhanden, aber signifikant schwächer als die übrigen Daten.

Die Verletzungen des Auslöschungsgesetzes der 2 -Achse sind so stark, daß zunächst von der Raumgruppe $P n$ ausgegangen wurde (trotz der eher zentrosymmetrische Intensitätsverteilung $\left(\left|E^{2}-1\right|=0.877\right)$ ließ sich die Struktur nicht in $P 2 / n$ lösen). Bei der Verfeinerung traten jedoch Probleme auf, vor allem ließ sich die Struktur nicht ohne weiteres anisotrop verfeinern.

Der Vergleich mit der Struktur des 1,2-bis-(3,3-Dimethyl-dithiolan-4-on)-ethen führte $\mathrm{zu}$ einem befriedigenden Strukturmodell in $P 2_{1} / n$ : Da das Molekül 1-(3,3-Dimethyldithiolan-4-on)-2-(4,4-dimethyl-thiolan-3-on)-ethen das Inversionszentrum nicht erfüllt, 

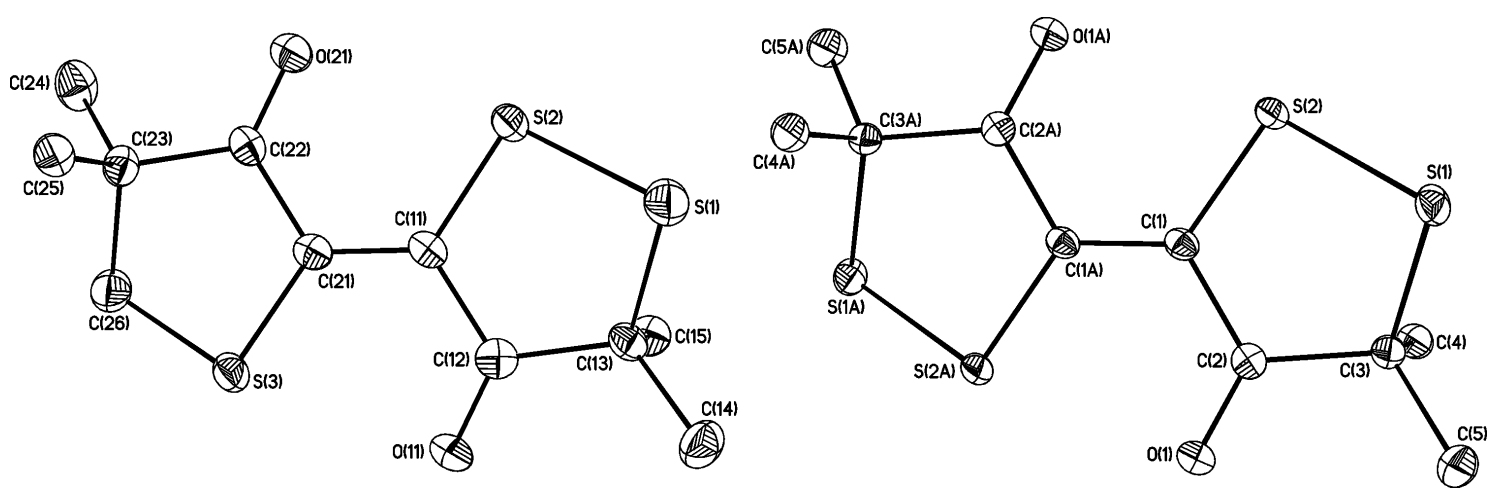

Abb. 8.1: Kristallstruktur des 1-(3,3-Dimethyl-dithiolan-4-on)-2-(4,4-dimethyl-thiolan-3-on)-ethen in $P n$ (links) und 1,2-bis-(3,3-Dimethyl-dithiolan-4-on)-ethen in $P 2_{1} / n$ (rechts).

muß es in der Raumgruppe $P 2_{1} / n$ mit $Z=2$ als über das kristallographische Inversionszentrum fehlgeordnet beschrieben werden [63]. Diese Fehlordnung des kompletten Moleküls kann jedoch verfeinert werden als Fehlordnung jener Atome, die der Punktgruppe $C_{2 i}$ widersprechen, das heißt, es ist lediglich eine Methylengruppe gegen ein Schwefelatom fehlgeordnet. Allerdings ist bei dieser Interpretation der $R 1$-Wert mit $6.02 \%$ im Vergleich zum $R_{\text {int }}$, der $2.98 \%$ beträgt, zu groß, so daß ein weiterer Versuch der Verfeinerung in der azentrischen Raumgruppe $P n$ unternommen wurde.

Die Probleme, die in $P n$ bei der anisotropen Verfeinerung auftreten, lassen sich mit Hilfe von 1,2- und 1,3-Abstandsrestraints und einem ADP-constraint lösen. Letzterer gleicht die anisotropen Auslenkungsparameter des Schwefelatoms S(1) denjenigen des Kohlenstoffatoms $\mathrm{C}(26)$ an und trägt damit dem Umstand Rechnung, daß die beiden Atome trotz des in $P n$ fehlenden Inversionszentrums Verwandt sind. Der R1-Wert ist mit 3.79\%四 erheblich besser als in $P 2_{1} / n$, und der Flack- $x$-Parameter verfeinert sich zu 0.19(13). Die Liste der größten Korrelationsmatrix-Elemente enthält einige Einträge mit Werten knapp unter 0.6. Da eine Ausweitung der ADP-constraints auf alle Atompaare nur eine geringfügige Verbesserung dieser Liste ergab, wurde der Variante mit nur einem entsprechenden Befehl der Vorzug gegeben.

Die Struktur wird vermutlich in der Raumgruppe $P n$ besser beschrieben als in $P 2_{1} / n$, es liegt also eine globale Pseudo-Inversionssymmetrie vor. Wie oben angedeutet, erschweren dadurch auftretende systematische Fehler die Verfeinerung, und es entsteht das Problem nur teilweise erfüllter Auslöschungsbedingungen, (vgl. Tab. 8.1).

\footnotetext{
${ }^{1} R 1=0.0379$ für $I>4 \sigma I, w R 2=0.0946$ für alle Daten.
} 


\section{4 $\left[\mathrm{Si}\left(\mathrm{NH}_{2}\right)_{2} \mathrm{CH}\left(\mathrm{SiMe}_{3}\right)_{2}\right]_{2}: P \overline{1}$ mit $Z=12$}

$\left[\mathrm{Si}\left(\mathrm{NH}_{2}\right)_{2} \mathrm{CH}\left(\mathrm{SiMe}_{3}\right)_{2}\right]_{2}$ kristallisiert in der triklinen Raumgruppe $P \overline{1}$ mit sechs unabhängigen Molekülen in der asymmetrischen Einheit. Die Moleküle sind aus einem $\left(\mathrm{NH}_{2}\right)_{2} \mathrm{Si}-\mathrm{Si}\left(\mathrm{NH}_{2}\right)_{2}$ Kern aufgebaut, und die tetraedrische Koordinationssphäre der Siliziumatome wird durch jeweils einen $\mathrm{CH}\left(\mathrm{SiMe}_{3}\right)_{2}$ Liganden komplettiert. Vier der sechs unabhängigen Moleküle liegen in syn-periplanarer, zwei in anti-clinaler Konformation vor.

Wie in Abb. 8.2 zu sehen ist, sind drei der sechs unabhängigen Moleküle paarweise mit den anderen dreien über drei lokale nicht-kristallographische Symmetrieelemente miteinander verbunden. Es handelt sich dabei um ein Inversionszentrum und zwei zweizählige Achsen, von denen eine nur bedingt erfüllt ist, da die $\mathrm{SiMe}_{3}$-Gruppen andere Torsionswinkel einnehmen.

Die Verfeinerung der Struktur bereitete keinerlei Schwierigkeiten. Durch die hohe Anzahl von unabhängigen Atomen war jedoch der Aufwand - auch hinsichtlich Rechenzeit größer, als für solch kleine Strukturen gemeinhin üblich. Eine detaillierte Beschreibung der Struktur einschließlich aller N-H-N-Wasserstoffbrücken, die die Moleküle im Kristallgitter miteinander vernetzen, findet sich in [65]. 

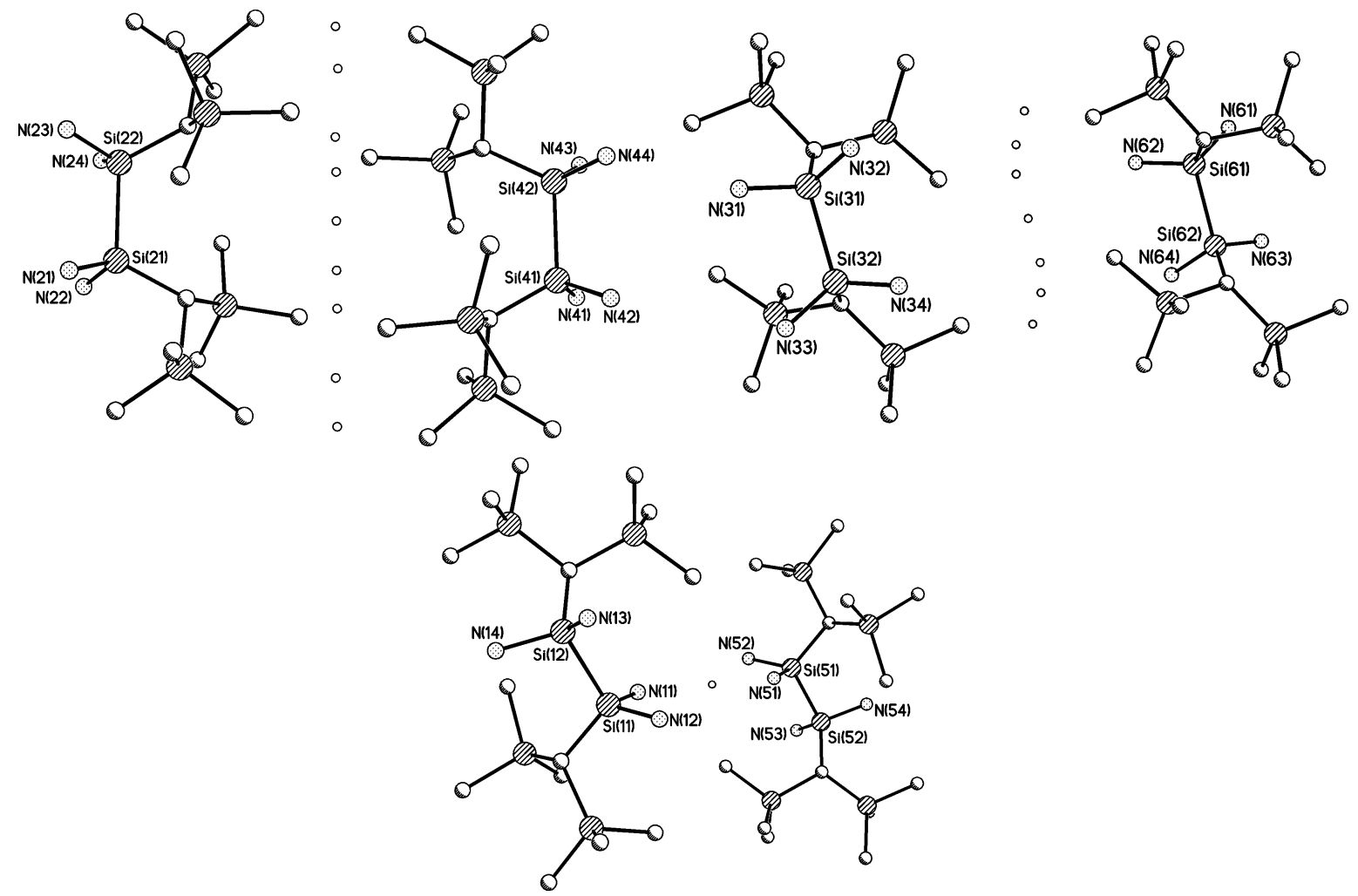

Abb. 8.2: Dreifache zweizählige nicht-kristallographische Symmetrie in der Struktur von $\left[\mathrm{Si}\left(\mathrm{NH}_{2}\right)_{2} \mathrm{CH}\left(\mathrm{SiMe}_{3}\right)_{2}\right]_{2}$. Die Punkte (dargestellt als kleine, nicht ausgefüllte Kreise) in der Mitte zwischen zwei NCS verwandten Molekülen markieren jeweils den geometrischen Schwerpunkt zweier durch NCS ineinander überführbarer Atome. Die zweizählige Achse in der Abbildung oben rechts wird relativ gut vom Kern der Struktur, nicht aber von den $\mathrm{SiMe}_{3}$-Liganden erfüllt, während die C2-Achse oben links und das Inversionszentrum unten nahezu perfekt erfüllt sind. 


\section{Kapitel 9}

\section{Verzwillingung}

Als verzwillingt bezeichnet man einen gesetzmäßig aus zwei oder mehr Domänen zusammengesetzten Kristall der selben chemischen Zusammensetzung. Dabei beschreibt das Zwillingsgesetz in Form einer $3 \times 3$ Matrix die genaue Art und Weise, wie sich eine Domäne geometrisch in die andere überführen läßt. Zusätzlich zum Zwillingsgesetz ist für die vollständige Beschreibung der Verzwillingung die Angabe des relativen Anteils der Domänen am Kristall erforderlich.

So simpel das Problem der Verzwillingung prinzipiell ist, so weitreichend und teilweise fatal können die Schwierigkeiten sein, die durch diese Eigenheit mancher Kristalle entstehen: Im Falle der nicht-meroedrischen Verzwillingung wird bereits das Auffinden der korrekten Elementarzelle zum Problem oder sogar unmöglich. Bei meroedrischen und pseudomeroedrischen Zwillingen - bei denen sich die Zellbestimmung im allgemeinen problemlos gestaltet - ist die Lösung des Phasenproblems häufig zumindest stark erschwert, und die Verfeinerung verläuft schwierig. Unerkannte bzw. nicht adäquat behandelte Verzwillingungen sind eine nicht zu unterschätzende Fehlerquelle für Röntgenstrukturen. Daher stellt diese Problematik einen wichtigen limitierenden Faktor in der modernen Kristallographie dar.

Das beobachtete Beugungsbild eines verzwillingten Kristalls ist als aus zwei (oder mehr) Beugungsbildern überlagert zu verstehen, da jede Domäne unabhängig ihr eigenes Bild beiträgt, in der Weise, als würde man zur selben Zeit zwei (oder mehr) verschiedene Kristalle der selben Substanz röntgen. Aufgrund der geforderten Gesetzmäßigkeit ist es jedoch häufig der Fall, daß die Gitter und damit auch die Beugungsbilder aller Domänen exakt überlappen, so daß das Beugungsbild auf den ersten Blick völlig unauffällig erscheint. 
Für das Entstehen von Verzwillingung liegt häufig ein kristallographischer Grund vor, der die gefundene Anordnung der Domänen plausibel erklärt. Deshalb kann es sehr schwierig sein, eine Verzwillingung mancher Moleküle zu verhindern. Beispielsweise können, wenn ein Molekül eine Pseudo-Eigensymmetrie besitzt, es also z. B. durch Drehung um eine zweizählige Achse fast mit sich selbst zur Deckung zu bringen ist, zwei verschiedene Orientierungen des Moleküls nahezu gleichwertig in das Gitter eingebaut werden.

Man stelle sich in einem Gedankenexperiment das Wachstum des Kristalls vor: Nach der Keimbildung beginnen sich an den Kristallkeim Moleküle in immer der selben Orientierung anzulagern, der Kristall wächst. Wenn zwei verschiedene Orientierungen des Moleküls energetisch nahezu gleichwertig sind, kann es vorkommen, daß sich irgendwann einige Moleküle in der anderen Orientierung an den wachsenden Kristall anlagern. Diese Moleküle sind der Ausgangskeim für eine zweite Domäne.

Diese Form der Verzwillingung wird desto wahrscheinlicher, je höher die Kristallisationstemperatur ist, da bei höherem Energieinhalt des Gesamtsystems die ohnehin kleinen Energieunterschiede der verschiedenen Orientierungen immer mehr vernachlässigbar werden. Um Verzwillingung zu vermeiden, kann es daher helfen, die Kristalle bei möglichst niedrigen Temperaturen wachsen zu lassen. Entsprechend findet man bei Kristallen, die durch Sublimation oder aus der Schmelze gewonnen wurden, besonders häufig Verzwillingungen.

Neben dem thermodynamischen Ansatz zur Zwillingsvermeidung gibt es noch einen kinetischen: Es kann helfen, die Kristallisationsgeschwindigkeit zu reduzieren, da bei langsamem Wachstum die Wahrscheinlichkeit von Fehlorientierungen ebenfalls sinkt.

Schließlich kann die Wahl des Lösungsmittels Einfluß auf Verzwillingungen haben. Allerdings treten Verzwillingungen nicht in manchen Lösungsmitteln bevorzugt auf und in anderen nur selten. Soll also Verzwillingung durch die Wahl des Lösungsmittels verhindert werden, müssen möglichst viele verschiedene Lösungsmittel ausprobiert werden.

\subsection{Arten der Verzwillingung}

Eine Klassifizierung verschiedener Zwillingstypen kann nach mehreren Gesichtspunkten erfolgen. Hier sollen vier Arten von Verzwillingung beschrieben werden: die meroedrische, pseudo-meroedrische, racemische (auch Inversionsverzwillingung genannt) und die nichtmeroedrische Verzwillingung. Sie sind geordnet nach ihrer sichtbaren Auswirkung auf das Beugungsbild. 


\subsubsection{Verzwillingung bei vollständiger exakter Überlagerung der Kristallgitter}

\subsubsection{1 meroedrische Verzwillingung}

Meroedrische Verzwillingung ist Verzwillingung innerhalb eines Kristallsystems. Bei Kristallsystemen mit zwei möglichen Lauegruppen (also tetragonal, trigonal, hexagonal und kubisch) besteht die Möglichkeit, ein Gitter niedrigerer Lauesymmetrie durch das Zwillingsgesetz so auf sich selbst abzubilden, daß dadurch die höhere Symmetrie erzeugt werden kann円, d. h. der Zwillingsoperator erfüllt die Restriktionen des Kristallsystems, nicht aber die der Lauegruppe. Die so entstehende höhere Symmetrie ist allerdings nur vorgetäuscht, da sie von den einzelnen Domänen für sich betrachtet nicht erfüllt wird.

Ein Spezialfall der meroedrischen Verzwillingung ist der racemische Zwilling, bei dem das Zwillingsgesetz die Inversionsmatrix (Matrix 9.8) ist. In diesem Fall erfüllt der Zwillingsoperator zwar die Lauesymmetrie (und damit natürlich auch die metrische Symmetrie), nicht aber die Punktgruppe des Kristalls. Da die Lauesymmetrie erfüllt wird, können racemische Verzwillingungen in allen Kristallsystemen vorkommen, nicht nur in denen mit zwei möglichen Lauegruppen.

Racemische Verzwillingung erzeugt keinerlei Probleme hinsichtlich Strukturlösung und -verfeinerung. Lediglich die absolute Konfiguration eines Moleküls muß geklärt werden, da es unerläßlich ist, jede nicht-zentrosymmetrische Struktur in ihrer korrekten absoluten Konfiguration zu verfeinern, um systematische Fehler zu vermeiden [66]. Ein Beispiel für racemische Verzwillingung wird in 9.7 auf Seite 113 gegeben.

\subsubsection{2 pseudo-meroedrische Verzwillingung}

Auch im Falle der pseudo-meroedrischen Verzwillingung wird höhere Symmetrie vorgetäuscht, allerdings imitiert hier nicht die niedrige Lauegruppe die höhersymmetrische, sondern die Verzwillingung ist kristallsystemübergreifend: ein Kristallsystem niedriger Symmetrie erscheint durch das Zwillingsgesetz als höhersymmetrisches. Dies ist nur möglich, wenn die metrische Symmetrie der Elementarzelle höher ist als vom Kristallsystem gefordert. Beispielsweise kann eine primitive monokline Zelle mit $a=b$ unmittelbar

\footnotetext{
1 Höhere Symmetrie wird tatsächlich nur dann erzeugt, wenn es sich um eine perfekte 1:1Verzwillingung handelt. Je größer der Unterschied in der relativen Populierung der beiden Zwillingsdomänen ist, desto stärker werden die Abweichungen von der höheren Symmetrie.
} 
in eine größere orthorhombisch $C$-zentrierte umgestellt werden. Die selbe Überlegung gilt für monokline Zellen bei denen eine der beiden Winkelhalbierenden der B-Ebene die selbe Länge wie $a$ oder $b$ hat. Ein solcher Fall wird am Beispiel des $\mathrm{C}_{22} \mathrm{H}_{22} \mathrm{~N}_{4} \mathrm{O}_{6}$ geschildert (vgl. 9.6, Seite 107).

\subsubsection{Verzwillingung ohne vollständige exakte Überlagerung der Kristallgitter}

\subsubsection{1 nicht-meroedrische Verzwillingung}

Bei der nicht-meroedrischen Verzwillingung handelt es sich im Grunde um eine mehr oder weniger willkürliche Verwachsung zweier oder mehrerer Kristalle. Mit anderen Worten: das Zwillingsgesetz - meist Rotation um eine zweizählige Achse - ist hier ein nichtkristallographisches. Daher überlagern sich die Beugungsbilder nicht mehr exakt, und man bekommt eine zum Teil chaotisch wirkende Ansammlung von Reflexen. Wenn es nicht gelingt, zumindest eine Elementarzelle mit Orientierungsmatrix zu finden, womit ein Teil der Reflexe beschrieben werden kann, bestehen keine Möglichkeiten, den gesammelten Datensatz überhaupt zu verwerten.

Ist eine Elementarzelle gefunden, können die Bilder entsprechend integriert werden, wobei alle Reflexe, die nicht zu der gefundenen Matrix passen, verworfen werden. Die so gewonnenen Daten sind dennoch problematisch, da durch zufällige Überlappung mancher Reflexe verschiedener unabhängiger Beugungsbilder die Intensitätsverteilung stark verzerrt werden kann. Handhabbar wird ein nicht-meroedrisch verzwillingter Datensatz erst, wenn für jede Domäne die passende Orientierungsmatrix gefunden ist. Der Datensatz ist dann zu behandeln als eine Mischung zweier oder mehrerer unabhängiger Datensätze in einer Datei.

Glücklicherweise ist in den meisten Fällen nicht-meroedrische Verzwillingung bereits makroskopisch als Verwachsung erkennbar, so daß entsprechende Kristalle entweder geschickt geschnitten oder von vornherein verworfen werden können. 


\subsection{Warnsignale für Verzwillingung}

Auch wenn dem Beugungsbild eine Verzwillingung nicht unmittelbar angesehen werden kann, gibt es doch einige Warnsignale, die auf mögliche Verzwillingung hinweisen [67]. Zwar kommt es selten vor, daß alle im folgenden aufgeführten Symptome gleichzeitig zu beobachten sind, aber bereits beim Auftreten mehrerer davon sollte eine Struktur sorgfältig auf etwaige Verzwillingung überprüft werden:

1. Der Mittelwert von $\left|E^{2}-1\right|$ ist deutlich erniedrigt.

2. Die metrische Symmetrie ist höher als die Lauesymmetrie (z. B. $2 / m$ bei $\alpha=\beta=$ $\left.\gamma=90^{\circ}\right)$.

3. Der $R_{\text {int }}$-Wert für die höhere Lauesymmetrie ist nur unwesentlich höher.

4. Die beobachteten systematischen Auslöschungen passen zu keiner Raumgruppe.

5. Obwohl die Daten gut aussehen, läßt sich die Struktur nicht lösen.

6. Die Raumgruppe ist trigonal bzw. hexagonal.

Die $\left|E^{2}-1\right|$-Statistik ist der einfachste und dazu ein relativ zuverlässiger Indikator für Verzwillingung, wenngleich er in Anwesenheit von Schweratomen - vor allem auf speziellen Lagen - an Aussagekraft verliert: Aufgrund der Überlagerung zweier oder mehrerer Beugungsbilder zu dem beobachteten Diffraktionsmuster verschmieren die Intensitätsunterschiede der Röntgenreflexe, da es unwahrscheinlich ist, daß starke Reflexe nur von starken und schwache nur von schwachen Reflexen überlagert werden. Daher sind die Intensitäten der beobachteten Reflexe einander viel ähnlicher als bei einem unverzwillingten Datensatz. Da der Mittelwert für $\left|E^{2}-1\right|$ desto größer ist, je größer die Unterschiede zwischen den Reflexintensitäten sind, wird eine Abweichung vom Erwartungswert (0.736 für nicht-zentrosymmetrische Strukturen und 0.968 für zentrosymmetrische) nach unten wahrscheinlich. Allerdings haben auch andere Faktoren - etwa die Anwesenheit von Schweratomen - Einfluß auf die $\left|E^{2}-1\right|$-Statistik, so daß eine Erniedrigung des Wertes für $\left|E^{2}-1\right|$ lediglich als Hinweis zu verstehen ist.

Ist die metrische Symmetrie höher als die Lauesymmetrie, sind die Bedingungen für eine pseudo-meroedrische Verzwillingung gegeben. Auch ein relativ guter $R_{\text {int }}$ für die höhere Lauesymmetrie ist ein Hinweis auf pseudo-meroedrische Verzwillingung. 
Trigonale bzw. hexagonale Raumgruppen sind überdurchschnittlich häufig von meroedrischer Verzwillingung betroffen, was mit der besonderen metrischen Symmetrie dieser Kristallsysteme zusammenhängt, die mehrere geometrisch äquivalente Orientierungen zuläßt.

Racemische Verzwillingung ist nur am sog. Flack-Parameter $x$ zu erkennen, der von manchen Verfeinerungsprogrammen, darunter SHELXL [3], berechnet wird [68].

$$
F_{c}^{2}=(1-x) F_{c(h k l)}^{2}+x F_{c(-h-k-l)}^{2}
$$

9.1 ist ein Spezialfall der unten eingeführten Gleichung 9.6. Der Parameter $x$ gibt den relativen Anteil der invertierten Komponente eines racemischen Zwillings an. Für den Fall, daß keine racemische Verzwillingung vorliegt, kann $x$ theoretisch nur zwei Werte annehmen, nämlich Null für die korrekte absolute Struktur des Moleküls und Eins für die invertierte absolute Struktur. Werte zwischen Null und Eins sind Zeichen für racemische Verzwillingung; ein perfekter (also im Verhältnis 1:1 verzwillingter) racemischer Zwilling würde für $x$ einen Wert von 0.5 ergeben.

Auch für nicht-meroedrische Verzwillingung gibt es Warnzeichen, die zum Teil unmittelbar dem Beugungsbild zu entnehmen sind [67]:

1. Einige Reflexe erscheinen als scharfe Punkte, andere sind gespalten.

2. Der Kristall scheint eine oder mehrere ungewöhnlich lange Zellkanten zu besitzen (viele sehr dicht beieinanderliegende Reflexe in einer Reihe).

3. Die Elementarzelle läßt sich nicht bestimmen.

4. $F_{o}^{2}$ ist in vielen Fällen größer als $F_{c}^{2}$, da die berechneten mit den gemessenen Intensitäten nur bedingt übereinstimmen; daher wird der Wert für $K=\bar{F}_{o}^{2} / \bar{F}_{c}^{2}$ systematisch erhöht.

Die ersten beiden Punkte sind Zeichen für willkürliche Überlagerung mehrerer Beugungsbilder, der dritte Punkt die unmittelbare Folge davon. Punkt vier bezieht sich auf die zufällige Überlagerung einzelner Reflexe, deren Intensität dadurch relativ zu den übrigen verstärkt wird. 


\subsection{Mathematische Entzwillingung verzwillingter Daten}

Häufig lassen sich verzwillingte Datensätze mit direkten oder Patterson Methoden lösen, und die Probleme treten erst bei der Verfeinerung auf. In einigen Fällen versagen jedoch alle Methoden zur Strukturlösung, so daß eine mathematische Entzwillingung des Datensatzes, die allerdings nur bei meroedrischen und pseudo-meroedrischen Verzwillingungen funktioniert, den einzig möglichen Ausweg darstellt [69]:

Man stelle sich das gemessene Beugungsbild als Überlagerung zweier wahrer Beugungsbilder vor. Zu jedem Reflex gibt es dann einen zwillingsverwandten Reflex, wobei der zweite aus dem ersten durch Anwendung des reziproken Zwillingsoperators erzeugt wird. Wenn $I_{a}$ und $I_{b}$ die gemessenen Intensitäten zweier zwillingsverwandter Reflexe sind und $I_{1}$ und $I_{2}$ deren wahre Intensitäten, dann gilt:

$$
I_{a}=(1-k) \cdot I_{1}+k \cdot I_{2}
$$

und entsprechend

$$
I_{b}=k \cdot I_{1}+(1-k) \cdot I_{2}
$$

wobei $k$ mit $0 \leq k \leq 1$ das relative Zwillings-Verhältnis ist.

Einfache arithmetische Umformung der Gleichungen 9.2 und 9.3 führt zu den wahren Intensitäten:

$$
I_{1}=\frac{\left[(1-k) \cdot I_{a}-k \cdot I_{b}\right]}{(1-2 \cdot k)}
$$

und

$$
I_{2}=\frac{\left[(1-k) \cdot I_{b}-k \cdot I_{a}\right]}{(1-2 \cdot k)}
$$

Auf diese Weise lassen sich für jedes zwillingsverwandtes Reflexpaar die wahren Intensitäten berechnen: aus einem verzwillingten Datensatz wird ein unverzwillingter.

Problematisch ist, daß $k$ normalerweise unbekannt ist und abgeschätzt werden muß. In der Praxis entzwillingt man die Daten mit verschiedenen Werten für $k$ und verwendet den Datensatz, der die beste $\left|E^{2}-1\right|$-Statistik ergibt.

Man entfernt mit dieser Methode zwar die systematischen Fehler der Verzwillingung aus dem Datensatz, rechnet aber neue systematische Fehler hinein, und zwar desto stärker, je näher der Wert für $k$ an 0.5 liegt.

\footnotetext{
${ }^{2}$ Den reziproken Zwillingsoperator erhält man aus dem realen durch Transponieren und Invertieren der Matrix.
} 
Sollten die beiden Zwillingsdomänen exakt gleich groß sein, das relative Zwillings-Verhältnis also genau 0.5 betragen, sind die Gleichungen 9.4 und 9.5 wegen Division durch Null nicht definiert. Das Problem ist demnach nur für nicht-perfekte Zwillinge lösbar, deren Wert für $k$ hinreichend weit von 0.5 abweicht (erfahrungsgemäß ist $k=0.65$ gerade noch handhabbar).

Bedauerlicherweise haben die überwiegende Mehrzahl aller auftretender Verzwillingungen $k$-Werte zwischen 0.4 und 0.6 , so daß die beschriebene Methode nur selten erfolgreich angewendet wurde. Ein Beispiel, bei dem mathematische Entzwillingung durchgeführt wurde, ist Mersacidin [70,71].

\subsection{Verfeinerung gegen verzwillingte Daten}

Da bei der mathematischen Entzwillingung immer unkalkulierbare und zum Teil erhebliche systematische Fehler in den Datensatz hineingerechnet werden, sind solche Daten selten geeignet, um gegen sie zu verfeinern [69]. Verfeinerungsprogramme wie SHELXL97 [3] verzichten daher auf Entzwillingung und berechnen die $F_{c}^{2}$-Werte wie folgt [67]:

$$
F_{c}^{2}=(o s f)^{2} \sum_{m=1}^{n} k_{m} F_{c_{m}}^{2}
$$

Dabei ist osf (overall scale factor) der allgemeine Skalierungsfaktor der Verfeinerung, $k_{m}$ ist der relative Anteil der Zwillingsdomäne $m$ am Gesamtkristall, und $F_{c_{m}}$ ist der berechnete Strukturfaktor der Zwillingsdomäne $m$; $n$ ist die Anzahl der Zwillingsdomänen. Da die Summe der relativen Anteile $k_{m}$ aller Zwillingsdomänen eines Kristalls genau Eins ergeben muß, können $(n-1) k_{m}$-Werte verfeinert werden, während sich der Wert für den verbleibenden Anteil $k_{1}$ nach Gleichung 9.7 wie folgt ergibt:

$$
k_{1}=1-\sum_{m=2}^{n} k_{m}
$$

Häufig liegen jedoch lediglich zwei Domänen vor, so daß gilt: $n=2$. Dadurch vereinfacht sich Gleichung 9.7 entsprechend.

Neben obiger Berechnung muß das Verfeinerungsprogramm das Zwillingsgesetz kennen, um erfolgreich gegen verzwillingte Daten verfeinern zu können. Hierzu reicht es aus, die entsprechende $3 \times 3$ Matrix einzugeben. 


\subsubsection{Zwillingsverfeinerung mit SHELXL}

Das Verfeinerungsprogramm SHELXL-97 bietet eine sehr bequeme Möglichkeit zur Verfeinerung meroedrisch oder pseudo-meroedrisch verzwillingter Strukturen:

Die Eingabe der Zwillingsmatrix erfolgt mittels des Befehls TWIN, der von den neun Werten des Zwillingstensors gefolgt wird. Der verfeinerbare Wert für den relativen Anteil der Domänen zueinander wird in Form des sog. BASF-Wertes (BAtch Scale Factor) angegeben.

Das Zwillingsgesetz zur Behandlung racemischer Zwillinge sieht in seiner MatrixSchreibweise wie folgt aus:

$$
\left(\begin{array}{rrr}
-1 & 0 & 0 \\
0 & -1 & 0 \\
0 & 0 & -1
\end{array}\right)
$$

Der entsprechende Befehl in SHELXL lautet:

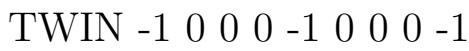

BASF 0.6

Oder, da die Inversionsmatrix das default-Argument des TWIN-Befehls ist, einfach nur

TWIN

BASF 0.6

Dabei wird (willkürlich) Verzwillingung im Verhältnis 60:40 angenommen (BASF 0.6).

Sollte sich diese Annahme als unrichtig erweisen, ändert sich der BASF-Wert automatisch bei der Verfeinerung.

Zur Verfeinerung von Verzwillingungen mit mehr als zwei verschiedenen Domänen wird an die neun Matrixelemente in der TWIN-Zeile eine zehnte Zahl angehängt, welche die Anzahl der Domänen angibt (default-Wert hierfür ist 2). Die nötigen zusätzlichen BASFParameter werden an den ersten angeschlossen. 


\subsection{Verzwillingung oder Fehlordnung?}

Der Übergang von Verzwillingung zu Fehlordnung ist fließend und eine Unterscheidung nicht immer einfach, da eine Verzwillingung im räumlichen Mittel immer als Fehlordnung um den Zwillingsoperator erscheint [72]. Insofern wäre Verzwillingung als Spezialfall der Fehlordnung aufzufassen. Dies ist jedoch nicht korrekt - vielmehr besteht ein Unterschied zwischen Fehlordnung um lokale oder globale Symmetrieelemente und echter Verzwillingung: Prinzipiell liegt bei Verzwillingung eine bestimmte Anzahl theoretisch makroskopisch unterscheidbarer Domänen vor, die, dem Zwillingsgesetz folgend, miteinander verwachsen sind. Es existiert also eine Fernordnung, wenngleich sich diese nicht auf den gesamten Kristall erstreckt, sondern nur innerhalt einer Domäne gilt. Bei einer Fehlordnung dagegen sind die Molekülorientierungen willkürlich über den Kristall verteilt; es liegen selten eine größere Anzahl von Elementarzellen der selben Moleküllage unmittelbar zusammen, wodurch eine strenge Fernordnung für den fehlgeordneten Teil der Struktur nicht mehr gilt.

Der Unterschied läßt sich am besten in einem weiteren Gedankenexperiment verstehen: Man stelle sich vor, was ein Röntgenphoton, das man als Wellenpaket endlicher Ausdehnung verstehen kann, auf seinem Weg durch den Kristall „sieht“. [3 Im Falle eines Zwillingskristalls wird das Photon fast immer innerhalb nur einer Domäne gebeugt und damit die Moleküle in nur einer Orientierung antreffen. Im Falle einer Fehlordnung bekommt es dagegen immer beide möglichen Orientierungen zu sehen. Im ersten Fall ist das beobachtete Beugungsbild eine einfache Überlagerung zweier unabhängiger Beugungsbilder (entspricht Summierung der $F_{o}^{2}$-Werte), während im Fall der Fehlordnung durch die unterschiedlichen Orientierungen zusätzliche Phasenverschiebungen und damit Interferenzen auftreten (entspricht Summierung der $F_{o}$-Werte).

In der Praxis läßt sich meist gut zwischen Verzwillingung und Fehlordnung unterscheiden, in Zweifels- und Grenzfällen - etwa beim Vorliegen von Schweratomen auf speziellen Lagen [72] - müssen jedoch beide Möglichkeiten ausprobiert werden. Dabei ist es nicht selten einfacher, zunächst eine Verzwillingung auszuprobieren, für deren Formulierung lediglich eine Matrix aufgestellt werden muß, statt Stunden oder Tage mit einer Fehlordnung zuzubringen, die sich hinterher als Zwilling entpuppt.

\footnotetext{
${ }^{3}$ Zum Zustandekommen von Interferenzeffekten ist tatsächlich ein einzelnes Photon ausreichend, wie Beugungsexperiemente am Doppelspalt ergaben. Die Ausdehnung, also Größe eines Röntgenphotons entspricht der mittleren Kohärenzlänge, die mit wenigen $100 \AA$ angegeben wird [5]; ein Photon "sieht" also durchaus mehrere Elementarzellen.
} 


\subsection{Problem der Verzwillingung von $\mathrm{C}_{22} \mathrm{H}_{22} \mathrm{~N}_{4} \mathrm{O}_{6}$}

An dem in 5.1.1 (Seite 45) beschriebenen Diffraktometer wurden bei einem Zählerabstand von $8 \mathrm{~cm}$ bis etwa $0.8 \AA$ komplette Daten gesammelt. Das Diffraktometersteuerprogramm SMART [73] lieferte die orthorhombische $C$-zentrierte Elementarzelle:

$$
a=8.138, b=14.932, c=34.265, \alpha=90.00, \beta=90.00, \gamma=90.00
$$

In XPREP [64 ergab sich anhand der Auslöschungen eindeutig die Raumgruppe $C 222_{1}$, wobei eine mit 0.689 leicht erniedrigte $\left|E^{2}-1\right|$-Statistik zunächst als nicht alarmierend angesehen wurde. Der erste Verdacht auf Verzwillingung entstand, als mit keiner Methode eine Lösung des Phasenproblems erreicht werden konnte.

Orthorhombisch $C$ ist theoretisch immer in monoklin $P$ mit $a=b$ umstellbar (Abb. 9.1). Die Transformationsmatrix für diese Umstellung lautet

$$
\left(\begin{array}{rrr}
0.5 & 0.5 & 0 \\
0 & 0 & -1 \\
-0.5 & 0.5 & 0
\end{array}\right)
$$

womit aus der ursprünglichen orthorhombischen Elementarzelle die folgende monokline wird:

$$
a=8.503, b=34.265, c=8.503, \alpha=90.00, \beta=57.18, \gamma=90.00
$$

Mit dieser Elementarzelle, die so nicht ihrer konventionellen Aufstellung entspricht, läßt sich die Struktur in der Raumgruppe $P 2_{1}$ lösen, wenn auch nicht mit SHELXS [49], sondern lediglich mit SHELXD [74]

Abb. 9.1 zeigt im orthorhombischen $C$-Gitter von $\mathrm{C}_{22} \mathrm{H}_{22} \mathrm{~N}_{4} \mathrm{O}_{6}$ zwei verschiedene aber äquivalente Aufstellungen einer primitiven monoklinen Zelle. Nach den allgemeinen Konventionen ist von zwei möglichen Aufstellungen, bei sonst gleichen Prioritäten, diejenige zu wählen, bei der alle Winkel möglichst nahe an $90^{\circ}$ liegen. Im vorliegenden Fall ist das die folgende Elementarzelle:

\footnotetext{
${ }^{4}$ SHELXD mit folgenden Parametern: FIND 40 PLOP 30456075
} 


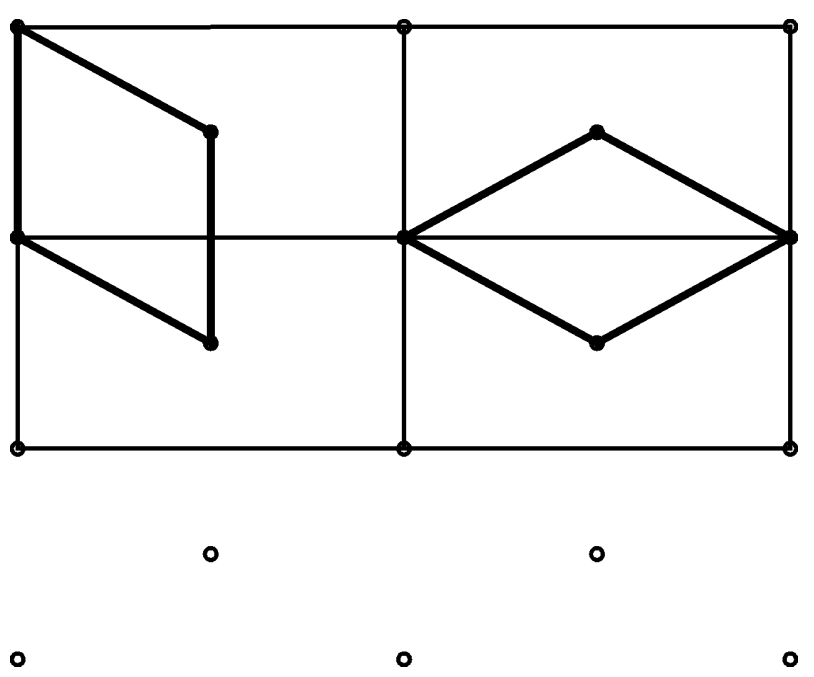

Abb. 9.1: Projektion des Gitters von $\mathrm{C}_{22} \mathrm{H}_{22} \mathrm{~N}_{4} \mathrm{O}_{6}$ entlang der langen Achse. Eingezeichnet sind vier orthorhombisch $C$-zentrierte Zellen, sowie im rechten Teil des Bildes die zuerst gefundene nichtkonventionelle und im linken Teil die konventionelle monokline Elementarzelle.

$$
a=8.138, b=34.265, c=8.503, \alpha=90.00, \beta=118.59, \gamma=90.00
$$

Bei dieser Zelle sind nicht, wie in der unkonventionellen Aufstellung, die beiden Zellkanten $a$ und $b$ gleich lang, sondern die kurze Flächendiagonale ist gleich lang wie $a$. Mit dieser Zelle läßt sich - wiederum nur in SHELXD - eine Lösung in $P 2_{1}$ mit $Z=4$ (also zwei Molekülen in der asymmetrischen Einheit) finden und verfeinern.

Die Verfeinerung verläuft allerdings nicht befriedigend: die Atome lassen sich nicht anisotrop verfeinern und der $R 1$-Wert bleibt bei 30 \%

Der Verdacht auf Verzwillingung bestand ohnehin schon, und tatsächlich weisen die Daten vier der sechs in 9.2 genannten Warnsignale auf, nämlich:

1. $\left|E^{2}-1\right|=0.7022^{6}$

2. Die metrische Symmetrie übersteigt die der Lauegruppe $2 / m$, da die kurze Winkelhalbierende genauso lang ist wie die Zellkante $a$.

3. $R_{\text {int }, \text { mono }}=0.093$ und $R_{\text {int }, \text { ortho }}=0.119$

4. Trotz „gut“ aussehender Daten keine Lösung in SHELXS.

Also wurde eine Zwillingsverfeinerung versucht:

\footnotetext{
${ }^{5} R 1=0.2959$ für $F_{o}>4 \sigma\left(F_{o}\right) ; w R 2=0.6665$ für alle Daten

${ }^{6}$ Der oben genannte Wert von 0.689 kommt bei Berechnung der Statistik im orthorhombischen Kristallsystem zustande
} 


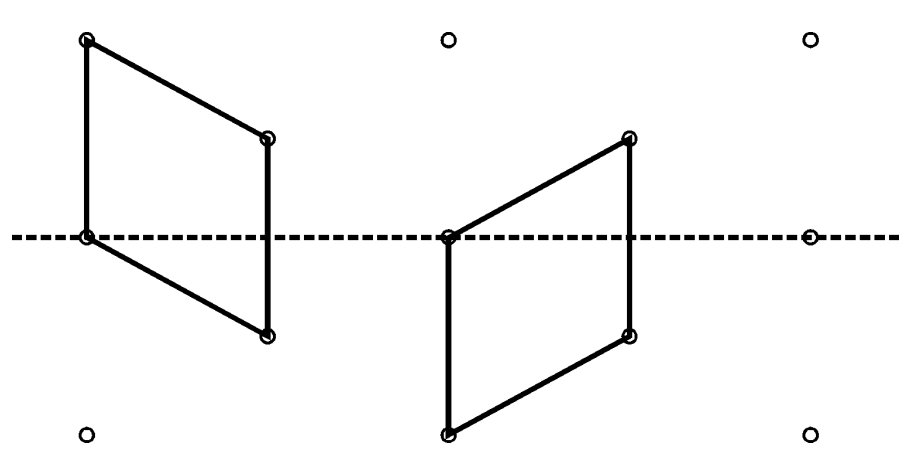

Abb. 9.2: Die beiden Möglichkeiten, die konventionelle monokline Zelle zu orientieren: Rotation um die gestrichelt eingezeichnete Achse überführt die eine in die andere Elementarzelle.

Zum Auffinden des Zwillingsgesetzes muß man verstehen, wie im jeweiligen Fall die selbe Zelle in zwei verschiedenen Orientierungen die selben Gitterpunkte erzeugen kann:

Abb. 9.2 zeigt die beiden möglichen Lagen der konventionellen monoklinen Elementarzelle. Die entsprechende Transformationsmatrix, die zugleich das Zwillingsgesetz darstellt, läßt sich aus der Zeichnung ermitteln und lautet:

$$
\left(\begin{array}{rrr}
-1 & 0 & 0 \\
0 & -1 & 0 \\
1 & 0 & 1
\end{array}\right)
$$

Dies entspricht einer Rotation der Zelle um die ehemalige orthorhombische $b$-Achse (in Abb. 9.2 gestrichelt gezeichnet). Durch diese Rotation entsteht scheinbar neue Symmetrie: Zusätzlich zu der monoklinen Zweizähligkeit sind im räumlichen Mittel zwei weitere senkrecht aufeinander und auf $b$ stehende zweizählige Achsen und darüberhinaus eine $C$ Zentrierung des Gitters entstanden. Aus $P 2_{1}$ wird so scheinbar $C 222_{1}$; es handelt sich bei $\mathrm{C}_{22} \mathrm{H}_{22} \mathrm{~N}_{4} \mathrm{O}_{6}$ mithin um eine typische pseudo-meroedrische Verzwillingung.

Wenn das Zwillingsgesetz einmal gefunden ist, bereitet die Umsetzung in der Verfeinerung keine Probleme mehr: In die .ins-Datei wurden folgende Zeilen eingefügt:

TWIN -1 $0000-10101$

BASF 0.6

Durch diese Veränderung verbesserte sich die gesamte Verfeinerung schlagartig: Der BASF verfeinerte sich auf $0.570(2)$, der $R 1$-Wert sank bei sonst unverändertem Modell auf $12.3 \% \rrbracket$, und es war möglich, alle Atome nach und nach anisotrop zu verfeinern. Aller-

${ }^{7} R 1=0.1227$ für $F_{o}>4 \sigma\left(F_{o}\right) ; w R 2=0.3093$ für alle Daten 


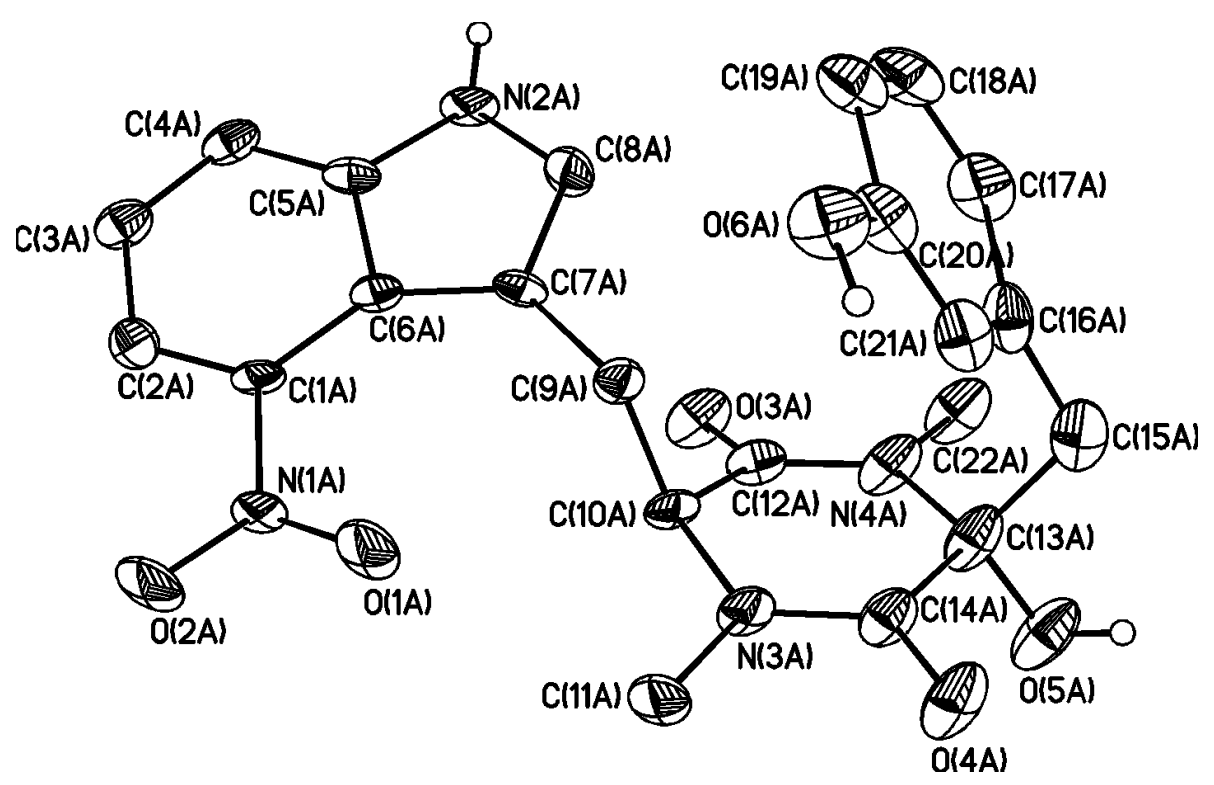

Abb. 9.3: Kristallstruktur von $\mathrm{C}_{22} \mathrm{H}_{22} \mathrm{~N}_{4} \mathrm{O}_{6}$ mit $50 \%$ Auslenkungsellipsoiden. Gezeigt ist eines der beiden Moleküle der asymmetrischen Einheit.

dings waren zunächst relativ strenge SIMU, DELU und ISOR restraints (vgl. 7.2.1.4, Seite 76) nötig, um die anisotropen Auslenkungsparameter positiv definiert zu halten. Nach mehreren Zyklen und dem Setzen aller Wasserstoffatome konnten SIMU und DELU auf ihre default Standardabweichungen zurückgesetzt und ISOR ganz entfernt werden. Zusätzlich wurden die beiden unabhängigen Moleküle der asymmetrischen Einheit mit Hilfe des SAME-Befehls (vgl. 7.2.1.4, Seite 76) hinsichtlich Bindungslängen und -winkeln einander angeglichen.

Die abschließenden Gütekriterien lauten wie folgt: $R 1=0.0550$ für $I>2 \sigma(I) ; w R 2=$ 0.1423 für alle Daten. Der GooF berechnet sich bei angepaßtem Gewichtungsschema auf $s=1.108$. Abb. 9.3 zeigt die Kristallstruktur von $\mathrm{C}_{22} \mathrm{H}_{22} \mathrm{~N}_{4} \mathrm{O}_{6}$ nach Abschluß der Verfeinerung.

Abb. 9.4 zeigt zwei verschiedene least-squares fits der beiden unabhängigen Moleküle einer asymmetrischen Einheit. In Abb. 9.4a wurde der aromatische Teile der Moleküle aufeinander abgebildet, in Abb. 9.4 b der andere. Wie man sieht, ist die Überlappung nahezu perfekt; die beiden Teile der Moleküle sind lediglich durch Rotation um zwei Bindungen (und zwar die Bindungen $\mathrm{C}(7)-\mathrm{C}(9)$ und $\mathrm{C}(9)-\mathrm{C}(10)$; vgl. Abbildung 9.3) zueinander verkippt.

In der Einleitung dieses Kapitels wurde behauptet, Verzwillingung habe häufig einen kristallographischen Grund (vgl. Seite 98). Hier kann dieser Grund in der Anordnung der beiden unabhängigen Moleküle in der asymmetrischen Einheit vermutet werden: Die 

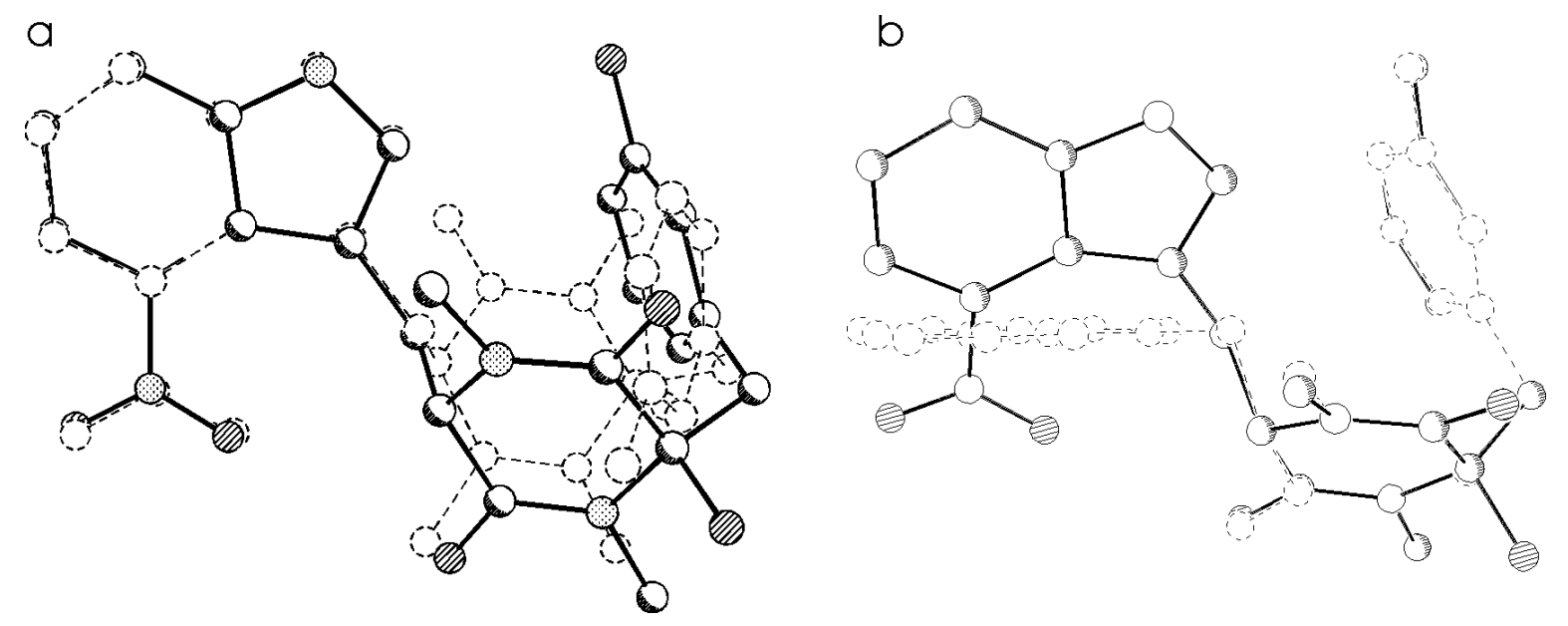

Abb. 9.4: Zwei least-squares fits der beiden unabhängigen Moleküle der asymmetrischen Einheit, wobei jeweils unterschiedliche Bereiche aufeinander abgebildet wurden.

beiden Moleküle lagern sich zu einem Gebilde zusammen, das eine höhere Symmetrie besitzt als ein einzelnes Molekül, nämlich eine Pseudo-Zweizähligkeit. Falls diese PseudoC2-Achse zugleich die Zwillingsachse ist (also die Achse, um die bei der Ausführung von Matrix 9.10 gedreht wird), wäre das Zustandekommen der Verzwillingung erklärt.

Abb. 9.5 zeigt die beiden unabhängigen Moleküle der asymmetrischen Einheit in der Elementarzelle (Projektion entlang der b-Achse); gestrichelt eingezeichnet ist die PseudoRotationsachse.

Wie in Abb. 9.5 zu sehen ist, verläuft die Pseudo-Drehachse exakt kollinear zu der Zwillingsachse, wie sie in Abb. 9.2 eingezeichnet ist. Damit ist ein kristallographischer Grund für die Verzwillingung gefunden. 


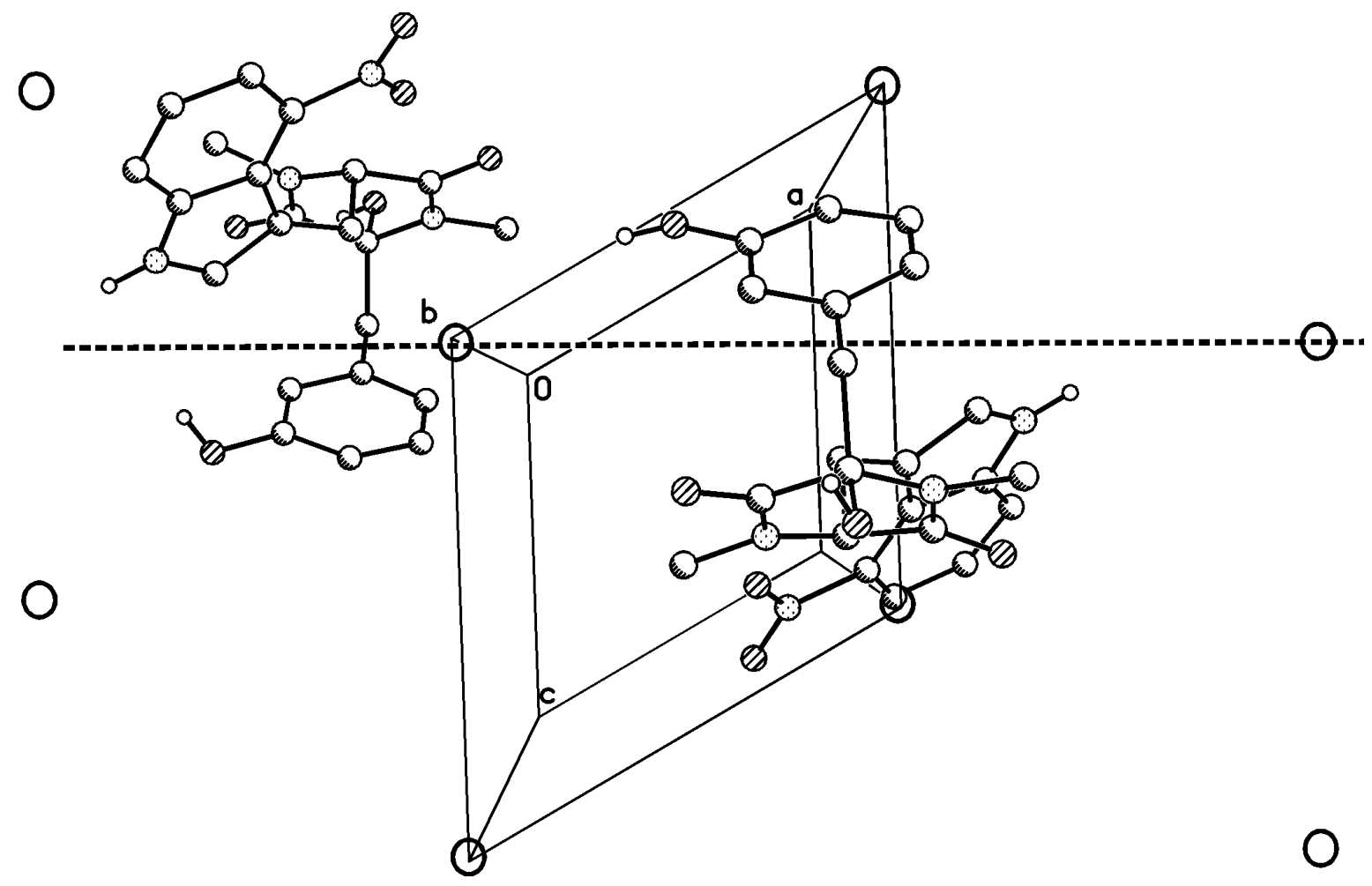

Abb. 9.5: Kristallstruktur von $\mathrm{C}_{22} \mathrm{H}_{22} \mathrm{~N}_{4} \mathrm{O}_{6}$. Darstellung beider Moleküle der asymmetrischen Einheit mit dazu versetzter Elementarzelle und eingezeichneter Pseudosymmetrieachse. 


\section{7 $\mathrm{CoNH}_{4} \mathrm{PO}_{4} \cdot 6 \mathrm{H}_{2} \mathrm{O}$ : ein Beispiel für Racemische Verzwillingung}

Bei der Kristallisation des Schwefel-Eisen-Proteins FhuF (siehe 2.3, Seite 7) wurden im Rahmen eines sparse-matrix-Screenings (siehe 2.2.2, Seite 5 und 2.3.3, Seite 12] zwar relativ kleine aber sehr gut streuende Kristalle von rosa-bräunlicher Farbe erhalten, die sich als $\mathrm{CoNH}_{4} \mathrm{PO}_{4} \cdot 6 \mathrm{H}_{2} \mathrm{O}$ herausstellten (vgl. 2.3.3, Seite 14).

$\mathrm{CoNH}_{4} \mathrm{PO}_{4} \cdot 6 \mathrm{H}_{2} \mathrm{O}$ kristallisiert in der orthorhombischen Raumgruppe Pmn $2_{1}$ mit einer halben Formeleinheit in der asymmetrischen Einheit, der Rest wird durch den kristallographischen Spiegel erzeugt. Das Co-Atom, zwei der koordinierten Wasser-O-Atome $(\mathrm{O}(1)$ und $\mathrm{O}(4))$, das P-Atom, zwei der Phosphat-O-Atome $(\mathrm{O}(11)$ und $\mathrm{O}(12))$ und das Ammonium-Ion liegen dabei auf dem Spiegel (Wyckoff a). Die Moleküle sind im Kristallgitter durch ein dichtes Netz von zehn kristallographisch unabhängigen Wasserstoffbrücken verbunden.

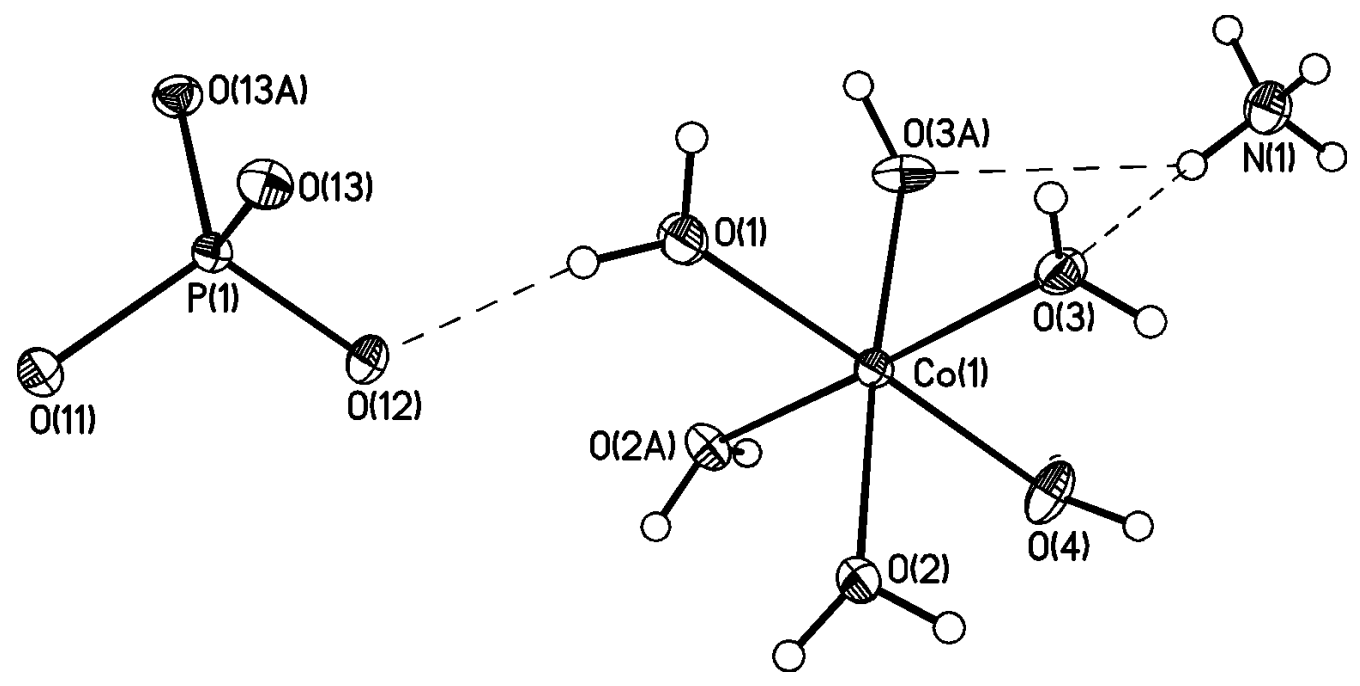

Abb. 9.6: Kristallstruktur von $\mathrm{CoNH}_{4} \mathrm{PO}_{4} \cdot 6 \mathrm{H}_{2} \mathrm{O}$ mit drei eingezeichneten Wasserstoffbrücken.

Abgesehen von den Schwierigkeiten bei der Frage, ob es sich um ein Sulfat- oder ein Phosphation handelt (siehe 6.2 auf Seite 65), verlief die Verfeinerung der Struktur völlig problemlos. Lediglich der Wert des Flack-Parameters [68 war mit $x=0.08(1)$ leicht auffällig. Der Wert war nahe genug an Null, um mit großer Sicherheit für die richtige absolute Konformation zu sprechen, aber doch signifikant größer Null, so daß gering ausgeprägte racemische Verzwillingung vermutet wurde.

Verfeinerung mit TWIN / BASF 0.2 verbesserte den $R 1$-Wert leicht von $1.64 \%$ auf $1.56 \%$; der BASF verfeinerte sich am Ende der Strukturverfeinerung auf 0.12(1), was einer Ver- 
zwillingungsrate von etwa 8:1 entspricht. Die abschließenden Gütekriterien der Verfeinerung ergaben sich zu: $R 1=0.0147$ für $F_{o}>4 \sigma\left(F_{o}\right) ; w R 2=0.0393$, GooF $=1.104$ für alle Daten. Höchstes Restelektronendichtemaximum: 0.23; niedrigste Elektronensenke: -0.31.

Diese racemische Verzwillingung ist ein Grenzfall: Der Flack- $x$-Parameter soll innerhalb von drei Standardabweichungen Null betragen. Zwar betrug im vorliegenden Fall der Flack-Parameter vor der TWIN-Verfeinerung das achtfache seiner Standardabweichung, so daß er als signifikant erhöht bezeichnet werden kann, sein absoluter Wert war mit 0.08(1) jedoch sehr klein. Es kann nicht ausgeschlossen werden, daß andere Effekte als racemische Verzwillingung zu dieser leichten Erhöhung des Flack-Parameters geführt haben, die jetzt über den Umweg der Zwillingsverfeinerung scheinbar korrigiert werden. 


\section{Kapitel 10}

\section{Artefakte}

Als Artefakte werden methodenimmanent unvermeidbare Fehler in der Röntgenstrukturanalyse bezeichnet. Dazu gehören Kettenabbruchfehler (scheinbare Restelektronendichtemaxima, die durch Abbruch der Fourier-Synthese entstehen und bevorzugt auf speziellen Lagen auftauchen) oder aufgrund von Libration円 zu kurz erscheinende WasserstoffSchweratom-Abstände. Auch C-C-Dreifachbindungen werden oft zu kurz bestimmt, da die relativ hohe Elektronendichte der Mehrfachbindungen zwischen den Kohlenstoffatomen diese scheinbar zusammenrücken läßt.

Der Begriff Artefakt wird in der Kristallographie häufig überstrapaziert und nicht selten als Erklärung oder Entschuldigung für vermeidbare Fehler bemüht. Einige solcher vermeidbaren Fehler sind:

1. Falsche Elementarzelldimensionen,

2. Zwilling als Fehlordnung behandelt,

3. Atomsorte(n) falsch bestimmt,

4. Raumgruppe falsch bestimmt,

5. Fourier Abbruchkanten mit H-Atomen verwechselt oder umgekehrt.

Roland Boese unterscheidet in diesem Zusammenhang zwischen vermeidbaren und „wirklich vermeidbaren Fehlern" [34]. Für letztere gibt er folgende Beispiele:

\footnotetext{
1 Librationseffekte lassen sich durch Tieftemperaturdatensammlung minimieren. Vergleiche hierzu auch 4.7 auf Seite 38.
} 
1. Tippfehler bei Zelldimensionen

2. Dejustage des Diffraktometers (falsche Nullpunkte usw.),

3. Strategiefehler bei Datensammlung, Datenreduktion und Verfeinerung,

4. Raumtemperaturmessungen.

Im folgenden zwei Fälle von Artefakten aus der eigenen Praxis:

\subsection{Fourier-Abbruchfehler in $\mathrm{C}_{30} \mathbf{H}_{47} \mathbf{N}_{9} \mathrm{Zr}_{5}$}

Die $\mathrm{Zr}(\mathrm{IV})$-Verbindung $\mathrm{C}_{30} \mathrm{H}_{47} \mathrm{~N}_{9} \mathrm{Zr}_{5}$ kristallisiert aus Toluol in Form grüner rhombischer Prismen in der tetragonalen Raumgruppe I4 mit einem Viertel Molekül in der asymmetrischen Einheit. Der Rest des Moleküls wird durch die vierzählige Achse erzeugt. Der Kern der Struktur besteht aus einer tetragonalen Pyramide, deren Ecken mit Zr-Atomen besetzt sind. Die vier Seitenflächen der Pyramide sind mit NH-Einheiten, die vier Kanten der Basis mit $\mathrm{NH}_{2}$-Einheiten überbrückt. Im Zentrum der Basisfläche der $\mathrm{Zr}_{5}$-Pyramide befindet sich ein N-Atom. Diese drei Stickstoffspezies können formal als $\mathrm{NH}_{2}^{-}-, \mathrm{NH}^{2-}$ - und $\mathrm{N}^{3-}$-Ionen verstanden werden. Die Koordinationssphäre jedes Zr-Atoms wird durch einen CpMe-Liganden vervollständigt.

Nach Abschluß der Verfeinerung fanden sich vier signifikante Maxima in der Differenzfouriersynthese. Die höchsten drei sind in unmittelbarer Nähe von Zr-Atomen zu finden, was eine Interpretation als Absorptionseffekt nahelegt. Das vierte Restelektronendichtemaximum mit $0.91 e^{-} / \AA^{3}$ jedoch befindet sich auf der Vierzähligen Achse genau gegenüber der Position von $\operatorname{Zr}(2)$ (siehe Abb. 10.1). I $^{2}$ Dies ist ein typischer Fall von Anhäufung scheinbarer Elektronendichte auf speziellen Lagen, ein Artefakt also.

Wäre die Position Q(4) mit einem weiteren Zr-Atom besetzt, würde sich die Symmetrie der Verbindung erhöhen: aus der $\mathrm{Zr}_{5}$-Pyramide würde ein $\mathrm{Zr}_{6}$-Oktaeder mit Spiegelebene senkrecht zur C4-Achse. Die Raumgruppe würde sich dementsprechend zu $I 4 / m$ ändern.

Eine ausführliche Beschreibung der Struktur findet sich in [75].

\begin{tabular}{llll}
\hline \multicolumn{3}{c}{ Koordinaten: } & \\
$\mathrm{Q}(4):$ & 0.0000 & 0.0000 & -0.7267 \\
$\mathrm{~N}(3):$ & 0.0000 & 0.0000 & -0.4925 \\
$\mathrm{Zr}(2):$ & 0.0000 & 0.0000 & -0.2604
\end{tabular}




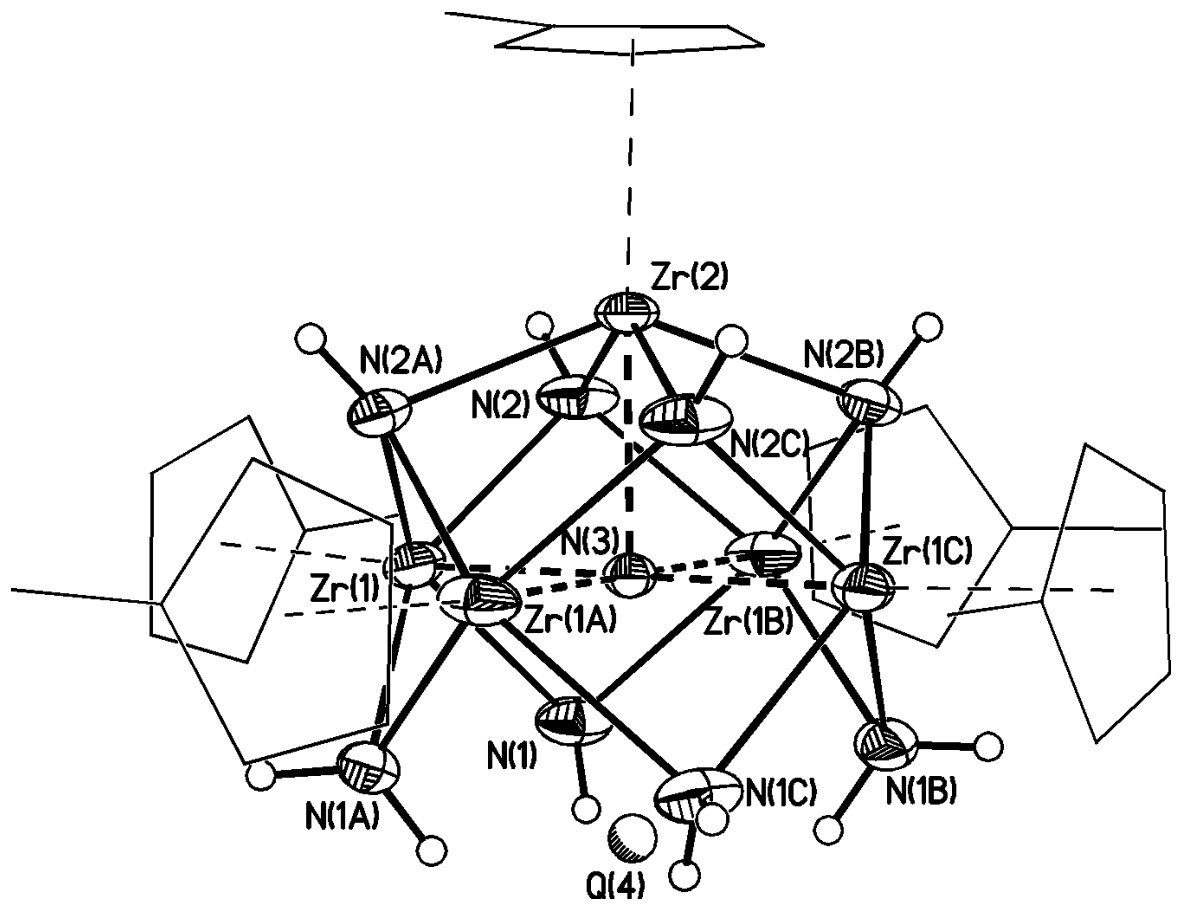

Abb. 10.1: Restelektronendichtemaximum Q(4) auf spezieller Lage in der Kristallstruktur von [( $\eta^{5}$ $\left.\left.\mathrm{C}_{5} \mathrm{H}_{4} \mathrm{Me}\right)_{2} \mathrm{Ti}(\mu-\mathrm{F})_{2} \mathrm{AlEt}_{2}\right]_{2}$ mit $50 \%$ Ellipsoiden für Zr- und N-Atome; die Kohlenstoffatome der CpMeLiganden sind der Übersichtlichkeit halber als durch Striche verbundene Punkte dargestellt.

\subsection{Hohes Restelektronendichtemaximum bei den Gruppe-13-Iminosilikaten}

Die in Kapitel [7 bereits zweimal erwähnte Substanzklasse der Gruppe-13-Iminosilikate [56] (7.3 und 7.4) zeigt in drei der untersuchten acht Strukturen vier relativ hohe Restelektronendichtemaxima, die sich signifikant vom Grundrauschen abheben und deren Höhe mit der Kernladungszahl des Gruppe-13-Metalls steigt. Das stärkste Restelektronendichtemaximum ist immer in der Nähe des exozyklischen Siliziumatoms anzutreffen (siehe Abbildung 10.2).

In der Hoffnung, die Restelektronendichtemaxima träten unter anderen Kristallisationsbedingungen nicht auf, wurde von dem methylierten In-Käfig, bei dem die Artefakte am stärksten in Erscheinung treten, ein aus Dichlormethan umkristallisierter Einkristall geröntgt. Der so gewonnene Datensatz führte aber zu Restelektronendichte in ähnlicher Höhe und an den selben Stellen. Immerhin können damit Lösungsmitteleffekte ausgeschlossen werden.

Dagegen scheint das Auftreten der Restelektronendichte raumgruppenabhängig zu sein: Die drei Strukturen, die die beschriebenen Restelektronendichtemaxima zeigen, sind die 


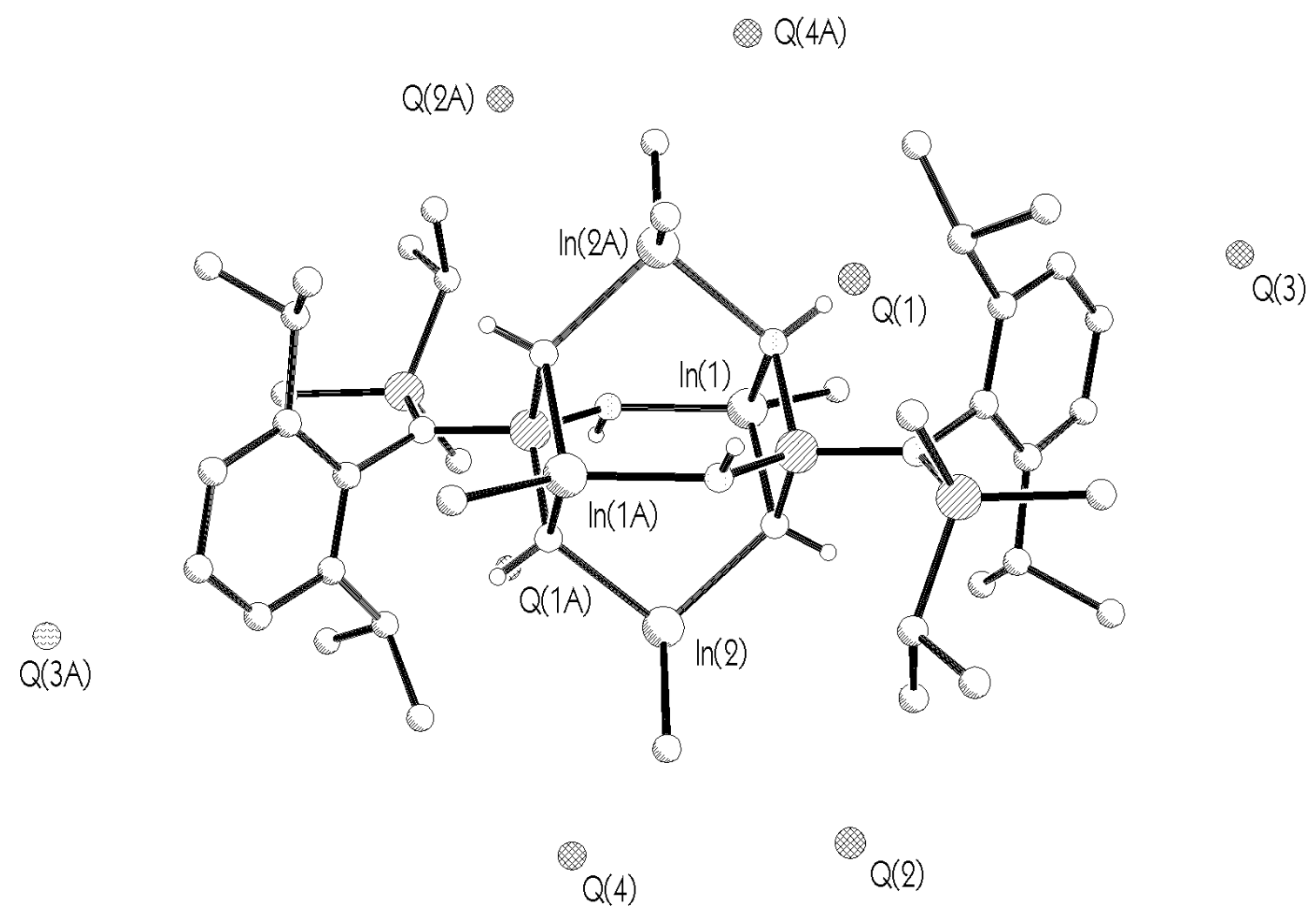

Abb. 10.2: Lage der vier höchsten Restelektronendichtemaxima des Me-In-Iminosilikats.

einzigen in der triklinen Raumgruppe $P \overline{1}$; alle anderen untersuchten Moleküle dieser Substanzklasse kristallisieren in monoklinen Raumgruppen. Versuche, die hohe Restelektronendichte als Fehlordnung oder Teilbesetzung zu interpretieren, schlugen jedoch fehl.

Da sich trotz intensiver Suche kein Grund für das Auftreten der hohen Restelektronendichtemaxima finden ließ, das Modell die betreffenden Strukturen jedoch gut beschreibt, wie sich an der gleichmäßigen Form der Schwingungsellipsoide und den relativ guten $R$ Werten zeigt!, muß der Effekt als zumindest zunächst unerklärbar hingenommen werden. Es scheint sich um einen nicht vermeidbaren Fehler der Methode zu handeln; mithin ist obige Definition des Artefakts erfüllt.

\footnotetext{
${ }^{3}$ Für den Me-In-Käfig: $R 1=0.0414$ für $I>2 \sigma(I) ; w R 2=0.1065$ für alle Daten.
} 


\section{Kapitel 11}

\section{Proteinkristallographie}

Die Proteinkristallographie hat sich in den letzten zehn bis 15 Jahren von einer exotischen Methode für mathematikbegeisterte Biologen bzw. für Kristallographen mit Hang zu unlösbaren Aufgaben zu der wichtigsten Strukturaufklärungsmethode für biologische Moleküle überhaupt entwickelt. Auch innerhalb der Kristallographie nimmt die Proteinstrukturaufklärung heute eine wichtige Stellung ein: Zwar werden immer noch erheblich mehr Kleinmolekülstrukturen pro Jahr bestimmt als Strukturen biologischer Moleküle, die Anzahl der Kristallographen, die sich vornehmlich oder ausschließlich mit Proteinen beschäftigen, dürfte aber inzwischen die Zahl der Kleinmolekülkristallographen übersteigen.

So gut wie alle Probleme, die aus der Kleinmolekülkristallographie bekannt sind, treten bei Proteinen ebenfalls auf, nur meistens unter ungünstigeren Umständen. Diese Umstände sind direkt oder indirekt Folge der relativ schlechten Auflösung der meisten Proteinstrukturen, die die Verfeinerung häufig schwierig gestalten.

Allerdings ist die Fragestellung der Proteinkristallographie im allgemeinen eine andere, als man sie von den kleinen Molekülen kennt: Im Wesentlichen geht es um den Zusammenhang zwischen Struktur und Funktion. Ziel ist es, die Wirkungsweise eines Enzyms oder Inhibitors zu erforschen und nicht, die exakte Länge der Peptidbindung oder die Konstitution der Aminosäuren zu ergründen.

Diese relativ unkristallographische Fragestellung verleitet leider häufig auch zu unkristallographischer Vorgehensweise bei der Proteinstrukturbestimmung. Die Tatsache, daß sich viele Proteinkristallographen mit Kristallographie nur soweit beschäftigen, wie es unbedingt nötig ist, verschärft dieses Problem. 
Der Schwerpunkt der vorliegenden Arbeit liegt klar auf dem Gebiet der Kleinmolekülkristallographie. Dennoch sollen einige typische Proteinprobleme nicht unerwähnt bleiben.

\subsection{Proteinstrukturen mit SHELXL}

Das Verfeinerungsprogramm SHELXL [3] war in seiner ursprünglichen Konzeption nicht für die Verfeinerung von Proteinstrukturen ausgelegt. Die aktuelle Version (SHELXL97.2) verfügt jedoch über vielfältige proteinspezifische Möglichkeiten [76], wobei ein Protein nach wie vor behandelt wird wie ein besonders großes Kleinmolekül. Da hierbei nur relativ wenige Näherungen gemacht werden, ist SHELXL exakter und - gerade hinsichtlich der Verfeinerung von Fehlordnung und Verzwillingung - flexibler als alle übrigen Proteinverfeinerungsprogramme.

Allerdings ist SHELXL auf ein gutes Daten-zu-Parameter-Verhältnis angewiesen, so daß bei Auflösungen von weniger als 2 bis $2.5 \AA$ andere Programme wie CNS [77] klar überlegen sind. Dies gilt umso mehr, als bei Aufösungen schlechter als $2.5 \AA$ Fehlordnungen und andere Feinheiten ohnehin nicht mehr beobachtbar sind, so daß bei nicht-atomarer Auflösung viele der Vorteile von SHELXL in den Hintergrund treten.

\subsection{Verfeinerung der tetragonalen Form von HEW- Lysozyme}

Am Anfang einer Proteinverfeinerung steht ein Modell, das entweder aus einer der Methoden zur Lösung des Phasenproblems hervorgegangen ist oder - bei bereits bekannten Proteinstrukturen wie Lysozyme - der Datenbank entnommen sein kann. Im vorliegenden Fall wurden drei Modelle aus der PDB versucht, wobei sich 1LZF am besten eignete.

Die Daten wurden aus drei Messungen am multi wire Detektor zusammengestellt und bei 1.1 A geschnitten. Für die ersten beiden Verfeinerungen wurde die Auflösung der Daten allerdings auf den Bereich zwischen 10 und $1.4 \AA$ beschränkt.

Nach 100 Zyklen in SHELXL, bei dem das PDB-Modell 1LZF als starre Gruppe behandelt und noch ohne Wassermoleküle verfeinert wurde, berechneten sich die Gütekriterien wie folgt: $R 1=0.2618$ und $R 1($ free $)=0.3079$ für $F_{o}>4 \sigma\left(F_{o}\right)$. In der Differenzfouriersynthese konnten 69 Maxima gefunden werden, die sich aufgrund der Abstände zu 
Proteinatomen als Wassermoleküle interpretieren ließen. Eines davon war lediglich halb besetzt. Bei der Betrachtung mit XtalView, einem Programm zur Visualisierung und Manipulation von Atomkoordinaten und Elektronendichte [78, wurde ein sog. peptide flip zwischen den Aminosäuren Arg114 und Cys115 erkannt und modelliert.

Das Modell wurde - mit den 68.5 Wassermolekülen - nun nicht weiter als starre Gruppe behandelt, sondern es fanden lediglich die proteintypischen restraints auf 1,2- und 1,3Abstände, Chiralvolumina und Planarität Anwendung. Dies verbesserte die $R$-Werte auf 0.2077 / 0.2582. In XtalView wurde ein weiterer peptide flip gefunden, und zwar zwischen den Aminosäuren Arg73 und Asn74. Außerdem gingen aus der Differenzdichte 28 weitere $\mathrm{H}_{2} \mathrm{O}$-Positionen hervor.

Im dritten Schritt der Verfeinerung wurde von dem Programm SHELXWAT [3] - jetzt bei voller Auflösung - in zehn Iterationen die Liste der Wassermoleküle automatisch auf 136.5 erweitert, was die $R$-Werte schrittweise auf $0.1982 / 0.2352$ verbesserte. Mit der Hilfe von XtalView wurden die Seitenketten von Lys12, Arg14, Asp18, Arg61, Arg73, Asn77, Ser86, Lys96, Lys97, Val99, Asn103, Gly121, Arg128 und Leu129 neu modelliert. Zusätzlich wurde eine Fehlordung der Seitenkette von Ser85 einbezogen und die Liste der Wassermoleküle auf 146.5 erweitert.

Nach weiteren 100 Zyklen hatten sich die $R$-Werte auf 0.1962 / 0.2276 verbessert. Es wurden keine neuen $\mathrm{H}_{2} \mathrm{O}$-Moleküle gefunden, aber eine Fehlordnung in Arg14 und eine neue Lage der Isopropylgruppe des Val99 modelliert.

In den folgenden Zyklen wurden alle Schwefelatome anisotrop verfeinert. Dies und die oben genannten Änderungen hatten ein Absinken der $R$-Werte auf 0.1895 / 0.2217 zur Folge. Es wurden acht neue Wasserpositionen gefunden, in XtalView wurden Fehlordnungen der Seitenketten von Arg45, Asn46 und Asn77 modelliert. Auffällig war die Position des höchsten Restelektronendichtemaximums Q(1): Für ein $\mathrm{H}_{2} \mathrm{O}$-Molekül waren die Abstände zu benachbarten Wasser- und Proteinatomen zu gering, zudem ließ die nur leicht verzerrt oktaedrische Koordination von ausschließlich Sauerstoffatomen eher an ein Kation wie $\mathrm{Na}^{+}$denken. Berechnungen mit der Bond-Valence-Methode bestätigten diese Vermutung (vgl. 11.3). Q(1) wurde zu Na(1) umbenannt.

Die oktaedrische Koordination wird geometrisch erst durch den genannten peptide flip Arg73-Asn74 möglich. Die Kristalle, die der Verfeinerung des Modells 1LZF zugrunde lagen, waren in Abwesenheit von Natrium gezüchtet worden, so daß der Verdacht nahe liegt, daß An- oder Abwesenheit von $\mathrm{Na}^{+}$die Modifikation von Lysozyme an den Aminosäuren Arg73 / Asn74 zu bestimmen in der Lage ist. Näheres zu dieser Überlegung unter 11.3 . 
Nach der Verfeinerung betrugen die $R$-Werte 0.1871 / 0.2218. Es konnten sechs neue Wassermoleküle gefunden werden; außerdem wurden Fehlordnungen der Seitenketten für Arg61, Arg73, Val109, Arg125 und Leu129 modelliert.

Die Verfeinerung ergab nur geringe Verbesserung des $R 1$ auf 0.1853 und sogar eine leichte Verschlechterung des $R 1$ (free) auf 0.2250 . Vier neue $\mathrm{H}_{2} \mathrm{O}$ wurden gefunden und die Fehlordnung von Leu129 wieder entfernt, dafür wurde eine Fehlordnung der Seitenkette von Asp18 modelliert.

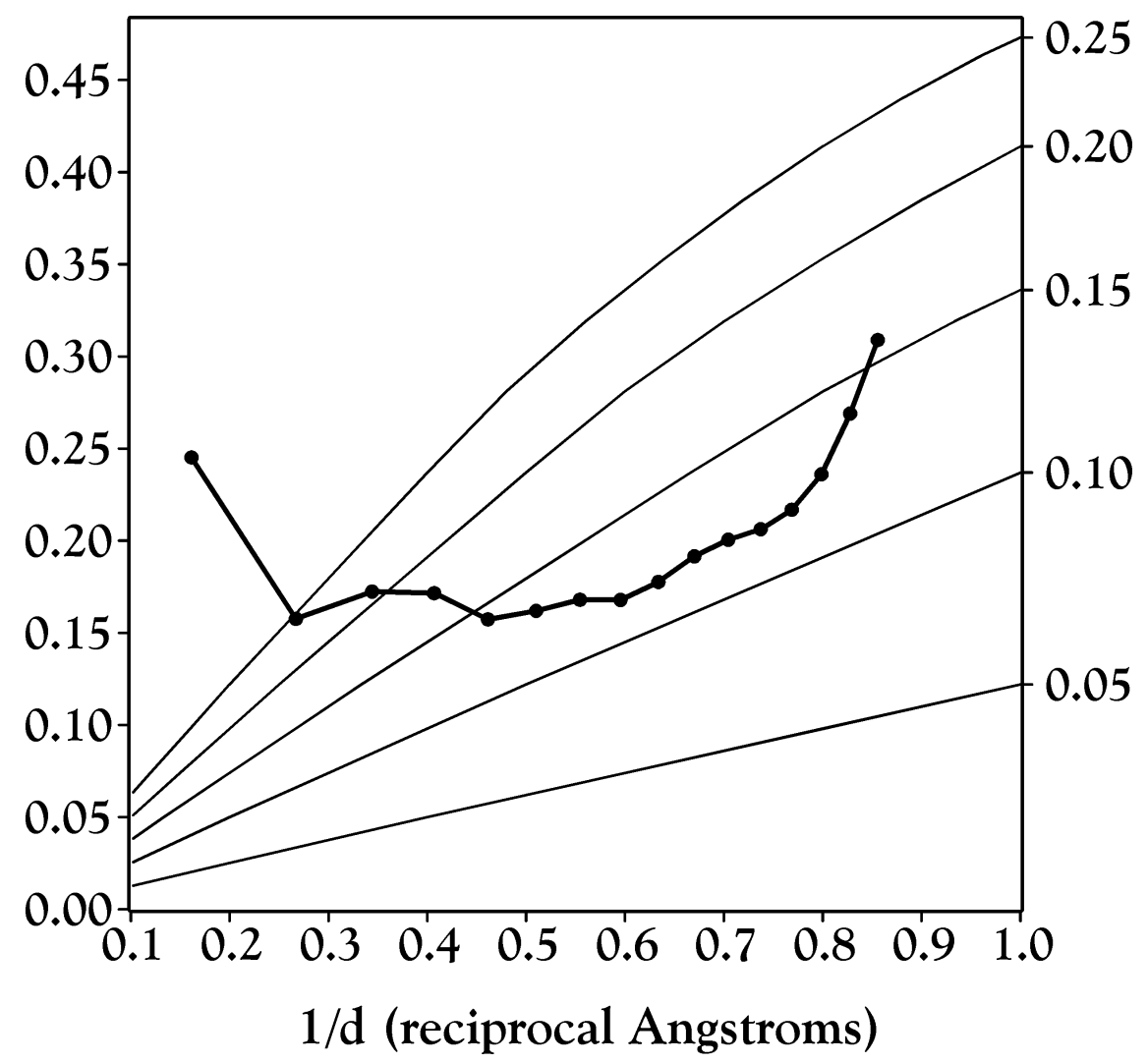

Abb. 11.1: Luzzati-Plot der Verfeinerung von Lysozyme. Es wird ersichtlich, daß die Daten ab etwa $0.8 \AA^{-1}$ (entspricht einer Auflösung von $1.2 \AA$ ) zu wenig Information enthalten, als daß gegen sie verfeinert werden sollte.

Mit 0.1839 / 0.2207 haben sich beide $R$-Werte weiter verbessert, auch der $R 1$ (free) hat seinen Abstand zum $R 1$ wieder verringert. Es ist zu vermuten, daß die explizite Modellierung der Fehlordnung der N-terminalen Aminosäure Leu129 zu einer Überinterpretation der Daten geführt hatte. Die Fehlordnung von Asp18 wurde ebenfalls wieder entfernt, allerdings unter Erhalt der zweiten Lage. Außerdem wurden drei neue $\mathrm{H}_{2} \mathrm{O}$ Moleküle gefunden. Der Luzzati-Plot [79] (siehe Abb. 11.1) legt eine Begrenzung der Auflösung auf $1.20 \AA$ nahe. 
Mit den geschnittenen Daten wurden die folgenden $R$-Werte erhalten: $R 1=0.1800$ und $R 1$ (free) $=0.2195$. Zwei Wasserpositionen wurden verworfen, und der neue Luzzati-Plot legt Schneiden der Auflösung bei $1.3 \AA$ nahe.

Erneutes Reduzieren der Auflösung führte zu $R$-Werten von 0.1763 / 0.2193. Außerdem wurde eine neue $\mathrm{H}_{2} \mathrm{O}$-Position gefunden.

Das Mitteln von Daten aus verschiedenen Messungen verursacht aufgrund der Tatsache, daß es keine zwei wirklich identischen Kristalle gibt, immer einen Fehler. Gleichzeitig jedoch verbessert sich die Qualität des Datensatzes hinsichtlich Vollständigkeit (falls möglich) und durch Redundanz auch in seiner Exaktheit. Zwei der drei Datensätze, die zur Verfeinerung bis zu diesem Stadium herangezogen worden waren, zeichnen sich durch relativ hohe Auflösung, aber sonst geringe Datenqualität aus. Der dritte Datensatz reicht nur bis $1.30 \AA$ ist aber insgesamt viel besser.

Da die Daten ohnehin bei $1.30 \AA$ geschnitten werden mußten - die gute Auflösung der beiden anderen Datensätze ist offensichtlich nur eine scheinbare - gibt es keinen Grund, weiterhin den zusammengefaßten Datensatz zu verwenden.

Verfeinerung gegen die neuen, nicht zusammengefaßten Daten des dritten untersuchten Kristalls ergab eine Verbesserung der Gütekriterien: $R 1=0.1717$ und $R 1$ (free) $=0.2161$. Die Liste der Wassermoleküle wurde auf 169.5 erweitert.

Im letzten Schritt wurden alle Wasserstoffatome an geometrisch berechnete Positionen gesetzt. Die abschließenden Gütekriterien lauten: $R 1=0.1664$ und $R 1$ (free) $=0.2071$ $F_{o}>4 \sigma\left(F_{o}\right)$ und $R 1=0.1849$ und $R 1($ free $)=0.2282$ für alle Daten.

Der Gang der Verfeinerung läßt sich zusätzlich in Abb. 11.2 und in Tab. 11.1 nachvollziehen. 


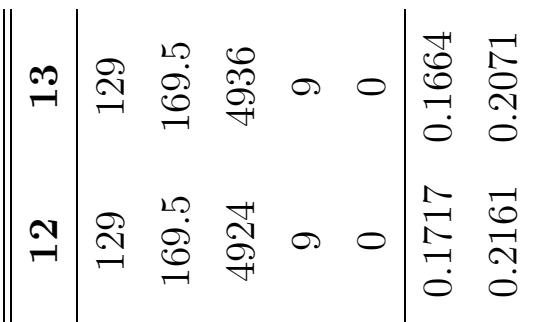

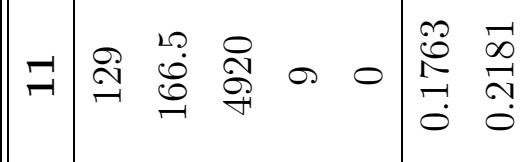

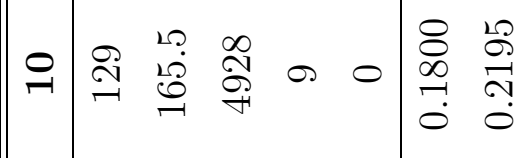

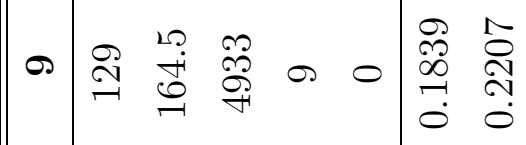

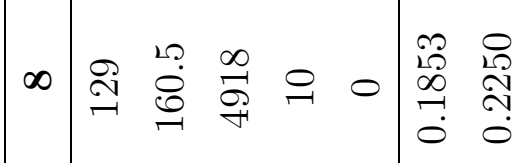

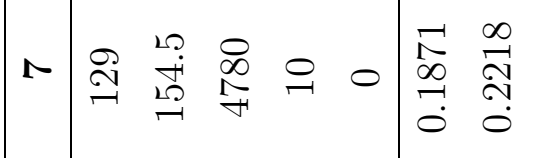

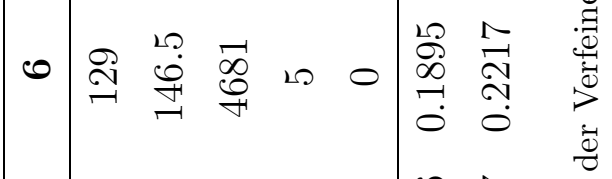

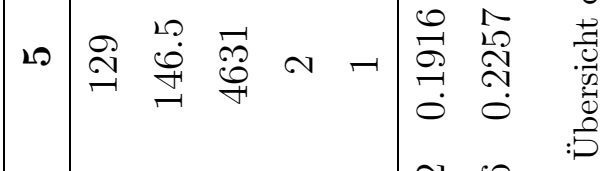

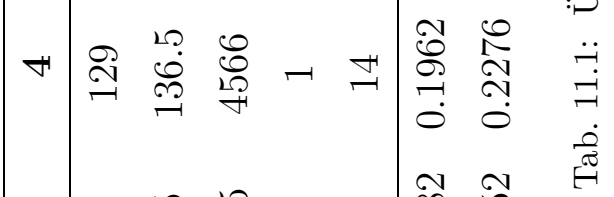

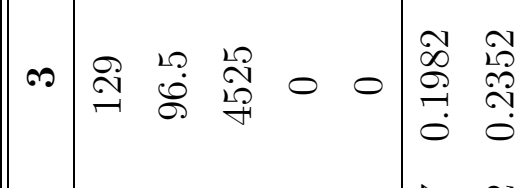

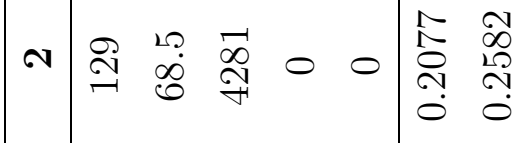

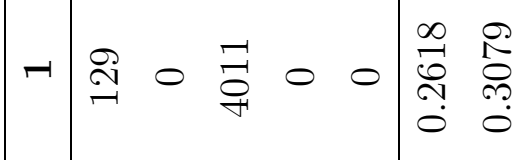

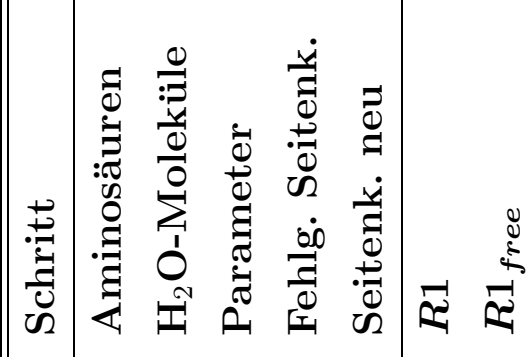




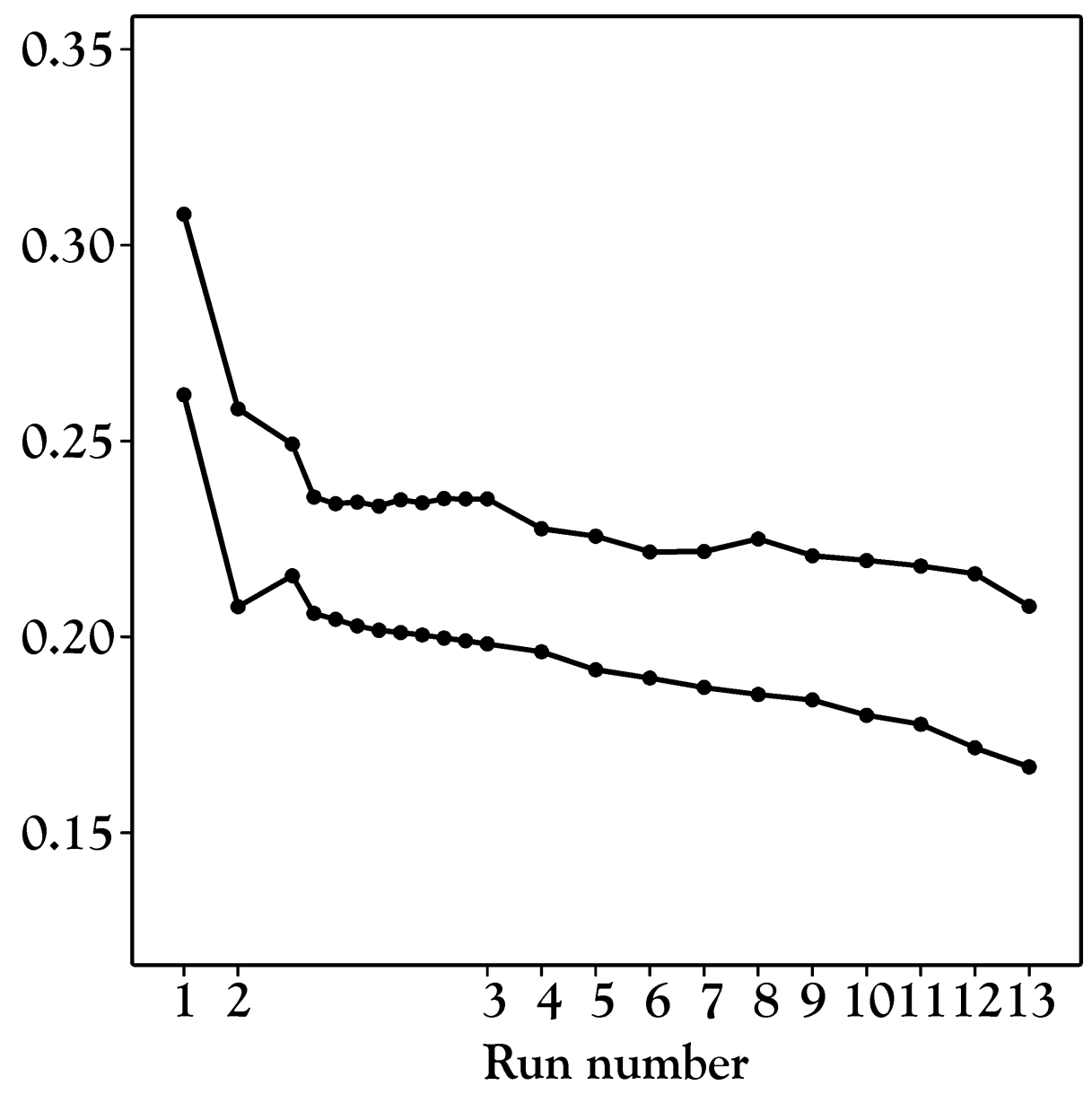

Abb. 11.2: Gang der Verfeinerung von Lysozyme. Aufgetragen sind $R 1$ (untere Kurve) und $R 1$ (free) (obere Kurve) gegen die laufende Nummer der Verfeinerunsschritte.

Das abschließende Modell dieser Verfeinerung wurde ausführlich kommentiert und steht zusammen mit dem Datensatz als Standard-Verfeinerung für tetragonales HEW-Lysozyme mit Natrium im Internet zur Verfügung.'T Diese Datei ermöglicht es, einen beispielsweise zu Test- oder Ausbildungszwecken gemessenen Datensatz durch eine Verfeinerung schnell zu überprüfen, ohne daß aufwendige Suchen nach einem Modell in Datenbanken oder eine eigene Lösung des Phasenproblems nötig wären.

Entsprechend wurde diese Datei beim Vergleich der verschiedenen Diffraktometer den Verfeinerungen zugrunde gelegt (vgl. 5.3, Seite 54).

\footnotetext{
${ }^{1}$ http://shelx.uni-ac.gwdg.de/shelx97/tutor/lyso-tet.tgz
} 


\subsection{Wasser oder Ion? Die Bond-Valence-Methode für Biologen}

In Proteinstrukturen finden sich so gut wie immer zahlreiche Restelektronendichtemaxima, die zwanglos als Wassermoleküle interpretiert und damit als Sauerstoffatome verfeinert werden können. Einige Programme (wie z. B. SHELXWAT) erlauben sogar, Restelektronendichtemaxima, die einen gewissen Mindestabstand zu allen anderen Atomen nicht unterschreiten, automatisch als Wasser in das Modell aufzunehmen. Trotzdem müssen nicht alle dieser Positionen notwendigerweise von Sauerstoffatomen besetzt sein. Es kommt häufig vor, daß Ionen wie $\mathrm{Cl}^{-}, \mathrm{Na}^{+}, \mathrm{K}^{+}, \mathrm{Ca}^{2+}$ in Proteinkristalle eingebettet sind.

Eine Möglichkeit, einige dieser Ionen zu identifizieren, bietet die Bond-Valence-Methode: Ausgehend von einer Theorie von L. Pauling [80], nach der sich die Bindungsordnungen aller von einem Ion ausgehenden Bindungen zu seiner Oxidations- bzw. Ladungszahl addieren, ermittelten Brese und O'Keeffe Listen von Standardbindungslängen, nach denen man Bindungsordnungen bzw. Ladungszahlen berechnen kann [81, 82]:

$$
\begin{gathered}
V_{i j}=\sum_{i} s_{i j} \\
s_{i j}=\exp \left[\frac{d_{0}-d_{i j}}{0.37 \AA}\right]
\end{gathered}
$$

Hierbei ist $V_{i j}$ die Valenzsumme und damit die Wertigkeit bzw. Ladungs- oder Oxidationszahl eines Atoms; $s_{i j}$ ist die Ordnung einer Bindung (z. B. 1.0 für eine perfekte Einfachbindung, 2.0 für eine perfekte Doppelbindung, 1.5 für die C-C-Bindungen in Benzol usw.). $d_{0}$ ist der theoretische Abstand einer Einfachbindung zwischen den Atomen $i$ und $j ; d_{i j}$ ist die gefundene Bindungslänge. Die Abstände sind in $\AA$ anzugeben. Die $d_{0^{-}}$Werte für sehr viele Atompaare sind den oben genannten Arbeiten von Brese und O'Keeffe zu entnehmen.

Scheinbare Wasserpositionen in hochaufgelösten Proteinstrukturen, die auffällig sind, weil sie z. B. relativ dicht an einigen Seitenkettenatomen des Proteins liegen oder weil ihre B-Werte sehr klein sind, können mit Hilfe der Bond-Valence-Methode getestet werden. Genauso können falsch zugeordnete Metallionen (beispielsweise $\mathrm{Na}^{+}$statt $\mathrm{Ca}^{2+}$ ) entlarvt werden. 
Ein gutes Beispiel findet sich in tetragonalem HEW-Lysozyme, das in Gegenwart von Natrium-Ionen kristallisiert wurde: oktaedrisch koordiniert von Sauerstoffatomen der Aminosäuren Ser60, Cys64, Ser72 (O $\gamma)$ und Arg73, sowie zwei Wassermolekülen befindet sich ein Restelektronendichtemaximum, das über eine Bond-Valence-Berechnung als Natrium-Ion identifiziert werden konnte (vgl. Abb. 11.3 oben): Mit den Gleichungen 11.1 und 11.2 folgt für eine Na-O-Standardbindungslänge von $d_{o}=1.80 \AA$ : $V_{N a O}=0.9$. Dies ist hinreichend nah an dem theoretischen Wert von $V_{\mathrm{NaO}}=1.0$, um die Anwesenheit eines $\mathrm{Na}^{+}$-Ions auf dieser Position zu stützen.

Der Vergleich der Umgebung der entsprechenden Aminosäuren in anderen in der PDB enthaltenen Lysozymestrukturen erbrachte folgendes Ergebnis: Es kann grundsätzlich unterschieden werden zwischen Lysozyme, das in Anwesenheit von Natrium (etwa aus $\mathrm{NaCl}$ ) kristallisiert wurde und Lysozyme, in dessen Kristallisationsbedingungen kein Natrium vorkommt. Im ersteren Fall findet sich immer die oben beschriebene oktaedrische Geometrie der vier Aminosäuren mit zwei Wassermolekülen (Abbildung 11.3, unten links). Im zweiten Fall liegt ein sog. peptide flip der Aminosäuren Arg73-Asn74 vor, und die Geometrie ist verändert (Abb. 11.3, unten rechts).

Obwohl die natriumhaltige Form die bei weitem häufigste ist, wurde nur in zwei LysozymeStrukturen in der PDB auch ein $\mathrm{Na}^{+}$-Ion verfeinert. In einigen Fällen war anstelle des Natrium-Ions ein Wassermolekül verfeinert worden, das allerdings aufgrund der Abstände zu den benachbarten Atomen an dieser Position nicht ausreichend Platz hätte, in anderen Fällen war die Position des $\mathrm{Na}^{+}$freigelassen worden. 


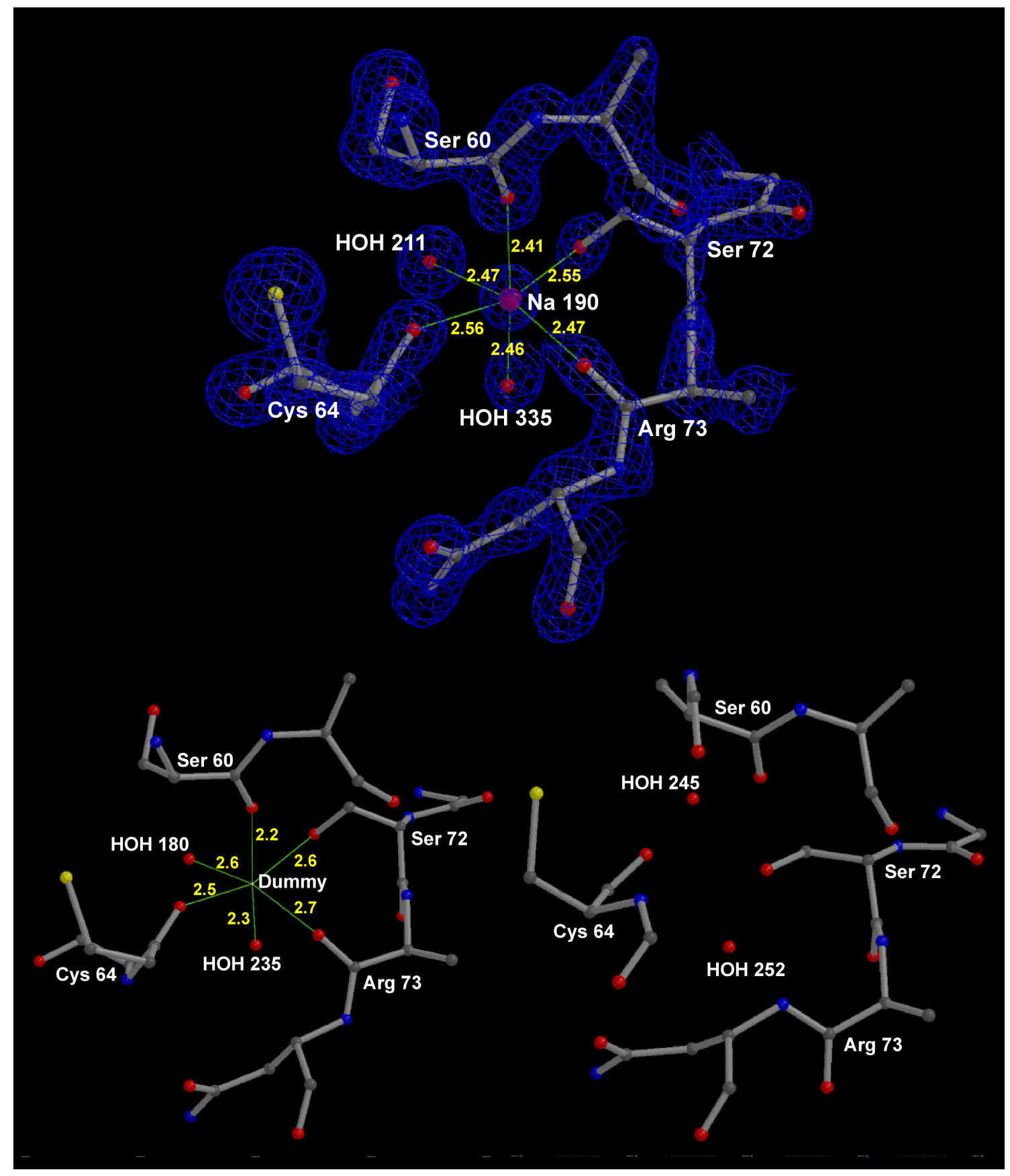

Abb. 11.3: Oben: Umgebung des Na-Ions in Lysozyme mit Elektronendichte und Bindungslängen $[\AA]$. Unten links: Der selbe Blick wie oben, aber auf eine andere Struktur von Lysozyme ohne Atom im Zentrum des Oktaeders; die Bindungslängen $[\AA ̊]$ wurden mit Hilfe eines „Dummy-Atoms “ berechnet. Unten rechts: Nichtoktaedrische Geometrie nach peptide flip Arg73-Asn74. 


\section{Kapitel 12}

\section{Ausblick}

Die moderne hochaufösende Einkristall-Röntgenstrukturanalyse gehört zu den mächtigsten Werkzeugen der Strukturaufklärung. Im Unterschied zu den spektroskopischen Methoden, die Strukturinformation lediglich indirekt über das energetische Verhalten eines Moleküls in einem bestimmten Spektralbereich zugänglich macht, wird bei Röntgenbeugung die dreidimensionale Elektronendichteverteilungsfunktion gemessen, was es ermöglicht, für jedes Atom die zugehörigen Raumkoordinaten zu errechnen.

In den letzten zehn bis 15 Jahren haben viele technologische Neuerungen - allen voran die Entwicklung moderner Flächendetektoren und die enormen Fortschritte auf dem Gebiet der elektronischen Datenverarbeitung - dazu beigetragen, die Röntgenstrukturanalyse immer schneller, effektiver und in immer höherem Maße automatisiert zu machen (Kapitel (4 und 5). Gleichzeitig ist auch die Nachfrage nach Röntgenstrukturen ständig gestiegen.

Sowohl auf dem Gebiet der Kleinmolekülstrukturen, als auch in der Proteinkristallographie geht der Trend eindeutig in Richtung „high throughput": Es ist nahezu unmöglich geworden, neue chemisch-präparative Ergebnisse zu veröffentlichen, ohne eine Röntgenstruktur vorzulegen. In einigen Bereichen der Pharma-Biologie werden Proteine in großem Maßstab einem screening unterzogen, indem sie mit verschiedenen potentiellen Wirkstoffen kokristallisiert und dann mit Hilfe der Röntgenstrukturanalyse strukturell untersucht werden. Dadurch wird neben anderen Problemen der Flaschenhals Kristallzucht (vgl. Kapitel 2) relativ immer enger und häufig zum limitierenden Faktor.

Die Tendenz hin zu immer mehr Strukturen in immer kürzerer Zeit wird sich in Zukunft noch verstärken. Moderne beamlines an Synchrotronen der dritten und demnächst vierten Generation sind in der Lage, einen vollständigen Datensatz von Lysozyme innerhalb 
weniger Minuten aufzunehmen, so daß die Kristallmontierung zum zeitlich limitierenden Faktor der Datensammlung wird. Bei voller Auslastung und zügigem Montieren können pro Beamline und Jahr an die viertausend Proteindatensätze gesammelt werden.

Auch auf dem Gebiet der chemischen Kristallographie ist es mit moderner Ausstattung theoretisch möglich, einen vollständigen Datensatz innerhalb weniger Stunden zu sammeln, was die Vermessung von zwei bis drei Strukturen pro Diffraktometer und Tag erlaubt.

Diese Flut von Datensätzen zu bewältigen ist nicht einfach, und Strukturverfeinerung als Fließband-Routine birgt einige Gefahren: Beispielsweise könnten Problemstrukturen mehr und mehr als nicht verfeinerbar, weil zu zeitaufwendig bezeichnet werden, und Mangel an Sorgfalt wird die Zahl der Verfeinerungsfehler erhöhen. In diesem Zusammenhang wird die Fehlersuche immer wichtiger werden [83]: Programme wie CHECKCIF [84], PROCHECK [85] und WHATCHECK [86], aber auch der twinning server von Todd Yeates [69, 87], die automatisch nach Fehlern in Datensatz, Raumgruppe und Verfeinerung suchen, sollten in Zukunft verstärkt zum Einsatz kommen und immer weiter ausgebaut und verbessert werden. Auch die in Kapitel 11 erwähnte Bond-Valence Methode (vgl. Seite 126) kann sowohl in der Kleinmolekül- als auch der Proteinkristallographie vielfach helfen, Fehler zu vermeiden, indem sie es ermöglicht, einem Atom das richtige Element zuzuordnen oder über die Oxidationsstufe zu entscheiden.

Eine weitere Gefahr ist die relativ verbreitete Ansicht, die Röntgenstrukturanalyse sei eine Routinemethode, [ die - im wesentlichen automatisiert - keiner besonderen Ausbildung mehr bedürfe. Die in dieser Arbeit angeführten Beispiele zeigen deutlich, daß längst nicht alle Strukturen als Routinefälle bezeichnet und behandelt werden können. Im Gegenteil - es gibt zahlreiche Fallen und Schwierigkeiten, die man kennen und erkennen muß, und Fehler, die man vermeiden sollte.

Vor allem auf dem Gebiet der Verfeinerung ist eine gute kristallographische Ausbildung heute so wichtig wie nie zuvor. Moderne Diffraktometer und Tieftemperaturmethoden erlauben es, auch von Kristallen, die noch vor zehn Jahren als hoffnungslos verworfen worden wären, Datensätze zu erhalten, wie das Beispiel des Cycloikositetraphenylens zeigt (vgl. 3.5). Das selbe Beispiel verdeutlicht, daß Verfeinerungen gegen diese Daten häufig besonders problematisch sind (vgl. 7.6).

Obwohl sie im Prinzip gelöste Probleme darstellen, sind Fehlordnung (Kapitel 7), Verzwil-

\footnotetext{
${ }^{1}$ Roland Boese beantwortete die Frage, ob die Röntgenstrukturanalyse eine Routinemethode sei, mit: „Im Prinzip ja, aber nur für den Routinier!“ [88]. Im gleichen Kontext könnte man auch antworten: „Im Prinzip ja, aber nur in Routinefällen!“.
} 
lingung (Kapitel 9) und Pseudosymmetrie (Kapitel 8) immer wieder eine Herausforderung für den Kristallographen, und die richtige Zuordnung der Atomsorte (vgl. Kapitel 6), sowie die Behandlung von Artefakten (vgl. Kapitel 10) sind auch heute nicht immer zufriedenstellend bewältigbare Aufgaben.

Diese Probleme treten bei Proteinstrukturen verstärkt und vielfach auch gehäuft in Erscheinung (vgl. Kapitel 11, Seite 119): Beispielsweise tritt das Phänomen des bulk solvent (vgl. 7.1.3) immer auf. Auch kann davon ausgegangen werden, daß es in jeder Proteinstruktur mehrere Fehlordnungen von Seitenketten gibt, obwohl ein aufösungsbedingt ungünstiges Daten-zu-Parameter-Verhältnis häufig deren Verfeinerung verhindert. Darüberhinaus ist - vermutlich aufgrund der Neigung zur Oligomerisierung (viele Proteine sind überhaupt nur als Oligomer biologisch aktiv) - nicht-kristallographische Symmetrie und als indirekte Folge davon Verzwillingung tendenziell häufiger anzutreffen als bei Kleinmolekülen.

Zusammenfassend kann gesagt werden, daß die Entwicklung auf dem Gebiet der hochauflösenden Einkristall-Röntgenstrukturanalyse klar in Richtung Automatisierung und high throughput geht. Dies wird einen großen Bedarf an gut ausgebildeten Kristallographen mit sich bringen, die in der Lage sind, auch schwierige kristallographische Probleme zu bewältigen, damit der gewünschte Zuwachs an Quantität nicht zu Lasten der Qualität geht. 


\section{Literaturverzeichnis}

[1] Röntgen, W. C. Über eine neue Art von Strahlen. Vorläufige Mitteilung. Sitzungsberichte der Physikalisch-Medizinischen Gesellschaft zu Würzburg (1895).

[2] W. H. Bragg und W. L. Bragg. The Reflection of X-rays by Crystals. Proc. $R$. Soc. Lond. A88, 428-438 (1913).

[3] G. M. Sheldrick. „SHELX-97“. Universität Göttingen (1997).

[4] http://shelx.uni-ac.gwdg.de/ peterm/tutorial/disord.htm.

[5] W. Massa. „Kristallstrukturbestimmung“. B. G. Teubner, Stuttgart (1996).

[6] P. Luger. „Modern X-Ray Analysis in Single Crystals“. Walter de Gruyter, Berlin, New York (1980).

[7] C. Giacovazzo (Herausgeber). „Fundamentals of Crystallography“. Oxford University Press, Oxford and New York (1998).

[8] A. McPherson. „Crystallization of Biological Macromolecules“. Cold Spring Harbor Laboratory Press, Cold Spring Harbor, New York (1999).

[9] P. MüLlER. Röntgenstrukrutanalytische Untersuchungen an metallorganischen Verbindungen und indigoiden Systemen. Diplomarbeit (1997).

[10] J. JANCARICK UND S.-H. KIM. Sparse matrix sampling: a screening method for crystallization of proteins. J. Appl. Cryst. 24, 209-411 (1991).

[11] R. Sousa. Use of Glycerol and Other Protein Structure Stabilizing Agents in Protein Crystallization. Acta Cryst. D51, 271-277 (1995).

[12] K. Müller, B. F. Matzanke, V. Schünemann, A. X. Trautwein und K. HantKe. FhuF, An iron-regulated protein of Escherichia coli with a new type of [2Fe-2S center]. Eur. J. Biochem. 258, 1001-1008 (1998). 
[13] H. Sticht und P. Rösch. The structure of iron-sulfur proteins. Progress in Biophysics and Molecular Biology 70, 95-136 (1998).

[14] E. PoHL. Persönliche Mitteilung (2000).

[15] A. George und W. W. Wilson. Predicting protein crystallization from a dilute solution property. Acta Cryst. D50, 361-365 (1994).

[16] A. McPherson. Growth and Handling of Crystals in High Throughput Production. In „Tagungsband ACA-Tagung, St. Paul, Michigan, USA“ (2000).

[17] R. Boese, H.-C. Weiss und D. Bläser. The Melting Point Alternation in the Short-Chain $n$-Alkanes: Single-Crystal X-Ray Analyses of Propane at $30 \mathrm{~K}$ and of n-Butane to $n$-Nonane at 90 K. Angew. Chem. Int. Ed. Engl. 38, 992-995 (1999).

[18] T. Kottke und D. Stalke. Crystal Handling at Low Temperatures. J. Appl. Cryst. 26, 615 (1993).

[19] A. F. Hollemann und E. WiberG. „Lehrbuch der Anorganischen Chemie“. de Gruyter, Berlin, 101 Auflage (1995).

[20] P. Yu, P. Müller, M. A. Said, H. W. Roesky, I. Usón, G. Bai und M. Noltemeyer. Difference in Reactivity of Cyclopentadienyltitanium Fluorides and Chlorides Using $\mathrm{AlR}_{3}(\mathrm{R}=\mathrm{Me}$, Et). Organometallics 18, 1669-1674 (1999).

[21] V. Hensel und A. D. Schlüter. A Cyclotetraicosaphenylene. Chem. Eur. J. 5, 421-429 (1999).

[22] P. Müller, V. Hensel, I. Usón, A. D. Schlüter und G. M. Sheldrick. Crystal Structure of a Cyclotetraicosaphenylene. Helvetica Chimica Acta 84, 778785 (2001).

[23] http://www.crystal.nasa.gov.

[24] R. Durst, P. Müller, C. Campana, S. Foundling, J. Phillips und M. PreSPRICH. The Optimal Gain and Dynamic Range of CCD Detectors for X-ray Diffraction. Poster, ACA-Meeting, Glasgow 1999.

[25] R. Durst, C. Campana, S. Foundling, J. Phillips und P. Müller. The Optimal Quantum Gain of CCD Detectors for Chemical and Macromolecular Crystallography. Poster, ACA-Meeting, Buffalo 1999. 
[26] R. Durst, C. Campana, S. Foundling, Z. Jin, J. Phillips, M. Pressprich Und P. MÜLler. The Design of CCD Detectors for Optimal Sensitivity and Dynamic Range: The New SMART APEX. Poster, ACA-Meeting, Buffalo 1999.

[27] U. W. Arndt und A. J. Wonacott (Herausgeber). „The Rotation Method in Crystallography“. North Holland, Amsterdam (1977).

[28] W. A. Hendrickson. Radiation Damage in Protein Crystallography. J. Mol. Biol. 106, 889-893 (1976).

[29] W. P. Burmeister. Structural changes in a cryo-cooled protein owing to radiation damage. Acta Cryst. D56, 328-341 (2000).

[30] M Weik, R. B. Ravelli, G. Kryger, S. McSweeny, M. L. Raves, M. Harel, P. Gros, I. Silman, J. Kroon und J. L. Sussman. Specific chemical and structural damage to proteins produced by synchrotron radiation. Proc. Natl. Acad. Sci. USA 97, 623-628 (2000).

[31] K. J. A. Davies. Protein Damage and Degradation by Oxygen Radicals. 1. General Aspects. J. Biol. Chem. 262, 9895-9901 (1987).

[32] D. Casico, R. Williams und A. McPherson. The Reduction of Radiation Damage in Protein Crystals by Polyethylene Glycol. J. Appl. Cryst. 17, 209-211 (1984).

[33] R. Henderson. Cryo-Protection of Protein Crystals Against Radiation Damage in Electron and X-ray Diffraction. Proc. R. Soc. Lond. B241, 6-8 (1990).

[34] R. Boese. Der Vergleich von Röntgenstrukturdaten - Fehler und Artefakte. In „Tagungsband der KSAM-Tagung, Frankfurt/Main“ (1999).

[35] T. P. Singh, W. Bode und R. Huber. Low-Temperature Protein Crystallography. Effect on Flexibillity, Temperature Factor, Mosaic Spread, Extinction and Diffuse Scattering in Two Examples: Bovine Trypsinogen and Fc Fragment. Acta Cryst. B36, 621-627 (1980).

[36] J. M. Harp, D. E. Timm und G. J. Bunick. Macromolecular Crystal Annealing: Overcoming Increased Mosaicity Associated with Cryocrystallography. Acta Cryst. D54, 622-628 (1998).

[37] Z. DAuter. Data-collection strategies. Acta Cryst. D55, 1703-1717 (1999). 
[38] K. Diederichs und P. A. Karplus. Improved R-Factors for Diffraction Data Analysis in Macromolecular Crystallography. Nat. Struct. Biol. 4/4, 269-275 (1997).

[39] Z. Dauter, M. Dauter, E. De la Fortelle, G. Bricogne und G. M. SheldRICK. Can Anomalous Signal of Sulfur Become a Tool for Solving Protein Crystal Structures? J. Mol. Biol. 289, 83-92 (1999).

[40] L. HÄмING. „CCD Flächenzähler in der Einkristallröntgendiffraktometrie“. Dissertation, Georg August Universität Göttingen (1997).

[41] M. TEICHERT. „Strukturaufklärung von tetranuklearen Magnesiumkomplexen - Datensammlungsstrategien mit dem SMART-CCD-System“. Dissertation, Georg August Universität Göttingen (1998).

[42] J. KäRChER. „COSMO, Programm zur Strategieplanung der Datensammlung mit Flächenzählern“. Bruker AXS (1998).

[43] J. KäRCHER. „Mersacidin-analoge Typ-B-Lantibiotike - Kristallisation, Datensammlung und Strukturaufklärung“. Dissertation, Georg August Universität Göttingen (2000).

[44] S. Foundling und Bruker AXS. Persönliche Mitteilung (2001).

[45] BRuker AXS. „SAINT, Programm zur Integration von Flächenzählerdaten“. (1994).

[46] E. POHL. „Strukturaufklärung biologisch aktiver Peptide - systematischer Vergleich von Röntgendetektoren anhand der Kristallstrukturen“. Dissertation, Georg August Universität Göttingen (1993).

[47] M. C. Vaney, S. Maignan, M. Ries-Kautt und A. Ducuri. High-Resolution Structure $(1.33 \AA)$ of a Tetragonal HEW Lysozyme Crystal Grown in the APCF Apparatus. Acta Cryst. 52D, 505-517 (1996).

[48] J. KÄrcher. Persönliche Mitteilung (2000).

[49] G. M. Sheldrick. Phase annealing in SHELX-90: direct methods for larger structures. Acta Cryst. 46A, 467-473 (1990).

[50] P. Müller, I. Usón, J. Prust und H. W. Roesky. Tetrameric $\mathrm{InCl}_{3}$, a new modification of a widely used compound. Acta Cryst. C56, 1300-1301 (2000).

[51] A. KÁlmán. Mean X-Bond Lengths of the $\mathrm{XO}_{4}^{n-}$ Tetrahedral Oxyanions. J. Chem. Soc. A. Part 2, 1857-1859 (1971). 
[52] F. H. Allen, S. Bellard, M. D. Brice, B. A. Cartwright, A. Doubleday, H. Higgs, T. Hummellink, Hummelink-Peters B. G., O. Kennard, W. D. S. Motherwell, J. R. Rodgers und D. G. Watson. The Cambridge Crystallographic Data Center: Computer-Based Search, Retrieval Analysis and Display of Information. Acta Cryst. B35, 2331 (1979).

[53] G. H. Miller und T. R. Welberry. A Three-Dimansional Model of CrystalGrowth Disorder. Acta Cryst. A35, 391-400 (1979).

[54] P. C. Moews und R. H. Kretsinger. Refinement of the Structure of Carp Muscle Calcium-binding Parvalbumin by Model Building and Difference Fourier Analysis. $J$. Mol. Biol. 91, 201-228 (1975).

[55] T. R. Schneider. „Röntgenkristallographische Untersuchung der Struktur und Dynamik einer Serinprotease“. Dissertation, Technische Universität München (1996).

[56] C. Rennekamp, P. Müller, J. Prust, H. Wessel, H. W. Roesky und I. Usón. Si-NH-M Cage Compounds - Molecular Iminosilicates Containing Group 13 Metals and Their Functionalized Halogen Containing Derivatives. Europ. J. Inorg. Chem. Seiten 1861-1868 (2000).

[57] H. M. Hutmacher, H. G. Fritz und H. Musso. Tetraasteran, Pentacyclo$\left[6.4 \cdot 0.0^{2,7} \cdot 0^{4,11} \cdot 0^{5,10}\right]$-dodecan. Angew. Chem. 87, 174-175 (1975).

[58] V. Hensel, K. Lützow, J. Jacob, K. Gessler, W. Saenger und A. D. SchlÜter. Repetitive Construction of Macrocyclic Oligophenylenes. Angew. Chem. Int. Ed. Engl. 36, 2654-2656 (1997).

[59] T. Steiner, E. B. Starikow, A. M. Amado und J. J. C. Teixeira-Dias. Weak hydrogen bonding. Part 2. The hydrogen bonding nature of short $\mathrm{C}-\mathrm{H} \cdots \pi$ contacts: crystallographic, spectroscopic and quantum mechanical studies of some terminal alkynes. J. Chem. Soc. Perkin Trans. 2, 1321-1326 (1995).

[60] M. G. Rossmann (Herausgeber). „The Molecular-Replacement Method. A Collection of Papers on the Use of Non-Crystallographic Symmetry". Gordon and Breach, New York (1972).

[61] M. G. Rossmann. The Molecular Replacement Method. Acta Cryst. A46, 73-82 (1990).

[62] H. Görbitz und E. Torgersen. Symmetry, pseudosymmetry and packing disorder in the alkohol solvates of L-leucyl-L-valine. Acta Cryst. B55, 104-113 (1999). 
[63] R. Gerke, L. Fitjer, P. Müller, I. Usón, K. Kowski und P. Rademacher. New Indigo Chromophores Containing Disulfide Donor Groups. Tetrahedron 55, 14428-14434 (1999).

[64] G. M. Sheldrick. „XPREP: Programm zur Datenanalyse und Erkundung des Reziproken Raumes“. Bruker AXS (2000).

[65] C. Ackerhans, P. Böttcher, P. Müller, H. W. Roesky, I. Usón, H. G. Schmidt und M. Noltemeyer. Halogenodisilanes: Precursors for many Disilane Derivatives. Inorg. Chem. 00, in press (2001).

[66] D. W. J. Cruickshank und W. S. McDonald. Parameter Errors in Polar Space Groups Caused by Neglect of Anomalous Scattering. Acta Cryst. 23, 9-11 (1997).

[67] R. Herbst-Irmer und G. M. Sheldrick. Refinement of Twinned Structures with SHELXL97. Acta Cryst. B54, 443-449 (1998).

[68] H. D. Flack. On Enantiomorph-Polarity Estimation. Acta Cryst. A39, 876-881 (1983).

[69] T. O. Yeates. Detecting and Overcoming Crystal Twinning. In „Methods in Enzymology“, Band 276, Seiten 344-358. Academic Press Inc., Orlando, Florida (1997).

[70] T. R. Schneider, J. Kärcher, E. Pohl, P. Lubini und G. M. Sheldrick. ab initio structure determination of the lantibiotic mersacidin. Acta Cryst. D56, 705-713 (2000).

[71] G. M. Sheldrick. UNTWIN: Programm zur Entzwillingung der Diffraktionsdaten des Mersacidins. Nicht veröffentlicht (1997).

[72] W. Hoenle und H. G. von Schnering. Can X-Ray crystal structure analysis dacide between twinning by pseudo-merohedry and statistical distribution in $\mathrm{YBa}_{2} \mathrm{Cu}_{3} \mathrm{O}_{7}$ ? Z. Krist. 184, 301-305 (1988).

[73] Bruker AXS. „SMART, Programm zur Diffraktometersteuerung und Datensammlung mit Flächenzählern“. (1994).

[74] I. Usón und G. M. Sheldrick. Advances in direct methods for protein crystallography. Current Opinion in Structural Biology 9, 643-648 (1999).

[75] G. Bai, P. Müller, H. W. Roesky und I. Usón. Intramolecular Coupling of Two Cyclopentadienyl Ring Systems of Zirconium - Unprecedented Formulation of a Dihydride and Preparation of the $\left[\left\{\left(\mathrm{MeC}_{5} \mathrm{H}_{4}\right) \mathrm{Zr}\right\}_{5}\left(\mu_{5}-\mathrm{N}\right)\left(\mu_{3}-\mathrm{NH}\right)_{4}\left(\mu-\mathrm{NH}_{2}\right)_{4}\right]$ Cluster in a Two Phase System. Organometallics 19, 4675-4677 (2001). 
[76] G. M. Sheldrick und T. R. Schneider. SHELXL: High Resolution Refinement. In „Methods in Enzymology“, Band 277, Seiten 319-343. Academic Press Inc., Orlando, Florida (1997).

[77] A. T. Brünger und L. M. RiCE. Crystallographic Refinement by Simulated Annealing: Methods and Applications. In „Methods in Enzymology“, Band 277, Seiten 243-268. Academic Press Inc., Orlando, Florida (1997).

[78] D. McReE. XtalView/Xfit - A versatile Program for Manipulating Atomic Coordinates and Electron Density. J. Struct. Biol. 125, 156-165 (1999).

[79] V. Luzzati. Traitement Statistique des Erreurs dans la Determination des Structures Cristallines. Acta Cryst. 5, 802-817 (1952).

[80] L. Pauling. Atomic Radii and Interatomic Distances in Metals. J. Am. Chem. Soc. 69, 542-553 (1947).

[81] N. E. Brese und M. O'Keeffe. Bond-Valence Parameters for Solids. Acta Cryst. B47, 192-197 (1993).

[82] M. O’Keeffe und N. E. Brese. Atom Sizes and Bond Lengths in Molecules and Crystals. J. Am. Chem. Soc. 113, 3226-3229 (1991).

[83] D. W. J. Cruickshank. Remarks about protein structure precision. Acta Cryst. D55, 583-601 (1999).

[84] http://iucr.sdsc.edu/iucr-top/journals/acta/c/services/checkcif.html.

[85] R. A. Laskowski, M. W. MacArthur, D. S. Moss und M. T. Thornton. PROCHECK: a program to check the stereochemical quality of protein structures. J. Appl. Cryst. 25, 283-291 (1993).

[86] R. W. W. Hooft, V. Vriend, C Sander und E. E. Abola. Errors in protein structures. Nature 381, 272-272 (1996).

[87] http://www.doe-mbi.ucla.edu/Services/Twinning/.

[88] R. Boese. Röntgenstrukturanalyse - „Quo vadis?“. In „Tagungsband der KSAMTagung, Frankfurt/Main“ (1999).

[89] S. E. Tsutakawa, T. Muto, T. Kaware, H. Jingami, N. Kunishima, M. Ariyoshi, D. Kohda und M. NAKagawa. Crystallographic and functional studies of very short patch repair endonucleases. Mol Cell 3, 621-628 (1999). 
[90] Bruker AXS. „FRAMBO, Programm zur Diffraktometersteuerung und Datensammlung mit Flächenzählern“. (1994).

[91] G. M. ShELDRICK. „SADABS: Program for absorption and other corrections“. Universität Göttingen (2000).

[92] MARRESEARCH. "A Scanner Control and Data-Acquisition Software Package“. (2000).

[93] Z. OTwinowski. „DENZO: An Oscillation data processing program for macromolecular crystallography." Yale University, NewHaven, USA (1993).

[94] Z. OTwinowski. „SCALEPACK: Software for the scaling together of integrated intensities measured on a number of separate diffraction images." Yale University, NewHaven, USA (1993).

[95] Stoe GmbH. „X-AREA 1.05“. (2000).

[96] P. Kraulis. Molscript: a program to produce both detailed and schematic plots of protein structures. J. Appl. Cryst. 24, 946-950 (1991).

[97] R. Esnouf. BobScript. J. Mol. Graph. 15, 132-134 (1997).

[98] E. A. Merritt und D. J. BAcon. Raster3D: Photorealistic Molecular Graphics. Methods. Enzymol. 276, 505-524 (1991). 


\section{Kapitel 13}

\section{Anhang}

\subsection{Kristallographische Daten der Strukturen}

Im Folgenden werden zu allen Kleinmolekülstrukturen, die in dieser Arbeit erwähnt sind, die wichtigsten kristallographischen Daten angegeben. 
13.1.1 $\left[\left(\eta^{5}-\mathrm{C}_{5} \mathrm{H}_{4} \mathrm{Me}\right)_{2} \mathrm{Ti}(\mu-\mathbf{F})_{2} \mathrm{AlEt}_{2}\right]_{2}$

\begin{tabular}{|c|c|c|}
\hline Identification code & CITRONE & \\
\hline Empirical formula & $\mathrm{C}_{32} \mathrm{H}_{48} \mathrm{Al}_{2} \mathrm{~F}_{4} \mathrm{Ti}_{2}$ & \\
\hline Formula weight & $658.46 \mathrm{~g} / \mathrm{mol}$ & \\
\hline Temperature & $133(2) \mathrm{K}$ & \\
\hline Wavelength & $0.71073 \AA$ & \\
\hline Crystal system & Monoclinic & \\
\hline Space group & $C 2 / c$ & \\
\hline \multirow[t]{3}{*}{ Unit cell dimensions } & $a=24.340(4) \AA$ & $\alpha=90^{\circ}$ \\
\hline & $b=7.916(2) \AA$ & $\beta=121.52(2)^{\circ}$ \\
\hline & $c=20.128(4) \AA$ & $\gamma=90^{\circ}$ \\
\hline Volume & $3306(1) \AA^{3}$ & \\
\hline $\mathrm{Z}$ & 4 & \\
\hline Density (calculated) & $1.323 \mathrm{Mg} / \mathrm{m}^{3}$ & \\
\hline Absorption coefficient & $0.579 \mathrm{~mm}^{-1}$ & \\
\hline $\mathrm{F}(000)$ & 1384 & \\
\hline Crystal size & $0.30 \times 0.20 \times 0.05 \mathrm{~mm}^{3}$ & \\
\hline Theta range for data collection & $2.15 \leq \Theta \leq 24.99^{\circ}$ & \\
\hline Reflections collected & 25618 & \\
\hline Independent reflections & $2916\left(R_{i n t}=0.1007\right)$ & \\
\hline Completeness to $\Theta=24.99^{\circ}$ & $100.0 \%$ & \\
\hline Absorption correction & Semi-empirical from equivalents & \\
\hline Max. and min. transmission & 0.9716 and 0.8456 & \\
\hline Refinement method & Full-matrix least-squares on $F^{2}$ & \\
\hline Data / restraints / parameters & $2916 / 26 / 181$ & \\
\hline Goodness-of-fit on $F^{2}$ & 1.062 & \\
\hline Final $R$ indices $[I>2 \sigma(I)]$ & $R 1=0.0477, w R 2=0.1054$ & \\
\hline$R$ indices (all data) & $R 1=0.0799, w R 2=0.1178$ & \\
\hline Largest diff. peak and hole & 0.491 and $-0.413 \mathrm{e} \AA^{-3}$ & \\
\hline
\end{tabular}




\subsubsection{Cycloikositetraphenylen}

\begin{tabular}{|c|c|c|}
\hline Identification code & KRINGEL & \\
\hline Empirical formula & $\mathrm{C}_{222} \mathrm{H}_{246} \mathrm{Cl}_{18}$ & \\
\hline Formula weight & $3552.29 \mathrm{~g} / \mathrm{mol}$ & \\
\hline Temperature & $133(2) \mathrm{K}$ & \\
\hline Wavelength & $1.54178 \AA$ & \\
\hline Crystal system & Rhombohedral & \\
\hline Space group & $R \overline{3}$ & \\
\hline \multirow[t]{3}{*}{ Unit cell dimensions } & $a=54.982(8) \AA$ & $\alpha=90^{\circ}$ \\
\hline & $b=54.982(8) \AA$ & $\beta=90^{\circ}$ \\
\hline & $c=8.549(2) \AA$ & $\gamma=120^{\circ}$ \\
\hline Volume & $22381(6) \AA^{3}$ & \\
\hline $\mathrm{Z}$ & 3 & \\
\hline Density (calculated) & $0.791 \mathrm{Mg} / \mathrm{m}^{3}$ & \\
\hline Absorption coefficient & $1.775 \mathrm{~mm}^{-1}$ & \\
\hline $\mathrm{F}(000)$ & 5652 & \\
\hline Crystal size & $0.20 \times 0.20 \times 0.10 \mathrm{~mm}^{3}$ & \\
\hline Theta range for data collection & $5.50 \leq \Theta \leq 56.86^{\circ}$ & \\
\hline Reflections collected & 291303 & \\
\hline Independent reflections & $6618\left(R_{i n t}=0.1136\right)$ & \\
\hline Completeness to $\Theta=56.86^{\circ}$ & $98.9 \%$ & \\
\hline Absorption correction & Semi-empirical from equivalents & \\
\hline Max. and min. transmission & 0.8425 and 0.7178 & \\
\hline Refinement method & Full-matrix least-squares on $F^{2}$ & \\
\hline Data / restraints / parameters & $6618 / 609 / 492$ & \\
\hline Goodness-of-fit on $F^{2}$ & 2.569 & \\
\hline Final $R$ indices $[I>2 \sigma(I)]$ & $R 1=0.1096, w R 2=0.3154$ & \\
\hline$R$ indices (all data) & $R 1=0.1197, w R 2=0.3197$ & \\
\hline Largest diff. peak and hole & 0.748 and $-0.418 \mathrm{e}^{-3}$ & \\
\hline
\end{tabular}




\subsubsection{Tetrameres $\mathrm{InCl}_{3}$}

\begin{tabular}{|c|c|c|}
\hline Identification code & RATT & \\
\hline Empirical formula & $\mathrm{C}_{24} \mathrm{H}_{66} \mathrm{Cl}_{12} \mathrm{In}_{4} \mathrm{~N}_{6}$ & \\
\hline Formula weight & $1323.50 \mathrm{~g} / \mathrm{mol}$ & \\
\hline Temperature & $133(2) \mathrm{K}$ & \\
\hline Wavelength & $0.71073 \AA$ & \\
\hline Crystal system & Triclinic & \\
\hline Space group & $P \overline{1}$ & \\
\hline \multirow[t]{3}{*}{ Unit cell dimensions } & $a=10.962(2) \AA$ & $\alpha=95.46(3)^{\circ}$ \\
\hline & $b=11.407(2) \AA$ & $\beta=109.57(3)^{\circ}$ \\
\hline & $c=11.674(2) \AA$ & $\gamma=114.20(3)^{\circ}$ \\
\hline Volume & $1207.8(4) \AA^{3}$ & \\
\hline $\mathrm{Z}$ & 1 & \\
\hline Density (calculated) & $1.820 \mathrm{Mg} / \mathrm{m}^{3}$ & \\
\hline Absorption coefficient & $2.574 \mathrm{~mm}^{-1}$ & \\
\hline $\mathrm{F}(000)$ & 652 & \\
\hline Crystal size & $0.30 \times 0.30 \times 0.10 \mathrm{~mm}^{3}$ & \\
\hline Theta range for data collection & $1.92 \leq \Theta \leq 27.06^{\circ}$ & \\
\hline Reflections collected & 45298 & \\
\hline Independent reflections & $5291\left(R_{\text {int }}=0.0457\right)$ & \\
\hline Completeness to $\Theta=27.06^{\circ}$ & $99.9 \%$ & \\
\hline Absorption correction & Semi-empirical from equivalents & \\
\hline Max. and min. transmission & 0.7829 and 0.5123 & \\
\hline Refinement method & Full-matrix least-squares on $F^{2}$ & \\
\hline Data / restraints / parameters & $5291 / 3 / 223$ & \\
\hline Goodness-of-fit on $F^{2}$ & 1.138 & \\
\hline Final $R$ indices $[I>2 \sigma(I)]$ & $R 1=0.0225, w R 2=0.0527$ & \\
\hline$R$ indices (all data) & $R 1=0.0262, w R 2=0.0541$ & \\
\hline Largest diff. peak and hole & 0.576 and $-1.080 \mathrm{e}^{-3}$ & \\
\hline
\end{tabular}




\subsection{4 $\left[\mathrm{CoNH}_{4} \mathrm{PO}_{4}\right] \cdot 6 \mathrm{H}_{2} \mathrm{O}$}

\begin{tabular}{|c|c|c|}
\hline Identification code & UNKE & \\
\hline Empirical formula & $\mathrm{H}_{16} \mathrm{CoNO}_{10} \mathrm{P}$ & \\
\hline Formula weight & $280.04 \mathrm{~g} / \mathrm{mol}$ & \\
\hline Temperature & $133(2) \mathrm{K}$ & \\
\hline Wavelength & $0.71073 \AA$ & \\
\hline Crystal system & Orthorhombic & \\
\hline Space group & $\operatorname{Pmn} 2_{1}$ & \\
\hline \multirow[t]{3}{*}{ Unit cell dimensions } & $a=6.941(1) \AA$ & $\alpha=90^{\circ}$ \\
\hline & $b=6.112(1) \AA$ & $\beta=90^{\circ}$ \\
\hline & $c=11.196(2) \AA$ & $\gamma=90^{\circ}$ \\
\hline Volume & $474.9(2) \AA^{3}$ & \\
\hline $\mathrm{Z}$ & 2 & \\
\hline Density (calculated) & $1.958 \mathrm{Mg} / \mathrm{m}^{3}$ & \\
\hline Absorption coefficient & $2.011 \mathrm{~mm}^{-1}$ & \\
\hline $\mathrm{F}(000)$ & 330 & \\
\hline Crystal size & $0.40 \times 0.10 \times 0.05 \mathrm{~mm}^{3}$ & \\
\hline Theta range for data collection & $3.33 \leq \Theta \leq 27.83^{\circ}$ & \\
\hline Reflections collected & 9807 & \\
\hline Independent reflections & $1207\left(R_{\text {int }}=0.0366\right)$ & \\
\hline Completeness to $\Theta=27.83^{\circ}$ & $100.0 \%$ & \\
\hline Absorption correction & Semi-empirical from equivalents & \\
\hline Max. and min. transmission & 0.9061 and 0.5002 & \\
\hline Refinement method & Full-matrix least-squares on $F^{2}$ & \\
\hline Data / restraints / parameters & $1207 / 14 / 97$ & \\
\hline Goodness-of-fit on $F^{2}$ & 1.104 & \\
\hline Final $R$ indices $[I>2 \sigma(I)]$ & $R 1=0.0147, w R 2=0.0392$ & \\
\hline$R$ indices (all data) & $R 1=0.0150, w R 2=0.0393$ & \\
\hline Largest diff. peak and hole & 0.229 and $-0.310 \mathrm{e}^{-3}$ & \\
\hline
\end{tabular}




\subsubsection{Unklares Zentralatom}

\begin{tabular}{|c|c|c|}
\hline Identification code & ORANG UTAN & \\
\hline Empirical formula & $\mathrm{C}_{20} \mathrm{H}_{30} \mathrm{O}_{4} \mathrm{~W}_{2}$ & \\
\hline Formula weight & $702.14 \mathrm{~g} / \mathrm{mol}$ & \\
\hline Temperature & $133(2) \mathrm{K}$ & \\
\hline Wavelength & $0.71073 \AA$ & \\
\hline Crystal system & Triclinic & \\
\hline Space group & $P \overline{1}$ & \\
\hline \multirow[t]{3}{*}{ Unit cell dimensions } & $a=8.264(2) \AA$ & $\alpha=109.03(3)^{\circ}$ \\
\hline & $b=8.583(2) \AA$ & $\beta=97.28(3)^{\circ}$ \\
\hline & $c=9.426(2) \AA$ & $\gamma=117.39(3)^{\circ}$ \\
\hline Volume & $529.8(2) \AA^{3}$ & \\
\hline $\mathrm{Z}$ & 1 & \\
\hline Density (calculated) & $2.201 \mathrm{Mg} / \mathrm{m}^{3}$ & \\
\hline Absorption coefficient & $10.868 \mathrm{~mm}^{-1}$ & \\
\hline $\mathrm{F}(000)$ & 330 & \\
\hline Crystal size & $0.30 \times 0.20 \times 0.20 \mathrm{~mm}^{3}$ & \\
\hline Theta range for data collection & $2.85 \leq \Theta \leq 24.99^{\circ}$ & \\
\hline Reflections collected & 8185 & \\
\hline Independent reflections & $1864\left(R_{\text {int }}=0.0763\right)$ & \\
\hline Completeness to $\Theta=24.99^{\circ}$ & $99.6 \%$ & \\
\hline Absorption correction & Semi-empirical from equivalents & \\
\hline Max. and min. transmission & 0.2198 and 0.1390 & \\
\hline Refinement method & Full-matrix least-squares on $F^{2}$ & \\
\hline Data / restraints / parameters & $1864 / 220 / 94$ & \\
\hline Goodness-of-fit on $F^{2}$ & 1.115 & \\
\hline Final $R$ indices $[I>2 \sigma(I)]$ & $R 1=0.0442, w R 2=0.1091$ & \\
\hline$R$ indices (all data) & $R 1=0.0486, w R 2=0.1112$ & \\
\hline Largest diff. peak and hole & 1.762 and $-3.118 \mathrm{e}^{-3}$ & \\
\hline
\end{tabular}




\subsubsection{Gallium-Iminosilikat}

\begin{tabular}{|c|c|c|}
\hline Identification code & GESUALDO & \\
\hline Empirical formula & $\mathrm{C}_{46} \mathrm{H}_{96} \mathrm{Ga}_{4} \mathrm{~N}_{8} \mathrm{Si}_{4}$ & \\
\hline Formula weight & $1152.55 \mathrm{~g} / \mathrm{mol}$ & \\
\hline Temperature & $133(2) \mathrm{K}$ & \\
\hline Wavelength & $0.71073 \AA$ & \\
\hline Crystal system & Monoclinic & \\
\hline Space group & $C 2 / c$ & \\
\hline \multirow[t]{3}{*}{ Unit cell dimensions } & $a=23.681(6) \AA$ & $\alpha=90^{\circ}$ \\
\hline & $b=10.805(3) \AA$ & $\beta=102.56(2)^{\circ}$ \\
\hline & $c=23.266(5) \AA$ & $\gamma=90^{\circ}$ \\
\hline Volume & $5810(3) \AA^{3}$ & \\
\hline $\mathrm{Z}$ & 4 & \\
\hline Density (calculated) & $1.318 \mathrm{Mg} / \mathrm{m}^{3}$ & \\
\hline Absorption coefficient & $1.954 \mathrm{~mm}^{-1}$ & \\
\hline $\mathrm{F}(000)$ & 2432 & \\
\hline Crystal size & $0.20 \times 0.20 \times 0.20 \mathrm{~mm}^{3}$ & \\
\hline Theta range for data collection & $1.76 \leq \Theta \leq 26.37^{\circ}$ & \\
\hline Reflections collected & 13287 & \\
\hline Independent reflections & $5937\left(R_{\text {int }}=0.0342\right)$ & \\
\hline Completeness to $\Theta=26.37^{\circ}$ & $100.0 \%$ & \\
\hline Absorption correction & Semi-empirical from equivalents & \\
\hline Max. and min. transmission & 0.6959 and 0.6959 & \\
\hline Refinement method & Full-matrix least-squares on $F^{2}$ & \\
\hline Data / restraints / parameters & $5937 / 11 / 320$ & \\
\hline Goodness-of-fit on $F^{2}$ & 1.127 & \\
\hline Final $R$ indices $[I>2 \sigma(I)]$ & $R 1=0.0297, w R 2=0.0656$ & \\
\hline$R$ indices (all data) & $R 1=0.0360, w R 2=0.0685$ & \\
\hline Largest diff. peak and hole & 0.370 and $-0.555 \mathrm{e}^{-3}$ & \\
\hline
\end{tabular}




\subsubsection{Bromo-Aluminium-Iminosilikat}

\begin{tabular}{|c|c|c|}
\hline Identification code & Bromo & \\
\hline Empirical formula & $\mathrm{C}_{44.56} \mathrm{H}_{84.68} \mathrm{Al}_{4} \mathrm{Br}_{2.44} \mathrm{~N}_{8} \mathrm{Si}_{4}$ & \\
\hline Formula weight & $1147.86 \mathrm{~g} / \mathrm{mol}$ & \\
\hline Temperature & $133(2) \mathrm{K}$ & \\
\hline Wavelength & $0.71073 \AA$ & \\
\hline Crystal system & Monoclinic & \\
\hline Space group & $P 2_{1} / n$ & \\
\hline \multirow[t]{3}{*}{ Unit cell dimensions } & $a=11.112(2) \AA$ & $\alpha=90^{\circ}$ \\
\hline & $b=15.113(3) \AA$ & $\beta=100.28(3)^{\circ}$ \\
\hline & $c=17.546(4) \AA$ & $\gamma=90^{\circ}$ \\
\hline Volume & $2899(1) \AA^{3}$ & \\
\hline $\mathrm{Z}$ & 2 & \\
\hline Density (calculated) & $1.315 \mathrm{Mg} / \mathrm{m}^{3}$ & \\
\hline Absorption coefficient & $1.882 \mathrm{~mm}^{-1}$ & \\
\hline $\mathrm{F}(000)$ & 1203 & \\
\hline Crystal size & $0.40 \times 0.40 \times 0.30 \mathrm{~mm}^{3}$ & \\
\hline Theta range for data collection & $1.79 \leq \Theta \leq 25.00^{\circ}$ & \\
\hline Reflections collected & 34689 & \\
\hline Independent reflections & $5098\left(R_{\text {int }}=0.0445\right)$ & \\
\hline Completeness to $\Theta=25.00^{\circ}$ & $99.9 \%$ & \\
\hline Absorption correction & Semi-empirical from equivalents & \\
\hline Max. and min. transmission & 0.6022 and 0.5199 & \\
\hline Refinement method & Full-matrix least-squares on $F^{2}$ & \\
\hline Data / restraints / parameters & $5098 / 283 / 343$ & \\
\hline Goodness-of-fit on $F^{2}$ & 1.036 & \\
\hline Final $R$ indices $[I>2 \sigma(I)]$ & $R 1=0.0318, w R 2=0.0836$ & \\
\hline$R$ indices (all data) & $R 1=0.0421, w R 2=0.0872$ & \\
\hline Largest diff. peak and hole & 0.608 and $-0.609 \mathrm{e}^{-3}$ & \\
\hline
\end{tabular}




\subsubsection{Iodo-Aluminium-Iminosilikat}

\begin{tabular}{|c|c|c|}
\hline Identification code & Iodo & \\
\hline Empirical formula & $\mathrm{C}_{44.78} \mathrm{H}_{84.18} \mathrm{Al}_{4} \mathrm{Br}_{2.30} \mathrm{~N}_{8} \mathrm{Si}_{4}$ & \\
\hline Formula weight & $1246.89 \mathrm{~g} / \mathrm{mol}$ & \\
\hline Temperature & $133(2) \mathrm{K}$ & \\
\hline Wavelength & $0.71073 \AA$ & \\
\hline Crystal system & Monoclinic & \\
\hline Space group & $P 2_{1} / n$ & \\
\hline \multirow[t]{3}{*}{ Unit cell dimensions } & $a=11.093(2) \AA$ & $\alpha=90^{\circ}$ \\
\hline & $b=15.084(3) \AA$ & $\beta=101.00(3)^{\circ}$ \\
\hline & $c=17.880(4) \AA$ & $\gamma=90^{\circ}$ \\
\hline Volume & $2937(1) \AA^{3}$ & \\
\hline $\mathrm{Z}$ & 2 & \\
\hline Density (calculated) & $1.410 \mathrm{Mg} / \mathrm{m}^{3}$ & \\
\hline Absorption coefficient & $1.407 \mathrm{~mm}^{-1}$ & \\
\hline $\mathrm{F}(000)$ & 1278 & \\
\hline Crystal size & $0.20 \times 0.10 \times 0.10 \mathrm{~mm}^{3}$ & \\
\hline Theta range for data collection & $2.31 \leq \Theta \leq 27.00^{\circ}$ & \\
\hline Reflections collected & 76585 & \\
\hline Independent reflections & $6399\left(R_{i n t}=0.0682\right)$ & \\
\hline Completeness to $\Theta=27.00^{\circ}$ & $99.9 \%$ & \\
\hline Absorption correction & Semi-empirical from equivalents & \\
\hline Max. and min. transmission & 0.8721 and 0.7661 & \\
\hline Refinement method & Full-matrix least-squares on $F^{2}$ & \\
\hline Data / restraints / parameters & $6399 / 167 / 308$ & \\
\hline Goodness-of-fit on $F^{2}$ & 1.044 & \\
\hline Final $R$ indices $[I>2 \sigma(I)]$ & $R 1=0.0430, w R 2=0.1201$ & \\
\hline$R$ indices (all data) & $R 1=0.0619, w R 2=0.1264$ & \\
\hline Largest diff. peak and hole & 1.374 and $-0.942 \mathrm{e}^{-3}$ & \\
\hline
\end{tabular}




\subsection{9 $\left(\eta^{5}-\mathrm{C}_{5} \mathbf{M e}_{5}\right)_{2} \mathbf{T i}_{2}(\mu-\mathbf{F})_{8} \mathbf{A l}_{4} \mathbf{M e}_{8}$}

\begin{tabular}{|c|c|c|}
\hline Identification code & ESEL & \\
\hline Empirical formula & $\mathrm{C}_{28} \mathrm{H}_{54} \mathrm{Al}_{4} \mathrm{~F}_{8} \mathrm{Ti}_{2}$ & \\
\hline Formula weight & $746.43 \mathrm{~g} / \mathrm{mol}$ & \\
\hline Temperature & $133(2) \mathrm{K}$ & \\
\hline Wavelength & $0.71073 \AA$ & \\
\hline Crystal system & Monoclinic & \\
\hline Space group & $C 2 / c$ & \\
\hline \multirow[t]{3}{*}{ Unit cell dimensions } & $a=17.143(3) \AA$ & $\alpha=90^{\circ}$ \\
\hline & $b=15.078(3) \AA$ & $\beta=97.61(3)^{\circ}$ \\
\hline & $c=15.257(3) \AA$ & $\gamma=90^{\circ}$ \\
\hline Volume & $3909(1) \AA^{3}$ & \\
\hline $\mathrm{Z}$ & 4 & \\
\hline Density (calculated) & $1.268 \mathrm{Mg} / \mathrm{m}^{3}$ & \\
\hline Absorption coefficient & $0.553 \mathrm{~mm}^{-1}$ & \\
\hline $\mathrm{F}(000)$ & 1560 & \\
\hline Crystal size & $0.30 \times 0.30 \times 0.20 \mathrm{~mm}^{3}$ & \\
\hline Theta range for data collection & $1.81 \leq \Theta \leq 26.99^{\circ}$ & \\
\hline Reflections collected & 26730 & \\
\hline Independent reflections & $4277\left(R_{\text {int }}=0.0446\right)$ & \\
\hline Completeness to $\Theta=26.99^{\circ}$ & $100.0 \%$ & \\
\hline Absorption correction & Semi-empirical from equivalents & \\
\hline Max. and min. transmission & 0.8975 and 0.8517 & \\
\hline Refinement method & Full-matrix least-squares on $F^{2}$ & \\
\hline Data / restraints / parameters & 4277 / $310 / 274$ & \\
\hline Goodness-of-fit on $F^{2}$ & 1.020 & \\
\hline Final $R$ indices $[I>2 \sigma(I)]$ & $R 1=0.0355, w R 2=0.0876$ & \\
\hline$R$ indices (all data) & $R 1=0.0662, w R 2=0.0981$ & \\
\hline Largest diff. peak and hole & 0.281 and $-0.290 \mathrm{e}^{-3}$ & \\
\hline
\end{tabular}




\subsubsection{1-(3,3-Dimethyl-dithiolan-4-on)-2-(4,4-dimethyl- thiolan-3-on)-ethen}

\begin{tabular}{|c|c|c|}
\hline Identification code & $\mathrm{BACH}$ & \\
\hline Empirical formula & $\mathrm{C}_{11} \mathrm{H}_{14} \mathrm{O}_{2} \mathrm{~S}_{3}$ & \\
\hline Formula weight & $274.40 \mathrm{~g} / \mathrm{mol}$ & \\
\hline Temperature & $133(2) \mathrm{K}$ & \\
\hline Wavelength & $0.71073 \AA$ & \\
\hline Crystal system & Monoclinic & \\
\hline Space group & $P n$ & \\
\hline \multirow[t]{3}{*}{ Unit cell dimensions } & $a=8.416(2) \AA$ & $\alpha=90^{\circ}$ \\
\hline & $b=8.100(2) \AA$ & $\beta=100.95(3)^{\circ}$ \\
\hline & $c=9.209(2) \AA$ & $\gamma=90^{\circ}$ \\
\hline Volume & $616.3(2) \AA^{3}$ & \\
\hline $\mathrm{Z}$ & 2 & \\
\hline Density (calculated) & $1.479 \mathrm{Mg} / \mathrm{m}^{3}$ & \\
\hline Absorption coefficient & $0.583 \mathrm{~mm}^{-1}$ & \\
\hline $\mathrm{F}(000)$ & 288 & \\
\hline Crystal size & $0.40 \times 0.40 \times 0.30 \mathrm{~mm}^{3}$ & \\
\hline Theta range for data collection & $2.51 \leq \Theta \leq 26.37^{\circ}$ & \\
\hline Reflections collected & 15158 & \\
\hline Independent reflections & $2240\left(R_{i n t}=0.0287\right)$ & \\
\hline Completeness to $\Theta=26.37^{\circ}$ & $100.0 \%$ & \\
\hline Absorption correction & Semi-empirical from equivalents & \\
\hline Max. and min. transmission & 0.8445 and 0.8003 & \\
\hline Refinement method & Full-matrix least-squares on $F^{2}$ & \\
\hline Data / restraints / parameters & $2240 / 60 / 143$ & \\
\hline Goodness-of-fit on $F^{2}$ & 1.044 & \\
\hline Final $R$ indices $[I>2 \sigma(I)]$ & $R 1=0.0379, w R 2=0.0917$ & \\
\hline$R$ indices (all data) & $R 1=0.0414, w R 2=0.0946$ & \\
\hline Largest diff. peak and hole & 1.016 and $-0.337 \mathrm{e} \AA^{-3}$ & \\
\hline
\end{tabular}




\subsubsection{1,2-bis-(3,3-Dimethyl-dithiolan-4-on)-ethen}

\begin{tabular}{|c|c|c|}
\hline Identification code & DVORAK & \\
\hline Empirical formula & $\mathrm{C}_{10} \mathrm{H}_{12} \mathrm{O}_{2} \mathrm{~S}_{4}$ & \\
\hline Formula weight & $292.44 \mathrm{~g} / \mathrm{mol}$ & \\
\hline Temperature & $133(2) \mathrm{K}$ & \\
\hline Wavelength & $0.71073 \AA$ & \\
\hline Crystal system & Monoclinic & \\
\hline Space group & $P 2_{1} / n$ & \\
\hline \multirow[t]{3}{*}{ Unit cell dimensions } & $a=8.265(2) \AA$ & $\alpha=90^{\circ}$ \\
\hline & $b=8.228(2) \AA$ & $\beta=101.14(3)^{\circ}$ \\
\hline & $c=9.178(2) \AA$ & $\gamma=90^{\circ}$ \\
\hline Volume & $612.4(2) \AA^{3}$ & \\
\hline $\mathrm{Z}$ & 2 & \\
\hline Density (calculated) & $1.586 \mathrm{Mg} / \mathrm{m}^{3}$ & \\
\hline Absorption coefficient & $0.756 \mathrm{~mm}^{-1}$ & \\
\hline $\mathrm{F}(000)$ & 304 & \\
\hline Crystal size & $0.70 \times 0.50 \times 0.20 \mathrm{~mm}^{3}$ & \\
\hline Theta range for data collection & $3.04 \leq \Theta \leq 26.37^{\circ}$ & \\
\hline Reflections collected & 10502 & \\
\hline Independent reflections & $1248\left(R_{\text {int }}=0.0366\right)$ & \\
\hline Completeness to $\Theta=26.37^{\circ}$ & $99.5 \%$ & \\
\hline Absorption correction & Semi-empirical from equivalents & \\
\hline Max. and min. transmission & 0.8635 and 0.6196 & \\
\hline Refinement method & Full-matrix least-squares on $F^{2}$ & \\
\hline Data / restraints / parameters & $1248 / 0 / 76$ & \\
\hline Goodness-of-fit on $F^{2}$ & 1.082 & \\
\hline Final $R$ indices $[I>2 \sigma(I)]$ & $R 1=0.0221, w R 2=0.0678$ & \\
\hline$R$ indices (all data) & $R 1=0.0245, w R 2=0.0590$ & \\
\hline Largest diff. peak and hole & 0.398 and $-0.230 \mathrm{e}^{-3}$ & \\
\hline
\end{tabular}


13.1.12 $\mathrm{Si}_{2}\left(\mathrm{NH}_{2}\right)_{4}\left((\mathrm{CHSiMe})_{2}\right)_{2}$

\begin{tabular}{|c|c|c|}
\hline Identification code & ACKER & \\
\hline Empirical formula & $\mathrm{C}_{14} \mathrm{H}_{46} \mathrm{~N}_{4} \mathrm{Si}_{6}$ & \\
\hline Formula weight & $439.09 \mathrm{~g} / \mathrm{mol}$ & \\
\hline Temperature & $133(2) \mathrm{K}$ & \\
\hline Wavelength & $0.71073 \AA$ & \\
\hline Crystal system & Triclinic & \\
\hline Space group & $P \overline{1}$ & \\
\hline \multirow[t]{3}{*}{ Unit cell dimensions } & $a=15.198(3) \AA$ & $\alpha=90(3)^{\circ}$ \\
\hline & $b=25.390(5) \AA$ & $\beta=97.61(3)^{\circ}$ \\
\hline & $c=25.527(5) \AA$ & $\gamma=90(3)^{\circ}$ \\
\hline Volume & $8254(3) \AA^{3}$ & \\
\hline $\mathrm{Z}$ & 12 & \\
\hline Density (calculated) & $1.060 \mathrm{Mg} / \mathrm{m}^{3}$ & \\
\hline Absorption coefficient & $0.309 \mathrm{~mm}^{-1}$ & \\
\hline $\mathrm{F}(000)$ & 2904 & \\
\hline Crystal size & $0.30 \times 0.30 \times 0.10 \mathrm{~mm}^{3}$ & \\
\hline Theta range for data collection & $1.65 \leq \Theta \leq 23.26^{\circ}$ & \\
\hline Reflections collected & 81603 & \\
\hline Independent reflections & $23689\left(R_{\text {int }}=0.0646\right)$ & \\
\hline Completeness to $\Theta=23.26^{\circ}$ & $99.9 \%$ & \\
\hline Absorption correction & Semi-empirical from equivalents & \\
\hline Max. and min. transmission & 0.9697 and 0.9129 & \\
\hline Refinement method & Full-matrix least-squares on $F^{2}$ & \\
\hline Data / restraints / parameters & $13589 / 503 / 1435$ & \\
\hline Goodness-of-fit on $F^{2}$ & 1.013 & \\
\hline Final $R$ indices $[I>2 \sigma(I)]$ & $R 1=0.0538, w R 2=0.1317$ & \\
\hline$R$ indices (all data) & $R 1=0.0931, w R 2=0.1530$ & \\
\hline Largest diff. peak and hole & 1.242 and $-0.357 \mathrm{e}^{-3}$ & \\
\hline
\end{tabular}


13.1.13 $\mathrm{C}_{22} \mathrm{H}_{22} \mathrm{~N}_{4} \mathrm{O}_{6}$

\begin{tabular}{|c|c|c|}
\hline Identification code & VIEH & \\
\hline Empirical formula & $\mathrm{C}_{22} \mathrm{H}_{22} \mathrm{~N}_{4} \mathrm{O}_{6}$ & \\
\hline Formula weight & $438.44 \mathrm{~g} / \mathrm{mol}$ & \\
\hline Temperature & $133(2) \mathrm{K}$ & \\
\hline Wavelength & $0.71073 \AA$ & \\
\hline Crystal system & Monoclinic & \\
\hline Space group & $P 2_{1}$ & \\
\hline \multirow[t]{3}{*}{ Unit cell dimensions } & $a=8.146(2) \AA$ & $\alpha=90^{\circ}$ \\
\hline & $b=34.305(7) \AA$ & $\beta=118.56(3)^{\circ}$ \\
\hline & $c=8.507(2) \AA$ & $\gamma=90^{\circ}$ \\
\hline Volume & $2088.0(7) \AA^{3}$ & \\
\hline $\mathrm{Z}$ & 4 & \\
\hline Density (calculated) & $1.395 \mathrm{Mg} / \mathrm{m}^{3}$ & \\
\hline Absorption coefficient & $0.103 \mathrm{~mm}^{-1}$ & \\
\hline $\mathrm{F}(000)$ & 920 & \\
\hline Crystal size & $0.40 \times 0.20 \times 0.10 \mathrm{~mm}^{3}$ & \\
\hline Theta range for data collection & $2.37 \leq \Theta \leq 26.00^{\circ}$ & \\
\hline Reflections collected & 47799 & \\
\hline Independent reflections & $4109\left(R_{i n t}=0.0928\right)$ & \\
\hline Completeness to $\Theta=26.00^{\circ}$ & $98.2 \%$ & \\
\hline Absorption correction & Semi-empirical from equivalents & \\
\hline Max. and min. transmission & 0.9897 and 0.9598 & \\
\hline Refinement method & Full-matrix least-squares on $F^{2}$ & \\
\hline Data / restraints / parameters & 4109 / 690 / 590 & \\
\hline Goodness-of-fit on $F^{2}$ & 1.109 & \\
\hline Final $R$ indices $[I>2 \sigma(I)]$ & $R 1=0.0550, w R 2=0.1403$ & \\
\hline$R$ indices (all data) & $R 1=0.0559, w R 2=0.1423$ & \\
\hline Largest diff. peak and hole & 0.414 and $-0.376 \mathrm{e}^{-3}$ & \\
\hline
\end{tabular}




\subsubsection{Zr-Pyramide}

\begin{tabular}{|c|c|c|}
\hline Identification code & ELEFANT & \\
\hline Empirical formula & $\mathrm{C}_{30} \mathrm{H}_{47} \mathrm{~N}_{9} \mathrm{Zr}_{5}$ & \\
\hline Formula weight & $989.87 \mathrm{~g} / \mathrm{mol}$ & \\
\hline Temperature & $133(2) \mathrm{K}$ & \\
\hline Wavelength & $0.71073 \AA$ & \\
\hline Crystal system & Tetragonal & \\
\hline Space group & $I 4$ & \\
\hline \multirow[t]{3}{*}{ Unit cell dimensions } & $a=13.188(2) \AA$ & $\alpha=90^{\circ}$ \\
\hline & $b=13.188(2) \AA$ & $\beta=90^{\circ}$ \\
\hline & $c=9.522(2) \AA$ & $\gamma=90^{\circ}$ \\
\hline Volume & $1656.1(5) \AA^{3}$ & \\
\hline $\mathrm{Z}$ & 2 & \\
\hline Density (calculated) & $1.985 \mathrm{Mg} / \mathrm{m}^{3}$ & \\
\hline Absorption coefficient & $1.558 \mathrm{~mm}^{-1}$ & \\
\hline $\mathrm{F}(000)$ & 980 & \\
\hline Crystal size & $0.40 \times 0.30 \times 0.30 \mathrm{~mm}^{3}$ & \\
\hline Theta range for data collection & $2.18 \leq \Theta \leq 27.98^{\circ}$ & \\
\hline Reflections collected & 20345 & \\
\hline Independent reflections & $2012\left(R_{\text {int }}=0.0252\right)$ & \\
\hline Completeness to $\Theta=27.98^{\circ}$ & $100.0 \%$ & \\
\hline Absorption correction & Semi-empirical from equivalents & \\
\hline Max. and min. transmission & 0.6522 and 0.5746 & \\
\hline Refinement method & Full-matrix least-squares on $F^{2}$ & \\
\hline Data / restraints / parameters & $2012 / 281 / 152$ & \\
\hline Goodness-of-fit on $F^{2}$ & 1.035 & \\
\hline Final $R$ indices $[I>2 \sigma(I)]$ & $R 1=0.0443, w R 2=0.1085$ & \\
\hline$R$ indices (all data) & $R 1=0.0458, w R 2=0.1099$ & \\
\hline Largest diff. peak and hole & 1.417 and $-1.983 \mathrm{e}^{-3}$ & \\
\hline
\end{tabular}




\subsubsection{In-Iminosilikat}

\begin{tabular}{|c|c|c|}
\hline Identification code & LASSO & \\
\hline Empirical formula & $\mathrm{C}_{40} \mathrm{H}_{84} \mathrm{In}_{4} \mathrm{~N}_{8} \mathrm{Si}_{4}$ & \\
\hline Formula weight & $1248.79 \mathrm{~g} / \mathrm{mol}$ & \\
\hline Temperature & $133(2) \mathrm{K}$ & \\
\hline Wavelength & $0.71073 \AA$ & \\
\hline Crystal system & Triclinic & \\
\hline Space group & $P \overline{1}$ & \\
\hline \multirow[t]{3}{*}{ Unit cell dimensions } & $a=10.1158(2) \AA$ & $\alpha=99.078(1)^{\circ}$ \\
\hline & $b=10.9389(2) \AA$ & $\beta=96.416(1)^{\circ}$ \\
\hline & $c=13.3201(2) \AA$ & $\gamma=111.077(1)^{\circ}$ \\
\hline Volume & $1335.21(4) \AA^{3}$ & \\
\hline Z & 1 & \\
\hline Density (calculated) & $1.553 \mathrm{Mg} / \mathrm{m}^{3}$ & \\
\hline Absorption coefficient & $1.830 \mathrm{~mm}^{-1}$ & \\
\hline $\mathrm{F}(000)$ & 632 & \\
\hline Crystal size & $0.20 \times 0.20 \times 0.10 \mathrm{~mm}^{3}$ & \\
\hline Theta range for data collection & $2.19 \leq \Theta \leq 23.25^{\circ}$ & \\
\hline Reflections collected & 28307 & \\
\hline Independent reflections & $3842\left(R_{\text {int }}=0.0641\right)$ & \\
\hline Completeness to $\Theta=23.25^{\circ}$ & $99.8 \%$ & \\
\hline Absorption correction & Semi-empirical from equivalents & \\
\hline Max. and min. transmission & 0.8382 and 0.7111 & \\
\hline Refinement method & Full-matrix least-squares on $F^{2}$ & \\
\hline Data / restraints / parameters & $3842 / 3 / 273$ & \\
\hline Goodness-of-fit on $F^{2}$ & 1.166 & \\
\hline Final $R$ indices $[I>2 \sigma(I)]$ & $R 1=0.0414, w R 2=0.0940$ & \\
\hline$R$ indices (all data) & $R 1=0.0616, w R 2=0.1065$ & \\
\hline Largest diff. peak and hole & 2.041 and $-0.779 \mathrm{e}^{-3}$ & \\
\hline
\end{tabular}




\subsection{Intensitätsstatistiken für die Daten von Lysozy- me und Actagardin}

Im Folgenden werden die mit XPREP [64] berechneten Intensitäts-, $\left|E^{2}-1\right|$ - und Auslöschungsstatistiken für die einzelnen Datensätze von Lysozyme und Actagardin angegeben. Für die Datensätze von Actagardin ist zusätzlich die Stärke des anomalen Signals als Funktion der Auflösung aufgeführt.

\subsubsection{Lysozyme}

\subsubsection{Euler-Vierkreis / SMART 1K}

\begin{tabular}{|c|c|c|c|c|c|c|c|c|}
\hline Resolution & \#Data & \#Theory & $\%$ Complete & Redundancy & Mean I & Mean I/s & $R$ (int) & $R$ (sigma) \\
\hline Inf -5.40 & 471 & 477 & 98.7 & 16.31 & 139.3 & 37.64 & 0.0945 & 0.0228 \\
\hline $5.40-4.20$ & 490 & 490 & 100.0 & 22.58 & 255.0 & 51.67 & 0.0752 & 0.0166 \\
\hline $4.20-3.65$ & 474 & 474 & 100.0 & 23.21 & 282.5 & 49.12 & 0.0815 & 0.0179 \\
\hline $3.65-3.25$ & 554 & 554 & 100.0 & 19.87 & 244.6 & 39.84 & 0.0923 & 0.0231 \\
\hline $3.25-3.00$ & 512 & 512 & 100.0 & 16.91 & 170.3 & 27.37 & 0.1201 & 0.0351 \\
\hline $3.00-2.80$ & 548 & 548 & 100.0 & 15.35 & 114.3 & 18.28 & 0.1686 & 0.0536 \\
\hline $2.80-2.65$ & 511 & 511 & 100.0 & 14.22 & 92.9 & 14.23 & 0.2059 & 0.0691 \\
\hline $2.65-2.50$ & 645 & 645 & 100.0 & 13.37 & 80.7 & 11.99 & 0.2336 & 0.0832 \\
\hline $2.50-2.40$ & 539 & 539 & 100.0 & 12.56 & 66.5 & 9.44 & 0.2828 & 0.1066 \\
\hline $2.40-2.30$ & 611 & 611 & 100.0 & 11.99 & 66.4 & 8.86 & 0.3047 & 0.1131 \\
\hline $2.30-2.20$ & 730 & 730 & 100.0 & 11.52 & 63.1 & 7.97 & 0.3486 & 0.1248 \\
\hline $2.20-2.10$ & 885 & 885 & 100.0 & 10.84 & 52.3 & 6.23 & 0.4176 & 0.1599 \\
\hline $2.10-2.05$ & 502 & 502 & 100.0 & 10.48 & 44.0 & 5.11 & 0.4949 & 0.1980 \\
\hline $2.05-2.00$ & 561 & 561 & 100.0 & 10.26 & 39.8 & 4.48 & 0.5417 & 0.2228 \\
\hline $2.00-1.95$ & 605 & 605 & 100.0 & 10.02 & 34.2 & 3.78 & 0.6244 & 0.2674 \\
\hline $1.95-1.90$ & 687 & 687 & 100.0 & 9.69 & 29.3 & 3.13 & 0.7096 & 0.3218 \\
\hline $2.00-1.90$ & 1292 & 1292 & 100.0 & 9.84 & 31.6 & 3.43 & 0.6657 & 0.2942 \\
\hline Inf -1.90 & 9325 & 9331 & 99.9 & 13.89 & 103.3 & 17.03 & 0.1607 & 0.0686 \\
\hline
\end{tabular}

Mean $|\mathrm{E} * \mathrm{E}-1|=0.690$ [expected .968 centrosym and .736 non-centrosym]

Systematic absence exceptions:

$$
41 / 43 \quad 42 \quad \mathrm{n}--\quad-\mathrm{b}-\quad-\mathrm{c}^{-} \quad-\mathrm{n}^{-} \quad-21-\quad--\mathrm{c}
$$

$\begin{array}{lllllllll}\text { N } & 30 & 19 & 3814 & 2591 & 2537 & 2586 & 84 & 1887\end{array}$

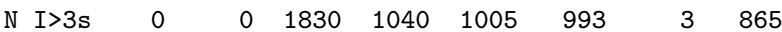

$\begin{array}{lllllllll}\text { <I> } & 6.3 & 7.3 & 140.9 & 105.0 & 141.6 & 120.0 & 17.3 & 144.0\end{array}$

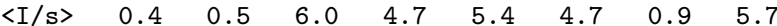




\subsubsection{Zweikreis / IPDS}

INTENSITY STATISTICS FOR DATASET \# 3 ly_ipds.hkl

Resolution \#Data \#Theory \%Complete Redundancy Mean I Mean I/s R(int) R(sigma)

$\begin{array}{rrrrrrrrr}\text { Inf - }-4.80 & 668 & 676 & 98.8 & 11.93 & 69.6 & 33.43 & 0.1330 & 0.0240 \\ 4.80-3.75 & 668 & 668 & 100.0 & 13.63 & 82.1 & 40.93 & 0.1366 & 0.0192 \\ 3.75-3.25 & 683 & 683 & 100.0 & 13.93 & 61.5 & 36.19 & 0.1380 & 0.0233 \\ 3.25-2.90 & 761 & 761 & 100.0 & 14.20 & 34.3 & 26.37 & 0.1472 & 0.0324 \\ 2.90-2.65 & 844 & 844 & 100.0 & 14.23 & 18.1 & 17.69 & 0.1607 & 0.0501 \\ 2.65-2.45 & 911 & 911 & 100.0 & 14.39 & 11.9 & 13.22 & 0.1732 & 0.0681 \\ 2.45-2.30 & 921 & 921 & 100.0 & 14.45 & 9.1 & 10.65 & 0.1891 & 0.0855 \\ 2.30-2.20 & 724 & 724 & 100.0 & 14.54 & 7.5 & 9.08 & 0.1997 & 0.1014 \\ 2.20-2.10 & 891 & 891 & 100.0 & 14.50 & 6.1 & 7.67 & 0.2122 & 0.1212 \\ 2.10-2.00 & 1091 & 1091 & 100.0 & 14.47 & 4.7 & 6.33 & 0.2284 & 0.1508 \\ 2.00-1.90 & 1307 & 1307 & 100.0 & 14.45 & 3.4 & 4.90 & 0.2572 & 0.1935 \\ 1.90-1.85 & 768 & 768 & 100.0 & 14.18 & 2.5 & 3.91 & 0.2886 & 0.2474 \\ 1.85-1.80 & 845 & 845 & 100.0 & 14.31 & 1.8 & 2.95 & 0.3544 & 0.3321 \\ 1.80-1.75 & 943 & 943 & 100.0 & 14.17 & 1.4 & 2.39 & 0.4200 & 0.4112 \\ 1.75-1.70 & 1061 & 1061 & 100.0 & 14.08 & 1.1 & 1.98 & 0.4817 & 0.4993 \\ ---------------------------------- \\ 1.80-1.70 & 2004 & 2004 & 100.0 & 14.13 & 1.2 & 2.17 & 0.4495 & 0.4532 \\ \text { Inf - 1.70 } & 13086 & 13094 & 99.9 & 14.15 & 17.6 & 12.82 & 0.1577 & 0.0485 \\ \text { Merged - [A] } & \text { lowest resolution }=26.93 & \text { Angstroms, } & 12118 & \text { outliers downweighted }\end{array}$

Mean $|\mathrm{E} * \mathrm{E}-1|=0.753$ [expected .968 centrosym and .736 non-centrosym]

Systematic absence exceptions:

$\begin{array}{lrrrrrrrr} & 41 / 43 & 42 & \mathrm{n}-- & -\mathrm{b}- & -\mathrm{c}- & -\mathrm{n}- & -21- & --\mathrm{c} \\ & & & & & & & & \\ \text { N } & 32 & 20 & 3025 & 2996 & 2973 & 2951 & 81 & 2187 \\ \text { N I >3s } & 0 & 0 & 1134 & 1034 & 965 & 1027 & 0 & 789 \\ \text { 〈I } & 0.7 & 0.6 & 26.1 & 19.2 & 24.5 & 21.4 & 0.9 & 26.2 \\ \langle\text { I/s }> & 0.3 & 0.3 & 4.7 & 4.0 & 4.5 & 4.2 & 0.3 & 5.0\end{array}$




\subsubsection{Platform / HiStar}

INTENSITY STATISTICS FOR DATASET \# 2 sad.hkl

Resolution \#Data \#Theory \%Complete Redundancy Mean I Mean I/s R(int) R(sigma)

\begin{tabular}{|c|c|c|c|c|c|c|c|c|c|}
\hline $\operatorname{Inf}$ & -3.65 & 1448 & 1450 & 99.9 & 39.93 & 107.0 & 153.97 & 0.0403 & 0.0052 \\
\hline 3.65 & -2.85 & 1462 & 1462 & 100.0 & 32.68 & 81.7 & 95.33 & 0.0448 & 0.0088 \\
\hline 2.85 & -2.45 & 1585 & 1585 & 100.0 & 28.13 & 33.7 & 58.29 & 0.0665 & 0.0161 \\
\hline 2.45 & -2.20 & 1634 & 1634 & 100.0 & 20.72 & 25.9 & 68.15 & 0.0703 & 0.0134 \\
\hline 2.20 & -2.00 & 1955 & 1955 & 100.0 & 19.48 & 19.0 & 53.36 & 0.0876 & 0.0176 \\
\hline 2.00 & -1.85 & 2059 & 2059 & 100.0 & 13.36 & 11.9 & 35.66 & 0.0912 & 0.0267 \\
\hline 1.85 & -1.75 & 1775 & 1775 & 100.0 & 11.52 & 7.5 & 23.91 & 0.1030 & 0.0409 \\
\hline 1.75 & -1.65 & 2229 & 2229 & 100.0 & 10.92 & 5.6 & 18.14 & 0.1253 & 0.0550 \\
\hline 1.65 & -1.55 & 2835 & 2836 & 100.0 & 10.30 & 4.3 & 13.32 & 0.1562 & 0.0746 \\
\hline 1.55 & -1.50 & 1703 & 1703 & 100.0 & 9.87 & 3.2 & 9.52 & 0.2019 & 0.1047 \\
\hline 1.50 & -1.45 & 1944 & 1944 & 100.0 & 9.54 & 2.7 & 7.95 & 0.2431 & 0.1262 \\
\hline 1.45 & -1.40 & 2251 & 2251 & 100.0 & 9.28 & 2.1 & 5.86 & 0.3144 & 0.1734 \\
\hline 1.40 & -1.35 & 2561 & 2563 & 99.9 & 8.58 & 1.7 & 4.44 & 0.3927 & 0.2319 \\
\hline 1.35 & -1.30 & 2951 & 2967 & 99.5 & 7.22 & 1.3 & 3.16 & 0.4807 & 0.3292 \\
\hline 1.40 & -1.30 & 5512 & 5530 & 99.7 & 7.85 & 1.5 & 3.76 & 0.4306 & 0.2786 \\
\hline $\operatorname{Inf}$ & -1.30 & 28392 & 28413 & 99.9 & 14.90 & 17.4 & 32.76 & 0.0562 & 0.0224 \\
\hline
\end{tabular}

Mean $|E * E-1|=0.733$ [expected .968 centrosym and .736 non-centrosym]

Systematic absence exceptions:

$$
41 / 43 \quad 42 \quad \mathrm{n}^{--} \quad-\mathrm{b}-\quad-\mathrm{c}^{-} \quad-\mathrm{n}^{-} \quad-21-\quad--\mathrm{c}
$$

$\begin{array}{lllllllll}\mathrm{N} & 84 & 53 & 6706 & 7486 & 7420 & 7398 & 227 & 4971\end{array}$

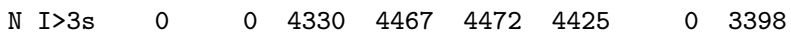

$\begin{array}{lllllllll}\text { <I> } & 0.4 & 0.3 & 55.5 & 35.0 & 45.7 & 38.2 & 0.5 & 53.0\end{array}$

$\begin{array}{lllllllll}\langle\mathrm{I} / \mathrm{s}\rangle & 0.3 & 0.3 & 14.7 & 11.4 & 12.3 & 11.5 & 0.3 & 14.8\end{array}$ 


\subsubsection{Einkreis / MAR345}

INTENSITY STATISTICS FOR DATASET \# 1 1y1_mar345.sca

Resolution \#Data \#Theory \%Complete Redundancy Mean I Mean I/s R(int) R(sigma)

\begin{tabular}{|c|c|c|c|c|c|c|c|c|c|}
\hline $\operatorname{Inf}$ & -4.40 & 828 & 845 & 98.0 & 23.91 & 397.1 & 63.00 & 0.0515 & 0.0182 \\
\hline 4.40 & -3.45 & 824 & 825 & 99.9 & 26.78 & 544.2 & 68.03 & 0.0472 & 0.0160 \\
\hline 3.45 & -3.00 & 820 & 822 & 99.8 & 26.67 & 337.2 & 65.88 & 0.0499 & 0.0158 \\
\hline 3.00 & -2.70 & 870 & 871 & 99.9 & 27.47 & 175.7 & 61.60 & 0.0540 & 0.0161 \\
\hline 2.70 & -2.50 & 821 & 821 & 100.0 & 28.04 & 127.2 & 60.31 & 0.0573 & 0.0151 \\
\hline 2.50 & -2.35 & 819 & 819 & 100.0 & 27.84 & 97.8 & 55.86 & 0.0623 & 0.0155 \\
\hline 2.35 & -2.20 & 1036 & 1037 & 99.9 & 27.57 & 90.2 & 51.57 & 0.0677 & 0.0172 \\
\hline 2.20 & -2.10 & 887 & 887 & 100.0 & 27.00 & 69.5 & 47.17 & 0.0736 & 0.0182 \\
\hline 2.10 & -2.00 & 1052 & 1052 & 100.0 & 26.90 & 53.3 & 41.85 & 0.0871 & 0.0203 \\
\hline 2.00 & -1.90 & 1273 & 1273 & 100.0 & 26.19 & 40.5 & 36.30 & 0.1021 & 0.0240 \\
\hline 1.90 & -1.80 & 1582 & 1583 & 99.9 & 25.80 & 23.6 & 30.65 & 0.1305 & 0.0279 \\
\hline 1.80 & -1.75 & 910 & 910 & 100.0 & 25.02 & 14.4 & 24.53 & 0.1682 & 0.0348 \\
\hline 1.75 & -1.70 & 1041 & 1041 & 100.0 & 25.07 & 11.4 & 22.36 & 0.1927 & 0.0390 \\
\hline 1.70 & -1.65 & 1158 & 1158 & 100.0 & 24.59 & 8.8 & 19.31 & 0.2399 & 0.0470 \\
\hline 1.65 & -1.60 & 1310 & 1310 & 100.0 & 23.92 & 6.9 & 16.08 & 0.2829 & 0.0578 \\
\hline 1.60 & -1.57 & 969 & 982 & 98.7 & 20.08 & 4.7 & 10.66 & 0.3586 & 0.0982 \\
\hline---- & ------ & & & & & -- & & -------- & ------- \\
\hline 1.70 & -1.57 & 3437 & 3450 & 99.6 & 23.05 & 6.9 & 15.64 & 0.2762 & 0.0609 \\
\hline $\operatorname{Inf}$ & -1.57 & 16200 & 16236 & 99.8 & 25.71 & 107.4 & 39.78 & 0.0620 & 0.0180 \\
\hline
\end{tabular}

Mean $|\mathrm{E} * \mathrm{E}-1|=0.733$ [expected .968 centrosym and .736 non-centrosym]

Systematic absence exceptions:

$41 / 4342 \quad n--\quad-b-\quad-c-\quad-n-\quad-21-\quad--c$

$\begin{array}{lllllllll}\mathrm{N} & 50 & 34 & 5847 & 6348 & 6295 & 6281 & 139 & 4638\end{array}$

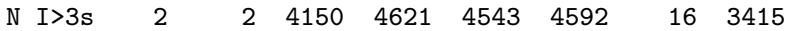

$\begin{array}{lllllllll}\text { <I> } & 1.3 & 1.2 & 141.4 & 128.3 & 152.1 & 127.2 & 1.7 & 164.8\end{array}$

$\begin{array}{lllllllll}\text { LI/s }\rangle & 0.8 & 0.8 & 7.9 & 7.9 & 7.8 & 7.9 & 1.2 & 8.2\end{array}$ 


\subsubsection{Einkreis / marCCD}

INTENSITY STATISTICS FOR DATASET \# 1 marccd.sca

Resolution \#Data \#Theory \%Complete Redundancy Mean I Mean I/s R(int) R(sigma)

\begin{tabular}{|c|c|c|c|c|c|c|c|c|c|}
\hline Inf & -4.30 & 857 & 905 & 94.7 & 18.42 & 630.0 & 44.27 & 0.0708 & 0.0256 \\
\hline 4.30 & -3.40 & 849 & 855 & 99.3 & 21.49 & 881.9 & 47.62 & 0.0620 & 0.0226 \\
\hline 3.40 & -2.95 & 883 & 883 & 100.0 & 22.23 & 587.1 & 50.32 & 0.0569 & 0.0205 \\
\hline 2.95 & -2.65 & 944 & 945 & 99.9 & 22.65 & 299.9 & 50.53 & 0.0534 & 0.0195 \\
\hline 2.65 & -2.45 & 910 & 910 & 100.0 & 22.75 & 221.5 & 50.21 & 0.0517 & 0.0196 \\
\hline 2.45 & -2.30 & 905 & 905 & 100.0 & 22.90 & 190.3 & 49.28 & 0.0516 & 0.0202 \\
\hline 2.30 & -2.15 & 1152 & 1152 & 100.0 & 23.08 & 159.5 & 45.26 & 0.0536 & 0.0221 \\
\hline 2.15 & -2.05 & 987 & 987 & 100.0 & 22.96 & 125.5 & 42.27 & 0.0574 & 0.0232 \\
\hline 2.05 & -1.95 & 1157 & 1157 & 100.0 & 23.02 & 95.9 & 39.87 & 0.0589 & 0.0245 \\
\hline 1.95 & -1.85 & 1443 & 1443 & 100.0 & 23.09 & 62.6 & 37.45 & 0.0650 & 0.0255 \\
\hline 1.85 & -1.80 & 846 & 846 & 100.0 & 23.00 & 44.6 & 36.01 & 0.0692 & 0.0259 \\
\hline 1.80 & -1.75 & 932 & 932 & 100.0 & 22.94 & 35.3 & 34.91 & 0.0744 & 0.0260 \\
\hline 1.75 & -1.70 & 1048 & 1048 & 100.0 & 23.18 & 30.2 & 34.14 & 0.0781 & 0.0263 \\
\hline 1.70 & -1.65 & 1185 & 1185 & 100.0 & 22.98 & 24.4 & 32.27 & 0.0827 & 0.0270 \\
\hline 1.65 & -1.60 & 1340 & 1340 & 100.0 & 22.98 & 21.8 & 31.03 & 0.0915 & 0.0280 \\
\hline 1.60 & -1.55 & 1412 & 1417 & 99.6 & 22.76 & 15.5 & 28.00 & 0.1034 & 0.0306 \\
\hline 1.65 & -1.55 & 2752 & 2757 & 99.8 & 22.87 & 18.5 & 29.48 & 0.0966 & 0.0291 \\
\hline $\operatorname{Inf}$ & -1.55 & 16850 & 16910 & 99.6 & 22.60 & 187.2 & 39.94 & 0.0608 & 0.0226 \\
\hline
\end{tabular}

Mean $|\mathrm{E} * \mathrm{E}-1|=0.735$ [expected .968 centrosym and .736 non-centrosym]

Systematic absence exceptions:

$\begin{array}{lrrrrrrrr} & 41 / 43 & 42 & \mathrm{n}-- & -\mathrm{b}- & -\mathrm{c}- & -\mathrm{n}- & -21- & --\mathrm{c} \\ & & & & & & & & \\ \mathrm{N} & 47 & 33 & 6306 & 5457 & 5393 & 5430 & 129 & 3650 \\ \mathrm{~N} \mathrm{I}>3 \mathrm{~s} & 13 & 7 & 5367 & 4826 & 4886 & 4842 & 0 & 3402 \\ \langle\mathrm{I}\rangle & 0.5 & 0.3 & 250.0 & 213.4 & 238.8 & 216.5 & 0.3 & 262.4 \\ \langle\mathrm{I} / \mathrm{s}\rangle & 1.8 & 1.4 & 7.9 & 8.1 & 8.3 & 8.2 & 0.4 & 8.6\end{array}$




\subsubsection{Actagardin}

\subsubsection{Zweikreis / IPDS}

INTENSITY STATISTICS FOR DATASET \# 4 acta-ipds.hkl

Resolution \#Data \#Theory \%Complete Redundancy Mean I Mean I/s R(int) R(sigma)

$\begin{array}{rrrrrrrrr}\text { Inf - }-6.05 & 92 & 94 & 97.9 & 19.57 & 98.2 & 5.53 & 0.0847 & 0.1595 \\ 6.05-4.75 & 92 & 92 & 100.0 & 22.42 & 79.3 & 6.52 & 0.1011 & 0.1490 \\ 4.75-4.10 & 99 & 99 & 100.0 & 22.67 & 103.7 & 8.79 & 0.1006 & 0.1118 \\ 4.10-3.70 & 97 & 97 & 100.0 & 22.92 & 99.4 & 8.73 & 0.1098 & 0.1106 \\ 3.70-3.40 & 101 & 101 & 100.0 & 22.93 & 88.4 & 8.17 & 0.1176 & 0.1182 \\ 3.40-3.20 & 101 & 101 & 100.0 & 22.94 & 54.1 & 5.55 & 0.1585 & 0.1804 \\ 3.20-3.00 & 121 & 121 & 100.0 & 22.99 & 53.4 & 5.80 & 0.1649 & 0.1719 \\ 3.00-2.85 & 119 & 119 & 100.0 & 23.25 & 39.4 & 4.29 & 0.2181 & 0.2183 \\ 2.85-2.70 & 142 & 142 & 100.0 & 22.98 & 24.8 & 3.02 & 0.3079 & 0.3303 \\ 2.70-2.60 & 113 & 113 & 100.0 & 23.13 & 26.0 & 3.33 & 0.2885 & 0.3008 \\ 2.60-2.50 & 129 & 129 & 100.0 & 23.21 & 21.2 & 2.76 & 0.3514 & 0.3564 \\ 2.50-2.40 & 152 & 152 & 100.0 & 23.04 & 19.8 & 2.64 & 0.3693 & 0.3760 \\ 2.40-2.35 & 97 & 97 & 100.0 & 22.96 & 16.5 & 2.25 & 0.4556 & 0.4391 \\ 2.35-2.25 & 195 & 195 & 100.0 & 23.08 & 18.4 & 2.58 & 0.3982 & 0.3871 \\ 2.25-2.20 & 123 & 123 & 100.0 & 23.15 & 14.5 & 2.09 & 0.5060 & 0.4767 \\ -------------------------------------------------------- \\ 2.30-2.20 & 230 & 230 & 100.0 & 23.06 & 15.3 & 2.18 & 0.4801 & 0.4595 \\ \text { Inf - } 2.20 & 1773 & 1775 & 99.9 & 22.82 & 45.7 & 4.49 & 0.1851 & 0.1978\end{array}$

Merged [S], lowest resolution $=27.31$ Angstroms, 2 outliers downweighted

Mean $|\mathrm{E} * \mathrm{E}-1|=0.737$ [expected .968 centrosym and .736 non-centrosym]

Systematic absence exceptions:

$\begin{array}{lrrrrrr} & 41 / 43 & 42=21 & \text { a-- } & \text { b-- } & \text { n-- } & --n \\ \text { N } & 62 & 21 & 1122 & 1120 & 1140 & 1504 \\ \text { N I }>3 s & 0 & 0 & 226 & 228 & 144 & 335 \\ \langle\mathrm{I}\rangle & 14.1 & 14.4 & 100.3 & 100.5 & 82.4 & 105.1 \\ \langle\mathrm{I} / \mathrm{s}\rangle & 0.3 & 0.3 & 1.8 & 1.8 & 1.4 & 1.8\end{array}$

Anomalous signal/noise ratios ( 1.0 is random). The first line is based on input sigmas, the second on variances of $\mathrm{F}+$ and $\mathrm{F}-$ (if not already averaged):

Inf $-8.0-6.0-5.0-4.0-3.6-3.4-3.2-3.0-2.8-2.6-2.4-2.2 \mathrm{~A}$

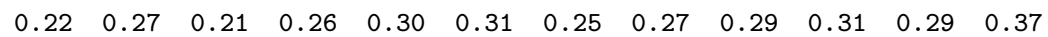

$\begin{array}{llllllllllll}1.96 & 1.85 & 1.21 & 1.21 & 1.19 & 1.21 & 1.00 & 1.00 & 1.06 & 1.08 & 1.00 & 1.21\end{array}$

76.6 Neighbors used on average for F+/F- local scaling

Rint $($ anom $)=0.0623$ before and 0.0633 after local scaling 


\subsubsection{Platform / HiStar}

INTENSITY STATISTICS FOR DATASET \# 2 acta_mwpc.hkl

Resolution \#Data \#Theory \%Complete Redundancy Mean I Mean I/s R(int) R(sigma)

\begin{tabular}{|c|c|c|c|c|c|c|c|c|c|}
\hline Inf & -6.25 & 85 & 87 & 97.7 & 173.64 & 94.4 & 119.30 & 0.0489 & 0.0060 \\
\hline 6.25 & -4.90 & 84 & 84 & 100.0 & 195.14 & 87.5 & 118.72 & 0.0612 & 0.0069 \\
\hline 4.90 & -4.25 & 84 & 84 & 100.0 & 193.96 & 116.4 & 133.92 & 0.0579 & 0.0063 \\
\hline 4.25 & -3.85 & 88 & 88 & 100.0 & 191.24 & 127.0 & 116.63 & 0.0592 & 0.0065 \\
\hline 3.85 & -3.55 & 86 & 86 & 100.0 & 185.77 & 105.6 & 108.50 & 0.0661 & 0.0074 \\
\hline 3.55 & -3.30 & 104 & 104 & 100.0 & 177.75 & 84.3 & 89.01 & 0.0793 & 0.0093 \\
\hline 3.30 & -3.10 & 111 & 111 & 100.0 & 177.16 & 57.5 & 75.45 & 0.1027 & 0.0116 \\
\hline 3.10 & -2.95 & 99 & 99 & 100.0 & 168.22 & 59.7 & 66.35 & 0.1070 & 0.0123 \\
\hline 2.95 & -2.80 & 122 & 122 & 100.0 & 166.24 & 37.9 & 48.51 & 0.1474 & 0.0171 \\
\hline 2.80 & -2.70 & 104 & 104 & 100.0 & 142.94 & 32.4 & 39.99 & 0.1820 & 0.0216 \\
\hline 2.70 & -2.60 & 113 & 113 & 100.0 & 127.27 & 29.4 & 35.80 & 0.2051 & 0.0252 \\
\hline 2.60 & -2.50 & 128 & 129 & 99.2 & 102.74 & 24.9 & 24.19 & 0.2513 & 0.0356 \\
\hline 2.50 & -2.40 & 149 & 149 & 100.0 & 80.30 & 21.1 & 18.55 & 0.3325 & 0.0437 \\
\hline 2.40 & -2.35 & 97 & 97 & 100.0 & 67.00 & 16.4 & 12.94 & 0.4458 & 0.0612 \\
\hline 2.35 & -2.30 & 88 & 88 & 100.0 & 58.36 & 22.5 & 16.84 & 0.3513 & 0.0493 \\
\hline 2.30 & -2.25 & 111 & 111 & 100.0 & 50.75 & 15.1 & 9.77 & 0.5743 & 0.0765 \\
\hline 2.35 & -2.25 & 199 & 199 & 100.0 & 54.12 & 18.4 & 12.90 & 0.4443 & 0.0618 \\
\hline $\operatorname{Inf}$ & -2.25 & 1653 & 1656 & 99.8 & 137.33 & 54.1 & 59.87 & 0.0962 & 0.0150 \\
\hline
\end{tabular}

Mean $|\mathrm{E} * \mathrm{E}-1|=0.789$ [expected .968 centrosym and .736 non-centrosym]

Systematic absence exceptions:

$41 / 43 \quad 42=21 \quad a--\quad b--\quad n--\quad--n$

$\begin{array}{lllllll}\text { N } & 704 & 220 & 13671 & 13683 & 13822 & 19204\end{array}$

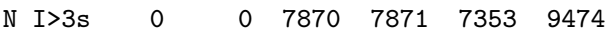

$\begin{array}{lllllll}<\mathrm{I}> & 1.7 & 1.8 & 88.0 & 87.8 & 72.5 & 83.1\end{array}$

$\begin{array}{lllllll}\langle\mathrm{I} / \mathrm{s}\rangle & 0.4 & 0.4 & 6.5 & 6.5 & 5.6 & 6.1\end{array}$

Anomalous signal/noise ratios ( 1.0 is random). The first line is based on input sigmas, the second on variances of $\mathrm{F}+$ and $\mathrm{F}-$ (if not already averaged):

Inf $-8.0-6.0-5.0-4.0-3.7-3.5-3.3-3.1-2.9-2.7-2.5-2.3 \mathrm{~A}$

$\begin{array}{llllllllllll}38.76 & 22.31 & 15.53 & 14.05 & 8.36 & 8.77 & 9.26 & 6.31 & 6.86 & 6.39 & 4.28 & 2.33\end{array}$ $\begin{array}{llllllllllll}42.38 & 25.21 & 17.88 & 16.30 & 10.07 & 11.24 & 11.29 & 7.28 & 8.53 & 7.09 & 4.58 & 2.07\end{array}$

88.9 Neighbors used on average for F+/F- local scaling

Rint $($ anom $)=0.1088$ before and 0.1091 after local scaling 


\subsubsection{Einkreis / MAR345}

INTENSITY STATISTICS FOR DATASET \# 2 acta_mar345.sca

Resolution \#Data \#Theory \%Complete Redundancy Mean I Mean I/s R(int) R(sigma)

\begin{tabular}{|c|c|c|c|c|c|c|c|c|c|}
\hline $\operatorname{Inf}$ & -4.55 & 207 & 212 & 97.6 & 13.97 & 762.4 & 26.30 & 0.0592 & 0.0364 \\
\hline 4.55 & -3.60 & 201 & 201 & 100.0 & 15.06 & 857.8 & 28.71 & 0.0613 & 0.0301 \\
\hline 3.60 & -3.10 & 225 & 225 & 100.0 & 15.02 & 530.2 & 28.68 & 0.0637 & 0.0288 \\
\hline 3.10 & -2.80 & 227 & 227 & 100.0 & 15.04 & 347.9 & 25.15 & 0.0765 & 0.0330 \\
\hline 2.80 & -2.60 & 214 & 214 & 100.0 & 14.78 & 224.8 & 22.28 & 0.0996 & 0.0377 \\
\hline 2.60 & -2.45 & 203 & 203 & 100.0 & 14.77 & 197.1 & 19.70 & 0.1049 & 0.0396 \\
\hline 2.45 & -2.30 & 263 & 263 & 100.0 & 14.74 & 156.2 & 19.34 & 0.1212 & 0.0416 \\
\hline 2.30 & -2.20 & 226 & 226 & 100.0 & 14.30 & 136.0 & 16.80 & 0.1790 & 0.0486 \\
\hline 2.20 & -2.10 & 259 & 259 & 100.0 & 14.56 & 103.3 & 15.80 & 0.1777 & 0.0557 \\
\hline 2.10 & -2.00 & 315 & 315 & 100.0 & 14.21 & 93.6 & 12.22 & 0.2486 & 0.0684 \\
\hline 2.00 & -1.90 & 378 & 378 & 100.0 & 14.23 & 68.2 & 10.80 & 0.2934 & 0.0844 \\
\hline 1.90 & -1.85 & 230 & 230 & 100.0 & 13.99 & 44.6 & 8.21 & 0.4096 & 0.1203 \\
\hline 1.85 & -1.80 & 257 & 257 & 100.0 & 13.77 & 38.4 & 7.23 & 0.4418 & 0.1354 \\
\hline 1.80 & -1.75 & 274 & 274 & 100.0 & 12.66 & 23.3 & 4.62 & 0.6306 & 0.2159 \\
\hline 1.75 & -1.70 & 310 & 310 & 100.0 & 10.59 & 19.4 & 3.81 & 0.6774 & 0.2622 \\
\hline 1.70 & -1.67 & 208 & 208 & 100.0 & 8.08 & 13.3 & 2.43 & 0.8209 & 0.4147 \\
\hline - & ------- & & & ----- & & & & ------ & ------ \\
\hline 1.80 & -1.67 & 792 & 792 & 100.0 & 10.65 & 19.2 & 3.73 & 0.6744 & 0.2706 \\
\hline $\operatorname{Inf}$ & -1.67 & 3997 & 4002 & 99.9 & 13.71 & 201.6 & 14.95 & 0.1112 & 0.0446 \\
\hline
\end{tabular}

Mean $|\mathrm{E} * \mathrm{E}-1|=0.756$ [expected .968 centrosym and .736 non-centrosym]

Systematic absence exceptions:

$$
41 / 43 \quad 42=21 \quad a--\quad b--\quad n--\quad--n
$$

$\begin{array}{lllllll}\mathrm{N} & 67 & 25 & 2329 & 2326 & 2339 & 2986\end{array}$

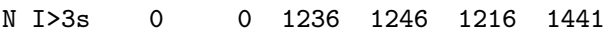

$\begin{array}{llllllll}<\mathrm{I}\rangle & 9.5 & 15.8 & 361.9 & 363.8 & 317.6 & 354.7\end{array}$

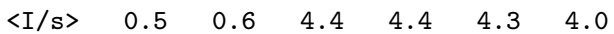

Anomalous signal/noise ratios ( 1.0 is random). The first line is based on input sigmas, the second on variances of $\mathrm{F}+$ and $\mathrm{F}-$ (if not already averaged):

Inf $-8.0-6.0-5.0-4.0-3.5-3.0-2.7-2.5-2.3-2.1-1.9-1.7 \mathrm{~A}$

$\begin{array}{llllllllllll}8.57 & 5.85 & 5.18 & 4.41 & 3.58 & 3.86 & 3.76 & 3.65 & 2.73 & 2.62 & 2.34 & 1.46\end{array}$ $\begin{array}{llllllllllll}12.26 & 9.09 & 6.91 & 5.92 & 3.84 & 4.29 & 3.70 & 3.39 & 2.45 & 2.01 & 1.69 & 1.27\end{array}$

104.0 Neighbors used on average for F+/F- local scaling

Rint $($ anom $)=0.1261$ before and 0.1263 after local scaling 


\subsubsection{Einkreis / marCCD}

INTENSITY STATISTICS FOR DATASET \# 1 marccd_acta.sca

Resolution \#Data \#Theory \%Complete Redundancy Mean I Mean I/s R(int) R(sigma)

\begin{tabular}{|c|c|c|c|c|c|c|c|c|c|}
\hline $\operatorname{Inf}$ & -3.35 & 473 & 505 & 93.7 & 8.76 & 449.6 & 26.37 & 0.0765 & 0.0457 \\
\hline 3.35 & -2.65 & 502 & 503 & 99.8 & 10.15 & 219.1 & 27.97 & 0.0719 & 0.0349 \\
\hline 2.65 & -2.30 & 514 & 514 & 100.0 & 10.22 & 113.7 & 29.14 & 0.0569 & 0.0324 \\
\hline 2.30 & -2.10 & 472 & 472 & 100.0 & 10.23 & 74.8 & 29.56 & 0.0589 & 0.0314 \\
\hline 2.10 & -1.95 & 495 & 495 & 100.0 & 10.11 & 55.2 & 32.33 & 0.0533 & 0.0270 \\
\hline 1.95 & -1.80 & 665 & 665 & 100.0 & 10.04 & 31.2 & 31.81 & 0.0579 & 0.0269 \\
\hline 1.80 & -1.70 & 592 & 592 & 100.0 & 10.07 & 19.9 & 29.17 & 0.0622 & 0.0273 \\
\hline 1.70 & -1.60 & 723 & 723 & 100.0 & 9.99 & 12.2 & 26.53 & 0.0788 & 0.0313 \\
\hline 1.60 & -1.50 & 954 & 954 & 100.0 & 9.89 & 8.5 & 23.74 & 0.0965 & 0.0377 \\
\hline 1.50 & -1.45 & 585 & 585 & 100.0 & 9.90 & 5.7 & 17.10 & 0.1322 & 0.0549 \\
\hline 1.45 & -1.40 & 662 & 662 & 100.0 & 9.80 & 4.1 & 12.40 & 0.1779 & 0.0775 \\
\hline 1.40 & -1.35 & 777 & 777 & 100.0 & 9.78 & 3.5 & 10.18 & 0.2115 & 0.0958 \\
\hline 1.35 & -1.30 & 875 & 875 & 100.0 & 9.67 & 2.6 & 7.23 & 0.2984 & 0.1359 \\
\hline 1.30 & -1.25 & 1030 & 1030 & 100.0 & 9.61 & 2.1 & 5.50 & 0.3889 & 0.1813 \\
\hline 1.35 & -1.25 & 1905 & 1905 & 100.0 & 9.64 & 2.4 & 6.30 & 0.3424 & 0.1580 \\
\hline $\operatorname{Inf}$ & -1.25 & 9319 & 9352 & 99.6 & 9.85 & 54.4 & 20.37 & 0.0735 & 0.0397 \\
\hline
\end{tabular}

Mean $|E * E-1|=0.761$ [expected .968 centrosym and .736 non-centrosym]

Systematic absence exceptions:

$41 / 43 \quad 42=21 \quad a--\quad b--\quad n--\quad--n$

$\begin{array}{lrrrrrr}\text { N } & 55 & 17 & 2657 & 2656 & 2663 & 3811 \\ \text { N I }>3 s & 4 & 0 & 1669 & 1672 & 1645 & 2363 \\ \text { <I } & 0.9 & 0.4 & 86.7 & 86.3 & 77.9 & 73.5 \\ \text { <I/s }> & 0.8 & 0.4 & 6.4 & 6.4 & 6.2 & 6.3\end{array}$

Anomalous signal/noise ratios ( 1.0 is random). The first line is based on input sigmas, the second on variances of $\mathrm{F}+$ and $\mathrm{F}-$ (if not already averaged):

Inf $-8.0-6.0-5.0-4.0-3.5-3.0-2.5-2.1-1.9-1.7-1.5-1.3 \mathrm{~A}$

$\begin{array}{llllllllllll}3.61 & 2.80 & 2.10 & 1.67 & 1.39 & 1.57 & 2.03 & 1.91 & 2.39 & 2.29 & 1.87 & 1.13\end{array}$

$\begin{array}{llllllllllll}2.83 & 3.34 & 2.32 & 1.88 & 1.88 & 1.85 & 2.46 & 2.34 & 2.64 & 2.31 & 1.84 & 1.20\end{array}$

120.0 Neighbors used on average for F+/F- local scaling

Rint $($ anom $)=0.0571$ before and 0.0566 after local scaling 


\subsection{Material und Methoden}

Alle Chemikalien wurden, sofern nicht anders angegeben, von den Firmen Aldrich Chemical Company (Milwaukee, USA), BioRad (München), Calibochem (Frankfurt); Fluka (Buchs, CH), Merck (Darmstadt, Pharmacia (Freiburg), Sigma (Deisenhofen), Serva (Hamburg) und Roth (Karlsruhe) in der Reinheit p. a. (pro analysi) bezogen.

Einfache Puffer und Salzlösungen wurden grundsätzlich nach folgendem Schema hergestellt: Die berechneten Chemikalienmengen wurden eingewogen, mit etwas weniger bidestilliertem Wasser als zum Erreichen der gewünschten Endkonzentration nötig aufgelöst und schließlich in einem Meßkolben mit bidestilliertem Wasser auf das endgültige Volumen aufgefüllt. Der pH-Wert von Puffern wurde mit konzentrierter $\mathrm{NaOH}$ oder $\mathrm{HCl}$ eingestellt, bevor die Lösung in einem Meßkolben mit bidestilliertem Wasser auf das endgültige Volumen aufgefüllt wurde.

\subsubsection{FhuF}

\subsubsection{Lösungen und Puffer}

Bindepuffer: 4 mM Imidazol, 0.5 M NaCl, 20 mM TRIS / HCl (pH 8.0): 0.14 g Imidazol, $14.61 \mathrm{~g} \mathrm{NaCl}$ und $1.21 \mathrm{~g}$ TRIS-Base wurden in $400 \mathrm{ml}$ bidest. $\mathrm{H}_{2} \mathrm{O}$ gelöst und mit $\mathrm{HCl}_{\text {conc }}$ auf pH 8.0 eingestellt. Danach wurde das Volumen mit bidest. $\mathrm{H}_{2} \mathrm{O}$ auf $500 \mathrm{ml}$ aufgefüllt und der Puffer steril filtriert.

Elutionspuffer: $0.25 \mathrm{M}$ Imidazol, $0.1 \mathrm{M} \mathrm{NaCl}, 8 \mathrm{mM}$ TRIS / HCl (pH 8.0): 1.70 g Imidazol, $0.58 \mathrm{~g} \mathrm{NaCl}$ und $0.10 \mathrm{~g}$ TRIS-Base wurden in $90 \mathrm{ml}$ bidest. $\mathrm{H}_{2} \mathrm{O}$ gelöst und mit $\mathrm{HCl}_{\text {conc }}$ auf pH 8.0 eingestellt. Danach wurde das Volumen mit bidest. $\mathrm{H}_{2} \mathrm{O}$ auf $100 \mathrm{ml}$ aufgefüllt und der Puffer steril filtriert.

FPLC-Puffer: $1 \mathrm{mM}$ DTT, $10 \%$ (v/v) Glycerol, $0.2 \mathrm{M} \mathrm{NaCl}, 20 \mathrm{mM}$ TRIS / HCl (pH 8.0): $0.15 \mathrm{mg}$ DTT, $100 \mathrm{ml}$ Glycerol, $11.69 \mathrm{~g} \mathrm{NaCl}$ und $2.42 \mathrm{~g}$ TRIS-Base wurden in $900 \mathrm{ml}$ bidest. $\mathrm{H}_{2} \mathrm{O}$ gelöst und mit $\mathrm{HCl}_{\text {conc }}$ auf $\mathrm{pH} 8.0$ eingestellt. Danach wurde das Volumen mit bidest. $\mathrm{H}_{2} \mathrm{O}$ auf $1000 \mathrm{ml}$ aufgefüllt und der Puffer steril filtriert.

Gegenstrompuffer: 10 mM DTT, $10 \%$ (v/v) Glycerol, $0.2 \mathrm{M} \mathrm{NaCl,} 20$ mM TRIS / HCl (pH 8.0): $1.54 \mathrm{mg}$ DTT, $100 \mathrm{ml}$ Glycerol, $11.69 \mathrm{~g} \mathrm{NaCl}$ und $2.42 \mathrm{~g}$ TRIS-Base wurden 
in $900 \mathrm{ml}$ bidest. $\mathrm{H}_{2} \mathrm{O}$ gelöst und mit $\mathrm{HCl}_{\text {conc }}$ auf $\mathrm{pH} 8.0$ eingestellt. Danach wurde das Volumen mit bidest. $\mathrm{H}_{2} \mathrm{O}$ auf $1000 \mathrm{ml}$ aufgefüllt und der Puffer steril filtriert.

Resuspensionspuffer: $\mathrm{Zu} 40 \mathrm{ml}$ Bindepuffer (siehe dort) wurde eine ProteaseInhibitortablette, EDTA-frei (Boehringer, Mannheim), $1 \mu \mathrm{l}$ Benzonase und $0.4 \mathrm{~g} \mathrm{MgCl}_{2}$ (entspricht $50 \mathrm{mM}$ ) gegeben und der Puffer steril filtriert.

Spaltpuffer: $2 \mathrm{mM} \mathrm{CaCl}$, $10 \mathrm{mM}$ DTT, $0.2 \mathrm{M} \mathrm{NaCl}, 20 \mathrm{mM}$ TRIS / HCl (pH 7.5): $0.15 \mathrm{~g}$ $\mathrm{CaCl}_{2} \cdot 2 \mathrm{H}_{2} \mathrm{O}, 0.77 \mathrm{mg}$ DTT, $5.85 \mathrm{~g} \mathrm{NaCl}$ und $1.21 \mathrm{~g}$ TRIS-Base wurden in $400 \mathrm{ml}$ bidest. $\mathrm{H}_{2} \mathrm{O}$ gelöst und mit $\mathrm{HCl}_{\text {conc }}$ auf $\mathrm{pH} 7.5$ eingestellt. Danach wurde das Volumen mit bidest. $\mathrm{H}_{2} \mathrm{O}$ auf $500 \mathrm{ml}$ aufgefüllt und der Puffer steril filtriert.

Waschpuffer: 60 mM Imidazol, 0.5 M NaCl, 20 mM TRIS / HCl (pH 8.0): 0.41 g Imidazol, $2.92 \mathrm{~g} \mathrm{NaCl}$ und $0.24 \mathrm{~g}$ TRIS-Base wurden in $90 \mathrm{ml}$ bidest. $\mathrm{H}_{2} \mathrm{O}$ gelöst und mit $\mathrm{HCl}_{\text {conc }}$ auf pH 8.0 eingestellt. Danach wurde das Volumen mit bidest. $\mathrm{H}_{2} \mathrm{O}$ auf $100 \mathrm{ml}$ aufgefüllt und der Puffer steril filtriert.

Trypsinpuffer: $2 \mathrm{mM} \mathrm{CaCl} 2 \cdot 2 \mathrm{H}_{2} \mathrm{O}, 20 \mathrm{mM}$ TRIS-Puffer (pH 8.0), $1 \mathrm{mM} \mathrm{MgCl} 2,100 \mathrm{mM}$ $\mathrm{NaCl}$ : Der Puffer wurde durch Zusammenpippettieren von Stammlösungen von $2.0 \mathrm{M}$ $\mathrm{CaCl}_{2} \cdot 2 \mathrm{H}_{2} \mathrm{O}(10 \mu \mathrm{l}), 1.0 \mathrm{M}$ TRIS (pH 8.0) $(200 \mu \mathrm{l}), 2.0 \mathrm{M} \mathrm{MgCl}_{2}(5 \mu \mathrm{l})$ und $5.0 \mathrm{M} \mathrm{NaCl}$ $(200 \mu \mathrm{l})$ hergestellt.

\subsubsection{Resuspensierung, Aufreinigung und Aufkonzentrierung}

Das Protein FhuF lag in tiefgekühlten $\left(-80^{\circ} \mathrm{C}\right)$ E.-Coli Zellen vor. Eine Portion (ca. $\left.5 \mathrm{~g}\right)$ wurde aufgetaut und in $40 \mathrm{ml}$ Resuspensionspuffer aufgeschlämmt: Das Resuspensat wurde mit $0.1 \mathrm{ml}$ einer Lysozyme-Lösung $(50 \mathrm{mg} / \mathrm{ml}$ ) versetzt und 3 mal 5 Minuten lang mit Ultraschall behandelt. Alle Schritte erfolgten unter Eiskühlung.

Anschließend wurde der Zellbrei für 20 Minuten bei $24000 \mathrm{~g}$ unter Kühlung $\left(4^{\circ} \mathrm{C}\right)$ zentrifugiert (Rotor SA300, 19000 rpm), der Überstand abdekantiert und steril filtriert.

Die Aufreinigung erfolgte bei $4{ }^{\circ} \mathrm{C}$ über eine Ni-NTA-Säule mit angeschlossener DialyseAustausch-Kapillarsäule (Kronlab, Sinsheim). Bei dieser Anordnung wird die die Ni-Säule verlassende Flüssigkeit direkt durch die Austauschsäule geleitet, wo im Gegenstrom ein Pufferaustausch erfolgt. Sowohl der Durchfluß durch die Säule (ca. $0.7 \mathrm{ml} / \mathrm{min}$ ), als auch der Fluß des Gegenstrompuffers durch die Austauschkapillaren (ca. $5 \mathrm{ml} / \mathrm{min}$ ) wurden mit Peristaltik-Schlauchpumpen geregelt. 
Nach dem Füllen mit ca. 5 ml Ni-NTA-Suspension wurde die Säule mit bidest. $\mathrm{H}_{2} \mathrm{O}$ gespült und mit Bindepuffer äquilibriert. Nach dem Proteinauftrag wurde mit 15 ml Binde- und $30 \mathrm{ml}$ Waschpuffer gespült und anschließend das Protein mit Elutionspuffer von der Säule eluiert.

Aufgrund der intensiv braunen Farbe des Proteins waren die relevanten Fraktionen leicht zu erkennen. Nach Konzentrationsbestimung (nach Bradford) und Gelelektrophorese wurden sie vereinigt und in einer AMICON-Konzentratorzelle (Filtertyp YM10) mit Stickstoffdruck auf die jeweils gewünschte Konzentration gebracht.

\subsubsection{Entfernen des His-tags}

Zur Abspaltung des His-tags wurden jeweils $15 \mathrm{ml}$ Protein-Lösung (Konzentration ca. $0.8 \mathrm{mg} / \mathrm{ml}$ ) in Spaltpuffer mit $100 \mathrm{ml}$ Enterokinase der Firma Invitrogen (Katalognummer E180-01) versetzt und bei Raumtemperatur inkubiert. Alle 30 Minuten wurde eine Probe für ein Gel genommen (vgl. Abb. 2.3) und nach sechs Stunden die Spaltung beendet.

Die abgespaltenen His-tags, sowie die ungespaltenen Proteinmoleküle wurden über eine Ni-NTA-Säule abgetrennt, die im Eluat verbleibende Enterokinase mit dem EK-Away-Kit der Firma Invitrogen (Katalognummer R180-01/02) entfernt.

\subsubsection{Gelfiltration}

Zur Gelfiltration wurde eine präparative Pharmacia Superdex 75 Säule (16/18, 5-70 kDa) verwendet. Zunächst wurde die Säule mit ca. $80 \mathrm{ml}$ Wasser und anschließend mit ca. 200 ml FPLC-Puffer äquilibriert, dann erfolgte Protein-Auftrag von $2 \mathrm{ml}$ in einer Konzentration von ca. $7 \mathrm{mg} / \mathrm{ml}$. Die Reinigung wurde bei einer Durchflußrate von $0.8 \mathrm{ml} / \mathrm{min}$ durchgeführt.

\subsubsection{Trypsin-Verdauung}

In Anlehnung an die von Tsutakawa beschriebene Methode [89] wurden $10 \mu$ l FhuF (Wildtyp ohne His-Tag, ca. $7 \mathrm{mg} / \mathrm{ml}$ ) mit $8 \mu \mathrm{l}$ Trypsin (aus dem Schweinepankreas, Sigma (Katalognummer T-7418), ca. $0.1 \mathrm{mg} / \mathrm{ml}$ in Trypsinpuffer) und $82 \mu \mathrm{l}$ Trypsinpuffer versetzt - das entspricht etwa einem zehnfachen molaren Überschuß von FhuF - und bei $25^{\circ} \mathrm{C}$ für sechs Stunden inkubiert. 


\subsubsection{Lysozyme}

\subsubsection{Lösungen und Puffer}

Kristallisationslösung: In ein Eppendorf-Reaktionsgefäß wurden etwa 25 mg Lysozyme der Firma ICN Biomedicals Inc. (Katalognummer 199831) eingewogen und mit Acetatpuffer (0.1 M, pH 4.7) bis auf eine Konzentration von $50 \mathrm{mg} / \mathrm{ml}$ aufgefüllt.

Kristallisation: Die Kristallisation erfolgte mit der hanging drop Methode über Gasphasendiffusion gegen 1.0 M NaCl-Lösung in $5 \mu \mathrm{l}+5 \mu \mathrm{l}$ Tropfen.

Kryopuffer: Als Kryoprotenktand für Lysozyme wurde eine 1.5 M NaCl-Lösung, die $0.2 \mathrm{M}$ Acetatpuffer (pH 4.7) und $5 \mathrm{mg} / \mathrm{ml}$ Lysozyme enthielt, im Verhältnis 60 : 40 mit Glycerol vermischt.

\subsubsection{Actagardin}

\subsubsection{Lösungen und Puffer}

Kristallisationslösung: In ein Eppendorf-Reaktionsgefäß wurden etwa 10 mg Actagardin (Fa. Aventis, Frankfurt/Main) eingewogen und mit bidestilliertem Wasser bis auf eine Konzentration $20 \mathrm{mg} / \mathrm{ml}$ aufgefüllt.

Kristallisation: Die Kristallisation erfolgte mit der hanging drop Methode über Gasphasendiffusion gegen $500 \mu \mathrm{l}$ Fällungsmittel (Hergestellt durch Zusammengeben von $35 \mu \mathrm{l}$ HEPES (1.0 M, pH 4.7), $125 \mu \mathrm{l}$ Ethanol, $100 \mu \mathrm{l}$ KI (1.0 M), $120 \mu \mathrm{l}$ PEG 4000 (40 \% ig, $w / v)$ und $120 \mu \mathrm{l}$ bidestilliertem Wasser) in $3 \mu \mathrm{l}+3 \mu \mathrm{l}$ Tropfen.

Kryopuffer: Als Kryoprotektand für Actagardin diente eine Lösung aus $35 \mu$ l HEPES (1.0 M, pH 4.7), $125 \mu \mathrm{l}$ Ethanol, $100 \mu \mathrm{l} \mathrm{KI} \mathrm{(1.0} \mathrm{M),} 120 \mu \mathrm{l} \mathrm{PEG} 4000$ (40\%ig, $w / v)$, $100 \mu \mathrm{l}$ PEG 300 und $20 \mu \mathrm{l}$ bidestilliertem Wasser. 


\subsubsection{Diffraktometer}

Die im Rahmen dieser Arbeit zur Sammlung von Röntgendaten verwendeten Diffraktometer sind sämtlich und detailliert in Kapitel 4 unter 5.3 (Seite 54) beschrieben.

\subsubsection{Software}

Zusätzlich zu den im Text erwähnten, bzw. allgemein üblichen fanden folgende Programme Verwendung: Das Diffraktometersteuerprogramm SMART [73] zur Sammlung der Daten am SMART 1K, SMART 6000 und SMART 6500, das Diffraktometersteuerprogramm FRAMBO [90 zur Sammlung der Daten am HiStar, die Programme SAINT 455 und SADABS [91] zur Integration und Korrektur aller Bruker-Daten, das Diffraktometersteuerprogramm der Firma marresearch [92] zur Sammlung der Daten mit dem mar345 und dem marCCD, die Porogramme denzo [93] und scalepack [94] zur Integration und Korrektur aller mar-Daten, das Programm X-AREA [95] zur Sammlung und Reduktion der ipds-ii-Daten und die Programme molscript [96], bobscript [97] und Raster3D [98] zur Anfertigung von Abb. 11.3 


\subsection{Publikationen}

\section{Veröffentlichungen in Fachzeitschriften:}

1. J. Belzner, U. Dehnert, H. Ihmels. M. Hübner, P. Müller, I. Usón, New Dichlorsilanes, and Silacyclopropanes as precursors of Intramolecularly Coordinated Silylenes, Chem. Eur. J., 4, No. 5, 852-863 (1998).

2. B. Räke, H. W. Roesky, I. Usón, P. Müller, Synthesis and Structure of $\left(\mathrm{CH}_{3} \mathrm{Si}\right)_{6}(\mathrm{NH})_{9}$ : A Si-N-Cage Made from Methyltrichlorsilane and Ammonia, Angew. Chem. Int. Ed., 37, No. 10, 1432-1433 (1998); Angew. Chem., 110, No. 10, 1508-1510 (1998).

3. H. Wessel, H. W. Roesky, M. L. Montero, P. Müller, I. Usón, Reactions of Group 4 Metal Cyclopentadienyl Trifluorides with a Trimeric Iminoalane, Organometallics, 17, No. 10, 1919-1921 (1998).

4. H. Wessel, H. S. Park, P, Müller, H. W. Roesky, I. Usón, $\left[\left\{\operatorname{MeAl}\left(\mu_{2}-\mathrm{F}\right)\right\}_{2} \mathrm{~N}(2,6-\right.$ $\left.\left.i \mathrm{Pr}_{2} \mathrm{C}_{6} \mathrm{H}_{3}\right)\right]_{4}-\mathrm{A}$ Molecular Al-F-N Cage Compound, Angew. Chem. Int. Ed., 38, No. 6, 813-815 (1999); Angew. Chem., 111, No. 6, 850-852 (1999).

5. P. Yu, P. Müller, M. A. Said, H. W. Roesky, I. Usón, G. Bai, M. Noltemeyer, Difference in Reactivity of Cyclopentadienyltitanium Fluorides and Chlorides Using $\mathrm{AlR}_{3}(\mathrm{R}=\mathrm{Me}, \mathrm{Et})$ : Synthesis and Structures of $\mathrm{Ti}(\mathrm{III})-\mathrm{F}(\mathrm{Cl})-\mathrm{Al}$ Compounds, Organometallics, 18, No. 9, 1669-1674 (1999).

6. B. Räke, P., Müller, H.W. Roesky, I. Usón, Synthesis and Structure of the Graphit Like $\left[\left(\mathrm{Me}_{3} \mathrm{Sn}\right)_{3} \mathrm{O}\right] \mathrm{Cl}$, Angew. Chem. Int. Ed., 38, No. 13/14, 2050-2052 (1999); Angew. Chem., 111, No. 13/14, 2069-2071 (1999).

7. J. Prust, P. Müller, C. Rennekamp, H. W. Roesky, I. Usón, New Approach to Dichloroindiumamides, J. Chem. Soc. Dalton Trans., 14, 2265-2266 (1999).

8. P. Yu, P. Müller, H. W. Roesky, M. Noltemeyer, A. Demsar, I. Usón, Organotitanium Fluorides as Matrices for Trapping Molecular $\mathrm{ZnF}_{2}$ and MeZnF, Angew. Chem. Int. Ed., 38, No. 22, 3319-3321 (1999); Angew. Chem., 111, No. 22, 3518-3520 (1999).

9. C. Rennekamp, H. Wessel, H. W. Roesky, P. Müller, H. G. Scmidt, M. Noltemeyer, I. Usón, A. R. Barron, An Alternative Approach to $\mathrm{Al}_{2} \mathrm{O}_{2}$ Ring Systems by Un- 
expected Cleavage of Stable Al-F- and Si-O-Bonds , Inorg. Chem., 38, No. 23, 5235-5240 (1999).

10. L. Fitjer, R. Gerke, W. Lüttke, P. Müller, I. Usón, Crystal Structure and Light Absorption of Vinylogous N,N'-Dialkylindigos, Tetrahedron, 55, 14421-14428 (1999).

11. R. Gerke, L. Fitjer, P. Müller, I. Usón, K. Kowski, P. Rademacher, New Indigo Chromophores Containing Disulfide Donor Groups, Tetrahedron, 55, 14428-14434 (1999).

12. C. Rennekamp, A. Stasch, P. Müller, H. W. Roesky, M. Noltemeyer, H. G. Schmidt, I. Usón, Reaction of Dimethylaluminiumfluoride with Primary Amines $\mathrm{RNH}_{2}\left(\mathrm{R}=t-\mathrm{Bu}, 2,6,-i-\mathrm{Pr}_{2} \mathrm{C}_{6} \mathrm{H}_{3}\right)$, J. Fluorine Chem., 102, 17-20 (2000).

13. C. Ackerhans, B. Räke, R. Krätzner, P. Müller, H. W. Roesky, I. Usón, Ammonolysis of Trichlorsilanes, Europ. J. Inorg. Chem., 5, 1861-1868 (2000).

14. C. Rennekamp, P. Müller, J. Prust, H. Wessel, H. W. Roesky, I. Usón, Si-NHM Cage Compounds - Molecular Iminosilicates Containing Group 13 Metals and Their Functionalized Halogen Containing Derivatives, Europ. J. Inorg. Chem., 5, 1861-1868 (2000).

15. P. Müller, I. Usón, J. Prust, H. W. Roesky, Tetrameric Indium Trichloride, a new Modification of a widely used Compound, Acta Cryst., C56, 1300-1301 (2000).

16. G. Bai, P. Müller, H. W. Roesky, I. Usón, Intramolecular Coupling of Two Cyclopentadienyl Ring Systems of Zirconium - Unprecedented Formation of a Dihydride and Preparation of the $\left[\left\{\left(\mathrm{MeC}_{5} \mathrm{H}_{4}\right) \mathrm{Zr}\right\}_{5}\left(\mu_{5}-\mathrm{N}\right)\left(\mu_{3}-\mathrm{NH}\right)_{4}\left(\mu-\mathrm{NH}_{2}\right)_{4}\right]$ Cluster in a TwoPhase System, Organometallics, 19, 4675-4677 (2000).

17. P. Müller, V. Hensel, I. Usón, A. D. Schlüter, G. M. Sheldrick, Crystal Structure of a Cyclotetraicosaphenylene, Helvetica Chimica Acta 84, Nr. 4, 778-785 (2001). 


\section{Vorträge und Posterpräsentationen:}

1. P. Müller, G. M. Sheldrick, Making the Most of Your In-House Data, Poster, ECMTagung 1998, Prag.

2. R. Durst, C. Campana, S. Foundling, J. Phillips, P. Müller, The Optimal Quantum Gain of CCD Detectors for Chemical and Macromolecular Crystallography, Poster, ACA-Tagung 1999, Buffalo.

3. R. Durst, C. Campana, S. Foundling, Z. Jin, J. Phillips, M. Pressprich, P. Müller, The Design of CCD Detectors for Optimal Sensitivity and Dynamic Range: The New SMART APEX, Poster, ACA-Tagung 1999, Buffalo.

4. P. Müller, Holes in Crystals, Poster IUCr-Tagung 1999, Glasgow.

5. R. Durst, P. Müller, C. Campana, S. Foundling, Z. Jin, J. Phillips, M. Pressprich, The Optimal Gain and Dynamic Range of CCD Detectors for X-Ray Diffraction, Poster, IUCr-Tagung 1999, Glasgow.

6. P. Müller, Handling of Troublesome Crystals, Seminar, Workshop im Rahmen der Tagung Contemporary Inorganic Chemistry II 2000, College Station.

7. P. Müller, S. Köpke, Identification of Metal Atoms in Protein Structures using the Bond-Valence Method, Vortrag, DGK-Tagung 2001, Beyreuth.

8. S. Köpke, P. Müller, G. M. Sheldrick, Mut zum Metall, Poster, DGK-Tagung 2001, Beyreuth.

9. P. Müller, All Electrons are Blue, Vortrag, ACA-Tagung 2001, Los Angeles. 


\subsection{Lebenslauf}

Persönliche Daten:

Name

Peter Müller

Geburtsdatum

5. 7.1970

Gebrutsort

Wörth

Staatsangehörigkeit

deutsch

\section{Schulbildung:}

$1977-1990$

Waldorfschule Mannheim mit Abschluß Abitur

\section{Hochschulstudium:}

1991-1994

Grundstudium Universität Kaiserslautern, Vordiplomprüfung am 14. 10. 1994

1994-1997

Hauptstudium Universität Göttingen,

1996-1997

Diplomarbeit am Institut für Anorganische Chemie der

Universität Göttingen im Arbeitskreis von Herrn Prof.

G. M. Sheldrick:

„Röntgenstrukturuntersuchungen an metallogranischen

Verbindungen und indigoiden Systemen“

Diplomprüfung am 30. 10. 1997

\section{Promotion:}

1997-2001

Anfertigung der vorliegenden Dissertation am

Lehrstuhl für Strukturchemie der Universität Göttingen unter Anleitung von Herrn Prof. G. M. Sheldrick:

„Probleme der modernen hochauflösenden

Einkristall-Röntgenstrukturanalyse“

Tag der mündlichen Prüfung: 2. 5. 2001 